\title{
EVOLVING \\ PERSPECTIVES ON \\ THE RIGHT TO \\ COMMUNICATE
}

EDITED BY

L.S. Harms

Jim Richstad

FOREWORD BY

Jean d'Arcy

East-West Center

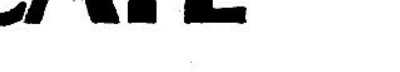




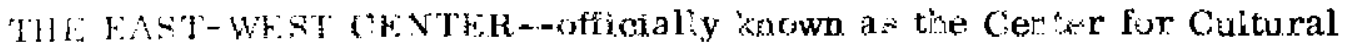

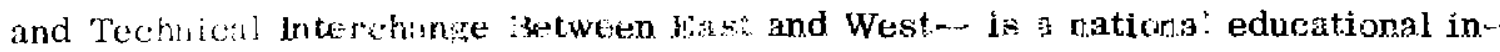
stitution fublishod in Hawai by the $\mathrm{L}$. S. Congress in 1960 to promote better relations anderetanding between the Laited States and the antions of Asia and the Pacifis: through croperative study, training, and research. The Center is administert d by a public, nonprofit corporation whose intermational Board of Governors conists of distinguished scholars, business leaders, and public servants.

Eich year more than 1, 500 raen and women from many mations and cultures participats in Center programs that seek cooperative solutions to problems of mutual consequence to East and Wett. Working with the Center's muitidisciplinary and multicultural staff, participants include visiting scholars and researchers; leaders and professionals from the academic, government, and business communities; and rrraduate degree students, most of whum a re enrolled at the Lniversity of Hawaii. For each Center participant from the United States, two participants are sought from the Asian and Pacific area.

Center programs are conducted by institutes addressing problems of communication, culture learning, environment and policy, population, and resource systems. A limited number of "open" grants are available to degree scholars and research fellows whose academic interests are not encompassed by institute programs.

The U.S. Congress provides basic funding for Center programs and a va riety of awards to participants. Because of the cooperative nature of center programs, financial support and cost-sharing are also provided by Asian and Pacific governments, regional agencies, private enterprise and foundations. The Center is on land adjacent to and provided by the Iniversity of Hawail.

TU FAST-WLST CONMLLNICA TION INSTITLTE concentrates on the role of con muxication in ecrnom ic and social development and in the sharing of knowlenge aross cultural barriers. The Intitute awards scholarsiaps for graduate stury in communication and related disciplines, prima rily at the iniversity of Hawa i ; conducts a variety of professional development projects for communication workt $r$ in specitized fielde of economic and social development; invites sellows and iaiting scholars to the center for study and research in communication anc to belp d-eign projecte: offers Jefferson Fel] owships for Asian, Pacific and [.S.

ournajist: for 1 semester at the Center and the University of Hawaij; conducts and ansist in designing ond carrying out research; arranges conferences and seminars relating $t$ ) sipnificant topics in communication; assembles revant communication materiale with emparis on Asian and Pacific material and makes these availabie for student: scholar:, and practitionere at the Center and elsewhere; and publishes papers, riports, newsietters, and other materials emanating from the above activities.

Cover design by Wendell Ogata 
EVOLVING PERSPECTIVES ON THE RIGHT TO COMMUNICATE 


\title{
EVOLVING PERSPECTIVES ON \\ THE RIGHT TO COMMUNICATE.
}

\author{
edited by \\ Jim Richstad \\ L.S. Harms
}

with a Foreword by

Jean d'Arcy

August 1977

\author{
East-West Center \\ East-West Communication Institute \\ 1777 East-West Road \\ Honolulu, Hawaii 96848
}




\section{ABSTRACT}

The "right to communicate" is an evolving and expanding concept that was first enunciated in 1969 by Jean d'Arcy. This collection of 22 original essays takes the first comprehensive look at this emerging idea and examines it from the ideologically and cutturally varied viewpoints of the contributors.

The right to communicate is comprised of all the familiar rights of press, speech, opinion-as found in Article 19 of the Universal Declaration of Human Rights-as well as of the concerns for privacy, and access to media and information. But as the essays here show, the right to communicate is more than a collection or reorganization of familiar rights, going far beyond them so as to merit being called a "new human right."

\section{ABOUT THE EDITORS}

Jim Richstad is Research Associate at the East-West Communication Institute, East-West Center. In that capacity he has lead research projects on International Communication, the Flow of the News, and has headed the JF seminar for mid-career journalists, held since 1967 at the EWC.

L.S. Harms is Professor of Communication at the University of Hawaii, Manoa. He is coeditor of Right to Communicate: Collected Papers and has presented several papers at international meetings on this topic. He is Executive Secretary of the Right to Communicate Working Group (based in Hawaii).

(C) 1977 by the East-West Center, East-West Communication Institute. All rights reserved.

Printed in the United States of America.

LIBRARY OF CONGRESS CATALOGING IN PUBLICATION DATA

\section{EVOLVING PERSPECTIVES ON THE RIGHT TO COMMUNICATE.}

Includes bibliographical references.

1. Communication, International-Addresses, essays, lectures. 2. Freedom of information-Addresses, essays, lectures. 3. Communication-Political aspects-Addresses, essays, lectures. I. Richstad, Jim. II. Harms, Leroy Stanley, 1928-

P96.I5E9

301.14

$77-22737$ 


\section{CONTENTS}

Preface: Dynamics of the Right to Communicate

PART I. The General Concept: Some Introductions

The Right to Communicate: An Evolutive Concept for a New Personal and Social Dimension of a Fundamental Human Right

ALDO ARMANDO COCCA

The Right to Communicate: Emerging Concept and International Policy JERZY MIKULOWSKI POMORSKI

It's a Long Way to Communication

HENRY R. CASSIRER

Is Asia Alone in Its Ambivalence?

Y.V. LAKSHMANA RAO AND LUI-TAN KWAN SIU

Four Rights of Communication: A Personal Memorandum HIDETOSHI KATO

PART 1I. Specific Communication Rights: Analysis of the Concept

The Right to Communicate: A Philosophical Framework for the Debate DESMOND FISHER

89

Freedom to Communicate: An American Perspective DONALD M. GILLMOR

A Right to Communicate: A Canadian Approach HENRY HINDLEY

Communications Rights: A Latin American Perspective LUIS RAMIRO BELTRAN S. AND ELIZABETH FOX DE CARDONA

The Right to Receive Communications: A Thought Worth Entertaining DON R. LE DUC

PART III. Basic Issue Areas: Resources, Needs, Rights

Scarcity, Abundance, and the Right to Communicate ITHIEL DE SOLA POOL 
Development Journalism and the Right to Communicate ASOK MITRA

Progress of Technology and Social Problems of Mass Communication B.M. FIRSOV

The Economic Dimensions of the Right to Communicate DONALD MCL. LAMBERTON

The Right to Communicate and the Arabian Nights Tales HAMDY KANDIL

PART IV. Communication Environment: Some General Perspectives

A Sociologist's View of the Right to Communicate

PAVEL CAMPEANU

The Right to Communicate as Seen in Developing Countries ALI MOHAMMAD SHUMMO

The Right to Communicate

A.F. KALIMMULAH

The Right to Communicate: The Indonesian Case ASTRID S. SUSANTO

The Right to Communicate 


\section{FOREWORD}

"Radio must be changed from a means of distribution to a means of communication. Radio would be the most wonderful means of communication imaginable in public life, a huge linked system-that is to say, it would be such, if it were capable not only of receiving but of transmitting, of allowing the listener not only to hear but to speak, and did not isolate him but brought him into contact."

These remarks are those of Bertolt Brecht in his book The Theory of Radio and date back to 1932. I found them in the August 1976 issue of Intermedia in a challenging article by Dr. J. Challis of the Australian Broadcasting Commission on what he calls the right to broadcast and the role to be played by local radio stations.

I must confess to not yet having read The Theory of Radio. I certainly shall. So, forty-four years ago, Brecht had a Tready seen what the contributors to this book of essays wanted to convey: the need for man to communicate, the need to use the right technology for this purpose, and the disrupting effects of oneway transmission. To all of us it is quite comforting.

Undoubtedly, it would be interesting to find out why the founding fathers of broadcasting, Lord Reith, David Sarnoff, and their contemporaries, did not conceive it according to such an objective, of communication rather than distribution. At a time when telegraph and telephone presented a two-way pattern of communication, why was radio established on the one "way model of the press? Why was it made a mass medium and not a medium of communication? The answers might be many: a search for a centralized public service, a search for profit or for power, a wish to educate or to indoctrinate, the state of the technology, etc. But the real answer may be that this need of communication for man was not clear enough to become a goal in itself at a time when it was still orally fulfilled at the community level in closed and still homogeneous societies.

Anyhow, it is essential to realize that practically everyone now is conscious of some of the wrong social and cultural consequences--upon the individual as well as upon societies-- of one-way transmission and at the same time is fully aware that the present state of communications technology permits quite a different objective and a different communication pattern. The new, unexpected popularity of citizens' band radio is but one demonstration--and not a trivial one--of what Brecht had called for.

This book of essays will be published after Unesco's General Conference in Nairobi. The right to communicate is on its agenda, and the delegates will 
consider the director mgeneral's report on it. It is to be hoped that the delegates will appraise the right as it presently stands: an evolving concept stijl to be studied in depth, but a concept rich in potential for developments in a field where the UN General Assembly has been stalled since 1954. Political reasons have been invoked for such a lack of progress. In this case they are only an excuse or a mask for something deeper and larger.

Actually, this concept of information is essentially linked to a given technology and to the use of the mass media, especially print. It cannot form the basis for a proper formulation of the law that, one day, will be established at the international level for the use of communication media. It only reflects the problems and preoccupations of one part of the world at a given time in history: the immediate pre-and post-war period. It is not large and comprehensive enough to provide answers to the difficult problems of our entire contemporary world. It fails to incorporate all the different legal, ethical, philosophical, and traditional approaches to communication within the various peoples on this planet. Moreover, as a possibility for achievement, it does not accurately reflect what the present communications technology gives us. A fresh new approach is required. A full study of a possible right of man to communicate might open the way to progress in. this entrenched field.

This book of essays therefore is intended to be a preliminary exploration of a possibly helpful concept. It is encouraging to see how so many contributors from various countries, East and West. North and South, already react to it. Without the impulse and the continuous efforts of L. S. Harms, who brought new dimensions to what was initially a statement of facts, this first step never would have been made. The reader's gratitude must go to him, to Jim Richstad who col "' laborated with him, and to the contributors who met the challenge of exploring a new and perhaps utopian world. 


\section{ACKNOWLEDGMENTS}

The authors of these essays developed their contributions in a very short time and without compensation. They all wrote in their personal capacities. We express our deepest thanks to each and evexy one of them.

The volume is a direct outgrowth of the work of Jean d'Arcy in this area, and we wish to acknowledge with thanks his foreword to this volume. The direct impetus for this collection, however, came out of discussions between Tomo Martelanc, Aldo Armando Cocca, and the editors at the close of the 1975 International Broadcast Institute conference in Cologne; they stressed to us the need for this volume and helped us select the authors.

Support of many kinds has been received from the Universicy of Hawail and the Communication Institute of the East-West Center. Small grants in support of this volume were received from Dr. Fujio Matsuda, President of the University of Hawaii, and program funds allocated to the Communication Institute were also made available. Kay Garrett, EWCI Publications Officer, has supervised the production of this volume. Phyllis Watanabe prepared the camera ready copy. Jackie Bowen has helped with final editing and references. The Social Sciences and Linguistics Institute, under the directorship of Dr. Donald Topping, has made Institute resources available to and provided a site for the Right to Communicate Working Group; Institute staff members have been most helpful, particularly Richard Barber. A special thank you is owed to the contributors to the Right to Communicate Fund which is maintained in Honolulu by the University of Hawail Foundation.

The dedicated and skillful work of Kathleen Ayumi Kie has, to a very great extent, made this volume possible. We know the authors join us in thanking her. 


\section{CONTRIBUTORS}

All of the contributors wrote in their personal capacities, and their institutional affiliations are listed only for information.

Jean d'ARCY of Paris is president of a French communication company and Chairman of the International Institute for Communications.

Luis Ramiro BELTRAN of Bogota is Representative for Latin America of the Division of Information Sciences in the International Development Research Center.

Pavel CAMPEANU of Bucharest is Director of the Research Department of Romanian Radio and Television.

Elizabeth Fox de CARDONA of Bogota is Assistant to the Representative for Latin America of the Division of Information Sciences in the International Development Research Center.

Henry R. CASSIRER of Annecy is an international consultant for communication and education.

Aldo Armando COCCA of Buenos Aires is Professor of International Law at Buenos Aires University and Ambassador-At-Large for Argentina.

Desmond FISHER of Dublin is Director of Television Development at Radio Telefis Eireann.

B. M. FIRSOV of Leningrad is Professor and Head of the Unit of Mass Communication in the Institute for Socio-Economic Problems in the USSR Academy of Sciences.

Donald M. GILLMOR of Minneapolis is Professor of Journalism and Mass Communication at the University of Minnesota.

L. S. HARMS of Honolulu is Professor of Communication at the University of Hawaii at Manoa.

Henry HINDLEY of Ottawa is retired as special policy advisor to the Deputy Minister of Communications in Canada.

A. F. KALIMULLAH of Rawalpindi is Director of Programmes in the Pakistan Broadcasting Corporation. 
Hamdy KANDIL of Cairo is Unesco Regional Communication Advisor for the Arab States.

Hidetoshi KATO of Tokyo is Professor in the Faculty of Law in Gakushuin University in Tokyo and a Research Associate at the Communication Institute of the East-West Center.

Donald McL. LAMBERTON of Brisbane is Professor and Chairman of the Department of Economics at the University of Queensland.

Don R. LE DUC of Madison is an attorney and Professor of Communication at the University of Wisconsin.

LUI-TAN Kwan Siu of Singapore at the time of writing was Assistant Researcher at the Asian Mass Communication Research and Information Centre (Amic).

A sok MITRA of New Delhi is Professor in the Center for Regional Development in Jawaharlal Nehru University.

Jerzy Milkuowski POMORSKI of Warsaw is Professor of Economics at the Institute of International Social and Economic Relations.

Ithiel de Sola POOL of Cambridge is Professor of Political Science at the Massachusetts Institute of Technology (M.I. T.).

Y. V. Lakshmana RAO is a communication consultant, and was Secretary-General of the Asian Mass Communication Research and Information Centre (Amic) in Singapore at the time of writing.

Jim RICHSTAD of Honolulu is Research Associate in the Communication Institute at the East-West Center.

Colin SHAW of London is Director of Television for the Independent Broadcasting Authority, and was Chief Secretary of the British Broadcasting Corporation at the time of writing.

Ali Mohammad SHUMMO of Khartoum is Minister of Youth for the Sudan.

Astrid SUSANTO of Jakarta is a Research Associate in Communication Science at the University of Indonesia and Acting Head of the Bureau for Information, Culture, Science and Technology at the National Planning Agency (BAPPENAS). 


\section{COMPANION PUBLICATION}

Evolving Perspectives on the Right to Communicate is the first book of original essays on the right to communicate. A companion volume, Right to Communicate: Collected Papers, was published in June 1977 by the Social Sciences and Linguistics Institute, University of Hawaii, and is available from The University Press of Hawaii (2840 Kolowalu St., Honolulu 96822). The Collected Papers, edited by L. S. Harms, Jim Richstad, and Kathleen A. Kie, contains eleven articles delivered at widely scattered places or published earlier, and an overview by the editors. These papers were used as basic reference materials by several of the writers in preparing the original essays in Evolving Perspectives, and are cited by many of them. As a convenience, the articles in the Collected Papers are listed below, by author and title:

Jean d'Arcy, "Direct Broadcast Satellites and the Right to Communicate" and "The Right of Man to Communicate"

Henry Hindley, "Communication Rights in an Instant World"

L. S. Harms, "Communication Rights of Mankind: Toward a Multicultural Worldview"

Olga Jurgens, "Communications: Individual Rights/State Rights"

Bertil Zachrisson, "Intervention at General Policy Debate at Unesco"

Y. V. L. Rao, "Information Imbalance in Asia"

Gunnar Naesselund, "Relations between and Perspectives within 'Development Support Communication,' 'Communication Policy Research and Planning, ' and 'The Right to Communicate' as Seen by Unesco"

Edward Ploman, "Present International Framework of the Right to Communicate"

Jerzy Mikulowski Pomorski, "Right to Communicate: National Legis lation or International Policy?"

L. S. Harms and Jim Richstad, "Right to Communicate: Human Rights, Major Communication Issues, Communication Policies and Planning" 
Jim Richstad, L. S. Harms, and Kathleen A. Kie, "The Emergence of the Right to Communicate: 1970-1975" 


\section{PREFACE: DYNAMICS OF THE RIGHT TO \\ COMMUNICATE-A.BRIEF HISTORY OF THE CONCEPT}

IIM RICHSTAD AND L. S. HARMS

The right to communicate as a distinctive concept was first enunciated by Jean d'Arcy in a 1969 article in the European journal EBU Review. 1. The article, "Direct Satellite Broadcasting and the Right to Communicate," provided an early world view of the meaning of the global communication revolution and the need for new social and political concepts to harmonize those technological capabilities with human information and communication needs.

Soon after this classic statement, a series of intensive studies in Canada developed some hard and practical parameters of the right to communicate, in an effort to meet the particular felt needs for communication in that country.

Other work soon followed and enlarged, expanded, enriched, and clarified what was meant, and what could be meant, by the right to communicate. Activity by mid 1977 was evident in many areas of the world, in many forums. This volume of essays is one result.

This paper is an attempt to explore the intellectual foundations of the right to communicate--to determine the components of the right and to identify where they developed, as well as to try to give a full answer to the question of why the right to communicate is new. We hope also, through this intellectual history of the idea, to give a deep sense of what the right to communicate can mean for humankind. We realize that this brief history is partial, incomplete, and fragmentary - some of the first words rather than the final ones. The right to communicate is an emerging and evolving concept.

Important conceptual attempts, perceptions, and involvements in the right to communicate came in discussions during the first half of the 1970s. These include the meeting of the International Broadcast Insticute in Nicosia in 1973, Mexico City in 1974, and Cologne in 1975. The right to communicate was introduced, dism cussed, shaped, described, and evaluated by this global organization.

Another milestone in the early 1970 s was the emergence in Unesco of the right to communicate concepts, leading to a study resolution and other, continuing activity. Unesco communication officials saw in the concept a way to bridge what was becoming a polarization between the concept of free flow of informa." tion and that of national control of communication, a possibility of keeping the debate open.

A particularly important development for the authors of this paper concerned the emergence of a new paxadigm of communication in a Honolulu conference in 1972. Out of that meeting came, at least for the authors, a strong affirmation of the basic principle that communication is an interactive process, a participatory process, a multiway process. 
In an earlier work, we described the development of the right to communicate as occurring in three overlapping stages, 2 Fixst, the pioneer stage, where individuals and institutions were essentially working separately on pieces of the concept, with little contact with each other. This phase includes the d'Axcy 1969 paper, the Canadian studies, and the new paradigm work in Honolulu. Second, there were organizing activities, when professionals and scholars started regular contacts with each other, when the right to communicate was increasingly recognized at conferences and seminars, and when it was beginning to be taken seriously. Third, the stage we are now in: the development of projects designed to fully explore and expand the concept, to apply it in a multicultural context, and to formulate the new methodologies necessary for research in the rich questions inherent in the right to communicate.

This paper traces the intellectual constructs of the right to communicate as they evolved from the different activities over the past seven years, in an attempt to show why we have a new and exciting concept for communication, one that opens a context for all humans, one that is based on human communication needs, and one that recognizes the present and future technology. As we move through the developments and into the more organized, global aspects of the right to communicate, there seem to emerge three general views of man and his relation to society and to communication. These views, expanded later in the papex, are the traditional Western view of freedom of expression, the Soviet-socialist view, and the increasingly coherent Thind World view. All contribute elements to what: can become a multicultural right to communicate, and all restrict in some sense what can develop. With that, we would like first to examine the d'Arcy 1969 paper.

D'Arcy, in his 1969 paper, initiated and focused much of the subse quent work on the right to communicate. He accurately predicted "the time will come when the Universal Declaration of Human Rights will have to encompass a. more extensive right than man's right to information, first laid down 21 years ago in Article 19. "This is the right of man to communicate." Further, he established the role of the new communication technologies in this transformation, particularly the direct broadcast satellite.

The ideas contained in the 1969 paper, although they have grown broader and deeper over the years, still contain much of what is meant by the term the right to communicate. D'Arcy immediately moved from the concept of freedom of information to the right to communicate, as something is needed to shape policy and the future developments of communication. He saw the new technologies-broadcasting satellites, computers, videotape recorders, and wixe distribution of sounds and images--as bringing freedom of exchange of information into a context of what has been a "scarcity of communication possibilities." He saw information liberation in the new technologies, and the need for a broader, new concept of social policy, the right to communicate. "The instruments of communi." cation," d'Arcy wrote, "still seem to be something quite separate from ourselves and we go on delegating their use to magicians, even if we do complain about them." This is the time, he said, to break the mental barriers of the past, to construct the communication-rich future that is now possible. The new technologies cannot be contained within the concepts of Article 19 and similar guidelines and laws: new ones are needed, within a broader right to communicate framework. The people of the world know man has walked on the moon because they have seen it through television. D'Axcy did not specify what he meant by a right to communicate, but he did place it in the context of technology and global interdependence and the growing 
possibilities of information abundance. Although much of the world will remain in an information-scarce condition for some time, the global view must be ready for the future information abundance.

The Canadian telecommunication studies of the early 1970 s explored many of the basic principles of a right to communicate. 3 These included such important concepts as that communication should satisfy the spiritual as well as the material life and that new technologies offer greatex access to information and wider participation in community affairs. Some explicit statements on the right to communicate were put together in a remarkable paragraph of Instant World:

The rights to hear and be heard, to inform and to be informed, together may be regarded as the essential components of a "right to communicate." ... But the realization of a "right to communicate" is a desirable objective for a democratic society, so that each individual may know he is entitled to be informed and to be heard, regardless of where he may live or work or travel in his own country. The people of Canada--as a body and as individuals --are therefore entivled to demand access to efficient telecommunications services on a non-discriminatory basis and at a reasonable price. 4

Here are clear intellectual foundations for the two-way process of communication--to hear and to be heard, to inform and to be informed--and for the concept of equity in communication resources. And for the concept of vesting communication rights in both society and the individual.

Later in the book is a classic statement: "If it be accepted that there is a 'right to communicate, ' all Canadians are entitled to it. "5

One of the most enduring themes of Instant World and of the right to communicate is that people should have equitable access to information and, more broadly, to appropriate communication resources. The point was reached where participants in the studies considered a "right to communicate' as a fundamental objective of Canadian society." 6 funther significant attribute of the right to communicate is that there should be safeguards against invasions of privacy. 7

Taken together, Instant World and the Telecommission studies provide the first extensive examination of the importance of the xight to communicate and some of the means to make such a right meaningful. Participants in the studies were aware of and impressed by the 1969 d'Arcy paper, Henry Hindley tells us.

As a result of Instant World came Canadian concern over communication policies that would put such concepts into effect. The use of communication. satellites to provide village service in the north of Canada, for example, and to link with Canada's own system the Indians and Eskimos who previously were out of the communication process is an example of implementation of some parts of the right to communicate. Another can be seen on the international scale, where policies are being implemented to preserve the Canadian-ness of the country's mass media systems to avoid dominance by the communication flow from the United States. These practical applications of the theoretical concepts of access to communication resources offer a means to test the concepts. 
The Canadian experience, still evolving and exploring parameters of the right to communicate, offers examples of applications not only on the national but also on the subnational and transnational levels.

A nother major contribution to the development of the right to communicate, at least from the authors' standpoint, gxew out of an early 1972 conference in Honolulu on Major. Issues in World Communication. 8 The conference examined the role of communication in population programs, communication in the future, and communication technology. In papers and discussion, it soon became apparent that the participants were not talking about the classic Lasswellian communication paradigm "Who says What, in Which Channel, to Whom, with What Effect?" or, more familiarly, "Who says What to Whom, How, with What Effect?" Although the Lasswellian formulation guided much of the communication research of the past forty-five years, it was found increasingly inadequate for modern needs. In the population communication papers, the themes included "the target that talks back." In communication technology papers and discussion, it was clear that the means to do almost any thing are available, or soon will be. This led Daniel Lerner to observe that the Lasswellian paradigm had been set aside, that a new, two-way, talk-back paradigm was emerging. In effect, the communication process was turned around, with the emphasis on user needs, not on the transmitter's message distribution patterns or strategy or effectiveness and manipulation. The authors wrote a paper developing this new paxadigm, trying to define it and what it would mean to communication thinking and research. In 1973, we said:

Among the frequent descriptors of the paradigm are the concept terms of participatory and participation, two-way interaction, interchange, message generation, system purpose, need discovery and satisfaction, communication rights, "grassroots," emergent and moral. .. The roots of the theory are anchored in the communication needs of man and the communication rights and responsibilities of mankind. 9

This new paradigm has become basic in our approach to the right to communicate. By 1972, Harms had met d'Arcy in Paris and was writing on the topic. In his 1973 paper on "Communication Rights of Mankind: Toward a Multicultural Worldview," 10 Harms examined several concepts that continue to be major considerations in development of a right to communicate. These include the point that the "right to communicate is a fundamental and universal Human Right" and that the right must be developed from a "multicultural worldview." Harms wrote: "To transcend the limitations inherent in any single cultural perspective, it becomes necessary to reconceptualize the problem of Communication Rights from the perspective of a multicultural worldview." Other points made by Harms were that the development of the right to communicate must grow from an "extensive multicultural dialogue" and that it is not something that will take place soon. Another important intellectual construct put the examination of the right to communicate in a context of "communication needs, communication technology, and communication policy." These three concepts have endured through most of the discussion on the right to communicate and are far from settled. A further contribution of the paper was the examination of several of the thirty articles in the Universal Declaration of Human Rights that bear on the right to communicate.

A nother important conceptual statement on the right to communicate was made by Harold Lasswell in a Honolulu speech in 1973: "The Future of World Communication: Quality and Style of Life."11 Lasswell presented two models of 
human organization, the oligarchic model and the participatory model. Both relate quite directly to communication patterns and processes that would be found in different social organizations. In the power-oriented oligarchic model, Lasswell said, communication was "used to indoctrinate and distract," whereas the "intermediate, resource-parsimonious technology" of the participatory model led to the use of communication to "provide attention opportunities that generate and re-edit common maps of man's past, present and future and strengthen a universal and differentiated sense of identity and common interest." 12 Lasswell in many ways was also contrasting what could be the mass media type of one-way communication with the multiway, nonlinear mode of communication, which would allow for wide participation of various people on their own terms. There is also a clear distinction between vertical and horizontal communication systems. Although these points were not fully developed but rather were implicit in the Lasswell paper, they are important particularly because they come from the man who developed the source-receiver communication paradigm that was so influential in research over the past forty-five years.

Further foundations for the right to communicate were laid in a series of experimental seminars on the right conducted at the University of Hawain by the authors since 1973.13 The seminars used contrasting approaches that still provide a framework for the right to communicate discussions: one of the seminar directors wanted to work with Karl Popper's clouds, another with his clocks. The urge to be more concrete in conceptualjzation was particularly strong in the students, who wanted parameters to work with. The intellectual content of the seminars developed the linkages between communication needs, technology, and policy, and the relationship of communication rights to other human rights. The immense difficulties of where the right was vested, in the individual or in the community, were somewhat resolved by saying that it had to be vested in both places, although for different reasons. A question that was never fully resolved was: must the right to communicate have the force of law behind it, or are we talking about moral precepts or guides? Some felt that enforceable rights were the only meaningful ones and we should forget about the rest. Other participants felt that the discussion, the statements, the examination of the alternatives in the right to communicate debate was a positive force, and that it was too early in the process to stress enforceable rights within a multicultural concept. The great problems of developing the multicultural concept were examined, and for many seminax hours a deep feeling of despair seemed to take hold because it. seemed so unlikely that the different human societies around the world, and the subsocieties within them, could ever come to agreement on such a topic as the right to communicate. Out of the working papers and documents for the seminars grew a comprehensive collection of essential first works on the right to communicate, which have been used as background materials for the present collection of essays. 14

Perhaps the most significant effort coming out of Hawaii resulted in a justification paper and proto-type resolution in fall 1974, when E. Lloyd Sommerlad was at the East-West Center in Honolulu and conferred with the authors. Sommerlad said he thought the time was right for a resolution in Unesco, and a draft would be most useful in creating a discussion. He further suggested that the authors take the first crack at it. The result, after many invaluable suggestions from Sommerlad, was a two-page statement highlighting the key elements of the right to communicate as then understood by the writers. 
The statement began with the note that communication is a basic human process, in local communities as well as in the global community. Article 19 of the Universal Declaration of Human Rights was cited:

Everyone has the right to freedom of opinion and expression; this right includes freedom to hold opinions without interference and to seek, receive and impart information and ideas through any media and regardless of frontiers.

Article 19, strong and comprehensive for its era, was found increas ingly unable to accommodate the rapid technological changes taking place--the widespread distribution and interaction capabilities never before possible--and the practical applications of the policy of the "free flow" of information. Many aspects of a general right to communicate were recognized in some societies by some groups of people, yet a comprehensive, universal, multicultural conceptualization of communication rights was far from existent. The justification statement then covered several of the basic constructs of the right to communicate.

In the communication era, the communication resources of man should be grounded in a two-way, interactive, participatory process. The world is being flooded with information useful to people, but that information needs to be organized, localized, individualized, easily and inexpensively available and responsive to human needs. And with a high degree of access comes concern about rights of privacy. Three special concerns of the communication era are the right of privacy, cultural preservation and diversity, and information overload. With wide access to vast quantities of information, there will be a need to balance the flow of information to avoid the extremes of both overload and scarcity, and to balance the sending and receiving of information.

The proto-type resolution stressed these themes, with emphas is on communication technology development, global interdependence, and the earlier work by Unesco on freedom of expression and association and cultural choices and freedom, and it related the development of communication policy science with the right to communicate. Again, communication was viewed as a two-way, interactive, participatory human process.

From Honolulu, the justification paper and resolution were carried to the annual meeting of the International Broadcast Institute in Mexico City for a series of intense evening meetings that tested the right to communicate in an international setting, The IBI had introduced the concept of a right to communicate at its Nicosia meeting in 1973, the first time an international group of communication professionals and scholars had paid serious attention to the development. In many ways, the 1973 Nicosia meeting set the stage for the intensive Mexico City debates.

A major challenge in Mexico City to the right to communicate papers came in the form of questioning of the free flow concept and the concern that the right to communicate was just another name for the free flow idea. Some members of the working group intensely opposed the notion of free flow, embedded in Article 19 , because, they said, it meant a one-way flow of information, from the developed to the developing countries, that was controlled to their advantage by the developed countries. Free flow meant little more than "information imperialism" to some of the participants. It soon became evident, as Daniel Lerner was to remark at a 1976 conference, 15 that the phrase "free flow" is such an emotionally loaded term 
that perhaps we need to retire it and find a replacement. Although, as many observers from many regions of the world have acknowledged, free flow is theoretically sound, the international communication flow has never been a free flow, but rather is the imbalanced, one-way flow noted above.

To make international communication equitable, concerns such as balance, access to communication resources, and cultural integrity need to be considered with the same urgency as free flow. The right to communicate at its core is an attempt to widen the parameters of communication to account for these very real and legitimate concerns in a serious way. The Mexico City discussions were a hard intellectual and multicultural test, and depth was added to the concept of a right to communicate. From Mexico City, the discussions of the right to communicate moved to Unesco headquarters in Paris and then to Sweden, where a resolution on the right to communicate was prepared for the November 1974 meeting of Unesco.

The Swedish resolution was introduced at the Unesco general conference by Minister Bertel Zachrisson, with emphasis on the role of the right to communicate in a democratic society. He said:

In education, science and culture, the right to communicate is essential. This right is indispensable in order to accord people their democratic rights and make it possible for everyone to exercise democratic control, and to grant all members of society participation in its development. The will of the people cannot be effectively expressed without a free public discussion and open communication. 16

The resolution itself referred to the Universal Declaration of Human Rights and the Charter of the United Nations; then it said that "communication is the foundation of all social organizations" and that "human communication must be an interactive participatory process." The insistence that communication must be an interactive participatory process was a stronger statement than had been made before. The problems of access and control were noted, along with the promises of communication abundance. Other points concerned "the plurality and equality of cultures and the potential now existing for all groups and individuals in society to give full expression to their cultural values." The emergence of a science of communication and the need for planning of communication resources were recognized, as was the point that "all individuals should have equal opportunities to participate actively in the means of communication." The resolution asked the director-general "to study and define the right to communicate."

A key element of the right to communicate--the right of participation in the communication process --was strengthened by an amendment by the Netherlands, which added the phrase: "ways and means by which active participation in the communication process may be possible."

The resolution that was passed, then, not only contained the call for a study and definition of the right to communicate but also urged investigation into ways in which humans could participate actively in the communication process. This addition to the Unesco study plan gave a practical application direction to the right to communicate discussions, and it would help to guide research proposals in Unesco and elsewhere. 
Gunnar Naesselund, director of the Unesco Department of Free Flow of Information and Development of Communication, interpreted the resolution as a turning away from what had become an increasingly sterile discussion on freedom of information. Naesselund said the right to communicate and active participation provide a chance to put aside the increasingly stylized debate on freedom of the press and freedom of information and "to see in the right to communicate the pattern of access and participation and of dialogue, or even a multilogue which will enrich not only individuals but also States in their relations with the outer world." $17 \mathrm{He}$ also saw in the resolution and study plan a chance for "a better balance between the rights of States and of individuals."

The Unesco study surveyed member countries and professional organizations, seeking to identify components of the right as they applied to nations, individuals, and media institutions. In all, more than forty specific components were identified in the Unesco survey, with priority listings for individual rights, rights of nations, and media institution conceras.

In a background paper prepared for media organizations from Sommer lad's office, 18 two new foundations to the right to communicate were put forward. The first related to the new international economic order and stressed that the "social aspect is at least as crucial as the economic aspect." The second, related concept is one that has been shown over and over in studies and applications of the use of communication in such national development programs as agriculture, education, public health, and, particularly, population. The letter notes that "the human being is at the center of the development process. This leads to a recognition that development cannot take place without popular participation, involvement and motivation. The implications for communication are obvious." The Unesco document $19 \mathrm{C} / 93$ was approved at the 19th General Conference in Nairobi in November 1976. An important long-term research program was included in the document.

Duxing the two years between the Unesco general conferences, several important events took place--in Sri Lanka, in Cologne, and in Honolulum-that further contributed to the development of the right to communicate. And one of the activities is responsible for the present volume of original essays.

After the Swedish resolution was passed in Unesco in November 1974, the first major discussion of the right to communicate was held in Sxi Lanka under the auspices of the Asian Mass Communication Research and Information Centre. 19 The announcement of the AMIC meeting noted that "The concept of the 'Right to Com municate' has provoked a great deal of inte rest among the international communica." tion fraternity," and in his keynote paper, AMIC Secretary-General Y. V. Lakshmana Rao stated:

It seems to me that the first question we need to find answers to is: What has happened since 194.8 that has brought about almost a total turn-around in our approach to the grandiose intentions in the field of flow of information? What is it that has gradually but perhaps inescapably led us to question all over again premises upon which the whole edifice had been built? Why is it that the same UN agency that had successfully established agreements to facilitate the free flow of information around the world, today finds it necessary to go through the whole exercise again and initiate studies to look into more or less the same question all over again under a different phrase: "The Right to Communicate"?20 
The AMIC conference was focused on Information Imbalance in Asia, and the right to communicate was discussed informally from time to time during the week in relation to the information imbalance problem.

In a special two-hour session on the final day of the AMIC conference, several panelists made some pointed and useful observations. For instance, Rosihan Anwar said, "Dialogue on the Right to Communicate could shift the concern in some Asian countries from the technology to the substance of communication. " Anwar. discussed the implications of concentration on up-down versus down-up communication in a country. He also asked, "What happens when institutions are not found to be adequate?" A. F. Kalimullah of Pakistan added that the problem of defining a multicultural right to communicate is bound to be a difficult one. He pointed out that "If I claim a right for myself, I. must be prepared to concede it to others." He felt that out of a beginning such as this, a "two-way traffic" will develop into a "mutual understanding." Kalimullah noted that "The right to communicate becomes relevant as we seek to treat all humans as one family." Anwar, Kalimullah, and the other members of the panel raised many of the same questions and voiced many of the same concerns that had been expressed elsewhere in the world.

The AMIC panelists in Sri Lanka recognized the difficulties, the problems, the hard realities that would have to be dealt with if a right to communicate concept were to evolve. Nonetheless, a "healthy optimism," as one observer put it, seemed to pervade the discussion.

The International Broadcast Institute conference in September 1975 in Cologne followed by a few months the AMIC conference in Sri Lanka. Working Group IV, in a series of meetings over four days, first discussed four papers that had been prepared as a background and then turned to the task of describing the right to communicate. The description developed by that thirty-person, culturally diverse group is repeated in its entirety below.

Everyone has the $x$ ight to communicate. It is a basic human need and is the foundation of all social organization. It belongs to individuals and communities, between and among each other. This right has been long recognised internationally and the exercise of it needs constantly to evolve and expand. Taking account of changes in society and developments in technology, adequate resources-human, economic and technological--should be made available to all mankind for fulfillment of the need for interactive participatory communication and implementation of that right. 21

This descriptive statement, we have found, is very rich and not only includes many of the essential ideas from the earlier discussions but also begins to organize them.

At the close of the IBI Cologne meeting it was becoming clear that the descriptive statement also pointed the way to an important next step. Both Tomo Martelanc and Aldo Armando Cocca strongly encouraged Harms and Richstad to collect a body of original thinking on the right to communicate concept. Jean d'Arcy gave his strong support to the idea, and thus the plan for this volume was a direct outgrowth of the Cologne meeting.

Since the d'Arcy paper in 1969, it has been apparent that a major influence of the right to communicate concept will be on communication policy. It 
now appears that this influence will be widely felt not only at the national level but also at the subnational and international levels, as has been evident in Canada. This influence was evident also during a week-long conference in Honolulu in April 1976 at the East-West Center on the topic of Fair Communication Policy. 22

At that East-West Center conference, a paper titled "Free Flow of Information, Balance, and the Right to Communicate" by E. Lloyd Sommerlad began to develop the essential links between the earlier free flow idea, the expanded idea of a free and balanced flow, the right to communicate, and the requirements for a body of fair communication policy. Sommerlad concluded:

The right to communicate is not just a new name for the free flow of information. It has much wider dimensions. . . The move to define and develop communication rights is an attempt to remedy the inadequacies of the free flow system. . . . It will involve a reallocation of resources so that communication rights do not belong only to the economically powerful. It could be the basis for the application of new communication technologies in the third world. . . A number of scholars have stressed that the study of communication rights requires a "multi-cultural perspective." The right must recognize the growing interdependence among nations, the importance of cultural plurality, and the value of maintaining cultural integrity while benefiting from the enrichment which flows from cultural exchanges. - . The "right to communicate" presupposes the availability of and access to resources, and this in turn depends on policy decisions and the planning and organization of a communication system--on the international no less than the national level. ...

This brings us back to the question: ... is a "world communication policy" a realistic aim? The problem can well be approached within the framework of studies on the xight to communicate. A great deal of patient research will be required, during which it should be possible to find some agreement on what should be the goal and purpose of communication in the world and on the structure of international communication systems that will establish "balance" and remove "dependency." Whatever the outcome, the search will be worthwhile. It will deepen our understanding of communication, and the multi cultural dialogue between East and West, North and South, industrialized countries and the third world will help identify common ground for greater international cooperation.

Throughout discussions at the Fair Communication Policy Conference in Honolulu, many of the basic issues that have been part of the right to communicate discussions in other parts of the world were again evident. For instance, the importance of two-way participation was stressed as a necessary "balancing" mechanism for communication, and the PEACESAT network was cited as one low-cost and effective example of such a mechanism. One participant observed that PEACESAT does embody many of the right to communicate concerns, and that its operating policy is indeed a "fair" one.

In the course of the East-West Center meeting, Wilbur Schramm remarked that he felt the "'Right to Communicate' is still a skeleton without flesh . . but nevertheless something that deserves our most serious thoughts." The essays in this volume, we feel, add that flesh and deserve our most serious thought. 
Today, an examination of the right to communicate organizing concepts leads to the observation that the general xight to communicate is differentiated from a specific communication right, or a set of communication rights. Further discussion and study can be expected to clarify the dimensions of a fourlevel concept somewhat like the one presented below, around which the original essays in this volume are organized:

1. Universal Right to Communicate: a comprehensive, multicultural, fair, and general human right that serves to clarify values and illuminate long "range communication goals. Provides a framework for examination of any specific right or a set of specific rights.

2. Specific Communication Rights: a set or collection of rights capable of being defined and acted upon. The set may add new rights, or fuse two old ones, and so on. A specific communication right has privileges and responsibilities, or guarantees and obligations, etc. , associated with it.

3. Communication Issues: clusters of related problems and ques tions under discussion, typically encompassing two or more specific rights and sometimes two rights in opposition. For example, a right to inform plus a right to be informed, or a right to be informed and a right to privacy.

4. Communication Environment: in the sociocultural context, human communicators react to or sense changes in the communication environment such as the structural and other problems that have generated "balance in communication flow" issues.

Obviously, further study and discussion will reshape and refine this preliminary outline, and at this early stage overlapping will be apparent.

In our view, the right to communicate is compatible with and inseparable from a participatory, interactive model of communication. That is the heart of the concept.

The importance of developing the right to communicate from a multicultural perspective has been stressed over and over again. And this is a major source of the difficulty in coming up with a simple definition of the right to communicate. In the past, definitions usually have developed within the framework provided by a single culture. The very great intricacies of culture and communication are well known, and they must be fairly reflected in any consideration of the right to communicate.

Beyond culture are broader contexts that shape communication sys tems and behavior. Although many such contexts can be outlined, one in particular seems to be important in the right to communicate. That is the contrasting views of what can be called the Western free flow concept, the Soviet-socialist national security concept, and a mixed concept in the Third World with concerns such as political and social integrity as related to international communication and national unity as it relates to domestic communication.

The Western view of free flow of communication and the Sovietsocialist view of security were brought together in the Conference on Security and Cooperation in Europe--the Helsinki agreements--with differing interpretations. 
Our purpose here is not to examine these contrasting views in detail--much has already been done on that--but to note that there are different bases from which each proceeds, and then to note that there are different and more diffuse concerns of the Third World. Communication does not, of course, stand by itself. The contrasts among the three general approaches in communication are found in other, perhaps more basic political areas as well. All three approaches are rich and provocative, and they force attention to different dimensions of the right to communicate. The degree of reconcilability of the three approaches is far from known, and it is hoped that the right to communicate framework will be large enough and will be kept open enough to let a full and rich interaction develop. This is one of the critical areas of development for the right to communicate.

We believe that the concept of a right to communicate is still open, and should remain open for some considerable time. We should be concerned at this stage not so much about what the right to communicate is in detail but about how the concept can inform, guide, and enrich activities of institutions and individuals. There is an understandable urge toward specifying particular rights, and a quest for the universal definition of the right to communicate. But, as the essays in this volume testify, there are many valid ways of looking at the right to communicate, and much can be learned about society and communication by examining the details of these different ways. The subject of the right to communicate is much too intellectually and practically fruitful to be closed off prematurely. It is time now for more differentiating of concepts, testing of contrasting views, and putting the right to communicate into practical terms at various levels of society and places in the world. 
NOTES

1. Jean d'Arcy, "Direct Broadcast Satellites and the Right to Communicate," EBU Review 118 (1969): 14.

2. L. S. Harms, Jim Richstad and Kathleen Kie, eds. , Right to Communicate:

Collected Papers (Honolulu: Social Sciences and Linguistics Institute, University

of Hawaii, 1977). Distributed by the University Press of Hawaii.

3. Instant World: A Report on Telecommunications in Canada (Ottawa: Information Canada, 1971).

4. Ibid., p. 3 .

5. Ibid., p. 229.

6. Ibid., p. 232 .

7. Ibid., p. 233 .

8. Jim Richstad and L. S. Harms, eds., World Communication: Population Communication, Communication Technology, Communication in the Future (Honolulu: East-West Communication Institute, 1973).

9. L. S. Harms and Jim Richstad, "An Emergent System Paradigm of Human Communication," op. cit., p. 83.

10. L. S. Harms, "Communication Rights of Mankind: Toward a Multicultural Worldview," in Right to Communicate: Collected Papers, op. cit.

11. Harold D. Lasswell, The Future of World Communication: Quality and Style of Life, no. 4. Papers of the East-West Communication Institute (Honolulu: EastWest Communication Institute, September, 1972).

12. Ibid., pp. 16-17.

13. L. S. Harms and Jim Richstad, "Right to Communicate: A Syllabus for a Graduate Seminar" (Unpublished. Honolulu: University of Hawaii, August 1976).

14. Harms, Richstad and Kie, Collected Papers, op. cit.

15. Conference on Fair Communication Policy for the International Exchange of Information, East-West Communication Institute, Honolulu, Hawaii, March 29April 2, 1976. Conference report published as New Perspectives in International Communication, Jim Richstad, ed. (Honolulu: East-West Communication Institute, March 1977).

16. Gunnar Naesselund, "Unesco Conference: 'Balanced Communication', " Intermedia 2, 5 (March 1975): 17.

17. Ibid. 
18. Unesco document CON/RPC. 49/28, Annex I (dated August 25, 1975).

19. Regional Conference on Information Imbalance in Asia, Colombo, Sri Lanka, April 21-26, 1975.

20. Y. V. Lakshmana Rao, "Information Imbalance in Asia: A. Working Paper," Presented at Regional Conference on Information Imbalance in Asia, Colombo, Sri Lanka, April 21-26, 1975, p. 2. (Conference reviewed in Media Asia 2, 2 (1975): 69-81.)

21. International Broadcast Institute A nnual Meeting, Cologne, 1975. Working Group IV, September 3, 1975. (Cited in Unesco document 19C/93, May 31, 1976 as Item 16 of the Provisional Agenda of the General Conference, 19th Session, Nairobi, 1976.)

22. Conference on Fair Communication Policy for the International Exchange of Information, op. cit. 


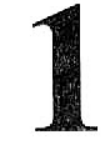

THE GENERAL CONCEPT: SOME INTRODUCTIONS 

The right to communicate differs enough from previous formulations to merit being called a new concept. To date, this new concept has been formulated in only a partial, preliminary, and tentative way. Consequently, the essays in Part I seek to outline and describe the concept rather than to provide a definitive statement about it. Even so, the authors, in one phrase or another, assert that it is becoming or has become a "genuine concept."

The concept of the right to communicate grows out of a new awareness of the role of communication in society. Since 1970, new dimensions have been added to human communication through developments in communication technology, global interdependence, and cultural pluralism. This new concept, then, is part of a new attitude about the interrelatedness of the major issues facing humanity and the human aspect in development. Understandably, the right to communicate is a complex idea.

To begin to grasp the possible scope and meaning of this new concept, the authors of the essays have provided, from a variety of perspectives, an introduction to the concept. In its line of reasoning and content, each essay differs quite markedly from the others. Even so, there are enough similarities that one may see in this variety an important unity as well.

The first essay, by Aldo Armando Cocca, introduces many of the themes that appear throughout the book. He begins with a close look at the notion of rights. He is careful to develop the inclusive and universal dimension of the right to communicate. He identifies a number of "converging elements" such as access and cultural integrity. Cocca moves on to discuss some of the specific communication rights encompassed by a general right to communicate, and he reviews a number of pertinent international instruments. He adds an important component by including a specific "right to be selective" and contrasts this $x$ ight with a "right not to communicate." Cocca then analyzes the descriptive statement prepared by the International Broadcast Institute Working Group IV at Cologne in 1975. He concludes that this statement "bears the promise of new advancements in this new human right but also in its consolidation."

Jerzy Mikulowski Pomorski begins his essay, as do several authors, with an examination of the earlier idea of free flow of information. He notes that the change in terminology is more than a word game. He finds the right to communicate to be markedly different and a "genuine concept." The author also examines in depth the related concept of human communication needs, and suggests that "to propose a model of patterns of human needs that goes deeply into reality necessitates a study of all aspects of social life." Pomorski also considers the relationship of the concept to the media. He follows with an examination of six dilemmas posed by the right to 
communicate: legal, historical, psychological, instifutional, economic, and sociological. He also notes the disparity between developed and developing countries. Pomorski concludes that "When we attempt to change... from the free flow approach, which expresses the contradiction between political West and East, to an approach toward resolving the modexnization problems of the Third World, we must raise many questions. . . and see them in a new, unusual way." He recommends "cross-cultura] research programs" and "set policies" that will lead to a "better understanding among nations."

The third essay is by Henry Cassirer, who questions many of the assumptions about communication that have developed over the past half century. Cassirer asks, "Who ever thought of building a railroad exclusively for carrying traffic from the capital to the provinces without any return?" He revives an early definition of communication that links transport and communication, and further questions whether one-way mass media can properly be considered to be media of communication. He then outlines the conditions for "genuine communication." In this outline, he sets the right to communicate in a very broad historical context and thereby maps the way for important future developments. Cassirer then relates observations by Bertolic Brecht to a number of developments in participatory communication., such as the "Canadian Farm Radio Forum." Although he finds that a long road has been traveled from Brecht's proposal to the recent developments in the right to communicate, Cassirex concludes that "It's a long way to communication."

The essay by X. V. Lakshmana Rao and Lui-Tan Kwan Siu begins with the question. "Why is there a sudden surge of interest in the 'right to communicate'?" In answering this question, the authors review the history of the idea of free flow of information embodied in Article 19. They identify two approaches: one approach attempts to "look into ways of better implementing Article 19"; the other approach aims "at a new definition" with emphasis on the development of the resources for communication. The authors proceed to survey the status of the right to communicate "in Asia as a region, in individual countries as nations, and among Asians as persons." They urge a "marriage between. . . stressing the importance of defining the concept and placing greater emphas is on implementation." They point out that "we have already been able to indicate clearly the ambivalence in the attitudes of governments and of societies in Asia" regarding this new concept. They conclude: "Let us be absolutely sure that flexibility is built from the start into any model that may emerge."

The final essay in this section, by Hidetoshi Kato, opens with an analysis of the author's communication activities during the campus unrest in Japan during the late 1960s. He reports, "I quit my university appointment, and in retrospect, I learned that to 'express' oneself is one thing and to communicate with somebody is another thing." In considering the xight to communicate concept, and its opposite, the right not to communicate, Kato distinguishes first between expression and communication. Then focusing on communication, he identifies, in addition, a "right to be communicated to" and a "right not to be communicated to." He finds in the general right to communicate concept a total of foux communication rights. From this perspective, he observes, "In many countries in Asia, people are annoyed because the big nations so consistently exercise their right to communicate. . . Indeed, somebody's right to communicate may be, in spite of the good will of the communicator, an anmoyance and a nuisance for somebody else." Kato concludes with a more formal statement of his line of argument and provides a diagram that displays 
the various alternatives. "One should appreciate his or her luck when he or she is involved in the happy combination" where the right to communicate and the right to be communicated with are in harmony.

The essays in Part I provide some of the possible introductions to the general concept of a right to communicate. Although the essays are quite different from each other in emphasis they are in agreement on several points: the concept is new, complex, and important. Taken together, they provide a multicultural introduction. 



\section{THE RIGHT TO COMMUNICATE: AN EVOLUTIVE CONCEPT \\ FOR A NEW PERSONAL AND SOCIAL DIMENSION OF A \\ FUNDAMENTAL HUMAN RIGHT}

ALDO ARMANDO COCCA

\section{PRELIMINARY CONSIDERATIONS}

Our position on such a delicate question, and even the consequences likely to be derived from an inadequate use of the term, 'right to communicate," may well depend upon the accuracy of the choice we make. Should we speak of a "right," or of a "freedom"? Perhaps it would be fair to say that the conception of law, as a fundamental question, has constantly been at stake and that, possibly, the present crisis is overriding those of the Renaissance and Romantic Ages.

In an era symbolized by accelerated technological development, we may observe a crisis of growth that has not struck law to the same extent it has struck science but that, nevertheless, is significant and cannot be overlooked.

The word right in English and the word Recht in German imply a conformity with a rule, a compliance with something in a straightforward manner, without hesitation or doubt. Conversely, the Spanish term derecho, the French term droit, and the Italian diritto or the Portuguese equivalent direito refer to law as anything that is legitimate.

The issue becomes more complicated upon a subjective approach to the contents of law, namely, when the description is made of the exercise of a right. Such exercise then is interwoven with the notion of freedom.

The concept of freedom has been understood in different manners throughout the centuries and nowadays still has a multitude of meanings.

Freedom implies a possibility of choice, an option in the alternative: it leaves a certain margin for indetermination; it amounts to a liberation from something or toward something; it means spontaneity, absence of interference, satisfaction of a requirement. It is always a dynamic, voluntary act.

Only in action does freedom exist. Whereas law lies static as a value and as a foundation, freedom needs constant activity because it is constantly under threat. To meet those threats, freedom finds support in law; freedom is the daily and constant putting into practice of law.

For reasons of legal security, law is bound to reach a degree of crystallization that does not occur in the case of freedom, because freedom would then lose its vigor and dynamism. Freedom is ever-changing, constantly in action before alternatives or options and, as a result of all actions, it is constantly developing. 
In accordahce with its scope, one may refer to personal freedom, private freedom, freedom of conscience, freedom of action, and so forth (including many possibilities of subjective freedoms, such as freedom of speech, of ideas, and of information). One can also refer to public freedom, political freedom, social freedom. However, within any of these possibilities, degrees of shades can be found, which differ from person to person and from one country to another. By way of example, it could be said that a social freedorn is apt to be exercised by some countries as a right and as a freedom by others. The British have given pride of place to civil freedom; thus, their policy rests on the full respect for the powers of the individual. The French, on their part, are more concerned about political freedom; hence, their social system is based on the necessity of the participation of the individual in the creation and exercise of power, that is, the necessity of offering each person better opportunities for the exercise of authority.

Freedom consists in being able to do anything that leads to the objectives set out by human society for the personality of man, in conformity with law. By virtue of the universal principle of the personality of man, the social structure, in each country, gives it expression, shade, and peculiarity.

In addition to law and knowledge, the existence of conscience should be borne in mind, that is to say, the act of evaluation. Man always acts as an agent, and, from the time of the Romans, the concept of freedom has brought in its wake a true idea of responsibility, both vis-a-vis his own self and vis-a-vis the international community. Thus, from the very beginning, freedom appears as a twofold notion: on the one hand, as a power to do something and, on the other, as a limitation. This is precisely the concept of freedom that predominated in the legal thinking of the Romans, and, it proved so efficient that this twofold notion has survived throughout the centuries.

Ever since Kelsen, modern lines of thought have proliferated, stating that there are two sides to the coin--that where there existed a right, there existed a. collateral duty: the individual could be thought of only as a nonautonomous constituent of the community. Thus, it follows that there cannot be personal freedom without social freedom.

Hegel was perhaps correct in saying that freedom is in itself a reality, in fact, a universal and concrete reality that should be harmonized with its historical moment and man's style of life. Indeed, this is the task of law.

It is also clearly evident that freedom cannot exist unless one is intimately convinced of its necessity. As expressed by Jaspers, man moves in the area of freedom that he himself has desired. Therefore, it is not possible to speak of absolute freedom. In this sense, Hartmann rejects any conception of "exterior freedom" and feels inclined to admit the existence of a positive freedom that lies within the conscience and unfolds in two directions: in the face of the regularity of nature and in the face of what must be. To fulfill that aspiration or reality, which lies in man, law comes into the picture.

Should the concept of freedom be misplaced, particularly if personal freedom is subordinated to political freedom or other motivations of convenience, the many paradoxes arising out of this improper use become relevant. Aristotle gives us the example of that tyrant who forces someone to commit a crime (for example, to murder his neighbor) by threatening extremely severe reprisals (such 
as the murder of one of his children) if the person refuses. The threatened person is therefore compelled to do something, at the same time, willingly and unwillingly. He does not want to commit the crime and in spite of this, he goes ahead. The great poet Ovid proclaimed the approval of what is right but the acceptance of what is evil. Saint Paul was still more categorical when saying that he did not the good he wanted to but the evil he did not want to (Romans 7:15).

The Buridan's Ass paradox is equally appropriate: if an ass has before it two identical bundles of hay, it would be unable to show preference for either and, thus, would die of hunger. This paradox is meant to show the freedom of a free choice when the latter is reduced to a liberum arbitrium indifferentiae (an indifference for individual choice).

Even though much has been said and written to explain these paradoxes, they still move us to reflection. The crux of the problem is, of course, the amount of personal attitude and subjective evaluation implied in the exercise of freedom.

Law is the nucleus, the essence. Freedom amounts to a means of putting law into practice. This obviously differs from one society to another, according to the idiosyncrasy of each community.

Humankind is above everything. Today it is a legal concept. States have so recognized this for the past fifteen years. Humankind has attained the maximum juridical level, the fullest juridical personality. This was so agreed by states that form part of the international community: the interests of humankind are above those of any state individually considered, because they include the interests and the requirements of all states that form part of the international community.

Humankind, in the last instance, is the person. It is a closing circle, that is, man-society-international community-humankind.

It took ages to complete this cycle, which started with the first human being and comes to an end with the human person, the latter possessing a new and different legal and a solid and stable philosophical foundation. Still, in the realm of juridical philosophy, it is possible to find the necessary firmness and stability to guarantee security.

Man has created the means and systems for coexistence and has gone through every alternative of life within society, thus establishing his own rights. What man cannot do is create something contrary or against the human person.

\section{IS FREEDOM OF INFORMATION A GENERAL PRINCIPLE OF INTERNATIONAL LAW?}

The changes and progress in applied technology do not offer any new problems regarding communications and broadcast; they merely give us another opportunity to consider and discuss them with a view to unifying criteria or adopting general rules of universal acceptance. 
The main issue that arises when dealing with the legal aspects visà-vis the freedom of communication is whether such freedom is, in fact, a legal principle and, at the international level if it is a principle of international law.

In the light of the debates recorded to date, particularly within the United Nations, where the Draft Convention on Freedom of Information was dis cussed for the first time at the Fifth Session of the Working Group on Direct Broadcast Satellites (Geneva, March 1974) and at the Thirteenth Session of the Legal Sub-Committee on the Peaceful Uses of Outer Space (Geneva, May 1974), it may be appreciated that no uniform opinion really exists purporting to give freedom of information the status of a legal principle of international law.

Freedom of information and the free circulation of social communica tion represent, for a large number of states, the following possibilities:

a modality of conduct

a rule of conduct

a practice

a custom

a style of life

a customary legal relation

a legal principle, and even

a constitutional principle within certain countries

These practices of modality, unwritten custom, or rule have an essentially evolutionary character that indicates an ever-increasing generalization of this concept.

Has the concept of freedom of information a universal reach? No doubt, apart from its local nature, it is easy to discover its regional and even continental scope. But it would be going too far to say that, nowadays, the concept is a universally recognized one.

According to the doctrine, for a principle of international law derived from an international custom to be such, the following conditions must exist (unless, of course, we resort to regulation by means of a treaty):

capacity and acceptance on the part of the interested parties constant and reiterated application

the matter must be of an international nature

no contradiction should exist in any part whatsoever of the juridical relation

Suppose that all these elements--to which, perhaps, one may add a uniform opinion on what is to be understood by freedom of information and free flow of social communication--are not found. Then we would simply have a rule of courtesy based on the comitas gentium, a provision of municipal law, a generalized extension of public municipal law to the international sphere, a statal declaration (adopted, according to modern practice, in the forum of an international organiza tion), a state policy, or a doctrine of uniform application by one or many states. All these manners of statal action are undetermined with respect to the time factor. Therefore, the legal validity of any of them will depend on the maintenance of that concordance, which should be expressed and activated in a voluntary and coherent manner. 
On our part, we certainly wish that freedom of information and the freedom of circulation or flow of social communication should turn out to be a uniform legal principle, moreover, a general principle of international law. To become such, it would be necessary that international customary law should accept them, thus making them binding, as a basis of the existence of the international community, and that they should pre-exist any conventional rule. On this assumption, they would have a peremptory nature--to use the words of the Vienna Convention on the Law of Treaties (Articles 53 and 64)--and would be binding on any member of the international community. They would be exempted from any kind of evidence, by virtue of their international character. Unfortunately, we have not yet attained such a degree of evolution and, for the time being, we must confine ourselves to conventional principles and rules embodied in treaties.

The way to reach the recognition of a new principle of international law begins within the international juridical conscience, and, where communication is concerned, the principle should--in view of its global nature--be of universal dimension.

One may find some precedents in international instruments and documents that mean significant steps toward a universal conscience. The instruments have been, in some cases, in the form of declarations or resolutions of an ample reach and, in others, of a more restricted (regional or continental) scope. In the latter case, their application has proved easier.

On the occasion of the Fifth Session of the Working Groups on Direct Broadcast Satellites (Geneva, 1974), the delegations of Argentina, Austria, Belgium, German Federal Republic, Indonesia, and Italy prepared a list of international instruments and documents applicable to social communication and divided these into four chapters, as follows:

1. United Nations

UN Charter (1945)

Outer Space Treaty (1967)

Declaration of Principles of International Law Concerning Friendly Relations and Co-operation among States (1970)

Universal Declaration of Human Rights (1948)

International Covenant on Civil and Political Rights (1966)

Declaration on the Strengthening of Internation Security (1970)

Convention on the Right of Correction (1952)

UNGA Resolutions 110 (II), 381 (V), 424 (V), 841 (IX), 1236 (XII), 1301 (XIII), 1721 D (XVI), 1815 (XVII), 1962 (XVIII), 2222 (XXII), and 3182 (XXVIII)

Economic and Social Council Resolution 756 (XXIX) also is relevant

2. International Telecommunications Union

International Telecommunication Conventions (Montreux, 1965, and Malaga-Torremolinos, 1973)

Radio Regulations

Final Acts of the World Administrative Conference on Space Communications (1971)

Recommendation on the Unrestricted Transmission of News (Montreux, 1965) 
3. Unesco

Resolution 7.22 on the Free Flow of Information (III, Beirut, 1948)

Declaration of Guiding Principles on the Use of Satellite Broadcasting for the Free Flow of Information, the Spread of Education, and Greater Cultural Exchange (1972)

4. Other documents (of a regional scope)

Declaration of Human Rights (Bogota, 1948) of a continental reach and which anticipated the Universal Declaration

European Convention on Human Rights (1950)

European Agreement for the Protection of Television Broadcast (Strasbourg, 1960, amended in 1965)

On the opportunity of the meeting of the International Broadcast Institute at Cologne (1975), Edward W. Ploman produced a list of relevant international instruments and texts, some of which are included below to supplement the foregoing enumeration.

Constitution of Unesco (1945)

General Assembly Resolution 59 (I) (1946)

International Convention on the Elimination of All Forms of Racial Discrimination (1965)

International Covenant on Economic, Social and Cultural Rights (1966)

The Proclamation of Teheran $(1968)^{\mathbb{1}}$

All the above instruments and documents tend to create the universal conscience necessary to convert freedom of information and the free flow of social. communication into a principle of international law.

We are equally on the right track toward the effective recognition of human rights, which implies that, when certain rights are conferred on individuals by an international convention, a parallel obligation arises for the state: the state must recognize the jurisdiction of the tribunal to which an individual might resort in case of violation of any of his rights on the part of the state, and the state also has the duty to comply with the decision of the tribunal.

The principle of respect for human rights appears in various parts of the UN Charter, such as the Preamble; Article I, paragraph 3; Article 13, paragraph 1 (B); Article 55 (c); and Article 62, paragraph 2.

The Universal Declaration of Human Rights is not, of course, a binding instrument. It does not establish any international tribunal, either; it is merely a declaration and not a ratified treaty.

The Universal Declaration speaks of a common ideal, just as the Montreux Declaration mentions a noble principle. Efforts must now be directed toward the transformation of these expressions--which are adequate and adjusted to the present state of the issue--into a legal principle that relates to freedom of information and the free flow of social communication.

The changes and progress of technology are conducive to a greater integration of humankind. To be true, it is the most complete integration of humanity. 
And it offers a valuable opportunity for the codification of new human rights. As a principle of law, its acceptance gives rise to rights and duties. This is the task of the jurist at the present time, and it is necessary, almost indispensable, to meet the challenge of technological progress and the hope of unity of all peoples, which is second nature to the human soul.

In the present circumstances, it is opportune to make reference to a report of the International Press Institute of Zurich (December 1975). The report pointed out that the most important setback with regard to freedom of the press during 1975, and possibly in the last ten years, took place in India. It also stated that freedom of the press has been deteriorating and even disappearing in countries of America, Africa, Asia, and Europe. The report concludes by observing that more than half of the world now lacks freedom of the press.

The case of the right to communicate is, indeed, quite the opposite: it has not already appeared and is not in the process of fading, but rather, it is working its way through and gradually gaining recognition.

\section{THE EMERGING CONCEPT OF THE RIGHT TO COMMUNICATE AND ITS PROSPECTS}

Does it become necessary, at the present stage of study, to define the right to communicate? I have asked myself this question repeatedly, in Nicosia, in Mexico City, and in Cologne. As was expressed at the last meeting of the International Broadcast Institute, it appears more appropriate today to develop some kind of working tool in order to continue the task. At a second stage, one should try to build up a concept before arriving at a definition. The term definition proceeds from the Latin word finibus, which means "to limit." Any tentative definition would therefore limit not only the field of action but also the field for reflection. Hence, it is more adequate to conduct the thinking toward a common idea.

This concept must be of a universal character. In the existing state of development of communication techniques, any attempt to give an idea of man's activity in the field of communication should be as wide and generic as the human race itself.

If it turns out to be difficult to define the word right in such a way that it bears a similar content in the Continental and common law, in Islamic law, Socialist law, Scandinavian law, Latin American law, Oriental law, and Eskimo law, the case of the term communicate is even worse.

Nor has right the same meaning in the different languages, and even within the same language it may be used in different manners. In accordance with an inquiry carried out personally during the last meetings of the International Broadcast Institute, it appears that, in French, there are two possibilities. Jean d'Arcy, the father of the right to communicate, refers to a "droit à la communication," where-as Ferdinand Terrou prefers to say "droit de la communication." Henri Piaget, on his part, is more inclined to the first expression, for a right of becomes rather a restrictive concept in the French language; it would appear to be confined to those who possess the means for communicating. It must be pointed out that in Spanish, this human right is of a subjective nature and, consequently, the expression "right 
to communicate" should be used. This is, in fact, my opinion, which, when expounded, was shared by Elizabeth de Cardona.

This point of view can be enlarged. In the first place, this right is, without doubt, based upon interrelation, upon the concept of "two-way traffic." That is why, in Spanish, the suffix se is added and we say "comunicarse" (to communicate oneself). It is by no means a right pertaining to institutions: it corres ponds to man, it is a right of the persons. Starting from man, it is extended to communities, but not to institutions. Man is always the subject par excellence of law. From man, the right passes on to the community and from there to humankind, its ultimate subject.

Likewise, we have two different expressions in German: "Das Recht auf Kommunikation" and "Das Recht zu Kommunizieren." In YugosJav, "Pravo na. komunicranje." In English, the "right to communicate," which I understand as a "right to express oneself" and which pertains to humankind.

This right of man, with its predominant charge of subjectivity, allows the framing of a concept for today and for tomorrow, for it is by no means linked to the state of technology or to the changes of government, as inclined to alterations as politics itself.

It has been stated that a "redefinition" becomes necessary. I believe that this right has not been defined so far, and that it would seem improper to do again what was never done before. In addition, any attempt to redefine would necessarily fall within the field of conflict, as it obviously implies a break of certain patterns, bearing in mind that a "definition" is a pattern within which a concept has been framed.

It is possible to find references to "rights and responsibilities" as applied to communication in several documents and interventions of the 1974 General Conference of Unesco. We feel that this tendency--which goes beyond those links to a concept not adequately shared, such as "freedom"--is an appropriate starting point for the formulation of the emerging concept of the right to communicate.

In like manner, important elements may be drawn from the 1975 report of Dag Hammarskjold, prepared on the occasion of the Seventh Extraordinary Sessions of the General Assembly of the United Assembly of the United Nations, which allows deep reflection regarding the right to communicate. The report expresses that a global effort should be made with a view to give the newly born international relations a human dimension and to foster the establishment of a genuine cooperation among people on a basis of equality, with recognition to their cultural, political, social, and economic diversity. The image of others should reach us free from the predominant ethnocentric prejudices that constitute the striking feature of most messages currently transmitted. 2

The above report also makes clear the need for the accurate use of expressions like "human dimension," "genuine cooperation," and "image of others," It is believed that every international modern text ought to master the use of such terms, which, unfortunately, are not very much resorted to in the present. As to the human dimension, I shall not further insist--as I have been doing since 1954-on the cycle referred to before: it begins with man and comes to an end at humankind, which is the most complete expression of man. Concerning international 
cooperation, the following resolution was adopted by the Seminar on the Teaching of International Law as Applied to Outer Space and Space Communications (Buenos Aires, 1972): "International cooperation, since the Space Treaty, is a legal obligation which conditions the legality of the activity carried out in outer space and celestial bodies, including space communications." A similar criterion has been sustained by Argentina at the United Nations and has gained support from a great majority of states. A genuine cooperation must not overlook the legal obligation that lies upon space communication at a global level and should endeavor that the putting into practice of these activities is for the benefit of all parties concerned. Finally, the image of others is also pointing at a human being involved in the interrelation. "Others" may be a person, a group, a community, but not an institution.

\section{CONVERGING ELEMENTS IN THE FORMULATION OF THE NEW CONCEPT}

In addition to the word law and the connotations of the expression freedom, the following elements, among others and in their present acceptance, must be taken into consideration.

Access: An access to all possible forms of the exercise of the right to communicate should be guaranteed on a basis of equality.

Assistance: This idea is closely linked to those of interaction and participation. Assistance not only should include communication facilities: it must be understood in its widest meaning and in an omnicomprehensive fashion.

Benefit: In contemporary international law, humankind is the beneficiary of all progress. The benefits must include humankind, as a whole, and the human person as its natural components.

Common heritage of mankind: This expression includes the greater juridical, political, social, and other implications. From 1954, when we explained the aspiration of humankind to achieve a patrimonial integration during the Fifth Congress of the International Astronautical Federation held in Innsbruck, (1954), and, ever since 1964, at the United Nations, within the Outer Space Committee, this principle has been embodied in General Assembly resolutions and we hope will shortly be included in international instruments on the seabed and ocean floor and on the natural resources of the moon and other celestial bodies. This principle ought to be extended to every sphere of international law, particularly to the international law of social communications.

Exchange: It helps to attain the largest possibilities. Likewise, an equal exchange should exist between the developed and the developing regions of the world.

Fourth political dimension: On the occasion of the Fourth Colloquium on the Law of Outer Space (Washington, D. C., 1961), we reiterated our concept previously expounded in the sense that, in the space era, politics acquires a fourth dimension from the moment that all approaches must be made from the basis of a policy for humankind. We also observed that all the nations of the world, at least, all those members of the United Nations, participate in this fourth political dimension, for this has been the first body that attempted a fourth political dimension, 
even without calling it so. ${ }^{3}$ The remaining dimensions of politics are as follows: personal, national, and international. For the purpose of social communication, as occurs in any advanced expression of international law, these three dimensions are not sufficient.

Humanity or humankind ${ }^{4}$ as a new subject of international law: From the very outset, the law of outer space suggested the recognition of humankind as a new subject of law. Such has been my attitude since 1954 in Innsbruck. The major academic confrontation took place during the meeting of the Instituto Hispano Luso Americano de Derecho Internacional (Buenos Aires, 1969). It had already been discussed at the United Nations in 1967. Nowadays, the thesis whereby humankind is considered as subject of space law, or subject of international law, or subject of rights, or juridical subject, has gained new support. This advancement of the science of law should be clearly recognized in the formulation of the right to communicate.

Improvements: The progress in regional and other systems, and in their respective facilities, will help to bring the countries closer together in the field of communications.

Information explosion: This is not a current expression, either. It reflects a realicy that urges new concepts and new means of social contact.

Integrity of cultures: As representatives of Argentina at the Third Session of the Working Group on Direct Broadcast of the United Nations (New York, 1970), we took the opportunity to anticipate that a due respect for the spirit of each couptry, its culture, and its history and national development was essential (Table V). 5 The 1972 Unesco Declaration devotes its Article 7 to the need for respect for the distinctive features of each culture, the value and dignity of every one of them, and the right of all the countries and peoples to maintain their culture as an element of the common heritage of mankind. The preservation of the cultural integrity becomes a fundamental requisite within the new conception of the right to communicate.

Interaction: At the present time, communication is a two-way process that includes the ample right to communicate and receive communication in a dialogue that grows and multiplies among nations, peoples, and persons.

Interdependence: This principle is not only relevant to the international law of communication., it is inherent in contemporary international life and is the necessary assumption for a peaceful and harmonious coexistence. Intexdependence is also necessary in the case of human groups.

International communication fraternity: It derives from the preceding principle, that is to say, the peaceful and harmonious coexistence tends to encourage an international communication fraternity for the well-being of all peoples and of all persons.

Interrelatedness: This is something further than a mere superficial contact; it should be an interpenetration as the only guarantee for the achievement of a true interaction. 
Instantaneity: It is the case of an "acting right"; in other words, it refers to the characteristic imposed by modern technology upon the right to communicate and its exercise: a particular dynamism.

Jus humanitatis: This Latin expression involves the notions of the fourth political and juridical dimension, common heritage of humankind--humankind as a new subject of law and of the things that are a common property of humankind (res communis humanitatis).

Multicultural conceptualization: This is a natural consequence of the respect for the original culture of each country, together with the idea of a cultural heritage of all humankind and the personal expressions of man.

Necessity: It may be understood as the ideal framework wherein the principles and consequences can be found. Lately, the question of necessity has been dealt simultaneously with that of freedom.

New social and cultural order: As a consequence of the establishment of a new international economic order and as a spiritual support thereto, the person should be placed in the nucleus of every developmental process, in view of the fact that what is spiritual will always be of greater value and should predominate over materialistic purposes.

New scientific and technological developments: All these developments are strongly linked to human rights. The United Nations General Assembly has, for the last years, been concerned about the question of achieving a close cooperation with Unesco and, in doing so, resorts to the Economic and Social Council and to the Commission on Human Rights.

Opportunity: It means both the opportunity to exercise and to participate in community decision making and development.

Participation: In contemporary international law, participation is a reality--indeed tangible--of an expression of international cooperation in constant evolution.

Plurality of cultures: The cultural unity of humankind is based on a cultural pluralism that integrates the common patrimony. The importance of this pluralism should not be overlooked.

Privacy: The means offered by technology may go against the right of privacy, which should be preserved at all cost.

Process: In practice, communication is a basic human process essential for many aspects of human development.

Protection: The adequate exercise of the right to communicate should be ensured, and measures should be taken against an improper exercise thereto, such as an exercise amounting to an abuse of rights.

Resources: This concept should be extended to communications, although it differs in kind from energy and material resources. When communication, in its double aspect of process and products, is considered a resource in 
society, there is a need for new approaches to be related to resource and economic policies.

Res communis humanitatis: As a resource--even though not a material one--the juridical nature of communications is that of a res communis humanitatis, in view of the spirituality of man. In this capacity, it must be included within private international law.

Responsibility: There is always an obligation for every right arising from this new conception. The principle of responsibility, which goes hand in hand with every act of human conduct, is thus born.

\section{VIRTUAL CONTENTS AND EVIDENCES \\ OF THE RIGHT TO COMMUNICATE}

At the 1974. Meeting of the International Broadcast Institute held at Mexico City, the above headings were discussed in detail and Henry Hindley included five possibilities, as follows:

(1) The right to speak

(2) The right to be heard

(3) The right to be replied to

(4) The right to reply to someone else

(5) The right to listen

This enumeration represents a useful guide to allow me a few reflections and observations on the matter. Taking into account that "living images will be as handy as books and newspapers have been for centuries, " as pointed out by Jean d'Arcy, 6 and the rapid development of television, I feel that there are two new evidences of the right to communicate:

(6) The right to see

(7) The right to be seen

These rights include the use not only of television sets but also of telephones with electronic screens.

I believe that a visual expression can be more effective or produce a greater impact than an oral one. Reference may be made in this connection to John F. Kennedy's electoral campaign and, more recently, the presidential campaign in France with the verbal television duel between Valéry Giscard d'Estaing and Francois Mitterand.

It is thought that, after these experiences, people shall begin to require that their candidates appear on television or other means of mass communication to explain their ideas and their merits. Because the audiovisual system of communication is at present the most complete, it will undoubtedly be chosen for the major events. And, of course, one may add to the voter's right to see, the candidate's right to be seen.

In a more general sense, it should be recalled that in July 1969 the peoples of all the world claimed the right to see, with their own eyes, man's first. 
landing on the moon. This exemplified extraordinary human prowess and man, irrespective of countries, wished to see it himself. In brief, man wanted to contemplate himself as well.

Hence the enormous concern of all states in the face of a new technological possibility, namely, direct broadcast by television, and the efforts directed to the drafting of an international legal framework on the matter before it is put into practice. Such concern was not evidenced in the case of international broadcast by radio, which has a global reach.

From the wording of Article 19 of the International Covenant on Civil and Political Rights (1966), one may pinpoint two other rights that it is not possible to exclude when dealing with the contents of the right to communicate.

(8) The right to express oneself in writing or in print

Attention should by all means be drawn toward this right, which has been not only subject to a precise legal treatment but also included in bills and constitutions of many countries.

Noteworthy, because of the accurate synthesis it implies, is another possibility included in the same article.

(9) The right to express oneself in the form of art

It is quite true that, in addition to speech, writing, and press, there are other possibilities of transmitting a human message with equal vigor. Such is the case of art. This expression comprises fine arts (painting and sculpture), dance, and music.

And finally, as a consequence of all these evidences of the right to communicate, one may refer to a right that involves all those already expounded.

(10) The right to be selective

A message disseminated among an anonymous audience cannot have an equal receptivity, an equal impact or an equal effect upon everybody. There is a particular reaction to the message. From this personal or collective reaction the right to be selective necessarily follows. This right is enriched and perfected as a result of the permanent exercise of options among several alternatives.

It has been stated that, collaterally, a right not to communicate arises, particularly in the sense of not answering; it is a form of omission. The example has been given of not answering the telephone.

I do not consider that this statement can be valid in the social interaction that the right to communicate implies. It is a double-purpose right. That is why the telephone should be answered, so as to respect the right of others to communicate, or to be replied to. However, if it is known who is calling, or the contents of the communication are known, the lack of answer ought then to be seen, not as a right not to communicate, but as a right to be selective. The same applies when someone who is watching television knows what will follow, or the contents of the next program, and either switches to another station or turns off the television set. 
If we bear in mind that the right to communicate is based upon the two-way principle and is an interactive and participatory process, creating from the outset an interpersonal or intexsocial reaction, it is not possible to affirm that a unilateral will could break the whole process with all its charge of human necessity.

It must not be forgotten that it is not an objective right to "communicate," but a subjective right to communicate oneself. That subjectivity has an enormous social implication.

\section{A DESCRIPTION OF THE RIGHT 'TO COMMUNICATE IN 1975}

A definition on the question was attempted at Cologne during the Meeting of the International Broadcast Institute of London. After some discussion, a "description" was arrived at. Said description was adopted by Committee IV, under the chairmanship of Gerald Long and with Bert Cowlan acting as Rapporteur; it was adopted by the General. Assembly on 4 September 1975. T'he Cologne text reads as follows:

Everyone has the right to communicate.

It is an objective declaration, not merely an aspiration. The word communicate is indeed subjectively charged. In Spanish it is said "to communicate oneself."

I. consider it adequately referred to as "right" and not as "freedom." It is the static law, essential to the human and social condition of persons and peoples. Freedom constitutes the modality of exercise of that fundamental law.

It is a basic human need and is the foundation of all social organization.

There are three words, the high value of which is reinforced when they are used together: basic human need. The element of "need" is linked to the notion of "resource" from the moment that resources satisfy needs.

The human aspect is combined both personally and socially to provide the foundation of all social organization. Subjective law is guaranteed as a. juridical. order and comes under the social order itself.

It belongs to individual and communities, between and among each other.

It is a two-way process; it is a question of interdependence. It is, in brief, a right of our times.

This right has been long recognized internationally, and the exercise of it needs constantly to evolve and expand.

Here are two aspects involved: one looking toward the past and the present, namely, international recognition, and the other pointing toward the present and the future: the constant need to evolve and expand. As a new concept is in process of creation, it prima facie appears somewhat inadequate to speak of the 
past. Perhaps it would have been more appropriate to say that the virtual contents or evidences of the right to communicate or merely some of its elements gained recognition.

It is adequately spoken here of the exercise of the right, and the verb need likewise is bound to resort to communication, as follows:

Taking account of changes in society and developments in technology, adequate resources--human, economic, and technological--should be made available to all mankind.

The expression "resources" should certainly be employed in this description because, as explained by Harms and Richstad, since 1948, communication has come to be regarded as an essential human resource. Communication resources can be planned, developed, and used. Historically, and still in many parts of the world, communication resources have been scarce. In recent years, many observers have noted the increasing abundance of communication resources. There still remain great differences in communication resources available to different nations, communities, and individuals. 7

In the same way, some observers have stated that communication is an important source of "food for the mind" and have even suggested the building of a "world fund" to bring communication resources up to a certain required level to serve communication needs.

From the economic approach of our days, it has also been said that needs create demands and demands create markets, and that the right to communicate could create a means for people to express their needs. Likewise, it has been affirmed that "the new trinity upon which economic development will be built is composed of the availability of matter, energy, and information. 8

It is also relevant to point out that a wise and equitable use of communication resources is needed, starting from the following points:

can be planned.

- Communication is an essential resource, the development of which

- Communication is an unusual resource because when communication is cooperative, information sharing does not deplete or use up the shared infor-mation, and quite often it increases that information.

- Communication resources should be abundant rather than scarce.

- Communication resources can be used to conserve, develop, and manage other essential resources, for example, telecommunication can sometimes be used to conserve and replace the need for transportation. 9

In the Cologne text, the word resource is used in its widest sense, in an explicit manner: it comprises human resources in the first place and economic and technological resources in the second.

One of the striking aspects of the Cologne text is that concerning the mention of "all mankind." The new subject of contemporary law thus appears as 
one of the most longed-for wishes of man. This definition would be unfinished and empty if humankind had not been included expressly: it is humankind as a whole, that is to say, as beneficiary of the exercise of the right to communicate.

Going on with the 1975 "description":

For the fulfillment of the need for interactive participatory communication and implementation of that right.

The term need is used here with a different reach. The terms interactive and participatory are of capital value in the final part of the text. When these $\overline{\text { terms }}$ are used together, the content of each is reinforced and a new and more vigorous formula is obtained. These terms are offered by international cooperation in its new dimension.

This last paragraph is generous in intention, in aspiration, and in hope.

And the description worded in Cologne bears the promise of new advancements not only in comprehension of this new human right but also in its consolidation. 


\section{NOTES}

1. Edward Ploman, "The Right to Communicate," Contribution to Working Committee IV, International Broadcast Institute Annual Meeting, Cologne, September 1-4, 1975.

2. Dag Hammarskjold, "El Desarrollo y la Cooperación Internacional, " Development Dialogue, no. 1-2 (1975), p. 18 of Spanish text.

3. Aldo Armando Cocca, "Legal Status of the Cosmonaut," Proceedings of the Fourth Colloquium on the Law of Outer Space (Norman, Oklahoma: University of Oklahoma Research Institute, 1963), pp. 15 et seq.

4. My distinguished colleague and friend, L. S. Harms (University of Hawaii at Manoa), uses the term humankind, which I believe highly appropriate in view of its greater spiritual content.

5. Aldo Armando Cocca, "Soluciones jurídicas a la cooperación regional, continental, intercontinental y global," Ensenanza del Derecho Internacional aplicado al espacio ultraterrestre y a las comunicaciones espaciales, Buenos Aires, 1972, p. 61.

6. Jean d'Arcy, "Direct Broadcast Satellites and the Right to Communicate, " EBU Review 118 (1969): 14.

7. L. S. Harms and Jim Richstad, "Right to Communicate: Human Rights, Major Communication Issues, and Communication Policies and Planning," Presented at the International Broadcast Institute Annual Meeting, Cologne, September 1-4, 1975.

8. Gunnar R. Naesselund, "Relations between and Perspectives within 'Development Support Communication,' 'Communications Policy and Planning, ' and 'The Right to Communicate' as Seen by Unesco," Paper presented at the International Broadcast Institute Annual Meeting, Cologne, September 1-4, 1975.

9. Harms and Richstad, "Right to Communicate." 



\section{THE RIGHT TO COMMUNICATE: EMERGING CONCEPT AND INTERNATIONAL POLICY}

JERZY MIKULOWSKI POMORSKI

The concept of the right to communicate has emerged from discussions of the freedom of information. It has emerged because that debate failed to resolve the issue, and part of the purpose of the introduction of a new concept is to approach the problem from another base. The replacement of one term by another term, in the manner of selling an old product under a new guise, seemed dangerous until the discussions in 1975, when it became apparent that the concept of a right to communicate is quite "genuine."

Replacement of the notion of free flow of information with the idea of a right to communicate has important consequences that require further discussion. These consequences can be promising as well ad discouraging. The new concept would be expected to be more suitable for legal negotiators and for scientific discussion. Although it seems that the concept will have wider application for debate among social scientists, it undoubtedly will be more difficult for international legislators to accept. The concept of free flow is more suitable for legal action than is the concept of right to communicate, which means that the use of the new concept may further delay international agreement on these issues. I hope, however, that a reasonable solution can be found.

The turn from a freedom of information concept to a right to communicate concept moves the problem from one of dressing it in legal language into the area of the behavioral sciences. The original concept was founded on the simple and rather naive concept of eighteenth-century natural rights, rights that were formulated out of basic human conditions that required legal protection. Rights were acknowledged in everyone who was recognized as a human being, which usually meant a citizen. The main concern of the right of everyone to have and to express opinions, were the influences on public opinion and the links between the concept of freedom of information and the legal status of the press and later to that of the other media.

The right to express one's opinions via the media and the right of access to the media were the main problems in such cases as when an authority tried to intervene in communication between people.

These rights are relatively easy to handle in legal practice. Positive law had to guarantee the freedoms of expression and access to information within socially acceptable limits. When these freedoms were suppressed or these rights were misused, they were subject to judicial or administrative evaluation. When issues arose on the international scene, the patterns of freedom and legal institutions of more powerful nations were often accepted as models. When less powerful nations did not follow their examples to the full extent, international public opinion blamed their systems as being faulty. This state of affairs militated against nations that were less powerful or were trying to reach goals that need massive efforts. It is no wonder that the freedom of information concept did not offer a basis for a more widely acceptable solution. Is the right to communicate a more promising concept? 


\section{COMMUNICATION AND HUMAN NEEDS}

The right to communicate concept contains two elements that distinguish it from the older concepts and that need to be examined. First, communication is used instead of information. Second, needs that must be satisfied are used instead of certain natural human rights that require legal protection. Both of them, communication and needs, complicate the issue. We must understand the consequences of the replacement that is being advocated, and we must be aware that new, unexpected problems are being added to existing topics. We can see this when we try to understand the range of legal intervention, for instance, that occurs when the right to communicate concept is applied. When we turn from the idea of information to that of communication, we have enlarged the scope of possible legal intervention from the media system to the whole sphere of human interaction, which involves the area that is presently regulated, to some extent, by penal law. When we substitute "natural rights of humanity" with human needs, we require discussions of what is meant by needs and then of what needs are satisfied by communication involvement. Finally, we must develop a criterion that determines when a person's needs are not satisfied and must build up mechanisms for legal protection to satisfy communication needs.

Human communication means, simply, the wide range of exchange of information of various contents, including food and water supply, postal service, transport of goods, trade, child-parent mutual affection, information circulation in the factory, power and people relations, and mass communication. When we define communication among people we must include all these different examples of communication. This means that the right to communicate includes the whole range of human interactions that are usually regulated by moral and legal systems within social institutions in the society. In this framework of the right to communicate are included problems of hunger as well as of coercive repression of public opinion. (I do not think we are prepared for this type of intervention, which can bring further problems.) An effective intervention has to affect the whole social system, not be restricted to the question of the right to have and express an opinion. When people complain that relations within the family in some parts of the world are founded on husband-father domination, 1 and seek to reform this into a more equal and democratic situation where, for instance, the wife and children have a greater voice in decision making, the necessity for cultural plurality in the human world must be kept in mind. Any serious intervention into family communication patterns without changing the basis of family relationships could create hopes without opportunities for their satisfaction. Changes in social structures are determined by factors more basic than communication patterns. Social transformations such as the industrialization-urbanization processes can create a need for changes in patterns of communication. Changes in patterns of communication are secondary to basic social and economic transformations. In the traditional rural family, the communication pattern will not change if the family structure survives. Thus, communication structures can be proposed for any social unit that is in the process of being transformed, but the substantial task of determining the cause of the transformation is not ours. To propose a model of patterns of human needs that goes deeply into reality necessitates a study of all aspects of social life.

\section{Two-way Exchanges}

Use of communication instead of information focuses our attention on a two-way exchange of contents instead of a one-way flow. In every part of society, 
taken as a system, the existence of the cixculation of ideas can be proved. As was shown by Mathilda and John Riley ${ }^{2}$ in their study, information sent from a source will affect the audience and its response will sooner or later be known to the source, Information sent through mass media channels as well as through the actions of authorities is fed back to the sender in a complex system of inceractions throughout: the system. The sender is informed about receiver responses, but these types of feedback are independent of the mass media channels of conmunication. Undoubtedly, people talk back ${ }^{3}$ when they receive information, but the medium remains a channel of one way flow. As seen in cases where the media are coupled with other, feedback channels, such as letters to the editor, audience research surveys, and wider access to local media, the mass communication system in society is two-way to a very limited extent. This extent is compaxably less than the face-to-face interaction of people of equal status. The object of the right to communicate is human communication. The object of mass media in the free flow issue does not enhance human communication. Mass media are, thus, on the margin of our interests if we really want to discuss communication. The emphasis on communication requires turning our interests from the media to an oral communication system, which is an unexpected by-product of this issue.

\section{Needs}

The second concept widely used in the right to communicate discus sion is needs, needs that can be satisfied by communication.

The expression "need gratification," or the meeting of audience needs by communication, was incorporated into the ideological sphere of mass communication theory. ${ }^{4}$ But when needs are used as a concept for research or as an aim for. social actions, their overly idealistic charactex is proved. The concept of needs used in our discussion is taken from abstract psychological or anthropological theories. Statements on the application of this concept in mass communication research made by those working on research in uses and gratification of needs can serve as good warning to us of the difficulties in this problem.

Summaxizing some of the studies of this approach, Karl E. Rosengren wrote, "Media in general, the needs in general, may be too abstract concepts to elicit true answers about gratifications really experienced."5

A critique of the field study done on the concept of needs is offered by Philip Elliott, who wrote in 1973:

As the explanatory variables "needs" appear to exist outside time and space. In searching for "basic human needs" the aim is to find needs which are true to human beings quo human beings. The basic concept tends to set the approach off in a direction which is too general, too static and too asocial for it to be effectively redirected at the latter stage by the reintroduction of social and psychological variables. Such variables are unlikely to turn out to be powerful predictors of need distribution and satisfaction if the needs themselves have been selected to represent the general human condition. 6

To discuss needs, we must make a distinction that is crucial for our

problem. The so-called basic or physiological needs and growth needs must be clarified. The classification of needs presented by Abraham Maslow is commonly 
accepted among psychologists. 7 Treating every individual or social action as being motivated by the drive to satisfy basic, psychosomatic needs leads to a position that electronic communication involvement is as important for survival as are breathing or eating. 8

Some right to communicate proponents propose that the idea of relating needs to communication is based on the belief that all our communication needs are basic and that their satisfaction is a price of survival. What is true for basic needs often is not true for growth needs, which are related to the communication of ideas and involve mass communication in general. We must also remember that growth needs are not physiological products of human individuals, but are the effects of society's influence through the educational system and other aspects of interhuman influence. The distinction was roughly summarized by Elliott:

Needs are founded on the idea of deficit motivation but as Maslow has pointed out this is only plausible when applied to basic or deficiency needs, cases where lack of satisfaction produces physiological consequences. Maslow contrasts these needs with the growth-needs which motivate healthy people towards self-actualization (defined as ongoing actualization of potential capacities and talents, as fulfillment of mission . . . as a fuller knowledge of, as acceptance of, the person's own intrinsic nature, as an unceasing trend toward unity .. within the person). ... If we must talk of needs in relation to media consumption then it seems clear that they are growth-needs not deficiency needs, that they are learnt not innate, that media consumption is founded on growth rather than deficiency motivation. But learnt needs are a product of social experience. In that case media consumption should be explained as part of a positive process of self-development taking part in a series of social situations.9

The next argument is related to the notion of social needs, and the division of those needs necessary for individuals and those necessary for social equilibrium. According to some authors, there is no difference among them, which means that social needs are needs of individuals that are shared with others. This meaning can be especially misleading for our topic. We have to remember that when dealing with social needs, we are often dealing with needs that are not requested or perceived by individual members of the society as necessary for their interests. An example is the belief held by many individuals that one must die for the independence of one's country, a belief that cannot be understood as a massive suicidal drive in the society. A more current and nonviolent example can be offered by the situation in developing countries. As Erskine Childers has pointed out, 10 one of the requirements of communication activity in A sia is to spread agricultural education by means of the media. Although undoubtedly this is a social need, the majority of the media users prefer to watch "Bonanza" or "The FBI" on the national television. systems and gratify their individual needs. A distinction between what are the needs of society and what are the needs of its particular members, as shown in these examples, is basic to our discussion.

Let us summarize the discussion to this point. Introduction of a new concept to the debate on the question of the free flow of information brings new problems. The scope of our interest is extended from the flow of information via media and the problems of public opinion formation to the whole question of human communication. The question of communication and its relation to needs turns our attention 
from the legal aspects of the freedom of expression concept to the more complex. field of all social sciences cognition. The new concept has a less suitable base for legal intervention than has the previous one. The idea of needs inherent within the right to communicate concept introduces new aims for scientific definition.

These issues, related to the right to communicate concept, are closer to behavioral science concepts and create a necessity for wide crosscultural research on patterns of human interactions and the satisfaction of individual and social needs. The need for a wide program of research is an important consequence of the right to communicate issue.

\section{THE RIGHT TO COMMUNICATE AND THE PLACE OF MEDLA}

The older concept of free flow has many problems that must be taken into consideration in the framework of the right to communicate.

The main characteristics of the free flow concept are: 1) Its relation to growth needs, which are essential to socialization and shaped by the system of education and other social institutions. In other words, human needs arising out of involvement in the free flow of communication depend on policies that enable man to send messages outside his neighborhood as well as to receive information from afar. But it is not enough to open the channels of external communication; just taking part in the flow involves "promotion." This promotion must be purposeful, and aimed toward better mutual understanding between peoples and toward the use of modern technology for development. 2) Its relation to mass media, which serve as devices for information flow. Communication via mass media is one-way in the traditional meaning, although it may be considered two-way to a very limited extent, which means that some feedback occurs through the complex channels of the social system but not through the media themselves. 3) Its relation to the internal problem of an individual's participation within society, and to the external problem of communication across borders.

\section{A LESSON FROM THE DEBATE ON FREE FLOW}

The external aspects of the concept of free flow have been discussed over the years by various international forums. The idea of building international relations in communication on the basis of the Universal Declaration of Human Rights has been a main topic of this debate. However, the complexity of the modern world has brought the debate to a deadlock. Recently, the issue has again been raised as a result of the new communication possibilities brought about by satellites. For some people, to pull this new tool into operation in the international information network is a simple and desirable matter. 11

On the free flow issue, the experiences with satellites are good examples of difficulties encountered when decisions are made too hastily on the interna tional scene, and they must be kept in mind. Some of the following points were made in my contribution to the International Broadcast Institute annual meeting held in Cologne, 1-4 September 1975. 12

The free flow of ideas, in the way it is traditionally presented, appears to be a rather poor solution because of its utopian and highly abstract character-- 
utopian because it projects the picture of a world that is far from the present state of affairs, abstract because it ignores the problems of the contemporary world and shows the human individual as free from any social bonds.

A state of affairs where individuals have full xights, unrestricted by the state or other authorities, to send and receive all messages solely in their own interest, is a projection of a happy future. If this ideal actually can be practiced so that everyone has an equal chance to enjoy this freedom regardless of social and economic differences, it can mean that the utopia of the free flow of communication can become a reality, or that access to some information is no longer necessary to keep power.

According to some views, it is enough to make one step and introduce into the legal system a rule to guarantee the full freedom of a flow of information. Is this solution possible? Every legislator has the right to make "bad" laws, laws that are dead letter, paralyzed by lack of administrative enforcements or limited by many legal exceptions, or laws that will produce more negative effects in their social functioning than are expected. Are we justified in proposing a bad law? Before this happens, we must consider the following dilemmas.

First Dilemma: Legal

Does the present state of the international legal system suggest taking action through national legislation as the only possible solution? First, we must call to mind the usually underestimated efforts of the League of Nations to make the international flow of information a means of peaceful international cooperation. In 1931, Poland and Sweden proposed resolutions aimed at regulation against propagation of aggression and false or biased information. Other, similar proposals have advocated international legislation in this field.

Second, the UN Universal Declaration of Human Rights, often quoted in the discussion, proclaims freedom of information as a fundamental human right. The UN General Assembly proclaimed the declaration as:

A common standard of achievement for all peoples and all nations, to the end that every individual and every organ of society, keeping this Declaration constantly in mind, shall strive by teaching and education to promote respect for these rights and freedoms and by progressive measures, national and international, to secure their universal and effective recognition and observance, both among the peoples of Member States themselves and among the peoples of territories under their jurisdiction. 13

Whereas resolutions proposed to the League of Nations had been understood as efforts to establish legal forms for international policy, to be followed by states as well as by professional journalistic organizations, the words of the Universal Declaration of Human Rights are often taken as a program for immediate national legislation. Is this interpretation proper? One has doubts. The above quotation shows instead that there are no genuine differences between the proposed policies of the UN and those of the League of Nations. In both, international cooperation based on these policies has to be taken as a necessary step until effective national legislation is possible. 


\section{Second Dilemma: Historical}

Our current practices in dealing with the flow of information among and between people of foreign countries is quite deplorable. The period between the League of Nations activity and the Universal Declaration of Human Rights was one of hostile war propaganda in the relations among the fighting councries. However, in the fifties, even after the adoption of the Universal Declaration, this same type of propaganda was a main weapon in the so-called Cold War.

When we think of the international flow of information, we too often mean those sad experiences when nations increase hostile feelings and spread slander rather than news. 14

\section{Third Dilemma: Psychological}

The media are thought to have a powerful influence on the human being. This power is often considered a factor of subversion rather than of intellectual and social development. That was common opinion when the League of Nations acted, as well as when the Universal Declaration. of Human Rights was adopted. Now, after years of mass communication studies, we are more skeptical. about this. We know now that the short-term impact of the media is not so great. But we have had a chance to discover that the long-term influence of mass communication is powerful. We know also that the effects of any tool depend on the way it is used and the aims with which it is applied.

However, the prospect of misuse of media power is still worrisome. Media, we used to say, are not powerful factors of change as we have expected, but they have the power to restrain audience disposition toward change. Many nations are building their future on programs of planned social and economic reconstruction, and the influence of media acting from outside the nation can have subversive effect.

Another kind of apprehension is caused by the medium that can be used as the first possible channel of the cross-border flow, that is, television. If we wish the free flow of information to be used by the audience to its social and cultural advantage, we should think of more suitable channels of communication. The written word, which can be reread and analyzed, is more convenient than are volatile pictures and sounds. Moreover, although television is used primarily as a medium of entertainment, we prefer the free flow of information to have a primarily educative value, so this medium would have to be changed to be used for our aims. Furthermore, research data collected all over the world indicate that television is almost the only medium that is used by persons who are less bright, less educated, and more passive than are the receivers of other media. 15

Using television as the main channel of cross-border flow seems the worst of the possible solutions, one that may lead to a lot of undesired effects.

\section{Fourth Dilemma: Institutional}

The individual. is, according to the Universal Declaration, a subject of freedom of information. He has to be free from restrictions, but who will protect him if the freedom is misused? In the time of the League of Nations, it was believed that the professional journalistic organizations could control the flow. But are these organizations able to fulfill such duties when there is no agreement among the 
journalists themsejves, even on the question of professional responsibility? If not the professional associations, then who should assume the responsibility? The United Nations and its organs? One can imagine the way in which protests by ceachers of biology, irxitated by foreign advertisements with phictures of human organisms, will be dealt with by an international organization.

It seems that the target of all radical attacks, presently the nationstates, will be those bodies that will act in the name of their citizens and organizations of citizens.

I think that the membexs of the international community, the states themselves, should be taken as the actors in control of, as well as partners in, building international policy.

Fifth Dilemma: Economic

Every individual has a right to communicate, but this right can now be enjoyed only by those who are economically powerful. The lack of equal economic positions of free legal subjects gives private and state monopolies an opportunity to strive for an unlimited world media market, and in this respect, restrictions by states will no longer be possible. This picture is so often shown and, it seems to many, xesults in the worst possible consequences of a proposed free flow solution. so further comments are unnecessary. 16

\section{Sixth Dilemma: Sociological.}

The assumptions that society is the sum of individual wills and that social interest is the result of individual interests do not correspond with reality. Each society is acting according to principles that are recognized by its members as good for the whole but not necessarily convenient for all of its parts. Acting in and for society requires the restraint of some individual aims and the respect for some restrictive laws. No planned social development would be possible without this premise. Calling for the rights of individuals and thus giving them international protection will restrict the achievement of some social goals. 17 In this case, the rights of individuals have to be balanced with the needs of society.

The dilemmas presented above suggest the following statements:

1. The present state of international rules, fncluding the Universal Declaration of Human Rights, does not lead us to national legislation as the only possible immediate solution, but rather it creates a need for international policy in this field as a first step.

2. The practice of international communication provides many examples of actions that militate against international cooperation. There ls a need to look at examples of such cooperation that one can approve.

3. The effects of communication can be dysfunctional. in relation to desired aims. The technological aspects of communication must be used with caution. The introduction of television as a main channel of international flow may have the effect that partners in this communication medium will be those who are less educated, less bright, and more passive in their social life. 
4. Nation-states, more than communication institutions, are likely to have control of the use and misuse of free flow, as well as to build the international policy in this field.

5. Free flow will be possible when economic differences do not establish barriers to the participation of individuals and communities. The concept of free flow should not give the opportunity for new exploitation of the media market by the rich.

6. The desired policy should, at the beginning, be directed toward social goals and not to the egoistic interests of individuals.

The quest for a policy at the international level seems to be a significant consequence of the free flow issue. In the process of formulating policy it is necessary to open channels for action instead of merely removing all limitations. A system of preferences should be established. For this aim, it is better to discuss the problem of freedom not in the meaning of freedom from but rather in terms of freedom tox. This old Marxian notion describes the conditions when lack of conm straints and vested power give the actor a chance to adopt purposeful policies if he is sufficiently motivated for action.

Freedom of information can be realized by the establishment of a web of communication channels between peoples of different national and geographic positions striving toward well-defined goals. As in every communication process, those goals will be the creation of common knowledge, opinions, and attitudes toward the problems of our world. We are motivated enough to establish spheres of shared values in many of the problems, between nations as well as at the internationa.l level.

The reported experiences of the free flow issue show international policy in this field as the necessary measure to develop more equal communication in the developed world. In this case, the fundamental step has been taken. Regardless of the rising pessimism manifested mainly by the Western media, the Helsinki Agreements laid the basis for a move toward better understanding among developed nations now divided by ideological diffexences and the tradition of the cold war. The Helsinki document is an invitation to open international or bilateral agreements on the exchange of ideas, cultural and artistic values, and scientific findings. Such agreements can introduce foreign. ideas on national scenes. The objective of the cooperation will be fairex understanding of other nations and their cultural heritages. Cooperation can not only open the chamnels for communications but also begin the policy of promoting values.

Despite various contrary opinions, a lot must be done and stereotypes about existing conditions for communication on an equal footing should be reconsidexed. The widely known Tampere study on the structures of national television programs, 18 and others on the structures of cinema programs 19 show that there are countries that discriminate against information and values of others instead of valuing any high artistic and humanistic qualities. Even in the field of media study, there are countries where the main research periodicals are more ethnocentric in their policy of information and publications review, whereas other countries seem to be more open for the world 20 
Since Helsinki, it is hard to say anything about the trend to open new channels of communication between nations whose representatives left their signatures on the document.

Better understanding among the divided nations of the developing world also was the traditional aim of a faixly perceived free flow concept.

\section{THE RIGHT TO COMMUNICA TE AND PROBLEMS OF THE DEVELOPING WORLD}

Another group of problems seems to be important and probably are more urgent than reconciliation between East and West on the European scene. They are related to communication as the factor of modernization in the developing world.

Perhaps it is true that, as Gumar Naesselund declared in his contri.m bution to the Cologne meeting, the right to communicate concept ought to be especially meaningful for the developing world. Using the new concept, we have a chance to shape it in the form that would be useful for the promotion of the idea of communication for development.

If, as Jean d'Arcy said, ${ }^{21}$ today we live in a revolution of communication, the question arises, Who are those we? Undoubtedly, it is the Western. capitalist world and to some extent the other developed nations but not the Third World, where a sufficient structure of communication is far behind the present. state of reality.

Gunnar Naesselund wrote, in his contribution to the International Broadcast Institute meeting at Cologne,

The Director General of Unesco had stated that it was becoming a matter of urgency for the developing countries to establish a communication infrastructure able to cover urban and rural zones alike, and accessible to all social classes. For the beginning of the First Decade, Unesco proposed as a minimum goal for this infrastructure, ten copies of daily newspapers, five radio receivers, two television sets and two cinema seats per 100 inhabitants. 22

At the same time, speakers for the developed world are talking about communication overdose and claims for the "right not to communicate." 23 In the question of access to communication, we are facing a continuum of situations, on one end of which are the communication-abundant societies and on the other end of which are those communities where oral, face-to-face communication is the predominant idea exchange. The access to communication channels in the new nations does not necessarily mean the proper use of media for educational and technological development. As Exskine Childers has pointed out, many media users in developing countries employ electronic devices to follow alien patterns of consumption and programs that are aimed for the rich and for developed nations. The differences in social needs and individual motivations in these cases are apparent.

The introduction of communication devices does not always create the expected effects. Developing not only a communication infrastructure but also a way 
of properly absorbing educational information and using it to promote innovations are very important problems of this world. 24

Looking from the perspective of developing countries, some of our Old World problems concerning the free flow concept change their proportions to the extent that even very understanding observers lose their patience. John A. Lent reported:

Territories of the Third World are now in the process of redefining the concept of press freedom that they inherited from colonialists. Because of the transitional nature of these societies, government leaders rationalize such modifications of press freedom concepts and maintain that they are in order. They claim that in emerging nations, unusual powers are sometimes necessary to force decisions that will benefit the people. They ask that the mass media show restraint in criticizing government, and at the same time promote national goals and identities. The press is implored to accept a deliberately guided press concept until the nation is stabilized, after which time the powers-that-be will lessen press restrictions. The questions asked by some critics are: How long will it take for stabilization? ${ }^{25}$

\section{CONCLUSIONS}

When we attempt to change from the free flow approach, which expresses the contradiction between political West and East, to an approach toward resolving the modernization problems of the Third World, we must raise many questions, many of a theoretical nature, and see them in a new, unusual way. The discussion in Colombo and elsewhere raises voices from the Third World. We can expect that the problems of relations between individuals and society, responsibility for communication content, and representation of elite and nonelite nations in the media will be perceived as more complex and at the same time more socially important.

Old ideological arguments of the developed world seem less important when we are facing the problems of the new nations.

This brief explanation of the problems related to the right to communicate issue leads us to two courses of action. The first is to develop a wide range of cross-cultural research programs in which the problems of communication systems and the individual and social needs for communication will be described and defined. The second is to set policies and goals that will be well defined and directed toward a better understanding a mong nations and of the role of communication in modernizing the developing world. This second task seems to be of greater urgency. 


\section{NOTES}

1. L. S. Harms and Jim Richstad, "Right to Communicate: Human Rights, Major Communication Issues, and Communication Policies and Planning, "Paper presented at the Intexnational Broadcast Institute Annual. Meeting, Cologne, September 1-4, 1975.

2. Mathilda and John Riley, "Mass Communicacion and the Social System," in Robert K. Merton et al., eds, Sociology Today, vol. 2 (New York: Harper \& R.ow, 1959), pp. 537-578.

3. L. S. Harms and Jim Richstad, "An Jnterchange Model of Human Communication," mimeo, 1974, po, 2-3.

4. Harold D. Lasswell suggests the use of the notion of values rather than of the concept of needs for mass communication research. See his "Structure and Function of Communication in Society," in Lyman Bryson, ed. "The Communication of Ideas (New York: Cooper Square Publishing, 1964).

5. Karl Eric Rosengren, "Uses and Gratification: An Overview," mimeo, Lund, 1972, p. 16.

6. Philip Elliott, "Uses and Gratification Research: A Critique and Sociological Alternative," in Jay G. Blumler and Elihu Katz, eds. "The Uses of Mass Communication (Beverly Hulls: Sage, 1975).

7. A. H. Maslow, Motivation and Personality (New York: Harper, 1954).

8. This misconception probably was supported by the E. L. Hartley and R. E. Hartley paper on the importance of communication needs satisfaction, "The Importance and Nature of Communication," in Charles S. Steinbergo Mass Media and Communication (New York: Hastings House, 1972), p. 8, which is usually understood as part of mass communication theory readings.

9. Phi]ip Elliott, "Uses and Gratification Research," op. cit., pp. 118, 12-13.

10. Exskine Childers, "When the Excuses Have to Stop," Intermedia 2, 5 (March 1975): $7-9$.

11. See, for instance, Oscar W. Riegel's "Direct Satellite Broadcasting and Inter" national Research," in Der Anteil der Massenmedien bei der Herausbildung des Bewustsein in der sich wandelnden Welt (Leipzig: International Association for Mass Communication Research, 1974), pp. 73-74.

12. Text in J. M. Pomorski, "Right to Communicate: National Legislation or International. Policy," in "The Global Context of the Formation of Domestic Communication Policies (London: International Broadcast Institute, 1975), pp. 51-55.

13. The Universal Declaration of Human Rights, Yearbook of the United Nations, $1947-1948$.

14. See, for instance, Clifton E. Wilson's "The Information Agent Abroad: New Dimension in International. Law," Journalism Quarterly 42, 2 (1965): 243-252 and Robert Holt, Radio Free Europe (Minneapolis: University of Minnesota Press, 1958), 
15. See T. Petho, "Television and the Press," in The Media Today and Tomorrow (Prague: International Organization of Journalists, 1974).

16. See Y. V. L. Rao, "Information Imbalance in Asia," Indian Press 2 (1975): 20. "Our first assumption suggests that the advantage of the concept of free flow of information has generally worked only in favor of the more industrially advanced countries in the world."

17. One of the participants in the Asian Mass Communication Regional Conference on Information Imbalance in Asia in Colombo, Sri Lanka, April 1975, expressed this problem for the developing countries as the dilemma of "GNPism versus social justice."

18. Tapio Varis, International Inventory of Television Programme Structure and the Flow of TV Programmes Between Nations (Tampere: Research Institute and the Institute of Journalism and Mass Communication, University of Tampere, 1973).

19. Compare the structures of film programs in various countries using the data from World Communications: A 200-Country Survey of Press, Radio, Television and Film (Paris: Unesco Press, 1975).

20. See an interesting comparis on of the book review contents in the Journalism Quarterly, Publitzistik and Zeszyty Prascznawcze in P. Dubiel, "Analiza porownawcza recenzji ksiazkowych w wybranach periodykach prasoznawczych" (A comparative analysis of the book review contents in selected journalist periodicals.) Zeszyty Prasoznawcze 1 (1976): 27-44.

21. Jean d'Arcy, "The Right of Man to Communicate," Paper presented at the International Broadcast Institute A nnual Meeting, Nicosia, 1973.

22. Gunnar R. Naesselund, "Relations between and Perspectives within 'Development Support Communication, ' 'Communications Policy and Planning, ' and 'The Right to Communicate' as Seen by Unesco," Paper presented at the International Broadcast Institute Annual Meeting, Cologne, September 1-4, 1975.

23. See the discussion at the International Broadcast Institute Annual Meeting in Mexico City in Intermedia 2 (1974).

24. See David Hapgood and Meridan Bennett, Agents for Change (Boston: Little, Brown, 1968).

25. John A. Lent, "Mass Media in the Developing World: Four Conundrums," Vidura 12 (June-A ugust 1975): $153-154$. 



\section{IT'S A LONG WAY TO COMMUNICATION \\ HENRY R. CASSIRER}

It is fashionable to say that we live in a society of communication. But, although modern society is crisscrossed by an ever tighter web of electronic transmissions and bombarded by channels of information and entertainment, it is predominately a society of noncommunication. Can we speak of communication when there is no dialogue or interaction? Any discussion of the meaning or validity of the right to communicate will have to begin with the concept of communication itself.

\section{ARE MODERN MEDIA COMMUNICATING?}

Communication is generally understood as the processes of transport or transmission of matter or ideas between places and people. Social communication is only one aspect of the broader communication pattern and intimately linked with it.

The modern media of communication are in turn part of the process of social communication. But some of these media have created a phenomenon hitherto unknown in the world of communication: the one-way channel.

Who ever thought of building a railroad exclusively for carrying traffic from the capital to the provinces, without any return? If roads were to carry vehicles only in one direction, what use would they have and what a pileup would result at one end! Shipping lanes and airlines, underwater cables or the telephone all serve to link places and people with each other in two-way communication.

But then came the mass media, the press and the cinema and, above all, radio and television broadcasting, produced in a few places at the center and distributed to the periphery. Aimed at "target audiences" and "consumers," these media take note of the public's response almost exclusively in quantitative terms, through sales and ratings. Their "success" lies in reaching the largest number of people at the lowest cost per customer, typical of the market economy. But the oneway character of these media is so deeply ingrained technologically that they fit equally well into the objectives and methods of a totalitarian propaganda machine. Whether in capitalist or socialist countries, the mass media tend to show the same characteristics: central production and dissemination from the top down, without corresponding response or feedback. They are essentially media of information and entertainment, far removed from the fundamental sense of communication.

is not:

To make the point even clearer, let us look at what communication

Communication is not the dissemination of information. When a speaker leaves the microphone convinced that he has put his point of view across, 
he has no way of knowing who has listened to him, whether he was understood, whether there is agreement with what he had to say, and what questions or points of view listeners would raise were he to meet face to face with them. When a husband only talks to his wife and never listens to what she has to say, one would never say that the couple are communicating with each other.

The mere confrontation of facts and opinions, even if it is reciprocal, also fails to produce true communication. When two people communicate, person to person or on the telephone, they not only confront their initial information, atti-tude, and ideas but progress to common concepts and agreements (or disagreements) in an evolving spiral of question and answer, statement and response. It is the essence of a process of communication that it goes beyond initial positions toward a state of mind or changed conditions, which can result only from interchange or interaction. The two-way traffic carried by conventional communications is far more than the mere exchange of goods or the travel of people. It results in new industries, new dependencies, new forms of the economy, new modes of habitat, and new mental horizons. Similarly, communication of ideas goes far beyond the obvious clash of opinions toward creating new mental and material conditions.

Nor is communication identical with expression. However vital free dom of expression is for the fulfillment of the individual and the democratic function"' ing of society, expression does not by itself ensure communication. It may lead to communication but is not identical with it, for communication implies the existence of a partner.

Finally, communication is not identical with modern communication technology. Even when this technology permits true communication, as in the telephone, it is only part of a broader communication process of both material and social dimensions. All modes of communication interact upon each other; it would be a dangerous distortion to single out any one mode as being communication sui generis. The transmission of voice, image, or print through telecommunications changes the patterns of physical transportation of men and goods. Conversely, road construction or air traffic has a profound impact on the horizon of social communication.

Even if we assume that our concern in the discussion of the right to communicate is only with social communication, it would be a profound fallacy to single out telecommunication as communication per se. This would cut telecommunication off from the broader context of communication between people, which alone is able to correct the authoritarian and unidirectional characteristics of modern communication technology. To limit the notion of communication to this technology serves only to cloud its noncommunicative character and to bar efforts to make it serve genuine communication.

\section{TOWARD GENUINE COMMUNICATION}

Professionals of mass communication, be they managers, producers, or researchers, customarily ignore the telephone when they speak of modern communication technology. Yet the telephone is an outstanding example of this technology, and it should be a challenge to find ways in which other forms of electronic communication may be endowed with the same flexibility and responsiveness. Nor is it helpful if studies on communication leave aside the significance of the cinema. 
Although the cinema also is subject to overcentralization and to divorce between producer and audience, it does offer comparatively greater opportunities for multiplicity of access and diversity of use than do the major media of telecommunication. Any workable theory of communication will have to be as appropriate to the cinema and to the print media as to the media of telecommunication (including the telephone), and it will have to see all of them in the widex context of social communication, itself operating in intexaction with material transport.

It may be argued that it is appropriate, nay, inevitable, to treat separately the operation, finance, and technology of the various channels of communication. From strictly administrative points of view this may indeed appear fully justifiable. But modern society witnesses an ever growing intertwining of all modes of communication. The evolution of technology, the multiple roles played by satellites and light-weight video, by computers and data transmission, highlights the need to view the communication process as a whole, rather than only its various parts. Ways also have to be found for closer communication between different forms of communication.

Communication media fail to live up to their potential unless they are responsive to the deeper communication needs of society and of the individual, unless they contribute to counterbalance and overcome the atomization and alienation characteristic of today's world. Some examples may help to make clearer what I have in. mind.

In the natural and social sciences it has become apparent that the traditional separation of knowledge and practices into individual disciplines, faculties, administrations, and professions constitutes an increasing obstacle to discovery and successful attainment of major objectives. The promotion of interdisciplinary or transdisciplinary approaches inevitably runs into deep-seated obstacles. Pride in the startling productivity of scientific specialization during the past three centuries is compounded by vested economic and ideological interests that defend the pursuit of distinct disciplines. It is difficult to go beyond them, as doing so implies a search for global, integrated concepts based on an understanding of a vast body of knowledge and ideas in numerous fields. Yet the exploration of outer space or the mastery of man's environment on earth, to cite only two contemporary preoccupations, requires that the effort be made, an effort that cannot be accomplished without appropriate methods of communication.

The second example touches man's inner world. 'The chasm in a world deeply divided against itself is not merely social, economic, or political, it penetrates the basic values held by the individual and incapacitates his personality. Such inner processes are of public significance because the truncated individual, and the value systems and institutions he creates, act in turn upon the world to further deepen its polarization. An instance is the low respect for manual labor. The age-old search for mens sana in corpore sano is frustrated by a system of values that divorces mind from hand, intellect from physical work. Communication through educational systems all over the world fosters the greater prestige of mental operations rather than the use of one's hands, a dichotomy that underpins the suprem acy of classes, castes, and bureaucracies while it creates an inferiority complex among those who live by manual labor and incites them to seek a way of life in which they would not have to soil their hands. Instead of deepening this gulf, how may channels for social communication help to overcome it and to promote a wholesome balance in society and within the individual person? 
To link what is apart and to make evident the inner unity of what at first glance appears far removed or in deep conflict-mthat is the preeminent role of communication. When communication establishes channels for physical transportation or the flow of ideas, through interchange and dialogue, it fosters contact between what is different or complementary so that new conditions, new awareness, and a new synthesis may emerge from dialectic confrontation and interaction.

\section{THE RIGHT TO COMMUNICATE}

Discussion of such a broad approach to communication would lead us well beyond the scope of this volume. The protagonists of the right to communicate focus essentially on social comminication and the role of modern technology. But even from this more restricted point of view it seems vital to keep the broader implications in mind. To play their distinctive, innovative role in society, the media of communication must not only go beyond the mere dissemination of information to the promotion of social interaction. They must also assure communica tion where it is woefully lacking, whether that communication be among people or among concepts and ideas, as well as among the social institutions that support and embody those concepts and ideas. There is little prospect for the right to commu* nicate as long as those who control the media are caught in the traditional frame of mind (fostexed by education, departmentalization, and conventional journalism) that deals with individual subjects one by one. It is impossible for man to deal effectively with rapid social change and conflict, with the impact of technology and the crisis of human values, without a global, comprehensive approach. But neither the mass media nor education generally prepare the citizen to see events, ideas, and values in their dynamic interdependence. The "communication" media continue to be a mainstay of the gulf that separates today's state of mind from the conditions that determine the future (or threaten the present). As usual, awareness lags far behind realities. The issues of environment, disarmament, and the economic impact of social values are significant examples of the interdependence of phenomena and the inadequacy of current concepts. But the mass media generally confirm the citizen in his pigeonhole way of thinking rather than help him to see beyond accepted formulas.

The problem is of philosophical dimensions, but the task is eminently practical: to turn the potential channels of communication in society, and more specifically the modern technological media, into genuine media of communication.

This task derives not from any dogmatic or idealistic preaccupation. with communication, but from awareness that a society that is incapable of open communication is unable to come to grips with its basic problems and to cope with the changes that impose themselves. The wisdom of genuine democratic participation and decision making, of relying on the knowledge, the aspirations, and the initiatives of the people and not only on the political will and the expertise of the authorities, lies in the realization that this is the least harmful and frustrating way of peacefully resolving the inevitable conflicts that shake society and herald change. In an era. in which mass media play a preeminent role in the manner in which society governs itself, one is compelled to ask how these media may also become vehicles of democratic participation and decision making, how they may effectively strengthen the flow of communication rather than distort or defeat it.

Will this issue be crystallized in the demand for the right to communicate? One can only welcome the new emphasis on communication, which goes 
beyond the stress on freedom of thought and expression as an acknowledgment that society disintegrates without communication. But can one speak of a "right" akin to the other rights proclaimed by the Universal Declaration of Human Rights, which proclaims in Article 2 that "everyone is entitled to all the rights and freedoms set forth in this Declaration"? The entire thrust of the declaration is on the rights of the individual. But can an individual claim a right that is meaningless unless he has found a partner who is equally determined to assert this right? Communication implies reciprocity, not only of individuals but of social groups, classes, and professions or occupations. Peasants, laborers, or slum dwellexs usually have few ways to make their voices heard and to receive response to their preoccupations. But can they (or, rather, can the individual peasant or worker) demand the right to communicate with authorities and the rest of the population unless these authorities recognize in turn the importance of communication, are prepared to operate the mass media as media of communication, and are ready to engage in dialogue through them? By whom and from whom is the "right" to communicate to be claimed?

A way out of this quandary within the context of the Universal Declaration may, perhaps, be found by adopting an approach similar to that which it takes with regard to the institution of marriage or to the principle that "the will of the people shall be the basis of the authority of government," that is, by an affirmation of certain principles that guide the right of the individual and a proclamation that the individual is entitled to benefit from these principles. To resolve the dilemma between the social nature of communication and the rights of the individual, one might conceive of an article of the declaration that asserts the importance of multi lateral communication in society and establishes the right of everyone, as an individual or in association with others, to participate in such communication. In a book devoted to the exploration of the subject by numerous personalities, it would be premature for me to suggest a precise wording for such an article whose idea would first have to be discussed from different angles.

In any case a mere affirmation of the principles of communication would never suffice to change its practice. The obstacles are not merely ideological but practical. Awareness about the shortcomings of the media as they are organized and operated today goes back a long way, but experience to change the pattern has been slow and difficult. A look at the past will help us to take a more realistic approach toward establishing genuine communication in the future.

\section{A HISTORICAL PERSPECTIVE}

Concern with the one-way nature of electronic mass communication goes back almost to its beginnings. As far as I am aware, the first clear recognition that the normal practice of broadcasting does not constitute communication came from Bertolt Brecht in a speech about the function of radio. 1 Brecht observed that "radio has one side where it should have two. It is a mere distribution machinery, it merely assigns." He therefore made a "proposal for a change of functions of radio: Radio is to be turned from a machinery for distribution into a machinery for communication." Explaining his proposal, which he called deliberately utopian, Brecht continued:

The radio could be the most magnificent communication machinery of public life one could think of, if it would know not only how to transmit but also how to receive, that is to say if it would not only 
make the listener listen but also talk, and would not isolate him but place him into relationship. Hence the radio would have to cease being a mere delivery agency and organise the listener into suppliers. All efforts of the radio to give to public affairs a truly public character are therefore absolutely positive.

Brecht made two other observations in this speech that have particular relevance for all initiatives to turn mass media into media of communication. He deplored what he called the Folgenlosigkeit, the lack of consequences, "which ren-" ders almost all our public institutions so ridiculous." Noting that radio is trying to offer entertainment that is as harmless as possible so that it should not have any consequences, he asked "whether there is not some possibility to confront the powers which exclude through an organisation of those who are being excluded. "He therefore called for "campaigns which make an impact on reality with the purpose of changing reality, if only at points of most modest significance, as for instance in the authorization of building constructions. . . . This would assure to radio a very different, incompaxably deeper effect and an entirely different social significance than i.ts present purely decorative stance, ${ }^{"}$

Second, Brecht called his proposals utopian because he was convinced that existing society could not put them into practice. He refused to get involved in mexely renovating institutions so they may function betrex within society as established today. But he also refused to renounce all efforts to change the function of radio because nothing could be done until society is changed. For Brecht, all efforts to render broadcasting more communicative are worthwhile because they may help to change the nature of society itself. "Through constant, never ceasing proposals for the better utilisation of such machinery in the interest of the public as a whole, we must shake up the social basis of this machinery and stimulate discussion about its use in the interest of the few."

Brecht the creative, visionary writer committed to social and political action sought to transform one-way dissemination into communication through his "proposals." In pragmatic Britain, on the other hand, efforts to complement the one-way character of broadcasting took their impetus from the democratic tradition and the practice of discussion as the favorite form of adult education. From 1927 onward, the British Broadcasting Company fostered the creation of Listening Groups in the hope that the combination of radio with gxoup discussion would eventually provide a great new source of informal education. 2 But by 1947 it was found that the cotal membership of Listening Groups had increased to only four thousand over a. period of nineteen years, while the number of individual license holders had risen to eleven million. The cause of this discrepancy was not only the spread of home radio as the normal pattern of reception but also the fruscration of discussion for its own sake. A retrospective $\mathrm{BBC}$ report noted in 1951 that "by 1944 even the $\mathrm{BBC}$ Listening Groups were beginning to be impatient of mere discussion and asking how they could make use of their conclusions in some form of action."3 Such frustration was the logical consequence of the Folgenlosigkeit denounced by Brecht.

It is in Canada that the first effective steps were taken to turn radio around so listeners could also speak on the air and so broadcasts would have practical consequences. The Canadian "Farm Radio Forum" 4 was created in 1941 in response to wartime pressures for increased food production. Adopting the slogan "Read-Listen-Discuss -Act," the farm forum went significantly beyond the British predecessor through its focus on study in relatively homogeneous rural groups 
(lack of homogeneity was one of the weaknesses of socially nonoriented discussiononly groups in Britain) and through its emphasis on action and the establishment of feedback channels. Here were the beginnings of genuine communication, as farmers' comments and complaints were aired to be answered in turn by authorities and specialists.

Canada also pioneered in the communicative use of film. The Canadian National Film Board, inspired by Grierson to employ film as an instrument of social awareness and creative expression, soon realized that distribution, utilization, and group discussion were as important to the social significance of the cinema as the films themselves. But inevitably there always remained a gulf and time lag between the finished film and its maker on the one side and the public's response on the other.

With the advent of television, early enthusiasts saw an even greater opportunity for the medium to become communicative by enabling people to meet with people in a common search for practical answers to realistic issues. "The Whole Town's Talking," a series of programs broadcast in 1951 by lowa State College's television station and produced by Robert Lewis Shayon, was a first and apparently stillborn attempt to take television to the community so that it might resolve issues through confrontation in front of the cameras.

About the same time, teachers in a rural area east of Paris took the initiative to create "teleclubs" for the reception and discussion of the new medium of television. This was the springboard for a significant experiment undertaken by Unesco, in cooperation with French television and its Director of Programs Jean d'Arcy, under the title "State of Emergency," a series of thirteen broadcasts designed for discussion and follow-up action in the villages. 5 The programs consisted largely of films, made in the rural areas, that offered peasants opportunities to speak their minds over the air and included a comment-and-answer section in which responses to earlier broadcasts could be replied to.

Farm forum and teleclubs began to make their way around the world, particularly in rural areas, as far as radio is concerned. With the aid of printed reports on significant experiences, 6 and frequently with the support of Unesco or the Food and Agriculture Organization of the UN, countries discovered that mass media could listen as well as talk, promote dialogue and participation, and create a real sense of involvement among both home audiences and organized listeners. Group reception-discussion turned out to be more than a way to bring broadcasting to those who could not afford a home receiver. It proved to be quite viable side by side with private listening-viewing because it added an active dimension to mass communication. I once visited such a group, which sat on the sand around the radio set in the dark of the night in a village of central Senegal. In answer to my question, I was told there were about forty radio sets in the village. "Why, then, do you come here to listen when you might just as well stay at home?" I inquired. A peasant promptly replied: "When I listen at home, I only pay half attention to what is said on the radio. When $\mathrm{I}$ listen here, I am much more attentive, and then we can also discuss the broadcast, decide on what to do about it and send our comments back to the station. All this I could not do alone at home." I had encountered the true application of the right to communicate.

From Japan to India, from Tanzania to Zambia, and from Ghana to Dahomey illiterate working people, peasants in far removed villages and women in 
the cities gained access to communication with each other and with the authorities and at the same time strengthened personal interaction within the local community itself. This is not the place to trace the history of this movement, or to analyze its strengths and weaknesses. Numerous were the difficulties and shortcomings of such projects. Even some of the most successful ones, including the Canadian national "Farm Radio Forum," withered away as the specific problems were overcome for which they had been created--quite a logical phenomenon in broadcasting whose great asset is its flexibility, which permits moving in as an educational fire brigade when the need is burning. A major obstacle widely encountered is the conventional attitude that communication is the exclusive concern of the media industries. There is generally lack of willingness to allocate supplementary funds and personnel to fieldwork and feedback channels so that genuine communication may come into being. In Senegal, only the president of the Republic could bring about cooperation between broadcasters and rural field services. Both resisted cooperation because the radio stations declared that the organization of reception in the villages was not its business while the Ministry of Agriculture declared that radio was not part of its concern. When mass media see themselves only as "distribution machines," they are incapable of functioning as communicators in society.

Yet the trend toward developing dialogue with community action groups through the mass media is far from dead. It continues to receive vigorous support from the grass roots elders whenever it has enabled them to gain answers to their preoccupations and to make their voice heard throughout the country. An outstanding example is the Rural Educational Radio of Senegal. 7 Started in 1969 in one vernacular language for a limited groundnut-growing region, it has spread today to all parts of the country and is broadcast in several national languages spoken in different regions. Through recordings in the field and a stream of lettexs, frequently dictated by the illiterate elder to the rare literate in the village, peasants and fishermen speak out week after week on subjects of concern to them and receive in turn replies and expert advice from authorities and specialists. The entire administrative, social, and political climate of the country has been changed through this fresh approach to communication. The Senegalese experience shows what may happen when radio sheds its one-way remoteness and becomes a forum of public dialogue in the service of action.

Action is the acid test of the relevance of the media. But to act, man must be conscious of his condition and of the issues he faces. A basic function of communication is to heighten such consciousness, to sharpen awareness, to open the mind to oneself and others, and to focus on the tasks ahead. 8

Society needs channels of democratic interaction through which people may express themselves, exert pressures, and participate in decision making. To have relevance to the citizen in his personal environment, it is desirable that such democratic interaction reach down to the local level. Hence, the importance of local communication, which today may use the many opportunities offered by new flexible media technology. The use of lightweight video, the employment of video and film for expression and dialogue in the "Challenge for Change" manner (also pioneered in Canada), the growth of local radio, the spread of cable television, and the many ways of employing $8 \mathrm{~mm}$ and $16 \mathrm{~mm}$ film are opening the doors for genuine communication and a concrete application of the right to communicate. 9

When the media, both local and national, become integral components of broad social, economic, and cultural policies and action programs, they have 
much to offer to the future of society. The challenge is clear: how to employ modern communication media so they may not only go out to the people but also reflect their aspirations, so they may truly constitute communication "for the people, of the people, and by the people."

To meet this challenge, and thus to lay the indispensable basis required by any right to communicate, calls not only for new ways to compensate for the one-way nature of the mass media (farm forums, teleclubs, confrontations through video, etc.) but for fresh concepts and policies that give new meaning to the role of modern communication technology in society.

A significant step in this direction was made by the meeting on Radio and Television in the Service of Education and Development, which was convened by Unesco in Bangkok in 1966.10 This meeting recognized that the media are resources akin to other major resources of society, such as land, water, or public utilities, to be used in the public rather than private or partisan interests. Here is the way the Bangkok meeting put it:

Today it is necessary to consider broadcasting as part of a country's so-called "infrastructure." While it is firmly accepted that harbours, roads, railways, waterways, electricity, post, telephone and telegraph services belong to this infrastructure, for which funds must be invested which do not necessarily yield immediate and clearly identifiable results, it is not generally recognised that broadcasting, and in particular educational broadcasting, belongs to the same category. Like schools, which are the subject of public policy and whose significance is not judged in terms of immediate profits, the establishment and use of broadcasting facilities represent a longrange investment expected to contribute to the promotion of the human and material resources of a nation. Like investment in education, these resources should be expected to yield results in the form of an informed, motivated and skilled public, and in the increasing availability of productive manpower.

This idea was echoed and endorsed by the Unesco meeting on Communication Policies and Planning (1972), 11 which took a stand against the conventional single-directional approach to communication and arrived at the following definition of the flow of communication:

An understanding of modern communication must go beyond the outdated vertical model, the one-way concept of flow. It is just as important to be aware of what people wish to do with the media as to ask what the media may do to the people. Communication flow should be seen as a multilateral process, in which not only one can communicate to many, but also one to one, and many to one or many to many.

A long road has already been covered from Brecht's proposals to the views of the Unesco meeting, and from the British Listening Groups of the 1920s to Senegal's Rural Educational Radio. And yet we have only begun to create those conditions under which any right to communicate, if "right" it be, can have practical meaning and reality. It requires more than the proclamation of an idea or the affirmation of a claim. To reach a state of genuine communication that includes the modern 
media, many ideological and practical obstacles will have to be overcome through imagination and action.

The road ahead is one of search, experimentation, struggle, and the clash of interests and concepts. It's a long way to communication. 


\section{NOTES}

1. Bertolt Brecht, "Der Rundfunk als Kommunikationapparat," in Bertolt Brecht, Gesammelte Werke (Frankfurt Am Main: Suhrkamp Verlag, 1968), bd, 18, pp. 127134. Reprinted in Dieter Prokop, Massenkommunikationsforschung, trans. Henry R. Cassirer (Frankfurt Am Main: Fischer Taschenbuch Verlag, 1972).

2. Jean Rowntree and Joseph Trenaman, Broadcasting and Further Education: Report on a Two-Year Experiment (London: British Broadcasting Company, 1951). Cited in Henry R. Cassirer, "Audience Participation, New Style," Public Opinion Quarterly, Winter 1959.

3. Ibid., p. 42 .

4. J. Nicol, A. A. Shea, G. J. P. Simmins; R. A. Sims, ed., Canada's Farm Radio Forum (Paris: Unesco, 1954).

5. J. Dumazedier, Television and Rural Adult Education (Paris: Unesco, 1956).

6. In addition to the publications already cited, see J. C. Mathur and Paul Neurath, An Indian Experiment in Farm Radio Forums (Unesco, 1959); Rural Television in Japan. A Report on an Experiment in Adult Education (Unesco, 1960). Also, Unesco, Reports and Papers on Mass Communication, nos, $16,25,38,51$.

7. Mass Media in an African Context: Evaluation of the Senegal Pilot Project. Reports and Papers on Mass Communication, no. 69 (Paris: Unesco, 1974),

8. Henry R. Cassirer, "Communications--Key to Man's Self-Awareness," in New York Academy of Sciences, Environment and Society in Transition 184 (1971).

9. No specific reference is made to the ample contemporary literature on these subjects, as it is well known among the specialists to whom the present volume is addressed.

10. "Radio and Television in the Service of Education and Development in Asja," Reports and Papers on Mass Communication (Unesco, 1967).

11. "Report of the Meeting on Experts on Communication Policies and Planning," COM/MD/24 (Unesco, 1972). 

IS ASIA ALONE IN ITS AMBIVALENCE?

Y.V. LAKSHMANA RAO AND LUU.TAN KWAN SIU

Whether it is the newspaper or any of the newer (or older) channels of communication, whether it is a philosopher or a media practitioner who is expounding, whether the ideas and the resolutions originate in the industrially advanced countries or in newly independent and developing countries, the fundamental concept of freedom of information and all the privileges, rights, and responsibilities that go with it are not new subjects for discussion.

Then why is there a sudden surge of interest in the right to communicate? Is this just another Western academic in-thing? What has happened since 1948 that has brought about almost a total turn-around in our approach to the grandiose intentions in the field of flow of information? What is it that has gradually but perhaps inescapably led us to question all over again premises upon which the whole edifice has been built? Why is it that the same UN agency that had successfully established agreements to facilitate the free flow of information around the world, today finds it necessary to go through the whole exercise again and initiate studies to look into more or less the same question all over again under a different phrase: "The Right to Communicate"?

Reading through some of the arguments on the right to communicate available thus far, one is mostly confused, but often comforted as well, at the issues and contradictions involved. Although an attempt is being made by Unesco through a questionnaire to member countries to arrive at some conclusions on a consensus (or lack of it) on the right to communicate concept, at this stage interested scholars are defining the right to communicate in many, many ways.

Basically, these activities reflect two approaches. One essentially attempts to look into ways of better implementing Article 19 of the United Nations Universal Declaration of Human Rights. How to guarantee and enforce this need for human rights? How to alleviate the problems that result when these rights are not allowed?

The other approach aims at a new definition for Article 19, which is being referred to as "dead letter" and "technologically illiterate." The proponents of this approach suggest that more emphasis should be placed on the use of resources, including the new technologies, and on the reallocation of resources to provide skills and allow for fairer access and participation.

Besides what to include in a definition of the right to communicate, there have been ideas also on how to make it work, such as the setting up of a mechanism to ensure that all nations would be legally obliged to enforce these rights; the setting up of institutions that would regulate these rights; etc. The right to communicate has also been looked at as a system of ethics for communication policy 
makers and planners, as the planning of communication resource development and utilization will play a central role in securing and enforcing communication rights.

Perhaps the difference in the two major approaches is a matter of semantics. Nevertheless, there seems to be a clear need for wider parameters of communication rights. No longer are freedom of speech and of the press adequate. Now, the means to acquire these freedoms are just as important. Formerly, the implied condition was for the state to recognize these freedoms by not enforcing any laws that would impinge on them. But now, that is not seen as being sufficient; the state is called upon not only to safeguard them but also to find ways in which these freedoms can be practiced with greater equity.

Unesco has attempted to define the scope of the right to communicate in the following manner:

It is involved in many and varled issues which differ in kind and scope, are understood in different ways in different societies and apply at several levels of social organisation.

It concerns states in their relationship with other states and the world at large as well as with their own citizens, communities in their relationship with citizens, the government and other communities; the media with government, information sources and the public; institutions and organisations and individuals with their total environment.

Aspects of the right to communicate are to be found in general, social, cultural and religious attitudes; in the constitutions of states; the policies, laws, regulations and activities of governments at varlous levels, in the constitutions and rules of organisations; in the policies and practises of the information media.

It is the purpose of this paper to survey the status of the right to communicate in Asia as a region, in individual countries as nations, and among Asians as persons. It is essential that this be read with a spirit of understanding and a willingness to compromise without letting political and commercial pressures or motives be attributed to people who talk of the right to communicate.

\section{AS A REGION}

Insofar as the Asian region is concerned, the essential relationship to consider is not that between the state and its citizens; it is, rather, the relationship between the exporting and the importing countries of the information industry. Issues such as "the right not to be communicated with" and the "lack of resources for communication" appear to be more relevant. The recent spate of discussions, ideas, and suggestions on the concept of the free flow of information, and on information imbalance, perhaps is already reaching the saturation point. Therefore, we shall not dwell too much on this area. But having had the privilege to be associated with these Asian gatherings, perhaps it is only fair for us to summarize the main points raised at several recent conferences in Asia, together with some "solutions" that have been suggested: 
1. Developing countries should impose controls on the flow of informational and entertainment materials:

a. to protect their own language, culture, behavioral patterns, values, beliefs, etc.

(The highest degree of nationalism is apparent, with some concession made for regionalism)

b. to increase their own capabilities in the production of materials; continued importation tends to make them complacent and lethargic

c. to protect themselves from being "brainwashed" into looking at world events the way the major news networks see them.

d. to be forced to train the needed personnel for their own networks

2. Developing countries should insist that "exporting" countries impose restrictions on their own producers (public and private), especially with regard to what they sell or distribute freely abroad, taking into account both quantity and quality of their productions.

3. Developing countries should reach agreements (bilateral) with exporting countries that are equitable, that is, send some, take some.

4. Developing countries should work toward "regional" agreements within Asia for exchange of informational and entertainment material, so as to exclude "foreign" material and "influence."

5. Research is needed, both quantitative and qualitative, to gauge the impact of imported materials (trend studies may show that the imbalance is, in fact, already lessening).

\section{AS NATTONS}

Very often it has been suggested that in most of the Third World, freedom of communication does not exist, governments speak for their citizens, and communication is very much controlled by governments.

Here we will attempt to analyze what their constitutions have to say about the fundamental rights and duties of citizens of twenty-four Asian countries in terms of the right to communicate. Of course, this exercise alone will not give an accurate picture, as the written constitution of a state is only a part of the fundamental law that is the basis of that state. There are other laws, some of which may not be written. One must also study how it is applied, the real background of a written constitution, etc. One should also take into account the socioeconomic, political, and cultural aspects of a country.

This would mean a massive project for which we do not have the time or resources available at this point. The objective of this quick exercise is not to see how much freedom is allowed in any one country and how it compares with others, 
but only to generate a broad picture of Asia objectively, as it is almost impossible otherwise to generalize for Asia. The objective also is to examine the context within which an Asian's right to communicate exists--since it seems to be generally assumed that it is the policies of the state that provide the entire framework within which he has to operate.

The selected variables are based on components of communication that are specifically referred to in the United Nations Universal Declaration of Human Rights, Articles 12, 18, and 19.

Article 12: No one shall be subjected to arbitrary interference with his privacy, family, home, or correspondence, nor to attacks upon his honor and reputation. Everyone has the right to the protection of the law against such interference or attack (freedom of privacy, freedom of correspondence).

Article 18: Everyone has the right to freedom of thought, conscience, and religion; this right includes freedom to change his religion or belief and freedom, either alone or in community with others and in public or private, to manifest his religion or belief in teaching, practice, workship, and observance (freedom of thought).

Article 19: Everyone has the right to freedom of opinion and expression. This right includes freedom to hold opinions without interference and to seek, receive, and impart information and ideas through any media and regardless of frontiers (freedom of opinion; freedom of expression; freedom of speech; freedom of writing; freedom of press; freedom of printing; freedom of publishing; freedom of broadcasting; freedom to use any other media).

It was decided that only those fundamental rights that are directly related to communication, that is, to Articles 12, 18, and 19, would be included in the analysis and to avoid too broad a definition of communication. At the nonmedia level, the variables are freedom of privacy; freedom of thought and opinion; freedom of expression and freedom of speech. At the media level, freedom of correspondence (include telegram and telephone); freedom of press; freedom of printing; freedom of publishing; freedom of broadcasting, and freedom to use any other media.

Table 1 shows that at the nonmedia level, the constitutions of all twenty-four countries, except Laos, guarantee some form of freedom in personal communication, especially freedom of privacy and freedom of speech. However, about one-third of the countries provide for freedom of thought and opinion, and about half of the countries provide for freedom of expression. If one combines freedom of thought and opinion with freedom of privacy, as thought and opinion are basically intrapersonal, then only three countries, Indonesia, Mongolia, and Laos, remain that do not have provision for these freedoms.

If one combines freedom of speech with freedom of expression, as speech is one form of expression, then all the countries studied, except Iran, Iraq, South Korea, and Laos, guarantee freedom of expression. 
Table 1. Freedom of Communication Not Involving the Media, As Provided in the Constitutions of Selected A sian Countries

\begin{tabular}{|c|c|c|c|c|}
\hline $\begin{array}{c}\text { Country } \\
\text { (and date of } \\
\text { Constitution) }\end{array}$ & $\begin{array}{l}\text { Freedom } \\
\text { of } \\
\text { privacy }\end{array}$ & $\begin{array}{l}\text { Freedom of } \\
\text { thought and } \\
\text { opinion }\end{array}$ & $\begin{array}{l}\text { Freedom } \\
\text { of } \\
\text { expression }\end{array}$ & $\begin{array}{l}\text { Freedom } \\
\text { of } \\
\text { speech }\end{array}$ \\
\hline 1. Afghanistan (1971) & Yes & Yes & Yes & Yes \\
\hline 2. Bangladesh (1973) & Yes & Yes & Yes & Yes \\
\hline 3. Burma (1974) & Yes & Yes & Yes & Yes \\
\hline 4. China (1975) & Yes & -- & -- & Yes \\
\hline 5. India (1973) & Yes & Yes & Yes & Yes \\
\hline 6. Indonesia (1973) & - & $\ldots$ & $\ldots$ & Yes \\
\hline 7. $\operatorname{Iran}(1971)$ & Yes & -- & -- & -- \\
\hline 8. $\operatorname{Iraq}(1924)$ & Yes & Yes & - & - \\
\hline 9. Japan (1973) & Yes & Yes & -- & Yes \\
\hline 10. Khmer Republic & Yes & -- & Yes & -- \\
\hline $\begin{array}{l}\text { 11. Korea, North } \\
\text { (1973) }\end{array}$ & Yes & -- & -- & Yes \\
\hline $\begin{array}{l}\text { 12. Korea, South } \\
(1974)\end{array}$ & Yes & Yes & -- & -- \\
\hline 13. $\operatorname{LaOS}(1971)$ & \multicolumn{4}{|c|}{$\begin{array}{c}\text { (Fundamental rights of citizens are not stated in the } \\
\text { constitution.) }\end{array}$} \\
\hline 14. Malaysia (1972) & Yes & -- & Yes & Yes \\
\hline 15. Mongolia (1971) & - & -- & -- & Yes \\
\hline 16. Nepal (1972) & Yes & -- & Yes & Yes \\
\hline 17. Pakistan (1973) & Yes & -- & Yes & Yes \\
\hline 18. Philippines (1973) & Yes & - & -- & Yes \\
\hline 19. Singapore (1972) & Yes & -- & Yes & Yes \\
\hline 20. Sri Lanka (1972) & Yes & Yes & Yes & Yes \\
\hline 21. Taiwan (1974) & Yes & -- & - & Yes \\
\hline 22. Thailand (1975) & Yes & - & - & Yes \\
\hline $\begin{array}{l}\text { 23. Vietnam, North } \\
(1971)\end{array}$ & Yes & -- & -- & Yes \\
\hline $\begin{array}{l}\text { 24. Vietnam, South } \\
\text { (1971) }\end{array}$ & Yes & Yes & -- & Yes \\
\hline
\end{tabular}

NOTE: -- represents no mention of such rights in the country's constitution. 
Table 2 shows that as one shifts from personal to media communica tion, there is a significant decrease in the specific guarantee of these freedoms in the constitutions of the countries studied.

Most Asian countries cater to the right to correspond, which also includes the use of telephones and telegrams without interference. Freedom of press is guaranteed in about half the countries listed. In some countries, freedom of speech seems to be used synonymously with freedom of the press; therefore, if we combine the two freedoms, then only Laos, Iran, and Iraq do not provide for them. This combining is arbitrary and may not even be proper, as there are a number of countries that guarantee freedom of speech but not freedom of the press.

The constitutions of very few countries mention freedom of printing and publishing. Those that do (Afghanistan, Burma, Iran, Iraq, Sri Lanka, and Taiwan) tend not to provide for freedom of the press. Therefore, it seems that in these countries one has the right to communicate through "print and publications" but not through the "press"! One can perhaps understand this distinction if one reads "press" as referring to the daily newspaper rather than as including books, brochures, etc.

Freedom of broadcasting is not guaranteed in any of the countries. However, it is interesting to note that there is one country that actually specifies in its constitution that the right to broadcasting belongs to the state. Article 31 of Afghanistan's constitution states that "the establishment and operation of public radio transmission and telecasting is the exclusive right of the state."

Freedom to use any other media is usually mentioned in connection with freedom of correspondence, for example, "the freedom and secrecy of people's communications, whether by writing, telephone, telegraph or other medium, are inviolable"; "the privacy and security of the home, property, correspondence, and other communications of citizens shall be protected." Rather than meaning technologies, freedom to use any other media refers more to private communication between persons.

One can argue that in breaking down these variables, one is stretching the definitions a bit too far, because freedom of expression and freedom of speech should include the means and modes of expression. One can also argue that freedom of the press encompasses print, publications, broadcasting, and other communication media. Whether a country is willing in practice to be so flexible has yet to be tested. A court case in India involves an Indian citizen who holds that because the right to broadcast is part of his fundamental right to the freedom of speech, which is guaranteed in the constitution, he has a right to operate an independent radio station. The writ is being opposed by the solicitor-general of India on behalf of the Indian government.

Therefore, at the very personal level, most countries in Asia, regardless of differences in political, socioeconomic, and cultural characteristics, subscribe to the United Nations fundamental human communication rights. Whether it is a democratic, socialist, or communist country, there is provision for freedom of thought and speech in the national constitution, although at the implementation level the conditions for these freedoms might be different. 
Table 2. Freedom of Communication Involving the Media, As

Provided in the Constitutions of Selected Asian Countries

\begin{tabular}{|c|c|c|c|c|c|c|}
\hline $\begin{array}{l}\text { Country } \\
\text { (and date of } \\
\text { constitution) }\end{array}$ & $\begin{array}{c}\text { Freedom } \\
\text { of } \\
\text { correspondence }\end{array}$ & $\begin{array}{l}\text { Freedom } \\
\text { of the } \\
\text { press }\end{array}$ & $\begin{array}{l}\text { Freedom } \\
\text { of } \\
\text { printing }\end{array}$ & $\begin{array}{l}\text { Freedom } \\
\text { of } \\
\text { publishing }\end{array}$ & $\begin{array}{c}\text { Freedom } \\
\text { of } \\
\text { broadcasting }\end{array}$ & $\begin{array}{l}\text { Freedom to } \\
\text { use any } \\
\text { other media }\end{array}$ \\
\hline 1. Afghanistan (1971) & Yes & -- & Yes & Yes & No & Yes \\
\hline 2. Bangladesh (1973) & Yes & Yes & -- & -- & -- & Yes \\
\hline 3. Burma (1974) & Yes & -- & -- & Yes & -- & Yes \\
\hline 4. China (1975) & Yes & Yes & -- & -- & -- & -- \\
\hline 5. India (1973) & -- & -- & -- & -- & -- & -- \\
\hline 6. Indonesia (1973) & -- & Yes & -- & -- & -- & Yes \\
\hline 7. Iran (1971) & Yes & -- & -- & Yes & -- & -- \\
\hline 8. Iraq (1924) & Yes & -- & -- & Yes & -- & -- \\
\hline 9. Japan (1973) & -- & Yes & -- & -- & -- & Yes \\
\hline $\begin{array}{c}\text { 10. Khmer Republic } \\
(1972)\end{array}$ & Yes & Yes & -- & -- & -- & Yes \\
\hline $\begin{array}{l}\text { 11. Korea, North } \\
(1973)\end{array}$ & Yes & Yes & $-\cdots$ & -- & -- & -- \\
\hline $\begin{array}{c}\text { 12. Korea, South } \\
(1974)\end{array}$ & Yes & Yes & -- & -- & -- & -- \\
\hline 13. Laos (1971) & (Fundamer & rights of & zens are $n$ & stated in the & onstitution. ) & \\
\hline 14. Malaysia (1972) & -- & - & -- & -- & -- & $\cdots$ \\
\hline 15. Mongolia (1971) & Yes & Yes & - & -- & -- & -- \\
\hline 16. Nepal (1972) & -- & Yes & -- & -- & -- & -- \\
\hline 17. Pakistan (1973) & -- & Yes & -- & -- & -- & -- \\
\hline 18. Philippines (1973) & Yes & Yes & -- & -- & -- & -- \\
\hline 19. Singapore (1972) & -- & -- & -- & -- & -- & -- \\
\hline 20. Sri Lanka (1972) & -- & -- & -- & Yes & -- & -- \\
\hline 21. Taiwan (1974) & Yes & -- & -- & Yes & -- & -- \\
\hline 22. Thailand (1975) & Yes & -- & Yes & Yes & -- & Yes \\
\hline $\begin{array}{l}\text { 23. Vietnam, North } \\
(1971)\end{array}$ & Yes & Yes & -- & -- & -- & -- \\
\hline $\begin{array}{l}\text { 24. Vietnam, South } \\
(1971)\end{array}$ & Yes & Yes & -- & Yes & -- & -- \\
\hline
\end{tabular}

NOTE: - - represents no mention of such rights in the country's constitution. 
As to mass communication, states are more careful in their provisions for freedom and usually are in control of the technologies, especially in broadcasting. Even if freedom of speech and press are allowed, there is usually a provisional clause that reads, "except in the interest of the security of the state or any part thereof, friendly relations with other countries, public order or morality, or in relation to contempt of court, defamation, or incitement to an offense." Many newspapers and journalists have been indicted on the basis of such conditional clauses. Besides these conditions, there are of course laws on press, publications, and broadcasting, and regulating councils to make sure that this freedom of communication is not violated.

Although these findings give a rather optimistic view of the right to communicate in the nations of Asia, if one looks closer there are of course other indications.

A study was recently done in the United States by Freedom House, as described by Raymond D. Gastil in "The Comparative Survey of Freedom." Drawing conclusions for each country on the basis of the continuing flow of information and behavior rather than on laws or formal systems, it gives a different perspective to the right to communicate concept in Asia.

The survey defined freedom in terms of both civil and political rights as traditionally understood in the constitutionally democratic states. Leaving the political rights aside, exercise of civil rights generally requires independent news media, which may mean private control of the press or radio and, more importantly, freedom from all the various forms of censorship that are found in the world.

A ranking of the twenty-four Asian countries, on a scale of $1=$ most free to $7=$ least free, shows that only Japan and Thailand scored less than 3 and the rest of the countries have a ranking of at least 5 . What the survey indicates is that in most Asian countries, one can expect to find struggling news media: reporters are regularly faced with censorship or even jail. States ranked 6 in civil rights "do not have independent judicial systems nor an independent press (although in a few cases the press may remain in private hands). The general public hears little beyond what the government wants it to hear." (Gastil, "The Comparative Survey of Freedom.")

In the two studies discussed above, one finds conflicting sets of findings. Constitutionally, freedom of communication is very much guaranteed in the Asian region, but it is practiced with a lot of constraints. What can be done to correct these? How can this freedom be made more legally binding in all nations than the existing laws seem to allow? On the other hand, should there be some control of such freedom, as no country in the world can allow "absolute" freedom anyhow? Is it desirable and worthwhile to devote time and resources in pushing for the right to communicate at the national level in Asia when most governments seem to own and operate at least the electronic media?

\section{AS PERSONS}

As we approach the communication era where we realize not only the abundant potential of communication technologies but also the power of those who possess and control them, it becomes important to establish who has access to 
communication systems within a society. Should the right of access be enjoyed only by those who are economically powerful enough, or should the state provide equal access to all its citizens?

One of the controversial issues on the right to communicate is the question of access to and participation in communication facilities and the opportunity to share in community decision making and development. We have attempted to analyze how much access is provided in the constitutions by adding two other variables: freedom of access to information, and freedom of access to means of communication.

Table 3 shows that only two out of twenty-four countries mention the issue of access in their constitutions. The Philippines Constitution Article 4(b): "The right of people to information on matters of public concern shall be recognised. Access to official records, and to documents and papers pertaining to official acts, transactions, or decisions, shall be afforded to the citizen subject to such limitations as may be provided by law." Thailand Constitution Article 46: "Every person enjoys an equal right of access to all means of communication. provided as public service."

It is interesting to find that most Asian countries seem to take the question of access for granted, not consider it important at all, or feel that the question of access does not arise because citizens are supposed to receive only whatever information is transmitted to them.

This, we feel, is an area that needs to be given more thought, as the foundation of the right to communicate lies in an individual's realization and practice of that right together with a responsible attitude.

Information is, after all, a versatile commodity, and the more people participate, the better the chances of generating quality information. Therefore, it is not fair to set artificial boundaries, or to keep information only in the hands of those with vested interests. Furthermore, it should not be just the privilege of those who are "qualified" and have the license to operate.

The other reason why the question of access is important is that basically, Asians have a tendency to respect authority without question. This is inherent in their general, social, cultural, and religious attitudes. Unfortunately, such qualities are often taken advantage of by select groups, usually those in power.

What is needed most is more pressure, with checks and balances, on the government to serve the people, to provide opportunities for better participation based on the public's needs. Also a campaign is needed to educate the people on their rights to information of public concern, to be information conscious, to know where and how to ask for information, and to express and to use the means of communication they are entitled to. 
Table 3. Freedom of Communication As Regards Access, As Provided in the Constitutions of Selected Asian Countries

\begin{tabular}{|c|c|c|}
\hline $\begin{array}{l}\text { Country } \\
\text { (and date of } \\
\text { constitution) }\end{array}$ & $\begin{array}{l}\text { Freedom of access } \\
\text { to information }\end{array}$ & $\begin{array}{l}\text { Freedom of access } \\
\text { to means of } \\
\text { communication }\end{array}$ \\
\hline 1. Afghanistan (1971) & -- & -- \\
\hline 2. Bangladesh (1973) & -- & -- \\
\hline 3. Burma (1974) & -- & - \\
\hline 4. China (1975) & & \\
\hline 5. India (1973) & -- & -- \\
\hline 6. Indonesia (1973) & -- & -- \\
\hline 7. $\operatorname{Iran}(1971)$ & -- & -- \\
\hline 8. Iraq (1924) & -- & $\cdots$ \\
\hline 9. Japan (1973) & - & -- \\
\hline $\begin{array}{l}\text { 10. Khmer Republic } \\
(1972)\end{array}$ & -- & -- \\
\hline $\begin{array}{l}\text { 11. Korea, North } \\
(1973)\end{array}$ & -- & -- \\
\hline $\begin{array}{l}\text { 12. Korea, South } \\
(1974)\end{array}$ & -- & -- \\
\hline 13. Laos (1971) & $\begin{array}{l}\text { (Fundamental rights } \\
\text { the constitution.) }\end{array}$ & zens are not stated in \\
\hline 14. Malaysia (1972) & -- & -- \\
\hline 15. Mongolia (1971) & -- & -- \\
\hline 16. Nepal (1972) & -- & -- \\
\hline 17. Pakistan (1973) & -- & -- \\
\hline 18. Philippines (1973) & Yes & -- \\
\hline 19. Singapore (1972) & -- & -- \\
\hline 20. Sri Lanka (1972) & -- & -- \\
\hline 21. 'Taiwan (1974) & -- & -- \\
\hline 22. Thailand (1975) & -- & Yes \\
\hline $\begin{array}{l}\text { 23. Vietnam, North } \\
(1971)\end{array}$ & -- & -- \\
\hline $\begin{array}{l}\text { 24. Vietnam, South } \\
(1971)\end{array}$ & -- & -- \\
\hline
\end{tabular}

Note: - - represents no mention of such rights in the country's constitution. 


\section{IS ASIA A LONE?}

On the other hand, it is perhaps impossible to visualize a time or a place where the right to communicate can and will be implemented in all its gloriously humanistic colors--especially after the experience that the world has had with the Universal Declaration of Human Rights. That vision of many years ago seems somewhat faded, to say the least. We might do a job of repainting. But is that what is needed? Such a question, we believe, can be answered with a categorical No. Then, obviously what we must aim at is a totally new concept, incorporating by all means the ideologies that seem to be universally acceptable but allowing for flexibility in the implementation mechanisms that are obviously called for.

In other words, we must seek a marriage between the two approaches we have attempted to described earlier in this article: stressing the importance of defining the concept and placing greater emphasis on the implementation of any such concept. Without such a marriage, we believe that any attempt at a definition of the right to communicate, any attempt at a grandiose formulation of a great idea, any attempt at obtaining the signatures of heads of countries, will all end up being merely symbolic. We believe that those who are working in this exciting new field now are not aiming for such a timeworn goal.

We also feel that in this article, which is obviously merely exploratory (and suffers from a number of limitations), we have already been able to indicate clearly the ambivalence in the attitudes of governments and of societies in Asia. With more effort, we could easily have shown that such a mbivalence is also prevalent in many, many countries outside Asia. In fact, such ambivalence, we could virtually assume, is universal. Asia does not have any monopoly.

If, therefore, any conceptualization, definition, and implementation of the right to communicate is to be attempted, let us be absolutely sure that flexibility is built from the start into any model that may emerge. The more rigid we make the concept, the quicker it is likely to warp or break under external pressure. Any engineer will tell us that, whether he deals with materials or men. 


\section{BIBLIOGRAPHY}

"Communications: Individual Rights/State Rights," Ottawa, Canada: Canadian Commission for Unesco. Summary of the discussions by Olga Jurgens at the Stanley House Seminar, New Richmond, Quebec, August 1973.

d'Arcy, Jean. "The Right of Man to Communicate," Paper presented at the International Broadcast Institute Annual Meeting, Nicosia, October 1973.

Gastil, Raymond D. "The Comparative Survey of Freedom - VI," in Freedom at Issue 34 (January-February 1976): 11-20.

Harms, L. S., Jim Richstad. "Right to Communicate: Human Rights, Major Communication Issues, and Communication Policies and Planning. " Paper presented at the Conference of the International Broadcast Institute Annual Meeting, Cologne, September 1-4, 1975. Contribution to Working Committee IV.

"Information Imbalance in Asia," Media Asia 2, 2 (1975): 69-81.

Naesselund, Gunnar R. "Relations between and Perspectives within 'Development Support Communication,' 'Communications Policy Research and Planning' and 'The Right to Communicate." Paper presented at the International Broadcast Institute Annual Meeting, Cologne, September 1-4, 1975.

Ploman, Edward. "Memorandum Concerning Communication Rights and Duties," International Broadcast Institute, April 14, 1975.

- "The Right to Communicate: Present International Legal Framework." Paper presented at the International Broadcast Institute Annual Meeting, Cologne, September 1-4, 1975. Contribution to Working Committee IV.

Pomorski, Jerzy M. "Right to Communicate: National Legislations or International Policy?" Paper presented at International Broadcast Institute Annual Meeting, Cologne, September 1-4, 1975.

Rao, Y. V. Lakshmana. "Information Imbalance: A Closer Look." Paper presented at Conference on Fair Communication Policy, East-West Communication Institute, Honolulu, March 10, 1976.

- "Information Imbalance in Asia--A Working Paper." Paper presented at the Regional Conference on "Information Imbalance in Asia," Kandy, April 1975.

, Brajesh Bhatia, Lena U. Wen Lim and Kwan Siu Lui-Tan. The Feasibility of Introducing Training for Communication Planning in the Asian Region: A Report to Unesco. A study done under Unesco Contract No. BOC 287178 with the Asian Mass Communication Research and Information Centre, Singapore, March 1976.

Unesco. Questionnaire on "The Right to Communicate." COM/RPC. 49/28, August 1975. 
The following constitutions are contained in Constitutions of the World, Albert P. Blaustein and Gisbert H. Flanz, eds. Dobbs Ferry, New York: Oceana Publications.

Beede, Benjamin R. "Democratic Republic of Vietnam," September 1971.

Blaustein, Albert P. "Bangladesh," May 1973.

Blaustein, Mark A. "Afghanistan," December 1971.

Bor, Frederic L. "Mongolian People's Republic," September 1971.

Bowen, G. Thomas. "Khmer Republic (Cambodia)," September 1972.

Brafman, Bruce J. "Pakistan," July 1973.

Bunnag, Marut. "Thailand," 1975.

Cooray, Joseph A. L. "Sri Lanka (Ceylon)," September 1972.

Flanz, Gisbert H. "Korea," June 1974.

- "Republic of Vietnam," September 1971.

- "Philippines," May 1973.

Groves, Harry E. G. Thomas Bowen. "Malaysia," September 1972.

Hecker, Hellmuth, Albert P. Blaustein. "India," May 1973.

Hsia, Tao-Tai, Kathryn A. Haun. "People's Democratic Republic of China," October 1975.

Ibrahim, Ahmad. "Singapore," September 1972.

Lee, T. S. Y. "Japan," February 1973.

Maung Maung. "Burma," December 1974.

McBeath, Gerald A. "Indonesia," May 1973.

Savannah, Linda, "Laos," September 1971.

Sedehi, Abolghassem. "Iran," December 1971.

Seymour, James, "Korean People's Democratic Republic," July 1973.

- "Republic of China," December 1974.

Sharma, Kunjar M. "Nepal," September 1972. 



\section{FOUR RIGHTS OF COMMUNICATION: \\ A PERSONAL MEMORANDUM}

HIDETOSHI KATO

Several years ago, when the so-called campus unrest disturbed the major universities in Japan, Kyoto University, where I was teaching, was no exception. Violent confrontation, militant protest demonstrations, and faculty-student "negotiation" on a mass scale occurred almost daily for more than a year. I sat in these negotiation meetings patiently, and tried very hard to listen to and understand what the students wanted to say. I had a candid opinion that the students had their "right to communicate" with the faculty, and as a professor, I thought that I also had a "right to be communicated to." The series of negotiations went on endlessly, until I found, to my surprise, that the students did not have much interest or intention of "communicating." They continued to talk, and even to shout, but in reality what they were doing was to "express" themselves to themselves; they had no wish to communicate something to somebody else. The $\overline{i r}$ information behavior was fundamentally "expressive" and not "instrumental." Naturally, they had a right to express themselves and subsequently to communicate with one another, but it was their business, and not mine. Thus I abdicated my right to be communicated to, rather regretfully but with relief. I quit my university appointment, and in retrospect I learned that to express oneself is one thing and to communicate with somebody is another thing. It may be argued that to express oneself is a process of intrapersonal communication, and in that sense, the right to communicate with oneself is one of the fundamental human rights, regardless of culture or social system. Indeed, in societies where heavy political control over interpersonal communication is maintained, people tend to rely on intrapersonal communication (such as keeping a personal diary, talking to oneself). This is more than a legal matter of "rights"; it is a matter of basic human "needs." As Susan Langer so aptly noted, "symbolic transformation" is a part of human nature, if not an instinct. Insofar as a person is a sane human being, with some skill in the manipulation of symbols (such as literacy), he or she will seek self-expression through various means. It is a need, rather than and more than a right.

However, an act of expression does not necessarily mean that it involves another person, a "communicatee," a receiver, or whatever that person may be called. I respected and cherished the "right of expression" of those radical students, but I thought that, at the same time, I was not obliged to be involved with their affair. There had to be the right not to be communicated to or, to be more exact, the "right to stay away from other people's acts of expression." Let me illustrate further. As a citizen of a "free nation" dominated by free enterprise, I have been called upon by many salespeople in the past twenty or thirty years. They were encyclopedia salesman, automobile dealers, real estate brokers, sales representatives of insurance companies, etc. They had, naturally, the right to express their interest and enthusiasm for their chosen business and the right to try to communicate that to me. But should I be obliged to be communicated to? Is it my duty to listen to them? The right to communicate is one thing, but it remains at the other party's discretion whether or not he or she is to be communicated to. If the other 
party were supposed to react positively to everyone who wishes to communicate and if he or she were obliged to listen to that person, our world would be extremely miserable. If I had had to give my full attention, as my responsibility as a citizen of a free nation, to all the sales talks (even commercials), I am sure I would have committed suicide by now. It would be both ridiculous and silly to entertain the right to communicate while disregarding the needs and interests of the person to whom a message is being transmitted. A communicator retains his or her right to communicate. It is his or her liberty to think and call on the other party (potential or prospective communicatee) as a "target." But a target has the right not to be communicated to as well as the right to be communicated to. I do not feel guilty or against humanity when I react negatively to a salesman by simply saying "No, " or when I turn off the television when a glamourous woman solicits me to buy a particular brand of shampoo or when a politician for whom I have little respect preaches all his nonsense. A target has its freedom to move, to escape, and even to disappear.

As a scholar interested in sociological surveys, I have met with hundreds, even thousands of people, and have asked them many questions to get relevant data that might fulfill my sociological interests. Very often, however, people did not want to talk to me. Many of them refused to be interviewed. I had to give up talking with these people simply because they did not choose to react to me. I recognized their right not to communicate and also their right not to be communicated to, for I also wanted to be respected in that regard. If peasants of a village, workers in a factory, and people on the streets were supposed to cooperate with a sociologist who asked questions they were not interested in, and if they were obliged to answer them, again, the world would be a terrifying place. No one should be forced to communicate or to be communicated to. Some people like to communicate on certain subjects, and some do not. Some people want to be communicated to, but some do not. These decisions depend on many factors: the individual personality, the subject and the content of the message, social context, timing, location, psychological mood, etc. A newspaper reporter has his right to know (or to be communicated to). If his information source is willing to answer his questions and satisfy his curiosity, it is a perfect arrangement. But the reporter should be reminded that neither he nor the public has the right to force an individual to talk (to communicate). Indeed, to force a person to communicate is regarded as against humanity and unconstitutional in many countries, including Japan. People, especially those who are engaged in media work, tend to emphasize their right to know in order to reveal something to the public, but a person under questioning also has a right not to be known. If I were, for instance, supposed to answer any questions about myself, honestly (such as how much money do I have, what did I do when I was a teenager) simply to entertain other people's right to know, again I say I would have killed myself twenty, even thirty years ago. I have my privacy, like everybody else, and I have the right to protect that privacy, even to the extent of fighting any body who endangers it. I think it is one of the constitutional rights. However, if the right to know dominates other rights related to communication, and especially when the right to know is exercised by authority and power, then such a society should be called a police state in its narrowest and strictest sense. The right to know (or to be communicated to) must be respected, but at the same time and with the same emphasis, the right not to be known should be preserved. An open, democratic society does not mean a completely transparent society, as one might innocently believe.

Unfortunately, human beings, at this stage of evolution, are not as honest and good-hearted as they should be. Rather, the evolution has made human 
mentality extremely complex, delicate, and sometimes dangerous. Except for those few people who are either "purely pure" or completely foolish (they often coincide), all of us have something to hide, something of a personal secret. Should I tell anybody about my income tax situation, my family problems, what I really think of somebody, my voting choices in the last election, and other such personal matters when and if I were asked? If I were honest enough to communicate to other people everything I know and feel, the result would be destructive--not only for myself but also for the whole society.

Nations share some aspects of these rights with the individual. If other countries are privileged with the right to be communicated to, is a given country obliged to communicate on various "personal" questions --the location of nuclear weapons, the number of jet fighters stationed at each air force base, the new scientific projects sponsored by the government, and other information that is usually known as "top secret"? Of course not. A sovereign state has the right not to communicate and the right not to be known. Indeed, because of many (often too many) top secrets, hundreds of authors have been able to live by writing espionage stories. Of course, politicians claim themselves to be honest, and, unfortunately, many of them really look honest. But within my limited knowledge, their honesty resembles that of the used car dealers, especially when they stress their honesty on behalf of themselves. In diplomacy, too, politicians exchange ideas, release communiqués, and sign treaties. But many of us (as well as many of them) are skeptical a.bout many aspects of international communication at the diplomatic level. Often, a diplomatic communiqué is no more than a sheet of paper signed by countries that have agreed not to communicate (in diplomatic terms, "mutual respect"). It is not a dis agreement. Rather, it is an agreement acknowledging that there are many existing and potential disagreements and that there are many things that each party does not want to communicate and does not want communicated to it.

In many countries in Asia, people are annoyed because the big nations so consistently exercise their right to communicate. When a person switches on his transitor radio, it is likely that the broadcast will be the Voice of America, messages from the Soviet Union, or another message from Peking. I approve, of course, of the right of these big nations to communicate, but it should be noted that many poor Asians are becoming schizophrenic because they cannot be sure which message on international relations is really true. It is natural, in this context, that some countries have decided to tell their people not to listen to certain foreign broadcasting, or have converted their radio broadcasting systems from AM to FM. Indeed, somebody's right to communicate may be, in spite of the good will of the communicator, an annoyance and a nuisance for somebody else; the problem is that many communicators are not aware of the irritating experiences of the communicatees. The communicatees, or hoped-for communicatees, have the right to turn off the switch and exercise the right not to be communicated to. It is natural and justifiable, in my personal opinion, for developing countries in Asia and elsewhere to resist or reject the importation of information from outside because such importation may threaten autonomous nation building. Some free nations may criticize such resistance or rejection on the basis of free flow of information; sometimes that argument sounds like an automobile salesman griping about the customer who slammed the door in his face. To try to sell an automobile is the salesman's business, and he has good reasons. But we have our freedom not to show any interest in his sales talks. To accept or to reject is our business, and not his. 
To sum up, it seems that there are at least four different kinds of rights in communication, whether it is interpersonal, intergroup, or international. They are:

1. right to communicate

2. right not to communicate

communicator's alternative

3. right to be communicated to

4. right not to be communicated to

communicatee's alternative

As there are two alternatives on the part of a communicator and two alternatives on the part of a communicatee, theoretically speaking, we can think of four sets of combinations: $1+3 ; 1+4 ; 2+3$; and $2+4$. Only in combination $1+3$ does communication takes place. That is the only set where a communicator and a communicatee have agreed to communicate on the basis of their respective alternatives. The accompanying diagram may be useful.

\begin{tabular}{|c|c|c|}
\hline $\begin{array}{l}\text { Commu- } \\
\text { nicatee }\end{array}$ & $\begin{array}{l}\text { 1. Right to communi- } \\
\text { cate }\end{array}$ & $\begin{array}{l}\text { 2. Right not to com- } \\
\text { municate }\end{array}$ \\
\hline $\begin{array}{l}\text { 3. Right to be com- } \\
\text { municated to }\end{array}$ & Communication & $\begin{array}{l}\text { "Tell } \\
\text { me, tell me" }\end{array}$ \\
\hline $\begin{array}{l}\text { 4. Right not to be } \\
\text { Communicated to }\end{array}$ & Shut up! & No Communication \\
\hline
\end{tabular}

As discussed in the preceding paragraph, the combination of 1 and 3 is a happy case. Both parties will find it interesting to communicate and to be communicated to. The combination of 2 and 4 also seems to pose no problem--each party is apathetic to the other. But combinations 1 and 4 , and 2 and 3, cause problems. As is clear from the diagram, both communicator and communicatee in either case must suffer from frustration of expectations. One wants to communicate but the other does not respond. A person wants to say something but the other party chooses not to listen. Both communicator and communicatee are irritated, frus trated, and dissatisfied in these instances.

In our everyday lives, we encounter all these different combinations of expectations. One should appreciate his or her luck when he or she is involved in the happy combination of 1 and 3 . 


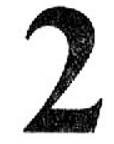

SPECIFIC COMMUNICATION RIGHTS:

ANALYSIS OF THE CONCEPT 

In Part I, the essays focused on the nature of the general concept of a right to communicate. In this section, and within the broad framework just sketched, the components of a right to communicate are examined more closely. Such an examination or analysis leads quite naturally to an enumeration or discussion of spe cific communication rights.

The distinction drawn between the right to communicate and a communication right is an important one because it reduces ambiguity and provides organization. In the past, when such a distinction was not made, discussions were often on two levels at the same time. Thus, the right to communicate is reserved for the general, pximary, comprehensive, inclusive, long-range, universal, moral, and ethical human right. Within that general concept, a number of specific communication rights can be identified and examined.

The essays in this section focus on one or more specific communica tion rights. A number of questions arise about any specific right, such as the balance between privilege and responsibility, between claim and duty, or between power and entitlement.

To facilitate the discussion of specific rights, a carefully drawn framework is useful. Desmond Fisher in his essay lays out such a framework and builds a. distinction between primaxy human rights and secondary human rights. Fisher begins his analysis with a consideration of "who is subject of the right to communicate- the individual or society or both." He suggests that one criterion for the restriction of a "secondary" right is the protection of a "primary" right. Fisher concludes his discussion with a delineation of a hierarchy of rights and provides two important charts.

The second essay, by Donald Gillmor, sets forth a detailed review of the U.S. First Amendment and notes the importance of debate and dialogue on "freedom of communication" in a society. He notes that difficulties are encountered in "those appeals that ask the courts to find implied rights in the sparse language of the First Amendment." Are there "implied rights to 'know', 'access', 'hear', or to 'travel in pursuit of information'?" The author adds that the First Amendment may protect the individual speaker from governmental repression but it does not assure that that speaker has access to radio, television, and newspapers to enable his ideas to have a wide impact. He observes the pattern of concentration of ownership of the means of communication and asks whose rights to communicate are at stake. In summing up the unsettled state of affairs surrounding the First Amendment, Gillmor adds, "What is important, however, and what must continue unabated is the dialogue itself." 
In his essay, Henry Hindley subdivides the general right to communicate into five specific rights: the right to speak, the right to be heard, the right to be replied to, the right to make reply, and the right to listen. He develops each of these rights in detail and draws attention to "the impracticality of definitions that are too widely drawn or are incompatible with differing social, legislative, and political structures as they exist in the world today." Hindley limits himself to a preliminary definition that he restricts to personal communication: "Any two or more, but not very many, individuals have the right at any mutualiy agreeable time and place to communicate on any agreed subject." He adds that "it is for others" to extend his essay to encompass larger communicating units such as nations.

Luis Ramiro Beltrán and Elizabeth Fox de Cardona present a situational analysis that focuses on specific communication rights, their first question being: "Do Latin A mericans effectively have at their disposal unrestrained options as senders of messages carrying information and/or opinion?" They examine media ownership distribution and find it "heavily skewed in favor of very small minorities of mass media owners and operators," in contrast to a less polarized situation elsewhere in the world. Combining this situation with the restrictions they find on the actual sending of messages--through violations of press freedom and other means, including self-censorship-me authors conclude that, "with but minimal exceptions, freedom of communication as senders of messages in Latin America is the privilege of . . powerful private and/or governmental minorities." And, "in order to maintain such communication privileges, some of them appear determined to prevent the rest of the citizenry from gaining effective means to perform their rights as senders of mass media messages." A similar situational analysis on whether "Latin Americans effectively have at their disposal unrestrained mass communication options as receivers of message-carxying information and/or opinion" traces availability of communication receiving facilities, such as radio receivers and cinema seats. A1though Latin America compares favorably with underdeveloped parts of Africa and Asia, the researchers find uneven opportunities to receive messages in a wideranging context, with a heavy concentration in larger cities, particularly for television and the press. Again, they find "receiving information is a privilege of powerful, and mostly urban, elitist segments of society." They conclude that "information freedom and communication rights, as contained in the international official statements to which we referred, are presently ineffective for the majority of individuals in Latin America." Beltrán and Fox de Cardona see little change possible until the structure of society "substantially changes in the direction of genuine democracy." Communication rights are limited by the social milieu, and by the state's communication rights on behalf of all the people. Internationally, the sovereign rights of countries should prevail over communication rights of international organizations, the authors observe.

The essay by Don Le Duc begins with an inquiry into whether a general right to communicate is a single unified doctrine, and asserts that it is not. To the list of specific rights proposed by Hindley, he adds a "right to entertainment" and includes "cultural" programming within that right. He advocates research that focuses "narrowly on the right of audiences to participate in the selection of their entertainment programming." He also urges that current approaches to "access" be broadened in scope to include the right of audience members to interact in the creation of entertainment. The author suggests that detailed study of specific rights and the isolation of basic communication law principles common to all nations could lead to a synthesis on the right to communicate. Above all, Le Duc urges that the the needed research be done soon. 
The essays in Part II examine specific communication rights within the broad framework of the general right to communicate. As should be expected, the variation in vocabulary sometimes obscures fundamental agreement. The analysis of specific rights begun here can be readily extended by other scholars, and certainly should be. 



\section{THE RIGHT TO COMMUNICATE: \\ A PHILOSOPHICAL FRAMEWORK FOR THE DEBATE \\ DESMOND FISHER}

\section{THE DIFFICULTIES}

By "demythologizing" the Bible, modern scriptural scholars have focused attention on the inner meaning rather than on the superficial details of such allegories as the creation of the world in six days; the garden of Eden with its tree of knowledge, its serpent, and its fig leaves; and the linguistic confusion of the would-be builders of the Tower of Babel. But the word babel remains to remind us of the basic message of the biblical story, that it takes communication to make a community; without it the community disintegrates. McLuhan's concept of the "global village," created by and dependent on communication, had its allegorical archetype in the Book of Genesis.

As communication is obviously necessary to community, it would be logical to postulate that communities as well as individuals have a right to communicate. And it would be tempting to draw up a list of the components of that right, a list that would be universal in time and in space and that could be made legally binding throughout the world, or, at least, established as a global bench mark aga inst which actual practices and attitudes in different countries could be measured.

The difficulty immediately arises that such a task involves simultaneously an affirmation of the existence of an ethical right; a definition or description of it; a judgment about who or what is the subject of it; an analysis of the freedoms deriving from it; and the formulation, for the individual and for society at its different levels, of a set of entitlements necessary for the exercise of and the proper limitation of those freedoms. Such a multipurpose declaration has to integrate concepts about ethics and law; human values and practical considerations; the individual and society. It is hardly any wonder that an undertaking of such magnitude and complexity has not been successfully concluded in the six years or so since it was first seen to be necessary.

\section{THE COLOGNE DISCUSSIONS}

The discussions on the issue at the 1975 meeting of the International Broadcast Institute in Cologne highlighted these difficulties. 1 The report of the working party assigned to consider the question began by recording its decision that "it would not attempt to formulate a policy for the Institute on the right to communicate." The working committee did, however, draft a "descriptive statement" of the right to communicate, which reads:

Everyone has the right to communicate. It is a basic human need and is the foundation of all social organisation. It belongs to individuals and communities, between and among each other. This right has been 
long recognised internationally and the exercise of it needs constantly to evolve and expand. Taking account of changes in society and developments in technology, adequate resources--human, economic and technological--should be made available to all mankind for fulfillment of the need for interactive participatory communication and implementation of that right.

It was a significant achievement for the committee to produce, in the time available, an agreed draft from the jumble of confused, confusing, and sometimes contradictory views and opinions of the thirty or so participants. Undoubtedly, this statement will help to advance understanding of the question in some areas. It is possible also that it may, to some degree, obscure other aspects.

areas:

Where the statement is seen to be unsatisfactory is in the following

- It does not define the right to communicate.

- It goes beyond previous statements in this field by declaring, with no supporting argumentation, that the right belongs to communities as well as to individuals.

- It does not try to incorporate earlier related declarations on the freedom of expression, freedom of opinion, freedom of the press, etc.

- It does not determine the responsibility of society to guarantee, to the individual and to society itself at its various levels, the exercise of these freedoms through individual and societal entitlements and the conditions in which such entitlements can legitimately be exercised or restricted.

- Finally, it attaches to a statement about a human right a humanitarian recommendation about the sharing of the human, economic, and technological resources necessary to establish the right to communicate as a realizable objective throughout the world.

These five criticisms of the Cologne statement are developed seriatim below.

\section{ENUMERATION VERSUS DEFINITION}

There were too many participants and too little time at the Cologne discussions to allow for a deeper consideration of the issue. It is true that many of the main speakers had the advantage of involvement in earlier discussions and seminars on the same topic. This meant, however, that they brought to the Cologne meeting previously developed attitudes and understandings that, at least at the beginning of the discussions, were not known to or shared by all the other participants. The discussions brought out the inevitable gap between those who believe that it is sufficient to state the existence of a right as a general principle and those who believe that it is necessary to give a detailed definition of the right, of the freedoms that derive from it, and of the limitations that can be placed on the exercise of such
freedoms. 
The Cologne working committee adopted the former course. The existence of the right to communicate was stated and left at that without any attempt being made to define it or to incorporate into it the earlier statements of freedom in the field of communication. The result is that, at present, the right to communicate is simply asserted as if it were self-explanatory, whereas all the literature about it in the past six years has amply shown how complex and comprehensive a definition of it is required. 3

It is hardly sufficient to introduce an important new concept Iike the right to communicate, declare it to be a basic human right, and expect it to be as generally and exactly understood as are other rights--to life, to liberty, to freedom of expression--that have been discussed for centuries and embodied for decades in a wide range of national and international instruments. What needs to be done in this context is to state the existence of the right to communicate; to define or describe what is meant by communication; to explain its significance as a basic human need and therefore a basic human right. The Cologne statement did not do this.

\section{INDIVIDUAL AND SOCIETY}

The Cologne discussions may also have been influenced by the shortage of time and by previously formed attitudes into an uncritical acceptance of the view that the right to communicate belongs not just to individuals--as is generally accepted, at least in Western countries, in the case of already recognized human rights--but also to society (or "communities," as the Cologne text put it).

The actual report of the working committee indicates how this basic point was skated over. The report states: "The committee noted that the right to communicate vested in the individual was sometimes contrasted with the right vested in the community. The committee found there need be no important conflict between the two concepts, except that in countries holding the view that rights vested in the community were exercised through governments as the repository of those rights. In such a view, the right of individuals to communicate may be exercised only to the extent that it does not conflict with the established social and political order."

The import of this - -and it was brought out much more clearly in the Cologne discussions themselves--is that, in defining the right to communicate, it is unnecessary to differentiate between the right of the individual and the right of society, for the individual can exercise his right only in society. In retrospect, it may be felt that the working committee avoided an ominously yawning east-west political gap at the cost of obscuring and confusing a philosophical and legal question of key importance.

The issue here is not whether communities or societies have rights in the field of communication. It is self-evident that they have. What is at stake is whether such community or societal rights are of the same intrinsic importance as the individual's right to communicate and may, therefore, legitimately be identified in a comprehensive definition as of the same order. The case for a community or societal right to communicate can be stated as follows: Communities, to coexist, require to communicate between themselves. This posits a right to communicate between communities as such. Such a right not only would extend to ordinary exchange of information but would have relevance, for instance, to broadcasting into another territory (for reasons of "cultural imperialism," for propaganda, for 
dissemination of genuine information, etc.) and to the jamming of such broadcasts. It would also establish the basis for the demand for the international transfer of resources to provide less developed countries with the capability of communicating both internally and with other communities.

It might seem legitimate to extrapolate such rights for society itself-at the level of a community, a tribe, a government, or whatever-from an agglomeration of the rights of the individuals in it. But a community or a society is not just the sum total of the individuals in it. Nor does the sum of the rights of the individuals in a society add up to the common good, which it would be universally recognized is the function of society to secure, however different might be the interpretations of what that common good is.

It is, however, precisely when the common good is being defined that difficulties arise and it becomes necessary to translate human rights, stated as a principle, into practical liberties for the citizen in a way that will not undermine society. Some way has to be found to ensure, on the one hand, that individual liberty does not become license and, on the other, that the state does not abuse the human rights and civil liberties of the individual.

\section{The Social Interest}

The difficulties were clearly illustrated in the paper submitted to the Cologne working committee by Jerzy Pomorski of the Cracow School of Economics. In it, he argued against precipitate acceptance of the view that the individual is the subject of the right to communicate. His premise, which would generally be in accord with the view of society and of the common good stated above, was:

The assumption that society is the sum of individual wills, and social interest resultant from individual interests, does not correspond to reality.

However, he went on:

Societies act according to principles recognised by its members as good for the whole, but not necessarily convenient for all. To act in society and for society requires the restraint of some individual aims and respect for some restrictive laws. ... Demanding the right of individuals and thus giving them international protection will restrict the achievement of some social goals. 4

Pomorski's contribution illustrated the great divergence between the rule of law approach and the fundamental assumptions in socialist countries about the question of human rights. His argument, in brief, was that as the exercise by the individual of a freedom deriving from an internationally accepted human right may have to be restricted in the interests of a specific society, it would be wiser, at least in present circumstances, not to state the right as belonging to the individual.

This reflects a very different concept of the common good and of the relationship between the individual and society that is now accepted in Western society. The Western view, if it may be so called, is that society exists to secure the common good, which is the maximum realization of each individual's basic rights, the exercise of which may be limited but only to protect the rights of some or all the other individuals in it. 
If both the individual and society are seen to be equally important subjects of the same right to communicate, then the guarantee of the right to the individual would be largely vitiated in any conflict on the issue with the state, and the basic assumption on which the rule of law in Western society is posited--that is, the right of the individual against society--would be denied.

\section{Existing Formulations}

Existing formulations in this whole area of human rights are specific on this point of where the right resides. It should be sufficient to quote some examples: 5

The Declaration of the Rights of Man and of the Citizen, promulgated in 1789, contained, in Article 11, the guarantee that "the unrestrained communication of thought or opinion being one of the most precious rights of man, every citizen may speak, write and publish freely, provided he be responsible for the abuse of this freedom in the cases determined by law."

The Universal Declaration of Human Rights (1948), Article 19, states that "everyone has the right to freedom of opinion and expression."

The European Convention on Human Rights (1950) states, in Article 10, that "everyone has the right to freedom of expression."

The International Covenant on Civil and Political Rights (1966) states, in Article 19 (Sections 1-2), that "everyone shall have the right to hold opinions without interference" and "everyone shāl have the right to freedom of expression."

The constitutions of many states, in legislating for rights in this area, also make the individual the subject.

The Austrian Constitution (Article 13) says that "everyone has the right within the limits of the law freely to express his opinion by word of mouth and in writing, print or pictorial representation."

The Danish Constitution (Article 77) says that "any person shall be at liberty to publish his ideas in print, in writing and in speech, subject to his being held responsible in a court of law."

The constitution of the German Federal Republic, Article 5, Section 1, reads: "Everybody shall have the right of freely expressing and disseminating his opinion by word of mouth, in writing and through pictures and to inform himself unimpededly from generally accessible sources."

The Italian Constitution, Article 21, reads: "All persons have the right freely to express their own opinions with the spoken or written word and any other means of dissemination."

\section{A Different Viewpoint}

The importance of seeing the individual as the subject of a basic human right is brought out when the foregoing declarations are compared with, for instance, 
the relevant section (Article 125) of the constitution of the USSR. This reads: "In conformity with the interests of the working people, and in order to strengthen the socialist system, the citizens of the USSR are guaranteed by law: (a) freedom of speech; (b) freedom of the press."

In such a formulation, the right of the individual is not specifically acknowledged. Instead, the right to the freedoms of speech and of the press are accorded to an a morphous body called "the citizens of the USSR." Further, the rights are limited to an extent that would be unacceptable in states with the form of democratic government existing in Western societies. Such societies accept that freedom of speech and of the press may be limited. But, as will be pointed out later, the criterion for any such limitation is to protect other rights or the rights of others.

In the case of the constitution of the USSR, the exercise of the freedoms would seem, if the article is being interpreted correctly, to be permitted only if it is in the interests of the working people (which can scarcely be identified without an ongoing public debate that itself depends on the individual's right to communicate) and the strengthening of the socialist system.

By imposing such arbitraxy and indefinite qualifications on what are seen in more liberal. societies as freedoms that may be limited only exceptionally and in order to protect more important rights, the constitution of the USSR effectively denies the individual, in this area of his life, any meaningful protection from society's pressures on him to conform, thus, in effect, denying him a fundamental freedom.

Obviously, a great deal of further consideration is necessary of this vital question of where the right to communicate is located. At this stage, it is sufficient to say that the Cologne statement, by putting the rights of society on the same level as those of the individual, seems to differ from the consensus of all important statements about freedoms in the area of communications over the past two hundred years and to have made an assumption without adequate justification. It has also undermined the protection of the individual against society that is the major achievement of previous declarations and constitutional provisions in this field.

\section{RIGHTS AND FREEDOMS}

Part of the difficulty in determining who is the subject of the right to communicate-the individual or society or both--arises from the fact that it is a new concept that is still in the process of being worked out. At this stage in its development, it seems to subsume or contain other rights that have been identified and, in various ways, recognized in the past, namely, the freedom of information, the freedom of communication, the freedom of opinion, the freedom of speech, the freedom of the press, etc. It is important to integrate these previously acknowledged freedoms into the overall concept of the right to communicate and to determine where and in what order of importance they fit into it.

Jurists recognize two distinct categories of individual liberties. They include among the primary rights the freedom of religious belief and the right of members of society to choose their own government. They do not regard freedom of speech, of assembly, and of association as among the fundamental human rights 
because they are not absolute and may be limited. 6 It was Jean d'Arcy who first noted the insufficiency of the concept of the right to information. "The time will come," he predicted, "when the Universal Declaration of Human Rights will have to encompass a more extensive right than man's right to information. This is the right of man to communicate." 7

By recognizing the need for expressing man's rights in the field of communication on a higher level than is identified in the existing "freedoms," d'Arcy has, in effect, proposed that the right to communicate should be considered as one of man's primary or absolute rights.

\section{"An Element of Life"}

The need of the individual to communicate with other human beings is self-evident. Man is a social animal. Left entirely to himself, he cannot develop, he cannot achieve his full dignity and potential as a human being. To be human, he must communicate.

Communication is a many-sided process. On the simplest level, it exists when two people are consciously in each other's presence. It is achieved more fully through gestures, expressions, signs, words, and actions and it may be one-way, two-way, or multidimensional. It is the chief means through which a human being influences and is influenced by other human beings, thus developing his personality and being enabled to achieve his potential as a human.

Gunnar Naesselund, director of Unesco's Department of Free Flow of Information and Development of Communication, put it in its proper dimension: "Communication," he wrote, "is not an end in itself, but rather a wide-ranging set of means by which human beings and their social institutions can discuss, react to and take steps towards goals defined by themselves. It is an element of life--an attitude and a demonstration of a basic faith in the potential of human beings. " 8

The right to communicate must, therefore, be included in the primary or absolute human rights that are the individual's entitlement because of his dignity as a human person.

From this basic right to communicate derive other and secondary entitlements (secondary in the philosophical sense but not in practical importance). Everyone has a right to learn and to impart knowledge (freedom of information), to hear and to express views (freedom of expression), to endeavor to persuade others or be persuaded by them (freedom of opinion). These freedoms in turn generate other and lesser (again in the philosophical sense only) freedoms, such as the freedom of the press, and the independence of broadcasting institutions, almost on the lines of the big fleas with little fleas upon their backs to bite 'em, etc.

It may be that, in their admirable efforts to stimulate thinking on a comprehensive and universally valid declaration in this whole field of human communications, trailblazers like Jean d'Arcy, L. S. Harms, and Jim Richstad have attempted to compress these different concepts into an insufficiently differentiated definition or description in a way that is complicating the discussion.

Certainly, the Cologne discussions did nothing to establish, as might have been done, a context in which the right to communicate could be understood in 
relation to, but distinct from, the previously accepted expressions of freedoms in the field of communication or to articulate together, in a coherent conceptual framework, the full range of rights in this particular area of human activity.

\section{ENTITLEMENTS AND RESTRICTIONS}

The philosophical construct proposed here is designed to remedy the situation explained in the previous section that noted the absence of a coherent statement of rights and freedoms in the whole area of communications. The framework offered could be represented by a series of concentric circles (see Figure 1). At the center is the right to communicate, the individual's absolute and fundamental right to form relationships with other human beings.

Round this core is a circle representing the secondary freedoms that derive from this right: the freedom of information, the freedom of expression, the freedom of opinion. These also attach to the individual but they are nonabsolute, as they give rise to entitlements the exercise of which may be limited or restricted.

Outside these again, in an outer ring, are the societal and institutional entitlements necessary for the exercise of the individual's freedoms: freedom of speech, freedom of the press, the independence of broadcasting organizations from state control, etc.

These entitlements need to be embodied in constitutional provisions, the legislation, ordinances, rules, or regulations that describe the rights being recognized and the limitations that may be placed on their exercise. Thus, the freedom of the press would be embodied in legislation entitling the media to publish what they think fit, subject to state security, public order, the protection of the individual's reputation, etc. In the same way, freedom of speech, the right of the individual to express a view, the right of the journalist to be given information would be recognized, subject to whatever restrictions are necessary to protect the common good or the rights of others.

This "exploded working model" of the definition of the right to communicate and all it involves is put forward mainly as means of illustrating the framework of the argument. But it also has practical importance.

If the basic human right, the freedoms that derive from it, and the practical entitlements necessary for their exercise are not hierarchically differentiated and are all wrapped up too intimately and intricately in the same definition or description, the affirmation of the basic right itself will be weakened. This will be true because the overall definition must allow for possible limitations on the exercise of the relevant freedoms and entitlements deriving from it, and in some way these limitations will be regarded as applying to the basic right itself.

Better by far to state the right in absolute terms as the inviolable core and, separately, specify the freedoms it entails, the practical entitlements necessary for their exercise, the circumstances that may justify limiting such exercise, and the extent of justifiable limitation. 


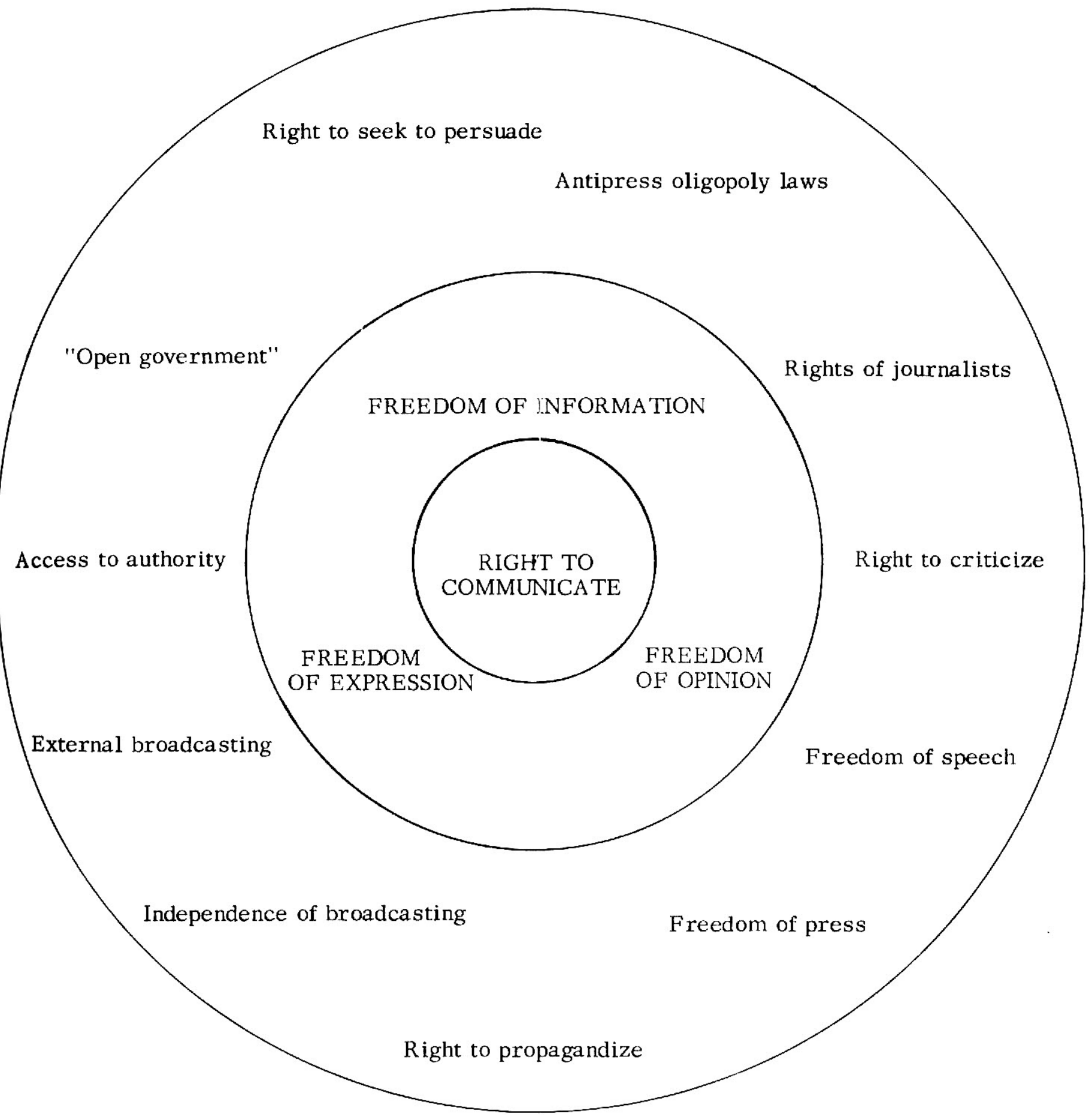

LIMITATIONS

Public order

Security

Public morality

Blasphemy

Libel-slander

Rights of others

FIGURE 1 


\section{Reconciling The Claims}

It will help, too, to consider briefly the criterion by which limitations on the exercise of the various entitlements deriving from the right to communicate may be determined. The report of the International Commission of Jurists' congress in New Delhi said: "Freedom of speech, assembly and association are not absolute. Their exceptions are justified by the necessity of reconciling the claims of different individuals to these rights and the criterion whereby this reconciliation can be effected is the concern of the law to ensure that as a whole the individual's status and dignity are observed." 9

This introduces a significant concept into the consideration of a society's rights to limit or restrict the freedom of expression, opinion, etc. What it means is that the only criterion that is acceptable for such limitation is to protect a primary right, be it a right to life, to religious belief, the free choice of government, or, if it is established in this category, the right to communicate. In other words, the entitlements deriving from freedom of expression may be limited but the criterion for so doing is the protection of other superior or equal rights, including, perhaps, another individual's freedom of expression.

This provides the basis for judging the actions of governments or of societies in limiting the exercise of freedoms in the field of communication. For instance, Article 10, Section 1, of the European Convention on Human Rights guarantees freedom of expression (including "freedom to hold opinions and to receive and impart information and ideas without interference by public authority and regardless of frontiers"). Yet this is limited in Section 2, which reads:

The exercise of these freedoms, since it carries with it duties and responsibilities, may be subject to such formalities, conditions, restrictions or penalities as are prescribed by law and are neces " sary in a democratic society in the interests of national security, territorial integxity or public safety, for the prevention of disorder or crime, for the protection of health or morals, for the protection of the reputation or rights of others, for preventing the disclosure of information received in confidence, or for maintaining the authority and impartiality of the judiciary.

This phraseology acknowledges that limitations may be permitted on the exercise of the freedom of expression but it specifies fairly thoroughly the conditions for such limitation.

In line with this approach, the philosophical framework suggested here would integrate into the concept of the right to communicate already accepted articulations of the freedom of information, expression, and opinion. Further, as shown above, it would put into an overall context entitiements expressed in phrases like "the freedom of the press," "the rights of the journalist," "the independence of the broadcaster," as well as obligations arising from laws or regulations in the fields of libel, privacy, impartiality, objectivity, etc.

The entitlements would be seen not as absolute rights pertaining to specific groups or interests but rather as responsibilities devolving on them because of the basic rights of the individual. The right of the press to inform would, therefore, be seen as deriving from its responsibility to inform the public, which in turn 
derives from the right of the individual to be informed and to express his opinion. The rights and freedoms of the journalist and the broadcaster would also be seen as deriving from their respective responsibilities in the field of communication. Any limitations on the exercise of the different entitlements involved would have to be necessitated by the responsibility of society to protect the rights of others.

By not providing such a framework into which could be fitted, at the appropriate hierarchical levels, the responsibilities and the entitlements both of the individual and of society and the limitations that might be permitted on their exercise, the Cologne statement added to the already existing confusion about the right to communicate.

\section{THE IMBALANCE OF RESOURCES}

The final part of the Cologne draft belongs to a wholly different category of statement from the earlier sections. It is clearly aimed at encouraging the developed world to provide the resources-human, economic, and technological-mnecessary for the improvement of communications in less fortunate countries where their absence is tantamount to depriving millions of individuals of their right to com municate. As the individual cannot realistically press a claim to the vast resources required in modern communication systems, it is inevitable that rights in this area. must be seen as attaching to communities ox to society as a whole.

The nature and extent of such rights need to be studied and defined. Undoubtedly, they exist and an incontrovertible case can be made for them. But this is not to accept that they are of the same basic importance as the individual's right to communicate. The Cologne working committee, in a laudable effort to emphasize the importance of communication between communities, tacked their recommendation about resources for this onto their description of the human right to communicate and asserted that the same $x$ ight as attached to the individual attached also to communities.

Logically, such a recommendation should have been expressed, if philosophically tenable, as an entitlement of societies, deriving from the individual's right to communicate. Or, if this does not stand up to philosophical analysis, the concern should have been expressed in a context other than a statement about a human right. By linking the two ideas, the Cologne statement weakened the emphasis on the right to communicate as a fundamental human right.

\section{THE HIERARCHICAL APPROACH}

It is not the intention, in putting forwaxd this analysis of the Cologne statement, to present an alternative draft. Quite obviously, an enormous amount of work has to be done, at many different levels, before a worthwhile definition or description of the right to communicate can be agreed upon. The aim is merely to suggest some aspects of the question that it would seem essential to incorporate in the final definition and to propose a philosophical context into which the various aspects touched on can logically be fitted.

If there is any value in the approach outlined, it is to bxing into the ongoing discussions the notion of a hierarchy of rights, freedoms, responsibilities, 
and entitlements, starting with the basic right of the individual to communicate, and being developed into a set of freedoms, entitlements, and obligations, devolving on the individual and on society in different ways, to enable the right to be freely exercised and expanded. (See Figure 2.)

Figure 2

RIGHT TO COMMUNICA TE

\begin{tabular}{|c|c|c|}
\hline Freedom of Information & Freedom of Expression & Freedom of Opinion \\
\hline Access to authority & Freedom of speech & Antipress oligopoly laws \\
\hline "Open government" & Freedom of the press & Right to criticize \\
\hline Rights of journalists & $\begin{array}{c}\text { Independence of } \\
\text { broadcasting }\end{array}$ & $\begin{array}{l}\text { Right to seek } \\
\text { to persuade }\end{array}$ \\
\hline & External broadcasting & Right to propagandize \\
\hline
\end{tabular}

LIMITATIONS

Public order

Security

Public morality

Blasphemy

Libel-slander

Rights of others 
The framework suggested may be summarized as follows:

1. Everyone has an absolute and primary right to communicate. Communication is any and all means by which an individual acts and is reacted to within society. It is a fundamental human need, the basic of all social activity, and the means by which a human being realizes his potential. His dignity as a person, therefore, demands that his right communicate be determined as universal and inalienable.

2. This right to communicate is recognized in freedom of information, freedom of expression, and freedom of opinion, which are, therefore, essential norms in society.

3. It is the responsibility of society, at its various levels and by various means, to provide through its laws and regulations the entitlements necessary to the exercise of these freedoms. (Under this heading would be included laws or arrangements relating to freedom of the press, independence of journalists, absence of censorship, rights to information, regulations against press monopoly or concentration, etc.)

4. It is also the responsibility of society, when necessary, to limit or restrict such entitlements in respect of individuals or of groups, but only to protect the rights of others.

5. From the above, arguments can be deduced for extending the entitlements mentioned to society as a whole, or to "communities," as the Cologne text had it. The idea here is that society as such would have no basic right to freedom of information, expression, or opinion but to the entitlements, embodied in legislation or regulations, through which these freedoms are exercised.

Finally, lest it be thought that the present attempt to reconstruct the Cologne statement is the work of a critical outsider, it may be tactful to state that the writer participated throughout the Cologne discussions. The only plea he can advance for not making at that time at least some of the points made now is that he came new to the whole subject and missed many of the nuances. He hopes that the approach suggested here will add some new dimension to the discussions, which are certain to continue for a long time to come until the right to communicate is fully understood, comprehensively defined, and formally ratified in national and international legislation throughout the world. 


\section{NOTES}

1. For a report of the Cologne discussions, see the International Broadcast Institute report, Annual Conference 1975, pp. 20-23.

2. An interesting example of a similar "enumeration versus definition" disagreement, involving the Committee of Government legal experts who drafted the European Convention, is described in The European Convention on Human Rights (Strasbourg: Directorate of Information of the Council of Europe, 1952), pp. 16-18. Unlike the International Broadcast Institute working committee, the ministers of the Council of Europe accepted a compromise text that partly defined the freedoms enumerated.

3. Page 2 of Annex 1 accompanying the letter on The Right to Communicate dated August 25, 1975 and signed by E. Lloyd Sommerlad, chief of Unesco's Division of Communication Research and Policies, illustrates the complexity of the task: "The right to communicate is involved in many and varied issues which differ in kind and scope, are understood in different ways in different societies and apply at several levels of social organisation. It concerns States in their relationship with other States and the world at large as well as with their own citizens; communities in their relationship with citizens, the government and other communities; the media with government, information sources and the public; institutions and organisations and individuals with their total environment. Aspects of the right to communicate are to be found in general social, cultural and religious attitudes; in the constitutions of States; the policies, laws, regulations and activities of governments at various levels; in the constitutions and rules of organisations; in the policies and practices of the information media. The right carries corresponding duties and responsibilities. From the point of view of the individual, the right to communicate raises such questions as the right and opportunity to speak and to be spoken to, to receive and to impart information. A corollary is the protection of certain personal rights, such as the individual's right to privacy, and 'not to be communicated with' if that is his wish."

4. J. M. Pomorski, "Right to Communicate: National Legislations or International Policy?" in The Global Context for the Formation of National Communication Policy (London: International Broadcast Institute, 1975), p. 53.

5. An excellent survey of legislation "on human rights and mass communication in the member States of the Council of Europe" was prepared by the council's Secretariat-General for a symposium on this theme in Salzburg, September 9-12, 1968. (Council of Europe AS/COL [68]7.)

6. Cf. "The Legislature and the Rule of Law," a working paper for the first committee of the International Commission of Jurists in New Delhi, 1959. Quoted in The Rule of Law in a Free Society, a report on the New Delhi Congress (Geneva: International Commission of Jurists), p. 213.

7. Jean d'Arcy, "Direct Broadcast Satellites and the Right to Communicate," EBU Review 118 (Geneva, 1969): 14. Reprinted in Right to Communicate: Collected Papers, L. S. Harms, Jim Richstad, and Kathleen A. Kie, eds. (Honolulu: Social Sciences and Linguistics Institute, University of Hawaii, 1977).

8. Gunnar Naesselund, "Balanced Communication," Intermedia 2, 5 (March 1975): $16-17$. 
9. "Legislature and the Rule of Law," op. cit. 


\section{FREEDOM TO COMMUNICATE: AN AMERICAN PERSPECTIVE DONALD M. GILLMOR}

A basic measure of the degree of freedom of expression in a society is the volume and accessibility of debate and dialogue on what this freedom means, how it is to be defined and applied, by whom, and how best it can be protected against any governmental or private interest that would suppress it.

English-language libraries are vast repositories of the fruits of continuing and sometimes exceedingly complex colloquies on this nuclear concept. John Milton's "Let [Truth] and Falsehood grapple,"1 James Madison's "Congress shall make no law, "2 John Stuart Mill's "All silencing of discussion is an assumption of infallibility, "3 and Oliver Wendell Holmes's "clear and present danger" 4 are more than touchstones in the long and brutal struggle for a right that literally had to be torn from the grip of authority, both sacred and secular.

The idea of freedom of expression has no meaning in the abstract. To be able to shout about it, to write about it, to disagree with others about it, to litigate about it is to have it. To have reached perfect consensus about it, to defer to authoritative proclamations about it, to have foreclosed debate on it, to fear to press grievances about it is to have lost it. Unless freedom of expression is constantly being reappraised, repudiated, reaffirmed, or acted upon with sometimes outrageous zeal it is pure metaphysics and cannot have a bearing on the everyday needs of the citizenry.

Law professor Harry Kalven, Jr. put it well: "I suggest that the presence or absence in the law of the concept of seditious libel (a law which would make criticism of government a crime) defines the society. If . . . it makes seditious libel an offense, it is not a free society no matter what its other characteristics."5 Freedom of expression, then, includes the right to question the fundamental postulates of a society.

More than a faith, freedom of expression is a process, a methodology, a key to self-government which demands on pain of social atrophy that the "debate on public issues. . . be uninhibited, robust, and wide-open, " 6 because freedom of expression is no less than the "thinking process of the community. "7 It may also be a basic individual human need. 8

Herbert Marcuse, an influential New Left philosopher, promulgates an antithetical view that would consider everything said so far to be pure illusion. Buyers and sellers in the marketplace of ideas are no more than marionettes tied to commercial and political strings. He adopts Plato's notion that there should be free discussion only if it is rational, free speech only for those who can be trusted to war against repressive tolerance, the Middle and the Right elements of the 
political spectrum. He proposes intolerance in the name of dissent. He is opposed to institutionalized tolerance, characteristic of a liberal democracy, because it disarms dissenters, the militant opposition. It gives them the illusion of having impact on the social order when in fact they have none. Marcuse advocates precensorship as a substitute for the illusion of freedom, precensorship by an intellectual elite in place of what we now have in his view, a dictatorship of non-intellectuals --politicians, generals and businessmen. 9

Marcuse, certainly, challenges the fundamentals of his country's system of freedom of expression, but, more importantly, he does so by participating persuasively in the process itself.

And speaking of precensorship, not even the hallowed "no prior restraint" 10 doctrine is absolutely secure in a genuine dialogue. It was challenged recently by the Supreme Court itself, key members of which held that in circumstances of jeopardy to national security the press could either be restrained from publishing or criminally prosecuted for what it did publish. 11 Whether the promise of severe postpublication penalties is in itself a prior restraint is a crucial question for Americans. 12

\section{II}

The presumption a judge is willing to make with respect to the constitutionality of a state or federal law which interferes with freedom of expression frequently depends upon where he places this complex of rights in the hierarchy of social and individual values, or whether he is willing to rank order constitutional rights at all. Those who would afford absolute protection to freedom of expression or those who would prefer it over other rights--such as the collective right to national security--because of the crucial contribution it makes to political freedom either reject outright or scrutinize most carefully laws that affect it. Judicial pragmatists rely instead upon ad hoc balancing tests which weigh one right against another in the peculiar circumstances of a case. 13 These judges also show deference to enactments of legislatures on the assumption that law-makers represent the most democratic branch of government and therefore the will of the people and should not be obstructed in their work unless what they do is patently unconstitutional. The composition of an appellate court at any particular time will determine which of these general approaches to the application of constitutional mandates will dominate.

Nevertheless there is some consensus. There is no disagreement anymore that liberty of circulation and distribution is an integral part of freedom of expression. 14 The Supreme Court has denied the Post Office judgmental authority over content. 15 Anonymous speech has the full protection of the First Amendment. 16 Freedom of expression includes the right to criticize and disparage judges as well as other public officials in the most vitriolic, scurrilous and even erroneous terms. 17 Punitive or discriminatory taxes against the press are not permitted. 18 And it is recognized that free expression often requires the collective effort of an assembly 19 or a petition for a redress of grievances. 20

The unorthodox, dissident or counter-culture press is protected by the First Amendment. "The history of this nation and particularly of the development of the institutions of our complex federal system of government," a federal district court said recently, "has been repeatedly jarred and reshaped by the 
continuing investigation, reporing and advocacy of independent journalists unaffiliated with major institutions and often with no resource except their wit, persistence, and the crudest mechanisms for placing words on paper."21. The scholastic and collegiate press is less well protected. 22

Still much remains unserted. For example, are "fighting words, "23 words that incite to riot, beyond the protective reach of the First Amendment? Should the police authoricy, in the furtherance of First Amendment interests, protect the audience from the speaker 24 or the spcaker from the audience? 25 Should speech plus activities, for example, parading, picketing, and door-to-door solicitation be given the same protection as pure speech, and, if not, what conditions ought to be attached to these important and frequent forms of communication? 26

More pexplexing is the problem of drawing the line between protected speech and unprotected illegal conduct in cases of symbolic speech such as the burning of a draft card, 27 the destruction of a flag, 28 or the wearing of black arm bands by school children to protest the Viet Nam war on behalf of their parents. 29 The Supreme Court has never issucd a unanimous decision in a symbolic speech case.

The Supreme Cout seems prepared to extend increasingly greater protection to commerical forms of communication, 30 and is moving away from its earlier position that purely commercial speech deserved little if any constitutional protection. 31

While the ragged edges of a theory of freedom of expression begin to emerge, the courts must still deal with urgent conflicts between freedom of speech and press and other rights - the right to one's good reputation, ${ }^{32}$ the right to personal privacy, 33 and the right to a speedy and public trial before an impartial jury. 34 They must also decide to what degree sexually explicit communication is protected by the first Amendment. 35 Do cameras in a courtroom constitute a denial of due process of law? 36 Does the common law precept that the state is entitled to every man's evidence in a court of law overxide the privilege of a journalist to protect the identity of his sources and the raw materials of his work (notes, tapes, etc.) on the assumption that by doing so he is contributing to the public's interest in a free flow of information? 37 Do labor laws which require journalists to belong to unions 38 or campaign financing law that entangle che press violate the First Amendment? The latter question was answered affirmatively in a recent Supreme Court decision. 39

Even moxe dificult are those appeals that ask the courts to find implied rights in the sparse language of the First Amendment. For example, is there an implied right of the public to know and to have access to news and public information? In the United States. Jegislatures have been more positive than the courts in responding to this question. 40 Is there an implied right to hear, 41 to $x$ fuse to listen, 42 to travel in pursuit of information? 43 These issues are in flux and a divided Supxeme Court has not spoken its last word. Only grudgingly has the High Court extended unequivocal Eirst Amendment protection to film, 44 and, as shall be noted, the broadcast media enjoy only a qualified freedom of expression.

Finally, does the First Amendment imply a right of access by members of the audience, not only to information and information sources, but to the major channels of mass communication themselves? This question has generated an explosion of speculation in recent years about the meaning of freedom of speech and press. The libertatian notion of a free marketplace of ideas in which everyone may participate 
equally, although a fighting faith in an earlier time and certainly parent to the First A mendment, no longer seems to contain assumptions appropriate to the economic, political and technological realities of today.

\section{III}

Even though the First Amendment may still protect the solitary speaker from any form of governmental repression, it does not assure that same speaker access to the great engines of public opinion--radio, television, and the newspapers--by means of which his ideas can have impact. At the same time, ownership of mass media outlets becomes concentrated in fewer and fewer hands (approximately 150 newspaper chains account for 68 percent of all daily newspaper circulation 45) making illusory the supposition that everyone has an equal opportunity to command a soap box in the marketplace. 46

So persons with something to contribute to a robust and uninhibited social dialogue are protected from governmental interference but not from the rigidities of a publisher. Courts adhering to traditional interpretations of the First A mendment have held recently that newspaper readers have no right to reply to editorial attacks against them, 47 and that one side of a legal dispute has no "right to make use of the defendant's printing presses and distribution systems without defendant's consent."48 A labor union had tried unsuccessfully to buy advertising space in Chicago's daily newspapers in order to explain its reasons for an attempted boycott of Chicago department stores.

Broadcasters, on the other hand, are required by the Fairness Doctrine (1) to devote a reasonable amount of time to the coverage of controversial issues of public importance, and (2) to do so fairly by affording a reasonable opportunity for contrasting viewpoints to be voiced on these issues. In 1969 a radio station belonging to the Rev. Carl McIntire in Red Lion, Pa. lost its license for refusing to permit a left-wing writer to reply free of charge to a personal attack made against him by a right-wing evangelist. In upholding the Federal Communication Commission's action, the Supreme Court declared that in broadcasting it is the public interest--not the private--that is paramount, and it held the Fairness Doctrine constitutional. 49

Later, when a group of anti-war businessmen and the Democratic National Committee sought to buy time on a Washington, D. C. radio station and the CBS network, respectively, Chief Justice Warren Burger held for the Court that granting a constitutional right of access to broadcast advertising would inevitably push the FCC into a review of day-to-day editorial and managerial decision and thereby offend the First Amendment. The Court also argued that if management were required to accept advertising, the system would be monopolized by those who could and would pay the costs. 50

The two decisions are difficult to reconcile with one another and with the Court's ruling in the newspaper access case. It must be remembered, however, that the broadcast media are regulated by government as a scarce public resource and are licensed every three years on condition that they be operated in "the public interest, convenience and necessity." Ironically it is the unregulated newspaper that may now be the scarce resource whereas broadcasting, through the gradual emergence of cable, is becoming the medium of abundance. 
There are other problems with the Court's argument. It may be too late to worry about the broadcast system being monopolized by those who are able to pay the costs of air time. The Federal Trade Commission estimates that 75 percent of all broadcast advertising is purchased by fewer than one hundred firms, and ten firms account for 22 percent of it. Ultimate control of the broadcast media is already vested in the public and, as Justice William Brennan observed in a dissenting opinion in the latter case, the government is already involved in an elaborate statutory scheme governing virtually all aspects of the broadcast industry.

Nevertheless, opponents of the Fairness Doctrine see it as a prologue to government control of programming and a device for discriminating against broadcast journalists. Former Supreme Court Justice William O. Douglas and Wisconsin's liberal Senator William Proxmire would repeal it as an affront to the First Amendment. 51

Proponents believe that responsible broadcasters have nothing to worry about and that only flagrant violations of the public trust have led to license revocation. They would not abandon the Fairness Doctrine until the broadcast spectrum has been greatly expanded by further developments in cable and satellite communications, developments which the television networks have successfully lobbied against. It sometimes appears as if the broadcast industry wants it both ways. Deregulation and thereby first-class citizenship under the First Amendment would mean removal of all restraints on the development of new and competitive technologies.

But there are problems with the Fairness Doctrine. Its two parts seem to be in conflict. Stations get into trouble only for disregarding the "opposing views" part of the FCC requirement. A hard-hitting investigative news staff will accrue a fat file of fairness complaints, usually having to do with particular programs. NBC's documentary on the failure of some corporate pension plans was an example. 52 A bland, penny-pinching station that never ventures into controversy will have a clean slate at license renewal time.

By fixing its attention on the second part of the Fairness Doctrine, the FCC does interfere with editorial discretion, journalistic judgment, and with the content of specific programs, which Section 326 of the Federal Communication Act expressly forbids. The result has been a quagmire of cases in which "stations are assayed in a way that so weights negative complaints against positive performance that it puts a premium on timidity. 53 At the same time, given the wide discretion accorded the broadcaster in his use of the Fairness Doctrine, his commitment "to devote a reasonable amount of time to the discussion of controversial issues" is, for the most part, a broken promise. Since novel, unorthodox and unrepresentative views may not find a vehicle for broadcast, accessibility for editorial advertising becomes all the more imperative.

When the Supreme Court sees the Fairness Doctrine as an alternative to viewers and listeners having access to the channels, others see access as a way of making the Fairness Doctrine work. Programs modeled on 60 Minutes and Bill Moyer's Journal, giving the audience a chance to talk back, may in the long run keep the FCC out of the newsroom and the broadcaster out of the courtroom. But Congress will have to reinforce its original intention to measure fairness in terms of the overall, three-year performance of the broadcast rather than on the basis of individual program complaints to the FCC. 54 
It is impossible to speculate on how entrepreneurs view these suggestions. It is a fact, however, that as time passes there are fewer and fewer entrepreneurs. Economic inevitabilities have brought the privately owned mass communications system to a point where the majority of FM radio stations are owned by AM stations; most of the larger AM stations are affiliated with television stations, as are about half of the existing cablecasting systems. The most significant broadcasting chains, owning five stations each, belong to the three major networks; together the three networks and their total of fifteen stations accounted for 52 percent of the total revenues of all television stations in 1974, and the networks produce or control 95 percent of all prime-time programming.

In 1973, more than 95 percent of the VHF stations in the top ten markets were owned by groups, while more than 75 percent of all commercial tele vision stations in the top one hundred markets were held by groups and newspaperbased groups controlled 25 percent of these strong signal stations. 55

More than 50 percent of all daily newspapers are chain owned and the ten largest chains account for one-fourth of total annual revenues for the industry and one-third of the circulation. Only fifteen American cities still have competing daily newspapers. In 1975 only New York City had more than two newspaper owners. Magazines are part of this cross-channel pattern of ownership, and nearly half of the major book companies own or are owned by newspaper, broadcast or magazine interests. All news media depend heavily upon two major wire services, AP and UPI, for a large percentage of their information. And industrial conglomerates are now heavily invested in the communications system.

Is it a paradox of press freedom that freedom from government requires governmental intervention in the form of tax reform, subsidies or antitrust enforcement? Or is such a notion the beginning of the end of a system of freedom of expression? And whose rights to free expression are at stake? The reporter's? The editor's? The publisher's? Or the audience's? And what rights ought to be protected? The freedom to howl in a closet? The right to own a channel? The right to receive information from as many diverse sources as possible? Certainly there are more questions than answers.

American newspapers are not exempt from general taxation, 56 from the application of labor laws, 57 or from antitrust legislation. 58 In the leading antitrust case, Associated Press et al. v. United States, Justice Hugo Black, speaking for the Court, said of the First Amendment that it "rests on the assumption that the widest possible dissemination of information from diverse and antagonistic sources is essential to the welfare of the public, that a free press is a condition of a free society." "Surely," he added, "a command that the government itself shall not impede the free flow of ideas does not afford non-governmental combinations a refuge if they impose restraints upon that constitutionally guaranteed freedom. Freedom to publish means freedom for all and not for some. Freedom to publish is guaranteed by the Constitution, but freedom to combine to keep others from publishing is not. Freedom of the press from governmental interference under the First Amendment does not sanction repression of that freedom by private interests."

The 1947 Commission on Freedom of the Press, a non-governmental body, put it more philosophically:

Clearly a qualitatively new era of public responsibility for the press has arrived; and it becomes an imperative question whether press 
performance can any longer be left to the unregulated initiative of the issuers. The moral and legal right of thinkers to utter their opinions must in any case remain intact; this right stands for the kernel of individualism at the heart of all free social life. But the element of duty involved in the right requires a new scrutiny. And the service of news, as distinct from the utterance of opinion, acquires an added importance. The need of the consumer to have adequate and uncontaminated mental food is such that he is under a duty to get it; and, because of this duty, his interest acquires the stature of a right. It becomes legitimate to speak of the moral right of men to the news they can use. "60

Does the First Amendment protect only the editorial output of the media, or does it also protect their capital investments, their organizational bylaws and technology, and the airwaves they use? Recommendations are now being made that conduit and content be separated in the interest of freedom of expression; the Constitution would protect the output of the journalist but not the business interests of his employer. 61 One media economist proposes that antitrust and legislative action be taken to divest newspaper printing and delivery systems from editorial and newsgathering services. Such a structural change would mean that printing plants would have a quasi-public utility status and would be open to anyone willing to pay the costs of access to transmission facilities. Cross-ownership of newspaper and television media in the same city would be prohibited. But because broadcasting systems do not show the same monopolistic tendencies of newspapers, the licensing and regulatory authority of the FCC over broadcasting would be abolished. 62

Congress and its creature, the FCC, have taken practically no steps toward goals of this kind, and the courts, where newspapers are concerned, would consider them unattainable. In fact Justice Potter Stewart said in a speech recently that "the Free Press Clause extends protection to an institution. The publishing business is, in short, the only organized private business that is given explicit constitutional protection . . . and it is . . . a mistake to suppose that the only purpose of the constitutional guarantee of a free press is to insure that a newspaper will serve as a neutral forum for debate, a 'marketplace for ideas, ' a kind of Hyde Park corner for the community. "63

Nevertheless, access is on the agenda and it will probably stay there. Never has there been so much potential for so much to be said to, and by, so many. America may have to modify its traditional concept of freedom of expression if it is to keep pace with expanding technologies and changing social needs. But it must achieve this by enlarging rather than contracting basic freedoms. And there may be risks involved.

Even though public access to communication channels implies an enlarged freedom of expression, a freer flow of information, a right to inform, to publish, to reply, and a more balanced flow of information, some consider the risks of experimentation too great. Paul Freund, an influential legal scholar, commenting on the Miami Herald case, referred to earlier, in which the Supreme Court held Florida's right of reply statute unconstitutional, said:

It must be acknowledged that if a newspaper were obliged to publish a reply to ever; editorial expression of opinion or report of events the institution of the press as the Framers understood it would come 
to an end. Either a newspaper would become an incoherent grab-bag of miscellaneous contributions or it would cease to venture into controversial ground at all. In either event it would lose its distinctive character and force, and the First. Amendment would have become self-defeating. 64

Freund deals with the contradiction between the constitutional status of broadcast and print media by arguing et difference in law between a legally conferred monopoly and one produced by market conditions. "There is a difference," he says, "between the long tradition of an independent press and the evolving character of broadcasting, with its unique, concentrated impact on viewers and listeners." 65 And he deals with the newspapes: scarcity argument by pointing to the remarkable diversity of print publications. One wonders how his model would accommodate systems which combine print and electronic technologies such as computer printouts or facsimile delivered by satellite, microwave or cable.

In a footnote to his opinior for the Court in the same case, Chief Justice Warren Burger makes reference to the belief of Thomas Emerson that a limited right of access may be enforced if it is done so by "governmental measures to encourage a multiplicity of outlets, rather than compelling a few outlets to represent everybody."66 Freund would agree; and their agreement is important because they are both eminent First Amendment scholars.

Emerson's The System of Freedom of Expression 67 is the most sophisticated effort so far to develop what he calls a "full protection" theory of the First Amendment. The theory depends at the outset on consensual definitions of freedom of speech, of law, of what the First Amendment intends in its use of the word abridge. The centerpiece of Emerson's theory is the distinction between conduct that consists largely of "expression" and is therefore protected by the Constitution, and conduct that consists largely of "action" and is not protected by the Constitution.

Emerson believes that government does have a role in facilitating expression, for example, protecting the public against private concentrations of ownership and power. He sees a positive role for government, which, in turn, requires him to give the First Amendment a broad interpretation that, at the very least, would include the right to form or hold beliefs and opinions, to have some right of access to the means of communication, to receive communication from others, and to obtain information on which to base decisions or to expedite further communication. 68

Only under such conditions can social change take place without violence and can the rage that is generated when speech is suppressed be dissipated. "The test of the openness of a society and the health of its system of freedom of expression," says Emerson, "is likely to be found in its tolerance for militant rhetoric."69 Does such rhetoric find meaningful outlets in contemporary society? There is disagreement. But it does seem that lack of public access to the major organs of news and opinion may be the greatest weakness of the existing system. Economic rather than political inequality may be the problem, and its solution will depend upon public action. What forms this action can safely take without destroying the freedoms we already enjoy is part of the urgent agenda of the immediate future. Public action will be in large part legislative, and law makers will require the best possible information for their decisions. 
What is most important, however, and what must continue unabated, is the dialogue itself. It will proceed through cases at law, resolutions, statutes, articles, books, research proposals, polemics, and, yes, even in demands for revolutionary changes in systems and subsystems, and, hopefully, in spirited classroom discussions.

Freedom of expression belongs to people who by the fortunes of history are free from fear. And tragically it is not a readily exportable blessing. 


\section{NOTES}

1. John Milton, Areopagitica (first published in 1644): "And though all the winds of doctrine were let loose to play upon the earth, so Truth be in the field, we do injuriously by licensing and prohibiting to misdoubt her strength. Let her and Falsehood grapple; who ever knew Truth put to the worse in a free and open encounter." Jebb, ed. (Cambridge University Press, 1918), p. 58.

2. Amendment I (1791), Constitution of the United States: "Congress shall make no law respecting an establishment of religion, or prohibiting the free exercise thereof; or abridging the freedom of speech, or of the press; or the right of the people peaceably to assemble, and to petition the Government for a redress of grievances."

3. John Stuart Mill, On Liberty, ed. Alburey Castell (New York: F. S. Crofts \& Co., 1947), Chap. II, "On the Liberty of Thought and Discussion," p. 17.

4. Schenck v. United States, 249 U.S. 47 (1919): "The question in every case is whether the words used are used in such circumstances and are of such a nature as to create a clear and present danger that they will bring about the substantive evils that Congress has a right to prevent." (emphasis added) For an extended discus sion of the "clear and present danger" doctrine, see Zechariah Chafee, Jr. , Free Speech in the United States (Cambridge, Mass.: Harvard University Press, 1941).

5. Harry Kalven, Jr., "The New York Times Case: A Note on the Central Meaning of the First Amendment," in Philip B. Kurland, ed. , Supreme Court Review (Chicago: University of Chicago Press, 1964), p. 205.

6. Associate Justice William Brennan for the United States Supreme Court in New York Times v. Sullivan, 376 U.S. 254 (1964), a landmark case that has made it impossible for public officials or public figures to win a libel judgment against a publisher without proof by the plaintiff of actual malice on the part of the defendant, that is "with knowledge that it (the publication) was false or with reckless disregard of whether it was false or not."

7. Alexander Meiklejohn, Political Freedom (New York: Harper \& Row, 1960). The quotation represents the major theme of this treatise.

8. Thomas I. Emerson, Toward a General Theory of the First Amendment (New York: Vintage Books, 1967), pp. 4, 18-19, 22-27.

9. Herbert Marcuse, "Repressive Tolerance," in Robert Paul Wolff, Barrington Moore, Jr. and Herbert Marcuse, A Critique of Pure Tolerance (Boston: Beacon Press, 1965), p. 110.

10. Near v. Minnesota, 283 U.S. 697 (1931), the landmark case. See also Bantam Books, Inc. v. Sullivan, 372 U.S. 58, 70 (1963) in which the Court says that "Any system of prior restraints comes to this Court bearing a heavy presumption against constitutionality."

11. New York Times v. United States; United States v. Washington Post (the Pentagon Papers case), 403 U.S. $7 \overline{1} \overline{3}(1971)$. See also, Nebraska Press Association v. Stuart, 44 LW 5149 (June 29, 1976). 
12. Donald M. Gillmor, Judicial Restraints on the Press (Columbia, Mo.: Freedom of Information Foundation, 1974). See especially the discussion of United States v. Dickinson, 465 F. 2d 496 (5th Cir. 1972), pp. 5-7.

13. Donald M. Gillmor and Jerome A. Barron, Mass Communication Law: Cases and Comment. 2d ed. (St. Paul: West Publishing Company, 1974), pp. 7-8, 25-26, 81-83. For the absolutist view of the First Amendment by one of its staunchest proponents see William O. Douglas, The Right of the People (Garden City, N. Y.: Doubleday \& Co., 1958). For a comprehensive statement of the preference doctrine see Robert B. McKay, "The Preference for Freedom," New York University Law Review 34 (November 1959): 1182-1222. Learned Hand's The Bill of Rights (New York: Atheneum, 1964) reflects the balance of interests doctrine.

14. Lovell v. Griffin, 303 U.S. 444 (1938).

15. Hannegan v. Esquire, 327 U.S. 146 (1946); Lamont v. Postmaster General, 381 U.S. 301 (1965).

16. Talley v. California, 362 U.S. 60 (1960).

17. Bridges v. California, 314 U.S. 252 (1941). The language is Justice Frank Murphy's in a similar case, Pennekamp v. Florida, 328 U.S. 331, 370 (1946).

18. Grosjean v. American Press Co. , 297 U.S. 233 (1936).

19. DeJonge v. Oregon, 299 U.S. 353 (1937).

20. Edwards v. South Carolina, 372 U.S. 229 (1963).

21. Quad-City Community News Service, Inc. v. Jebens, 334 F. Supp. 8 (D. C. Iowa $1971)$.

22. Robert Trager, Student Press Rights (Urbana: ERIC and Journalism Education Association, 1974).

23. Chaplinsky v. New Hampshire, 315 U.S. 568 (1942).

24. Feiner v. New York, 340 U.S. 315 (1951).

25. Terminiello v. Chicago, 337 U.S. 1 (1949).

26. Walker v. Birmingham, 388 U.S. 307 (1967), Shuttlesworth v. Birmingham, 394 U.S. 147 (1969); Amalgamated Food Employees Union Local 590 v. Logan Valley Plaza, Inc. , 391 U.S. 308 (1968), Lloyd Corp. v. Tanner, 407 U.S. 551 (1972);

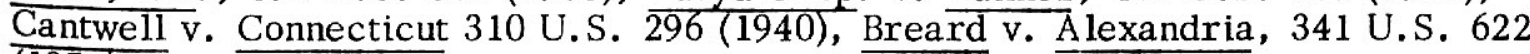
(1951).

27. United States v. O'Brien, 391 U.S. 367 (1968).

28. Street v. New York, 394 U.S. 576 (1969).

29. Tinker v. Des Moines Independent School District, 393 U.S. 503 (1969). 
30. Bigelow v. Virginia, 421 U.S. 809 (1975).

31. Valentine v. Chrestensen, 316 U.S. 52 (1942).

32. Gertz v. Robert Welch, Inc., 418 U.S. 323 (1974).

33. Cantrell v. Forest City Publishing Co., 419 U.S. 245 (1974).

34. Nebraska Press Association v. Stuart, 44 LW 5149 (June 29, 1976).

35. Miller v. State of California, 413 U.S. 15 (1973); see particularly Justice William Brennan's dissent in a companion case, Paris Adult Theatre I v. Slaton, 413 U.S. 49 (1973).

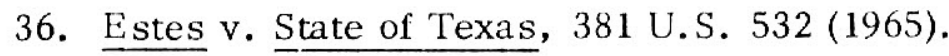

37. Branzburg v. Hayes, 408 U.S. 665 (1972).

38. Evans v. American Federation of Television and Radio Artists, 354 F. Supp. 823 (S.D.N.Y, 1973), reversed, 496 F. 2d 305 (2d Cir. 1974); Buckley v. Valeo, 96 S. Ct. 612 (1976).

39. American Civil Liberties Union v. Jennings, 366 F. Supp. 1041 (D. C. D. C. 1973).

40. Freedom of Information Act, Pub. L. 89-554, 6 September 1966, 80 Stat. 383; Pub. L. 90-23 1, 5 June 1967, 81 Stilt. 54; Pub. L. 93-502 1-4, November 21, 1974, 88 Stat. 1561. The 1974 Amendments to the Act supersede the Supreme Court's holding in Environmental Protection Agency v. Mink, 410 U.S. 73 (1973).

41. Kleindienst v. Mandel, 408 U.S. 753 (1973).

42. Public Utilities Commission v. Pollak, 343 U.S. 451 (1952).

43. Zemel v. Rusk, 381 U.S. 1 (1965).

44. United States v. Paramount Pictures, 334 U.S. 131 (1948); Joseph Burstyn, Inc. v. Wilson, 343 U.S. $495(1952)$.

45. Daniel B. Wackman, Donald M. Gillmor, Cecilie Gaziano, and Everette E. Dennis, "Chain Newspaper Autonomy as Reflected in Presidential Campaign Endorsements," Journalism Quarterly 52, 3 (Autumn 1975): 411-420.

46. Jerome A. Barron, Freedom of the Press For Whom? (Bloomington: Indiana University Press, 1973). For an analysis of and a rejection in part of Barron's access thesis see Benno C. Schmidt, Jr., Freedom of the Press vs. Public Access (Aspen, Col. and Springfield, Mass.: Aspen Institute Program on Communications and Society and Praeger Publishers, Inc., 1976).

47. Miami Herald Publishing Co. v. Tornillo, 418 U.S. 241 (1974).

48. Chicago Joint Board, Amalgamated Clothing Workers of America, AFL-CIO v. Chicago Tribune Co. , 307 F. Supp. 422 (N. D. Ill. 1969). 
49. Red Lion Broadcasting Co., Inc. v. Federal Communications Commission, 395 U.S. 367 (1969).

50. Columbia Broadcasting System, Inc. v. Democratic National Committee, 412 U.S. 94 (1973).

51. William Proxmire, "Repealing the Fairness Doctrine," TV Guide, April 12, 1975.

52. National Broadcasting Company, Inc. v. Federal Communications Commission 516 F. 2d 1101 (D. C. Cir. 1974).

53. Fred W. Friendly, The Good Guys, The Bad Guys and the First Amendment (New York: Random House, 1976), p. 221.

54. Ibid., pp. 227-228 ff.

55. Television Fact Book, No. 42 (1972-73 edition).

56. Territory of A laska v. Journal Printing Co. , 135 F. Supp. 169 (D. C. A laska $1 9 5 5 \longdiv { \text { . } }$

57. Mabee v. White Plains Publishing Co., 327 U.S. 178 (1946); Oklahoma Press Publishing Co. v. Walling, 327 U.S. 178 (1946); Associated Press v. National Labor Relations Board, $3 \overline{0} \overline{1 \text { U.S. }} 103$ (1937).

58. Associated Press et al. v. United States, 326 U.S. 1 (1945); Citizens Publishing Co. v. United States, 394 U.S. 131(1969).

59. Associated Press et al. v. United States: ibid.

60. Commission on Freedom of the Press, A Free and Responsible Press (Chicago: University of Chicago Press, 1947), p. 125.

61. Anne W. Branscomb, The First Amendment As a Shield Or a Sword: An Integrated Look at Regulation of Multi-Media Ownership (Santa Monica, Calif.: The Rand Corporation, 1975), pp. 99-100.

62. Bruce M. Owen, Fconomics and Freedom of Expression (Cambridge, Mass.: Balinger Publishing Company, 1975), pp. 183-189.

63. Potter Stewart, "Or of the Press," Hastings Law Review 26 (1975): 631. Also quoted in Benno Schmidt, Freedom of the Press vs. Public Access, op. cit. , p. 238.

64. Paul A. Freund, "The Legal Framework of the Tornillo Case," in Roy M. Fisher, The Trial of the First Amendment (Columbia, Mo.: Freedom of Information Center, 1975), p. 27.

65. Ibid.

66. Miami Herald Publishing Co. v. Tornillo, 418 U.S. 241 (1974). 
67. Thomas I. Emerson, The System of Freedom of Expression (New York: Vintage Books, 1971), p. 671 .

68. Thomas I. Emerson, "Communication and Freedom of Expression," Scientific American (September 1972): 163.

69. Ibid., p. 167. 


\section{A RIGHT TO COMMUNICATE? A CANADIAN APPROACH \\ HENRY HINDLEY}

A nonstop reading of all the material available in December 1975 on the right to communicate is a daunting experience; the effect is similar to that of eating too many baked beans: a mild discomfort caused by an excess of wind. Nonetheless, three clear impressions remain.

First, one recalls a statement by George Orwell on the debasement of the English language:

As soon as certain topics are raised, the concrete melts into the abstract and no one seems able to think of terms of speech that are not hackneyed; prose consists less and less of words chosen for the sake of their meaning, and more and more of phrases tacked together like the sections of a prefabricated henhouse.

The second impression arises directly from the first, in that the several authors show little consistency in the use of the word communicate. The English language is agreeably flexible, and words that are inherently imprecise can often be endowed with a precise meaning if they are used consistently within a given context. In Canada, for instance, the word communications is increasingly used as an elegant variation on "public relations"; should this usage gel, people may come to think that the Department of Communications is a Department of Information (which is a euphemism for a propaganda ministry) rather than a Department of Telecommunications, which it really is. It is therefore important to make and maintain a clear distinction, not necessarily by definition but through consistent usage, between communications and telecommunications, the latter entailing the use of electronic media. In this way it may be possible to examine whether the restrictions on a right to communicate may be eased or augmented by the use of telecommunica tions.

The third impression is that writers on the right to communicate tend to confuse the issue by trying to deal with too many issues at once. Article 19 of the Universal Declaration of Human Rights declares that: "Everyone has the right . . . to seek, receive and impart information and ideas through any media and regardless of frontiers." Who is everyone? Individuals? Persons? (But let us not forget that corporations are, legally, persons.) Communities? (But what is the definition of a community?) Nations? (But can nations be distinguished from countries?) The wider the definition given to "everyone," the more confused the arguments become. The following is an attempt to pin down the definition of "everyone":

The proposed right [to communicate] asserts that any two or several men have the right at any mutually agreeable time and place to communicate for any mutual purpose. 2 
If this is what we are talking about, it must le accepted that the wording is, in effect, very much narrower but more illuminating than that of Article 19. The notion of mutual agreement as to the time and place for communication concedes that there are practical restrictions on the rights to speak or be hea rd (which will le dealt with below). The words "for any mutual purpose" are more controversial. The participants in a communication may le: mutually agreed as to time, place, and subject, but their purposes may be in direct opposition. Some attention also has to to given to what is meant by "scveral" men. Of the many dictionary definitions of the word several, the following clearly excludes corporations, communitics, nations, and countries: "more than one [individual], usually more than three, but not very many. "3

In the increst of simplification, therefore, and in the hope that a closer examination of one aspect may provide illumination on others that are even more complex, it may be helpful to concentrate first on the right of two or a few people to communicate (that is, "to seck, receive and impart information and idcas"), and to examine whether any restrictions on such a right are justifiable. To what extent does the use of telecommunications affect the exercise of such a right to communicate, subject to justifiable restrictions, and does the use of telecommunications modify the restrictions that may be justifiable?

\section{THL: RIGHT TO SPEAK}

"liveryone has the righl of freedom of . . . expression" (including) "freedom 10.. . impart information and ideas..." Are there any restrictions on this "right," and, if so, can they be justificd?

Existing restrictions on the right to spcak ${ }^{4}$ might be classified as social and conventional, legal, political, and cconomic, and they differ from one society or country to another. It may $b x$ useful, without attempting a rigid classification, to look at a list of some of these restrictions, most of which are applicable whether or not the use of telecommunications is involved.

It is rude to shout. False information should not be imparted; perjury

is criminal. People should not be frightened unnecessarily; it is antisocial, to say the least, to shout "Fire!" in a crowded place where there is no fire. It is rude to interupt when someone else is speaking. Sometimes the excrcise of the right to freedom of expression may have unwelcome physical conscquences; call someone a son of a bitch (there are other expressions in common current usage that are more certain to occasion the same response) and you may get a poke in the nose. The question of whether there is any absolute right to pester or bore people, or to solicit for immoral or pecuniary purposes, is examined below, under the heading "The Right 10 Bo lleard."

Certain ethical considerations attach to the disclosure of information that may well be regarded as private by the individual concerned; this raises the equally complex question of who is entitled to what information, a question that merits independent consideration. The restriction imposed by the courts on hearsay evidence has some relevance to personal communications; annoyance, pain, and grave misunderstandings are all too often occasioned by a chain reaction from successive repetitions, gradually distorted in transit as often as not, of who said what about whom. Another problem, which is of prime concern to the mass media but has some relevance 
in personal communications, arises when information involving positive identification has been imparted about a person charged with a particularly newsworthy offense who is subsequently acquitted; there is a presumptive obligation to impart information about the acquittal with equal prominence or emphasis, but, as the nature of offenses is generally more newsworthy than the facts of acquittals, how is such an obligation to be enforced?

Certain legal restrictions on the right to use or impart information vary so widely from one country to another as to defy generalizations. The laws governing libel and slander afford one prime example; things can be written or said in the United States, for instance, that would incur penalties in the United Kingdom or Canada, a factor that is of great concern to those responsible for the international distribution of information. Similar variations occur in laws governing intellectual property; in both Canada and the United States the revision of obsolete laws on copyright has been dragging on for an inordinate period of years, largely because of the additional complications introduced by the rapid development of telecommunications. However, the problems relate more to the mass transmission of information by cable and satellite than to personal communications, and therefore lie outside the scope of this somewhat simplified approach to the right to communicate. Another wide field of restriction arises from laws governing obscenity and pornography. These laws vary not only from one country to another but also, in some cases as in the United States, in the way they are applied from one part of a country to another. Moreover, concepts of obscenity or pornography change with experience; information that would have been regarded, even in the most permissive societies, as obscene or pornographic as recently as four or five years ago is now thought unobjectionable by some, but only some, members of the English-speaking community, while still deemed shameful throughout the rest of the world. Many would agree that obscenity and pornography (like "violence on television") are "a bad thing" without being able to define them, because the concepts may differ in two communities only a few miles apart and may change, for a particular community or individual, from one year to the next. Perhaps, insofar as personal communications are concerned, the only justifiable restriction is that of not giving offense to the other party; however, if this is to be applied to the mass media, the wider the audience, the more severe must the restrictions be.

It becomes even more difficult to generalize when dealing with political restrictions on the right to speak or impart information. It would perhaps be more accurate to say that it is easy to generalize in the widest possible terms, but the generalizations may be applicable only in long-established democratic societies. There are many countries in which everyone has an unchallenged right to hold opinions without interference, but is there any country in the world where anyone has freedom to express those opinions, or to impart information and ideas, wherever and whenever he pleases?

Dealing first with wherever, is there any legislative assembly in the world (the United Nations cannot, of course, be fairly regarded as a legislative assembly) that permits people who are not members to participate in its discussions? Is there any religious body or sect in the world that tolerates interruption of its formal rites? As an example of restrictions on whenever, in Canada political broadcasts are prohibited (in the relevant area) during the twenty-four hours preceding the day of a federal, provincial, or municipal election; the idea, of course, is to prevent one party or candidate hogging the air waves so late in the day that no "equal time" can be provided for opponents, but there are many who do not believe that this 
restriction is justifiable. On balance, however, it seems reasonable to concede that there is a time and a place for everything, and that there may be justification for restricting the places where, and the times when, the right to freedom of expression may be exercised.

This apparently innocuous principle, however, carries within it the germs of restrictive disease. It can easily be extended, perhaps justifiably to some extent, in times of emergency. But what is an emergency? The word is as hard to define as obscenity or pornography. If it be accepted that a shooting war is an emergency, is it permissible for a government to restrict the right to seek, receive, and impart information and ideas? It is presumably to be accepted that there must be restrictions on people seeking information in case they are enemy spies, and on receiving or imparting information that may be advantageous to the enemy. But what about ideas? It can be argued that enemy propaganda is likely to impart ideas that will arouse alarm and despondency, and that therefore there must be restrictions on the communication of ideas. At that point, obviously, it is not only the right to freedom of expression that is being curtailed, for this is the beginning of interference with the freedom to hold opinions--we are now only seven years away from 1984 .

In considering the justification for restrictions on the right to speak or impart information and ideas in times of emergency, it should be recognized that there are many countries in the world--perhaps the majority--that a re in a permanent state of emergency, not because there is a revolution or a civil war in progress but because the structure of government is inchoate and experimental. It is noteworthy, for instance, that parliamentary systems of government have been abandoned in such a large number of formerly colonial countries. Those of us who live under long-established democratic regimes are often smugly, if covertly, contemptuous of other systems of government, forgetting that it is only the principle of democratic government that is long-established, and that our systems are the relatively recent outcome of centuries of political evolution. Even in the United Kingdom, the home of the 'Mother of Parliaments', universal suffrage is a twentiethcentury phenomenon. Yet we expect countries that have been quite otherwise administered for as long as their history is discernible to adapt themselves in the twinkling of an eye to democratic systems unrelated to their continuing social structures, and to accept concepts of personal freedom that we ourselves have failed to implement in full.

It is at least arguable that restrictions on the right to freedom of expression may be necessary in the interest of peace, order, and good government in the earlier stages of political evolution, particularly in countries where facilities for telecommunication are inadequate or rudimentary. We may deplore, but we should not be too hasty in casting stones. The concept of personal freedom is no more than an idle fancy in the absence of a stable government, and the establishment of stable government may be impossible without central control of communications. The dangers are obvious, for central control of communications facilitates the establishment of governments that are altogether too stable, their stability and permanency being dependent on the denial of almost all forms of personal freedom even to hold opinions, let alone to express them. As Jean d'Arcy has said: "At each step of human history, the formulation of law and the organization of social structures have been conditioned by the technology of communications." 5

We are clearly justified in our attempts to promote the establishment of a universal right to communicate, but we should not be too sanctimonous about it. 
Above all, it must be recognized that the progressive steps taken in different parts of the world have not all been of the same length or taken at the same pace; indeed they have not all been taken in the same direction. For those of us who live in the more affluent societies, perhaps the best we can do to help those that are less fortunate is to assist in the development of telecommunications facilities that will provide wider opportunity to exercise a right to freedom of expression. But the process will be evolutionary, and it would be nugatory to expect instant results. As a British Minister of Agriculture once said when being heckled by a group of farmers about the tardy effects of governmental support measures: "You can leave a ram all night in a field with a lot of ewes in it, but you don't expect to find it full of lambs in the morning."

\section{THE RIGHT TO BE HEARD}

As communication is by definition a two-way process, does a right to speak imply a right to be heard? If there is freedom to impart information and ideas, is anyone under an obligation to receive them?

Justice Brandeis of the United States Supreme Court, in a statement of historic importance, spoke of "the freedom to be let alone--the most comprehensive of rights and the right most valued by civilized men." 6 This freedom should be absolute with regard to personal communications between private citizens; in other words, there must be a right not to be pestered with unwanted communications. If spoken to, there is no obligation to listen; junk mail can be thrown away unopened.

This right is not so easily exercised when telecommunications are used. It is true that the telephone may be left unanswered, that the radio or television can be switched off. But, as there would be no point in having a telephone if it always went unanswered, should there be a right not to be pestered by this means? Should random telephone canvassing be prohibited? What protection should be afforded to people against being pestered by newshounds? The embarrassment, bad enough when only notes are being taken, is increased a thousandfold if a camera is being used. Michael Arlen, referring to a recent television interview with a young, nervous, and possibly retarded black boy, described it as "basically little more than a careless act of aggression." 7 Is it possible to afford protection against aggression of this kind without restricting the holy cow of freedom of the press or other mass media?

It has been remarked that discussion of a right to impart information and ideas often veers toward possible freedom of access to facilities, and to telecommunication facilities in particular, implying that anyone of a mind to address a mass audience is entitled to be heard. No such entitlement has ever been recognized where no use is made of telecommunications. Speakers and their supporters do not expect free use of a hall or a theatre; they have to rent one. The orators at Marble Arch in London have to bring their own soapboxes to stand on. The church used by a preacher is maintained at the cost of the parishioners. Anyone may write a book (although perhaps few can) but has no entitlement to printing and publication, and, even if his book is published, nobody is under any obligation to read it. Why, then, is it supposed that there should be a right of personal access to telecommunication facilities? The plain fact of the matter is that the use of facilities of any kind costs money. Who should be required to pay? In Canada, every cable operator is required to provide at least one channel for "community programming" at his own 
expense, but nobody has defined the "community"; moreover, it is left to the cable operator to select those who may have access when there is insufficient time available for all. Already complaints are being heard from groups or individuals who claim to have been "denied access", in the belief, presumably, that everyone is entitled to free access. Scarcity of facilities is giving way, it is said, to abundance; the technological advances that make abundance possible have already effected enormous reductions in costs but can never eliminate cost altogether. Is it suggested that there should be a right of free access to the telephone, to take another instance?

The discussion above has been limited to communications between private citizens, but different considerations apply to communications between private citizens and those in authority over them, in which there should undoubtedly be a right to be heard. In addition to the almost universally accepted right of recourse to courts of justice, it is only relatively recently that the very commonly accorded right of direct access to the sovereign has been rendered impracticable by increases in population. The result has been the tardy development of a right to be heard by an ombudsman for those who believe themselves to be oppressed. But there are dangers in extending this concept of a right to be heard by officialdom into a right to be heard directly in the legislative process. The town meeting where every citizen has a right to be heard is an excellent institution in communities small enough for all the citizens to be familiar with the problems under discussion and the probable effects of possible solutions. The same conditions do not apply in larger communities--on a national scale, for example, it is not to be expected that every citizen should be coversant with all the problems or capable of appreciating the relative merits of optional solutions - -and this has led to the evolution of representative democracy, an inestimably valuable institution that is now endangered by abominable devices for the computerization of remote-access expressions of opinion on any subject whatsoever, however complex or emotionally charged. As Emerson (or was it Lord Melbourne?) said: "If a hundred thousand people are of a unanimous opinion on any subject, they are almost certainly wrong."

To sum up, it may be said that, while everyone should have a right to be heard by those in authority, any right to speak certainly does not entail a right to be listened to. The principle that emerges is that a right to communicate must be conditional on mutual agreement between the parties to the communication as to the time and place and subject matter.

\section{THE RIGHT TO A REPLY}

Obviously, a person who may have the right to speak is not entitled to insist on a reply from anyone who is under no obligation to listen. 8 But there should be a right to elicit a reply from those who offer services to the public, either at public expense (for example, police, fire services) or against payment (so long as payments are not in arrears). With regard to those in authority, for practical reasons there has to be some latitude; there should be a right to be replied to by somebody, not necessarily the individual to whom the original communication was addressed, even if the reply is no more than a formal acknowledgment. It is an unfortunate fact of life that the responses of the bureaucracy to approaches by individuals are all too often inadequate; only the more sophisticated citizen is aware that importunity very often pays off. 
But is this enough? A right of freedom to seek and receive information and ideas implies that there is someone at the other end to impart them. Any information? All ideas? What are the practical limits? Perhaps none on the freedom to seek, but the right to receive information must necessarily be limited, at best, to information that is available and not secret or confidential, and the right to receive ideas can be implemented only if the conceiver of the ideas is willing to impart them.

\section{THE RIGHT TO MAKE REPLY}

Here again, in direct personal communications there are social, conventional, and practical restrictions on any right to make reply. The other party may decline to listen or claim that he was communicating with someone else. In response to a public statement, anyone may write a letter to a newspaper, but the editor is under no obligation to print the letter and, should he do so, nobody necessarily has to read it. Yet there is a growing insistence on some kind of a right to make reply to statements made or opinions expressed through the broadcasting media. What are the practical limits to the concept of "equal time"? Even with subjects that have a limited number of angles, the problem presents great difficulties to broadcasters. For a subject that has a virtually infinite range of angles, who is to decide which of them are of sufficient importance to merit equal time, and, for those that are, an even more difficult decision is, who is entitled to expound them? Clearly, some pragmatic thinking is required if the right to make reply is not to be allowed to develop into an inhibition on the right to speak.

\section{THE RIGHT TO LISTEN}

Here we approach a can of very ugly worms. It is rightly regarded as shameful to eavesdrop on private conversations or to read other people's private letters. Should there be a ban on listening to police messages on shortwave radio bands that are accessible to anyone with suitahle equipment? Or is it enough to prohibit the publication of such informacion as may have been cither inadvertently or deliberately overheard? In some countries it is a criminal offense to receive foreign broadcasts; are there any circumstances in which it is justifiable to restrict freedom to receive information and idcas? Whatever may be one's persona! views, there is no easy answer to this question, and no answer that has any real chance of international acceptance in the world as it is today. Perhaps the best hope is for a gradually widening acceptance of a right of freedom to receive information and ideas, whether imparted in writing or by the broadcasting media, that are originally intended for direct reception by the general public in any particular country. The disregard of frontiers is a more distant, but perhaps not unachicvable, objective.

\section{CONCLUSION}

The purpose of the forcgoing recital of the difficulties encountered in identifying and implementing the right to communicate was not to diminish the value of the immense amount of thought and work that have been devoted to the development of the concept, but rather to draw attention to the impracticality of definitions that are too widely drawn or are incompatible with differing social, legislative, and political structures as they exist in the world today. For personal communications 
a lone we are left in practical terms with a definition on the following somewhat cumbersome lines:

Any two or more, but not very many, individuals have the right at any mutually agreeable time and place to communicate on any agreed subject, provided that the communication is not obscene or otherwise offensive to either party, that the information imparted is not known to be false, that unauthorized use is not made of the intellectual property of others, that others are not libelled or slandered, and that the purpose of the communication is not to incite the overthrow of government, other than by lawful means; further, everyone has the right, subject only to the social, conventional, and legal restrictions in effect in his society, to impart information and ideas to the general public, provided that he can obtain access to the facilities for doing so at his own or others' expense; and everyone has the right to seek information and ideas, and to receive any information that is available and not secret or confidential and such ideas as others may be willing to impart.

It is for others, should they wish to do so, to consider the application of rights based on the foregoing to groups, communities, nations, and countries in their communications with each other. For the moment, enough is clearly enough. 
NOTES

1. George Orwell, "Politics and the English Language," Shooting an Elephant and Other Essays (New York: Harcourt, Brace \& Co., 1950), pp. 79-80.

2. "Long-range Goals," Spectra (author and issue not identified).

3. Chambers Twentieth Century Dictionary (1972).

4. "To speak" is here used to mean to communicate verbally, either orally or in writing. There are, of course, other means of personal communication, for example, through music or the dance; it is worth recalling that Verdi's operas La Traviata and Un Ballo in Maschera were regarded as politically subversive, that the music of Wagner and Richard Strauss has had an undeniable political impact, and that Nijinsky's Sacre de printemps and L'après-midi d'un faune were once thought obscene.

5. Jean d'Arcy, "The Right of Man to Communicate," Paper presented at the International Broadcast Institute Annual Meeting, Nicosia, October 1973. Reprinted in Right to Communicate: Collected Papers, L. S. Harms, Jim Richstad, and Kathleen A. Kie, eds. (Honolulu: Social Sciences and Linguistics Institute, University of Hawaii, 1977).

6. Context not known to author at time of writing.

7. "THE AIR-The Interview," New Yorker, November 10, 1975, p. 142.

8. In many countries, language is an important aspect of the right to communicate. In Canada, English and French are, by statute, official languages, and enormous sums of money are being spent to ensure that a citizen is entitled to receive service in the official language of his choice anywhere in the country. The implications of such rights in a country like India, for example, are mind-boggling. 



\section{COMMUNICATIONS RIGHTS: \\ A LATIN AMERICAN PERSPECTIVE}

LUIS RAMIRO BELTRAN S. AND ELIZABETH FOX DE CARDONA

What are the rights to communicate? The question is perhaps as old as man, the communicating animal, himself. Yet, formal attempts to seek a universally valid answer apparently started only in the days of the French Revolution. In fact, the Declaration of Human Rights and of the Citizen states that "All citizens can manifest in words, in writing or through the press, their own ideas."

\section{THE OFFICIAL INTERNATIONAL STATEMENTS}

The first pertinent statement agreed on at the official international level is Resolution 59, 1946, of the United Nations General Assembly:

Freedom of information is a fundamental human right and is the touchstone of all the freedoms to which the United Nations is consecrated.

The nature of such a paramount freedom was partially stipulated in 1948 in Article 19 of the Universal Declaration of Human Rights:

Everyone has the right to freedom of opinion and expression; this right includes freedom to hold opinions without interference and to seek, receive and impart information and ideas through any media and regardless of frontiers.

The essence of this still rather general postulate, the right to freedom of opinion and expression, was ratified in 1965 in Article 5 of the International Convention on the Elimination of Forms of Racial Discrimination. It was reiterated in Numeral 1. of Article 19 of the 1966 International Covenant on Civic and Political. Rights. Numeral 2 of this article somewhat expanded and clarified the basic statement of the 1948 Declaration as follows:

Everyone shall have the right to freedom of expression; this right shall include freedom to seek, receive and impart information and ideas of all kinds, regardless of frontiers, either orally, in writing or in print, in the form of art, or through any other media of his choice.

This same principle was adopted by the American Convention on Human Rights in November 1969 in San Jose, Costa Rica (Article 13). And a similar concept was expressed by Pope John XXIII in his encyclical Pacem in Terris and included in the resolutions of the Second Vatican Ecumenical Council. 
When Unesco was established to help "further universal respect for justice, for the rule of law and for the human rights and fundamental freedoms," its constitution included the obligation to "collaborate in the work of advancing mutual knowledge and understanding of peoples, through alll means of mass communication and to that end recommend such international agreements as may be necessary to promote the free flow of ideas by word and image."

These attempts at defining communication rights have remained at a broad, abstract, theoretical level, lacking operational specificity. Concepts such as "freedom of information" and "free flow of ideas" remain problematic and lend themselves to diverse interpretations. In fact, work in the UN on a draft Convention on Freedom of Information has not advanced since 1961, because of conflicting legal and ideological positions. 1

Nevertheless, international agreement, at least around two general. notions, has been reached:

1. Human beings have the right to freely express opinion and

2. Such a right embraces those of seeking and receiving information as well as that of 'imparting it through any means of communica.tion.

In spite of their broadness, it should not be impossible to establish to what degree these ideal postulates fit a given situation. This, however, demands a minimum precision of terms. For instance, although i.t can be assumed that professional. communicators to some extent have a common meaning for "information," the same assumption cannot be made about "freedom," without which no systematic analysis of the fitness mentioned above is plausible.

\section{A PRAGMATIC VIEW OF FREEDOM}

Instead of hunting for a compromise definition among the many juridical, political, philosophical, and even rhetorical comotations of this term, we opt here to subscribe to a stand adopted by a group of professional communicators in Canada, which we find simple and practical. In a 1973 conference on communication rights sponsored by the Canadian National. Commission for Unesco, it was stressed that freedom should not be looked at as a state, for it is not. The seminar proposed rather that:

Basically freedon lies in the possibility of choice between alternatives. Freedom cannot exist in a void. . . Freedom exists only in action; it is constantly being produced by the act of free choice. 2

The commission further stated in connection with communication that the notion of freedom inclides: ( 1 ) the freedom of sending a message, (2) the freedom of consciotisty receiving a message, and (3) the existence of sources of information.

This latter statement coincides with one that had been placed before the United Nations in 1953 by Lopez, which asserted that "a man's right to comminnicate information is meaningless by itself unless in relation with the right of the others to receive that information." "For this reason, the draft project for a Convention on Freedom of Information presented to the Fourteenth UN General Assembly 
proposed that the contracting states oblige themselves to "respect and protect the right of every person to have at his disposal diverse sources of information. "4

In search of precision, Terrou ${ }^{5}$ postulated that the right to information cannot be reduced to the mere right of getting to know facts or coming in contact with events. Seeking, using, discarding, storing, and giving diffusion to information also are a part of this right. Thus, Brewer-Carias understands freedom of information as: "the sum of the traditional principles of freedom of thought, freedom of opinion, freedom of expression and freedom of the press, applied to the modern media of communication." 6

\section{A COMPOSITE FRAMEWORK FOR ANA LYSIS}

Those notions, placed side by side with the internationally agreed on statements summarized above, provide us with a useful foundation to appraise the Latin American situation regarding "communication rights." They enable us to carry out a situation analys is in terms other than whether or not there is government press censorship in the region--the traditional, partial, and not very fruitful approach to the subject.

are briefly as follows:

These terms, derived by us from the preceding joint considerations,

Freedom of communication exists when human beings effectively have at their disposal unrestrained options as senders and as receivers of messages carrying information and/or opinion, and when they have uninhibited access to information sources.

A communication option is an alternate opportunity available to a person in order to voluntarily engage in communication. Options may refer to time, space, energy, skills, resources, etc., or to combinations of these.

The more the communication options a person has to choose from and the more the information sources to which the person enjoys access, the more the freedom of communication that person has.

If every human being has the right to communicate, then every human being must have at his free disposal a fair range of significant options to communicate, along with appropriate access to information sources. If he has these, his right is effcctive; if not, his right is ineffective.

The more the freedom of communication a person has, the higher the degree to which that person's right to communicate is effective.

\section{LATIN AMERICA: THE SENDING OPTIONS}

The first central question to which our situational analys is addresses

itself is: Do Latin Americans effectively have at their disposal unrestrained options as senders of messages carrying information and/or opinion? 
Granted that, obviously, not each and every person could have absolutely equal options to act as a sender, nevertheless, how are such options distributed? Setting aside interpersonal communication situations in which the distribution could approximate equity, given their decisive influence in today's society, let us focus on mass communication situations. We admit from the start that, because of practical determinants (technology, financing, and sophistication of skills) the sender's role in mass communication is normally performed in Latin America, as everywhere else, by a small number of professional communicators grouped in a limited number of complex organizations. The question here is, however, just how small are these numbers in the region? Who actually does the sending? Do the opportunities for many persons to perform as senders remain fairly and reasonably open?

\section{Media Ownership Distribution}

The pattern of mass media ownership is one key indicator available to answer these interrogations: it provides a clear measure of access opportunities to the sender's role.

A comprehensive and detailed survey of media ownership in all countries of the region has not yet been accomplished, but several studies have provided basic pertinent data for some of these. A few summary illustrations of distribution patterns follow:

1. Schenkel ${ }^{7}$ found a high degree of concentration in Mexico, Argentina, Chile, Colombia, and Peru, the data on the last being prior to the reforms started in December 1969 with the Statute of Press Freedom. Concentration was most acute in the case of television, closely followed by radio.

2. Lane ${ }^{8}$ reported that one-half of the television stations of Brazil belonged to one company that also owned a large number of daily newspapers and radio stations in different regions of the country.

3. Lowry ${ }^{9}$ showed that forty out of Mexico's fifty television stations were owned by the same company under different names, and according to Mas, 10 one person totally dominated the business for fifteen years. Similarly, as reported by Alisky, 11 one person in Mexico owns the region's largest newspaper chain of thirty-six dailies.

4. Muraro 12 illustrated the vertical and horizontal concentration of the television industry in Argentina, where production and distribution of programming is centralized in three companies, representing the three capital city stations and their affiliates and making up twothirds of the television industry. What remains is constituted by the official station and small independents. He also demonstrated the close ties of these chains with industrialists, landholders, politicians, the church, and foreign enterprise.

Other researchers focused not on concentration per se but on the relation of mass media ownership with the ownership of the major means of production. Clear linkages of this nature were detected in Peru by Malpica 13 and Roca, 14 which 
will not be discussed here as the situation has been substantially modified since then by the present government.

In Chile, Lagos Escobar 15 found the following situation:

1. Of the ten Santiago dailies, three belonged to a banking group, one was the property of the Catholic church but also was connected to a financial group, and another fell within the interests of other banking concerns; these five dailies had the largest national circula tion.

2. Two mining companies exerted almost total control over the press in the northern zone, a Santiago-based financial group controlled two of the three dailies of Valparaiso, and a corporation controlled most of the main dailies in the country's southern region.

3. Two banking groups owned the country's two main radio stations, and a firm tied to the banking circuit owned many of the chief magazines of the country.

4. Finally, banking groups also owned the main film-producing company of Chile. Catalan 16 and Mattelart 17 later confirmed, amplified, and updated this information. Mattelart concluded:

Thus, information is but one of the numerous commercial products made and managed by a few groups ruled by the double law of profit and competition. On the other hand, the study of the power structure of information leads us to question the real meaning of press and opinion freedom which, in reality, are synonyms of freedom of property: the liberty which allows the emitter the possibility of conducting his business at his will and which represents for the receiver the danger of . . an imposition of behavior models addressed to strengthening the cohesion of a system of domination. 18

Of the 335 radio stations operating in Colombia today, 189, or almost $60 \%$, form part of one of the five major radio chains. One of the biggest of them is owned by the chief stockholder in the Colombian soft drink, sugar, glass, and textile industries. All but one of these radio chains are among the principal programmers of the commercial television. Sixty percent of the television time of the two stateowned stations is concentrated in the hands of three companies, who have formed a cartel of common interests and effectively work together in a jointly owned production color television studio. In addition to radio ownership, these television programmers publish the leading national magazines and have investments in banking and real estate. Similarily, three of the big provincial dailies are related to sugar, oil, and beer interests as well as to banks, airlines, and the motion picture distribution business. 19

Venezuelan commercial television is owned by two powerful groups directly linked to major industrialists. The country now has the largest editorial house in Latin America, which owns two dailies and four weeklies, enjoys exclusive distribution rights for five Spanish versions of U. S. magazines, and puts out altogether 17 million copies per month. 
Exploring a similar dimension, Mujica 20 argued that several of the main dailies of Argentina, Chile, Uruguay, and Colombia belonged to traditional families unsympathetic to social change and connected with business interests in the United States; two of the main dailies in Mexico and all of those in Central America were placed in this latter category by Mujica. Roca 21 in Peru and Brunner 22 and Mattelart 23 in Chile provided evidence that the main dailies in those countries had a consistent news and editorial policy to discourage attempts at social transformation. This pro-status quo attitude was confirmed by Schenke124 for five countries, including Chile and Peru, where one individual alone once owned forty-five radio stations. 25

A few other analyses have directed their attention to possible multinational mass media ownership situations. For instance, Mas 26 and Malpica 27 found that the same person who once ran Cuba's television owned, in Argentina, the largest television production company of Latin America (along with one national. channel), as well as simultaneously owning one network in Peru and having comparable interests in Venezuela.

Evidently, mass media ownership in Latin A merica is almost exclusively private, especially in the print media. The state is rarely a media owner. The only country of the region in which the regime of private mass media ownership has been completely replaced by a regime of exclusive state ownership is Cuba. Peru is the only country in which a novel ownership pattern of the press, nonstate and nonprivate, is being tried. The main Peruvian dailies are now sectorial community nonprofit cooperatives.

The director of Venezuela's Institute of Communication Research, Antonio Pasquali, underlines the overwhelming predominance of private over public ownership in the case of radio:

Latin America is the only region in the world in which broadcasting is almost totally controlled by private enterprise though many nations in the area preserve it de jure for the Public Sector. . . . Some of our countries appear in the international yearbook as "mixed regimes." In the best case, such regimes are fictions or a mix created by governments when they establish a few weak stations which, through so-called cultural programs, actually help the massive and evasive consumeroriented output of private broadcasting. One piece of statistics on one episode will suffice to corroborate the inauthenticity of the formula: in Venezuelan radio broadcasting, private radio broadcasting power is in a 65 to 1 ratio to that of the Public Sector. 28

In summary, the essential features of the mass media ownership pattern in Latin America are the following:

1. In general, a high level of concentration

2. An oligopolistic format particularly acute in the cases of radio and television

3. A tendency toward an international monopoly format in the case of television 
4. The marked predominance of private over public property

5. A clear connection between media property--especially that of major daily newspapers and television channels--and property of major means of production (banking, mining, and agricultural businesses) identified with the status quo

This indicates quite clearly that the distribution of message-sending options in Latin America is heavily skewed in the favor of very small minorities of mass media owners and operators and in disfavor of the vast majority of the 300 million human beings who inhabit the region. This is in marked contrast with the much less polarized situations prevailing in most of Europe, in parts of Asia, in Canada, and even in the United States.

It could perhaps be argued that the Latin American situation may be accidental rather than the design of a stubborn will bent on concentration. If it were so, the situation could be modified with relative ease, as options for performing the sender's role would actually remain open to many. This, however, hardly seems to be the case. For instance, in the region there is a traditional resistance to mass media ownership by the state, stemming from financial and political groups. Attempts at it are readily regarded as threats to democracy in general and, specifically, as assaults on freedom of enterprise and on freedom of information. Private interests tolerate no more than a daily government gazette to publish only laws and decrees, or at best, modest radio and television stations. This is only if and when these latter get no revenue from advertising but are financed solely from the national budget.

The most recent illustration of such a militant opposition to changes in the ownership pattern occurred with the law that created a National Council of Culture of Venezuela. This instrument includes a provision for the state to build and operate a parallel public system of radio and television capable of performing for the country the mass development-education job that private radio and television do not. Parliament passed the law with some modifications, but not without strife. As reported by Pasquali, 29 the Venezuelan Chambers of Radio and Television mounted a minute-by-minute campaign against the measure in an attempt to persuade the audience that their freedoms were being endangered by the government and thus to turn it against the legislature that was considering the law's project. The fact that the strategy failed in no way denies the aggressive, obstructionist attitude of private interests against the modification of the media ownership pattern in the public interest.

At times the manifest will also exists to impede the loosening of the concentration of message-sending options even when the state is not the new owner. This, too, was recently exemplified in Venezuela. Using its legal faculties, the government was about to grant new licenses for private operation of radio stations. According to Pasquali, 30 the established interests were successful in blocking that action. Their argument was that additional private radio stations would harm the business of the existing ones. Thus, within the nongovernmental domain, the rights of some were denied at the expense of those of others, both of which groups were identified with the liberal-capitalist creed of "information freedom," "freedom of enterprise," "free competition," and "private initiative." 


\section{Message Interference}

Media ownership distribution indicates the situation in terms of access to sender options. Another very important indicator is the interference with the freedom of message emission, a phenomenon involving the reduction or elimination of sending options. Whereas the former indicator refers to the accumulation of possibilities for sending performances, the latter refers rather to the actual curtailment of these. Put together, these indicators are helpful in determining whether opportunities for sending behaviors are fairly and reasonably open in a given situation.

Intentional interference with the emission of messages is not a rare event in Latin America or, for that matter, in many other parts of the world. Almost everywhere freedom demands unending vigilance, and hardly any right can prevail without having to be defended. Moreover, rights themselves normally imply duties addressed toward avoiding abuses in their implementation. These duties impose limits to said rights. This is a moral and legal principle that has already earned universal validity. In fact, in its second numeral, Article 29 of the Universal Declaration of Human Rights stipulates:

In the exercise of his rights and freedoms, everyone shall be subject only to such limitations as are determined by law solely for the purpose of securing due recognition and respect for the rights and freedoms of others and of meeting the just requirements of morality, public order and the general welfare in a democratic society.

By themselves, limitations such as these are unavoidable sources of interference with message emission. In fact, most countries, including those of Latin America, have legislation that inhibits inflammatory, slanderous, pornographic, and insurrectional communication. Some countries have rules aga inst disclosure of diplomatic and national defense secrets, and many have rules for outright censorship of the mass media in situations of national emergency or state of siege. This seems to be true of capitalist and of socialist-inclined countries as well as of civilian and military regimes.

When the restraining rules are clear and public and have been legally established, their message interference ability is a restriction on freedom that can be willingly accepted by the message senders as an act of responsibility. It is when the rules are ambiguous, disguised, and illegal, or when they are otherwise arbitrarily applied, that conflict with this type of interference is aroused. The press of Latin America, for instance, has fought for decades a relentless battle against censorship, especially that characterized by prepublication clearance of their messages by government authorities. In a recent series of lectures delivered at the Centre of Latin American Studies of Cambridge University, Callado makes this point unequivocally:

As a journalist, and also as a writer, but less as a writer, I feel the grip of censorship all the time. The worst aspect of it is that, after 10 years of military dictatorship, censorship is now tacit in most newspapers. The censorship office frequently telephones the papers to let them know that it is forbidden to publish some news item or other or to editorialize on something or other. It happens sometimes that the newspapers do not even know, yet, what is really being 
forbidden, have not heard yet that a particular event had taken place. They know by phone, that they have (sic) better not even try to find out. In a certain sense, the news is killed before it is born. 31

Although perhaps censorship is now tacit in most newspapers in Brazil, the immediacy of outright censorship was brought home by the recent death of a well-known journalist, film maker, and news director of Sao Paulo's cultural television station, Vladimir Herzog, in a military prison. According to a military statement, Herzog, who had voluntarily reported for questioning at the headquarters of the second army corps in Sao Paulo the morning after military police had come to his office to take him for questioning, had hanged himself after writing a confession that he had been a militant of the Brazilian Communist party since 1971 or 1972 . As reported by Latin America, "Herzog's arrest formed part of a wider pattern of repression. Eleven journalists have been arrested in Sao Paulo in the past two weeks. .. The meeting in Sao Paulo two weeks ago of the Inter-American Press Association when local journalists took advantage of an international forum to complain of the difficulties under which they work appears to have particularly incensed the military. . . Frequently the censor has refused to allow even the most veiled criticism of the economic situation, and this has been notably true during the past few weeks when discussion of the controversial contratos de risco, involving an end to the country's traditional policy of oil nationalism, has been virtually forbidden. "32

In protest of Herzog's death, according to Latin A merican Report, "30, 000 students at the University of Sao Paulo went on strike for a week and were joined by the Catholic University and other schools in the city. The Journalists Association organized an ecumenical memorial ceremony at the Sé Cathedral, officiated by Rabbi Henry Sobel, Cardinal Evaristo Arns and Pastor James Wright, accompanied by Helder Camara, Archbishop of Olinda and Recife." 33

On 22 October 1975, Brazil's President Geisel made the following declarations in reply to the Inter-American Press Association, which were recorded by Latin America: "There is scarcely a country in the world with as much freedom as Brazil emphasising in particular the freedom of the Press." 34

On 21 January 1976, United Press International (UPI) published a cable reporting that "The President of Brazil, Ernesto Geisel removed the military commander of the Sao Paulo region a few hours after the army announced the second death of a political prisoner in three months in the military interrogation center in Sao Paulo. The order of Geisel, which was put into effect immediately, gave no reason for the removal of General Ednardo D'Avila Mello."35

On 22 January, UPI reported that "General Dilermando Gomes Monteiro, new commander of an army unit in which two political prisoners died in interrogation centers, promised to defend human rights 'above all things. "' The news agency added that Gomes Monteiro was appointed by President Geisel to the Sao Paulo post previously occupied by General D'Avila Mello. 36

again notes:

Looking at the overall Latin American scene, the Brazilian Callado

With the downfall of democracy in Uruguay and Chile, the area of free intellectual expression in that immense continent is getting reduced to the size of a handkerchief. . . Suddenly the countries which are 
relatively free will experience a hardening of the control. The terrible case of Chile, where there was an ample freedom until September of last year and where reigns now the worst climate of official terror in Latin America, illustrates the point. 37

Callado refers to the date of 11 September 1973, when the legally elected socialist democratic regime of the Popular Unity was overthrown in one of the bloodiest military coups of Latin America's history. As reported by Abelandia Rodriguez, apparently the only researcher who has been able to survey the communication situation in the current post-Allende days, the military government has taken, directly or indirectly, close to complete authoritarian control of the mass communication system. This obviously included, from the start, the total deprivation of sending options for media that had supported the leftist experiment. It has also come to measures of stiff message interference with the very conservative media who had so decisively contributed to the downfall of Allende and who are enthusiastic supporters of the military regime that assumed power after that leader's violent death. Concluded Rodriguez:

All the values of liberal democracy, "constitutionality," "legality" and "freedom of expression" have been repressed or simply suppressed. In Chile, the rules of the game for freedom of expression have been mocked. Even liberal pro-North America organisms and harsh enemies of the Popular Unity, such as the SIP (Inter-A merican Press Society) have denounced the CIA, the communications media, the journalists and the opposition groups of having received North A merican capital to fight the Popular Unity with more than words, programs and songs and have accused the military Chilean regime of curtailing "the exercise of a free and independent journalism. "38

According to a United Press International wire from Santiago, the most recent evidence of that situation is a December 1975 decree granting provincial military chiefs the authority to suspend for six days the press publications or radio and television transmissions that spread opinions or news that may cause "alarm" or "dislike" or which may "disfigure the true dimension of the facts." The wire adds that the National Press Association, which groups the owners of newspapers and magazines, asked the government to revoke the decree and asked President Pinochet for an interview on the matter. 39

A 16 January UPI wire from Santiago reports that El Mercurio, one of Allende's staunchest opponents, "reiterates its opposition to a legislation considered restrictive for the Press that has been put into effect by the military Government."40 A 22 January 1976 UPI wire announced the protests of the Chilean Association of Radio Stations (ARCHI) for the closure of the Christian Democrat station, Radio Balmaceda, which was closed by government decree for having carried out a "campaign of anti-patriotic propaganda in spite of multiple warnings it had received." ARCHI affirmed that the closure is a measure "whose seriousness affects all Chilean radio stations." As reported by the official daily El Cronista, Monsenior Francisco Fresno, president of the Episcopalian Conference, and authorities of the Catholic church discussed the recent decree considered restrictive for the press and the situation of Radio Balmaceda with General Pinochet. 41

Message interference of an arbitrary nature has also been recorded at times in those few Latin American situations where substantive political exercises to depart from the traditional capitalist system are taking place. 42 
Cuba, the country undergoing the region's most profound revolutionary social change, confronted, in 1971, a serious instance of the dilemma of the expres sion of views divergent from the official line. The incident occurred during a period of economic difficulties caused by low sugar production in Cuba. Leftist poet Herberto Padilla was one of those who engaged in outspoken criticism of the situation. He was imprisoned for a month and denounced. After he admitted his guilt in a confession and was released, he publicly manifested that he had erred in his criticism. Because this case of dissent involved an intellectual identified with and working within the Cuban revolution, it received wide diffusion outside the country. Criticism expectedly came from the established press of the region, Europe, and the United States. However, some leading Latin Amexican intellectuals, although sympathetic with the Cuban process in general, also expressed disagreement with the government procedure in this case, while others maintained solidarity with it.

Peru also is undergoing a unique process of overall social transforma tion. This includes radical legal reform of the private communication system in favor of the majorities, but--according to governmental statements prior to 1976-not in the direction of state monopoly. The main dailies of Lima, the capital city, which belonged to conservative financial groups opposed to the process, were expropriated in 1974 in order to be turned over to associations of workers, peasants, educators, and intellectuals. This transfer was to have taken place in July 1975, but was postponed until July 1976. However, the President announced in early 1976 that the transfer would not take place until the proper conditions existed, and on March 15, six. new "more moderate" editors were named in replacement of the previous government appointed directors. 43 In addition there have been changes in the structure and function of television and radio aimed toward expanding messagesending and -receiving options. These reforms will not be discussed here in relation to assaults on the right to communicate, as they call for different treatment as a separate category of analysis that lies beyond the scope of the present paper. 44

However, mention has to be made of the case of an internationally known Peruvian novelist, Mario Vargas Llosa. Although publicly identified with the social transformation undertaken in his country by the military government, he voiced some criticisms of the expropriation of the dailies and was attacked for it by the pro-official media.

The New York Times reported the case as follows: "Mr. Vargas Llosa, whose own politics lean towards socialism, asserts that he is largely sympathetic to the broad aims of the revolution proclaimed by the armed forces. - . During the recent rioting in Lima against the military Government, he strongly denounced any attempt by conservative opponents to take advantage of the crises. He has applauded the agrarian reform. . . He has welcomed Government plans to give industrial workers a large share of ownership in their companies. "45 Yet, Vargas Llosa had observed:

Now the Government has isolated itself from public debate. Look at newspapers six months after their expropriations. They carry only the most timid sort of criticism. 46

However, Vargas Llosa had noted: "I don't think there was anything remarkable about the newspapers when they were privately owned. They defended minority class interest." 47 After attacks on him by the expropriated newspapers, thirty four Peruvian intellectuals and artists signed a declaration supporting the novelist: 
"We consider that silence in any country is the worst enemy of the civic spirit. To impose it is the temptation of power, but to submit to it is an unexcusable weakness for those who feel that the country is the business not of the few but of everyone. "48

Setting this controversial situation outside of the analysis for the reason already mentioned, this essay will instead touch upon a few specific instances of direct repression of sending options that took place in Peru, before and after the "socialization" of the big Lima dailies, within the period of President Velasco Alvarado.

Before the press measures occurred, a case was reported of repression against the center-right weekly Caretas, which culminated with the exile of its director, Enrique Zileri. But it was long after the expropriation of the dailies had taken place that other message-curtailing operations took place in the country. These were reported by Latin America: "The deportation on 5 August of 28 predominant political opponents was both the culmination of a campaign against 'infiltrators' in the media and a crushing blow to some of the country's most militant unions. "49 Among the deported were nine newsmen, including the chief staffers of left-wing magazine Marka. Latin A merica continued: "Marka was also accused of encouraging strikes, land invasions and political violence, and of trying to cause trouble between Peru and Chile. . . Marka also made the mistake of denouncing the increasing number of arbitrary arrests and acts of repression, and was particularly outspoken in defending small left-wing journals in trouble with the authorities, such as Palabra Socialista, Masas and Tinta." 50 The following edition of Latin America informed that: "The growing wave of protests against last week's deportations has been met by further arrests, and a warning from interior minister General Pedro Richter Prada that what goes on in Peru is of no concern to anybody outside. This blunt rebuff was directed at the organizing committee of the Congreso Latinoamericano de Periodistas, which is due to take place in Lima later this year. The committee, in the person of a left-wing Venezuelan senator, had protested against the closure of Marka." 51

Just as it is paradoxical to see the conservative mass media of Chile that had fostered the establishment of the present military regime rise now in defense of the freedom of the press being denied by that conservative regime itself, some found hard to understand the repression against a pro-communist publication by a socialism-inclined government in Peru. Said Colombia's E1 Tiempo in an editorial:

What is most attention-calling and should interest the fervent admirers of the Peruvian experiment is the blow that has been given to the leftwing journalists and even to those who from any channel of opinion have favored to a great extent the acts of the Junta, but who dared to dissent in matters certainly not transcendental. The magazine Marka, of a clear leftist tendency, was closed and, not satisfied with that, the government expelled its directors. 52

The Marka incident was so serious that it is said to have contributed to the substitution of President Velasco Alvarado by President Morales Bermudez on 20 August 1975. Not surprisingly, one of the first official acts of the new president was to authorize the return of the exiled journalists. This indicated a will to respect the right to public dissent within the legal limitations usual to most countries. Such attitude appeared confirmed by a public presidential statement that was quoted in an issue of the newsletter of the Inter-American Press Society. According to this 
publication, General Morales Bermudez affirmed that the revolution was strong and was not afraid of any criticism, and he invited the press to express itself freely. He objected to the imposition of "parameters" by the former administration and declared:

If parameters exist concerning public opinion then there is no opinion. The parameters disappear because they are illogical. It is preferable that the people say what they think and do not hide their thoughts. 53

However, in March of the next year, the government or Morales Bermudez dismissed and replaced the directors of the six socialized national newspapers by more moderate editors. According to Latin American Report 54 these papers, which since their expropriation had "generally maintained an obsequious line of support for official policies, had increasingly contested the economic austerity measures announced last January. In addition to the changes of the six dixectors, employment guarantees of journalists were suspended for 90 days to permit a reorganization of the staffs. The socialized dailies were not handed over to the labor communities which were supposed to run them on their own as of July 1976. In July 1976, 12 periodicals of varying political leanings, including the reorganized Marka, were closed. 55 Recently the Peruvian Government announced that it was studying a new Press law.

Dramatic as the struggle for press freedom often is in Latin America, it refers to only one type of interference with message emission in the case of one kind of medium. Government censorship of the press is but one of the tools in the repressive arsenal of the enemies of communication rights, be they "leftists" or "rightists." The problematics of communication freedom is certainly broader and more complex than that. For, even if there was no direct official censorship at all, there would still be other grave dangers on the scene. Some of them, such as seizure of editions or closing of radio stations, newsprint distribution control, the forcing of newspapermen to belong to officially approved associations of professional communicators, subsidizing, bribing, and differential taxation on equipment imports and revenue, obviously stem from the authorities. But other, no less ominous threats cannot be blamed on these.

Attending the First Latin American Encounter of Journalists in Caracas, Carlos Andres Perez, the president of the Republic of Venezuela, observed:

Freedom of consciousness is not limited and freedom of expression is not limited only by governmental measures, but also by the prevalence of interests over the essential context of the right to information that a country has. . . . Liberty of information exists in our country in what refers to the behavior and attitude of the government which in no way interferes or meddles with it. But we could not deny that this liberty of information does get meddled with by partial interests in society. 56

What those interests are and what some of their procedures are that curtail the sending options in Venezuela have been documented by researcher and National Senator Eleazar Diaz Range1, 57 a socialist politician and newsman who presided at the Venezuelan Association of Journalists. Following are brief summaries of a few of the cases he studied. 
1. Between 1961 and 1962, most of the country's mass media exhibited a line of information and opinion unfavorable to the revolutionary process that was occurring in neighboring Cuba. The daily El Nacional attempted to depart from the scheme and tried an independent line open and, at times, sympathetic to that process. The National Association of Advertisers decided to boycott the paper on the grounds that it had conducted an unethical campaign against one of its members. The most important national advertisers (The Mendoza group, the Vollmer group, and the Electricity Company) and foreign advertisers operating in the country (Sears, CocaCola, General Electric, Chrysler, Pan American, Colgate-Palmolive, and Standard Oil [Creole]) were among the dozens who stopped placing ads in the deviant news paper and made their decision public. After a year and a half of boycott, during which the paper suffered serious losses, its board of directors replaced the rebel editor and co-owner with a lawyer who represented the Rockefeller interests in the country. Much of the staff also was removed. The paper altered its policy in the direction desired by those who had performed the boycott, and their ads soon reappeared in its columns.

2. A union informed the Ministry of Labor, in September 1969, that the work supervision regime of the General Electric Company in a suburban Caracas plant included corporal punishment and detention in a sort of private jail. Having verified the case, the ministry sent communiqués about it to all mass media. None were published. Therefore the minister himself reported it publicly at the closing session of a Congress of Intellectual Workers. Radio and television remained totally silent, and of forty newspapers, only one reported on the minister's presentation, some five days later. Venezuelan media receive a share of the $\$ 40$ million spent yearly by $\mathrm{G}$. E. in advertising.

3. On 26 July 1972 , the daily El Globo was ready to print a front-page banner headline story with the news that the president of Sears of Venezuela had been cited by the National Court of Finance in regard to the illegal importation by his company of eight hundred television sets through the Maracaibo seaport. Somehow Sears promptly learned of this, and immediately the paper received several phone calls that threatened an advertising boycott by all North American firms in the country. The story was removed from the front page of El Globo, and no other paper picked it up.

4. In early 1969, the Municipality of Guarenas, in the State of Miran$\mathrm{da}$, sued the Electricity Company for five years of overdue taxes. As the company forms part of the mighty Vollmer-Zuloaga financial group, most mass media sided with it against the municipality. Nevertheless, the judge ordered the company to pay its taxes, a decision never reported by the media. The Venezuelan Association of Journalists accused media and advertisers of having given an intentionally biased treatment to the case. They denied the charge. The association substantiated its charge by measuring the space (text, illustrations, and ads) that six big dailies had given to the case, and found a ten-to-one relationship in favor of the company and against the municipality. Of those dailies, five refused to publish these results, and the sixth, which might have published them, just happened to stop its publication during those days.

5. In March 1969 , a plane of the airline Avensa, an affiliate of the Boulton financial group, crashed in Maracaibo, killing more than one hundred fifty persons. Technical, judicial, and parliamentary investigations found clear indications that the tragedy was the result of negligence on the part of the airline. Yet, with the exception of La República, a semiofficial daily whose financial support did 
not come mainly from commercial advertising, no other medium reported these investigations. Instead, the press played up a statement by an official who pronounced the airline free of guilt. This official was also the editor of Panorama. Avensa is an important advertiser: although in March 1968 it has spent in advertising a total of some 14 million Bolivares, in March 1969--the month of the plane crash--its total advertising bill had reached 24 million. Avensa's advertising in Panorama went from roughly 4,400 Bolivares in March 1968 to approximately 8, 700 in March 1969.

Diaz Rangel goes on to examine in his research an array of devices used by private interests to hinder the message-emitting options of those who are opposed to them. The devices include: social discrimination through graphic information; biasing of electoral news so as to harm parties and candidates committed to social change; manipulation of sports and crime news in favor of the elites; and intentional disregard for consumers' defense information that reveals false advertising and warns about dangerous products.

What he reports for Venezuela is not very different from what happens in other countries of the region in this respect, such as the press manipulation against landless peasants reported in Peru in 1969 by Roca. 58 Roca documented a strong bias in news, editorials, and ads against those peasants in six Lima dailies during a period of invasions of huge farm estates. And he demonstrated the direct and strong connections that three of those dailies had with concentrated ownership of agricultural lands. Other cases in Peru, prior to the present government's coming to power in 1968, have been reported by Alfonso Benavides Correa 59 as examples of overwhelming advertising pressure against a radio station, a television channel, and a political weekly that took a line favorable to the vindication of national interests from the domain of the International Petroleum Company. (This analyst has also reported comparable situations in Brazil.) Benavides concluded, "Advertising has eminently political character and it is only channeled to the diffusion media which defend the political positions that the group of large (particularly foreign) firms desires. "60

Conspiratorial commissioning of message interference against the communication rights of the majorities does not constitute the only problem. Omission, innocent or not, also is present, as occurred recently in Recife, Brazil. The two commercial television networks did not inform their audiences of a catastrophic inundation that was affecting the city, being unwilling to interrupt their soap-opera broadcast. 61 Are media supposed to have the right to deprive a sizable part of the population of their right to learn about events that threaten their very existence?

None of these restrictions on sending opinions are government-imposed limitations. Therefore, few ever complain and the media involved in the cases remain silent. "The SIP 62 is not concerned with any other limiting factor," points out Diaz Rangel. 63 This lends support to his view that the fight against restrictions on information freedom varies according to the circumstances. He asserts that:

When these [restrictions] have a State origin, be them or not of a legal character, it is easier to denounce them and fight them. If, instead, they are limitations caused by the economic power imperceptible for press readers, television watchers or radio listeners, this fight becomes difficult, complex and long since it must start by 
creating consciousness of this reality among journalists themselves and uncovering its existence to the whole society. 64

As we have seen, pressures from private and public interests can work against communication rights in Latin America in numerous ways. Yet, their joint influence accounts, in addition, for one grave and hidden form of message curtailment that research can barely tap but that cannot be ignored: self-censorship out of fear or convenience. This phenomenon runs the gamut from the socialization and social control of communication professionals by media owners to undisclosed silence--restrictive operations that originate outside the professional messageproducing environments. It is not unusual for news adversely affecting the interests of foreign or national financial groups to get "washed out" or flatly "killed" as it makes its way from the newsgatherers to the editing desks. And the same is true for news whose diffusion is undesired by governments, or for "boat-rocking" television programs. Just as public officials and powerful advertisers train media owners in the exercise of a "discretion" with which they may buy their endurance and livelihood, owners train their staffs in the implicit code of what is and what is not to be said. Even worse, they train them at times in the strategies of biased selectivity and intentional distortion of information. Those staffers who militantly resent these conditioning procedures often have no choice but to leave one media institution in search of a less oppressive one, or, in the long run, perhaps to leave the profession altogether. Omission, then, covertly adds its weight to overt commission against freedom of communication.

We conclude that, with but rare exceptions, freedom of communica tion as senders of messages in Latin America is the privilege of powerful private and/or governmental minorities. The UN-proclaimed right to impart information

and express opinion without interference appears effective almost exclusively for those few who, by virtue of the society's present structure, enjoy concentrated economic and/or political power. To maintain such communication privileges, some of those with such power appear determined to prevent the rest of the citizenry from. gaining effective means to exercise their rights as senders of mass media messages. The devices employed range from open persuasion and subtle coercion to outright extortion and direct repression. Along with these direct message-interference procedures, the acute concentration of mass media ownership in private mercantile and conservative hands explains much of the situation.

\section{LATIN AMERICA: THE RECEIVING OPTIONS}

The second central question to which our situational analysis addresses itself is: Do Latin Americans effectively have at their disposal unrestrained mass communication options as receivers of messages that carry information and/or opinion?

Again, we recognize from the start that a symmetrically equitable distribution of those opportunities among the population must not necessarily exist. For instance, children and elderly people may have lower levels of communication needs and of information absorption, and some members may require a higher degree of access to information than others.

What needs to be defined, then, is whether the distribution of opportunities for performing message-receiving roles in Latin America follows a normal 
curve. Whereas message-sending situations through the mass media generate, by definition, a tendency toward concentration in favor of a small number of media owners and operators, message-receiving situations within the same system should generate, also by definition, a tendency for dispersion of the messages among wide layers of a country's population.

The specific question then is: Are message-receiving opportunities fairly and reasonably open to a good number of persons?

Looking at summary data on mass media availability in the region is a useful way to begin a survey of the situation.

In 1961, Unesco set minimum desirable standards of mass media availability for every 100 inhabitants in underdeveloped countries. They were the following: 10 newspaper copies, 5 radio receivers, 2 television receivers, and 2 cinema seats per 100 people. Latin American figures for 1961 were: 7.4 newspaper copies, 9.8 radio receivers, 1.5 television receivers, and 3.5 cinema seats. 65 By 1971 , the figures for Latin America had changed to: 7.5 newspaper copies, 11.3 radio receivers, 5.7 television receivers, and 2.7 cinema seats. 66 The survey shows that the region had remained below the desired minimum in newspaper copies and had decreased its figure for cinema seats; in contrast, it has experienced appreciable growth in television sets. Mexico more than doubled its number of radio receivers in less than a decade.

Although the above figures show that in 1971 Latin America met the minimum standards set by Unesco for underdeveloped countries, the question re mains, what is the distribution of message-receiving options? A North American researcher summarized the situation as follows:

The overall diversity of Latin America is reflected in the availability of mass media. The differences are tremendous, not only between but within the countries. In the big cities, we find the full range of media readily obtainable, both print and electronic, except in a few cities still without television. In the hinterland, there are few if any media to be found. 67

Indeed, research has verified a pronounced degree of concentration of the mass media sending facilities in the cities of Latin America. This is especially marked in the larger cities in the cases of press and television, and to some extent in the case of the cinema. Radio is the least urban-concentrated medium, yet it never reaches about one half of the population, some 150 million people.

This structural situation has brought about a pattern of acute concentration of message-receiving opportunities in favor of urbanites and to the neglect of the rural masses. Furthermore, within both urban and rural areas, concentration is evident. Two studies exemplify this situation. The first was a comparison of mass media use opportunities between a sample of urban professionals in several Latin American countries and an equivalent sample in the midwest region of the United States of America. Other than in the case of television, which is much more available in the United States, the Latin American exposure standards were found as high as those of the United States and higher in books and radio consumption. 68 (Comparable results were obtained in a study with students at a Costa Rica University.69) The other study was done with a sample of Brazilian peasants residing not 
over two hours from a state capital, acceptably endowed with mass media facilities, and fairly well linked by roads to the countryside. They were interviewed to find out their level of information on matters often treated by the media. These were some of the results: 95 percent of the peasants did not know that coffee was the chief export of their country; 80 percent did not know the meaning of the word democracy; 48 percent did not know the name of the president of the Republic. 70 Even in Argentina, one of the relatively more developed countries of the region, the situation is similar. A United States Information Agency 71 survey of comparative intake as between urbanites and ruralites in Argentina found that, for urbanites, consumption of media was: newspapers 65 percent; radio 59 percent; television 32 percent; and cinema 6 percent. The figures for ruralites were: 46 percent, 61 percent, 1 percent, and 5 percent, respectively.

Such contrasts in information levels can be explained by several factors. A prominent one is the way the mass media organize the distribution of their messages. In Colombia, for instance, Garcia 72 reported in 1966 that of an average circulation of 800,000 daily copies of thirty-two newspapers, 83 percent was accounted for by the three largest cities, the remainder going to the rest of the cities and to the countryside. He reported also that of Mexico City's six largest newspapers' total daily circulation of 665,000 copies, 80 percent was within that city, the rest in all other cities and in rural areas. As Bostian and Oliveira 73 showed in the case of Brazil, not even radio really escapes this skewed distribution, which disfavors the peasantry. And, of course, rural television is hardly in existence at all.

A number of other studies have documented the fact that mass media are eminently urban-oriented in Latin America. As has been observed, however, a marked stratification of information opportunities also occurs within the urban domain. High and low socioeconomic and education groups in San Jose, Costa Rica, were interviewed to record their media use for the preceding day. Except in the case of radio, subjects in the high group were found to expose themselves to mass media more than did subjects in the low group. 74 A similar close association between social structure and media exposure was found in Peru by the Catholic University. 75 Such a correlation was verified also in Santiago de Chile by Carter and Sepulveda. 76 And Martin 77 found in Barquisimeto, Venezuela, that whereas the high income and education strata of the mass media audience enjoy the freedom of selecting any media mix they may wish, the low income and education strata suffer a severely limited scale of media exposure opportunities, with radio at the top and books at the bottom. He concluded that individuals of low income and education are restricted in their freedom of access to information in the mass media. Acute information stratification has been documented also in the countryside. In a rural community of Rio Grande do Sul, Brazil, Blair 78 found that media information exposure patterns were positively related to socioeconomic status, particularly in terms of occupation. Another example, out of the many provided by research, is in rural. Mexico, where mass media consumption standards were found by Canizales and Myren 79 to be directly related to whether the ruralites were land owners or tenants, the former having more access to information sources. Comparable results for a similar situation were obtained in a Peruvian rural community by Mejia. 80

Even when ruralites are reached by the mass media, their rights to be informed are unlikely to be satisfied. As so few of them have any significant purchasing power, the media seem not to care about shaping the content and the style or code of their messages in ways that would be understandable and interesting to 
nonurbanites. For instance, news of rural education needs and other peasant community programs were ranked lowest in the agricultural pages of four Colombian dailies and a rural weekly that were content-analyzed by Gutierrez Sanchez 81 in 1966. A similar but more recent and more complex study conducted also in Colombia found that, on a scale of seven content categories, land reform was the last. 82 Felstehausen 83 found comparable results for radio in a region of Colombia itself. Brazilian, Chilean, and Mexican studies, including that of Ruanova 84 on farm magazines, produced similar results. Cordero 85 found that in Costa Rica, a country whose livelihood is eminently based on agriculture, the dailies assign very limited space to information about it while devoting much space to commercial farm advertising.

Given that the mass media are strongly urban oriented, they codify their messages in styles corresponding to the urban audiences. Thus, the rural population is ignored not only in terms of content but also in terms of code: messages are geared toward urbanites even in the case of agricultural publications. This happens not only in private mass media but also in government-produced massive agricultural communication materials, as has been verified, for instance, by Spaulding 86 in Mexico and Costa Rica, by Ruanova 87 and Magdub 88 in Mexico, by Fonseca and Kearl 89 in Brazil, and by Amaya 90 and Gutierrez Sanchez 91 in Colombia. His analysis of 122 articles in the agricultural pages of four dailies and one rural weekly in Colombia led Gutierrez Sanchez to conclude, "that which may be of direct value in improving agriculture is beyond the comprehension of those who could best use the information." 92

In summary, then, the message-receiving options are heavily concentrated in the larger cities, especially in the cases of television and press; concentration is appreciably less acute in the case of radio and somewhat less acute in the case of the cinema. Within each city, a minority of the population has far more access to mass media messages than does the majority. Within the rural areas, even smaller minorities are the ones who enjoy access to those messages. In general, the distribution of mass communication opportunities in Latin America follows the pattern of steep stratification that characterizes the prevailing socioeconomic structure. The higher the income, education and status, the higher the level of access to mass media messages. The greatest portion of the population, low-class urbanites and the peasantry, appear to have as low levels of access to communication as to food, health, shelter, and education. Receiving information is a privilege of powerful, and mostly urban, elitist segments of society. This is reflected not only in terms of differential access to message-getting options but in the fact that the content and code of these are exclusively couched in the terms of those minority audiences, which constitute the market for consumer goods and services.

The evidence leads us to conclude that the right to receive messages in Latin America is inoperative for the vast majority of its inhabitants.

\section{CONCLUDING REMARKS}

We started with the conviction that, in essence, freedom of communication exists when human beings effectively have at their disposal unrestrained options as senders and receivers of messages that carry information and opinion. Under that principle, we engaged in an overview of the Latin American situation as it is described by the pertinent empirical documentation available. Our exploration 
was centered around concrete indicators of the distribution of sending and receiving options. In the former case, mass media ownership patterns and an inventory of the most common forms of interference with message emission were the guiding points upon which we relied. In the latter case, we were guided by a few of the many existing studies on how the opportunities for access to mass media messages are distributed among the different social strata. We found the central phenomenon to be an acute concentration of sending and of receiving options in extremely powerful economic and political minorities, be they located in the private or the public domain, be they identified with capitalism or with socialism, and be they made possible by civilian or military rule.

Our survey of the situation has led us, then, to conclude that information freedom and communication rights, as contained in the international official statements to which we referred, are presently ineffective for the majority of individuals in Latin America. Thus:

In general terms, information freedom remains the freedom of a few opposed to the right of the many, since at present the importance and magnitude of information media has provoked either the concentration of some or all of these in State hands or in the hands of economic or political groups but, in either case, in the hands of a few. 93

It could be asked whether such a deplorable situation can be explained solely by the inadequacy of the postulates vis-aे-vis social reality or by the structure of this reality being such that no statements whatever would be truly applicable to it. Put another way: Is it that those freedoms and rights are too imperfect, idealistic, vague, and perhaps even alien to the Latin American societies, or is it that these societies are so organized that the observance of those or any better statements on rights is hardly possible?

We will not attempt to answer these questions here. But we can anticipate our opinion that both could well be answered affirmatively. On the one hand, the statements are highly individualistic as they had their origin when individuals were afraid of the autocratic powers of their kings or emperors. They developed somewhat further after the big industrial nations had taken humanity through two world conflagrations as a result of which colonialism died, imperialism was strengthened and expanded, and communication technology made great global strides. On the other hand, the makeup of the Latin American societies is one where, with rare exceptions, mighty minorities exert internal domination over the great majority of the people and have the economy, the technology, the culture, and the communications working almost exclusively for the continuation of their privileges.

Consequently, little would be gained by elaborating and refining the definitions of freedoms and rights to communicate if the edifice of society remains hardly conducive to their true and widespread implementation. If that structure one day substantially changes in the direction of genuine democracy, then the statements would not remain rhetorical and would become increasingly meaningful, valid, and useful.

It is probably the duty of scholars and scientists to contribute to changing the statements. It is the duty of each and every citizen to contribute to changing the nature of his society, and of the system by which it is ruled, if he is 
convinced that it should not continue as it is. This latter duty, also a basic right of the people, is set forth in Article 28 of the Declaration of Human Rights:

Everyone is entitled to a social and international order in which the rights and freedoms set forth in this declaration can be fully realized.

The term international in this statement is of extraordinary importance in the case of Latin America. Heavily dependent as this region clearly is on economic, cultural, and political influx from the United States of America, the occurrence of significant changes in the internal structure of its society cannot be divorced from the need to change the present unfair nature of that international relationship. It should be kept in mind that this relationship includes an unduly strong influence of the United States over the region's communication system and processes, which contribute to limiting the communication freedom of Latin Americans.

We wish, then, to conclude with the following propositions for further dialogue on communication rights:

1. An individual's freedom of communication is limited by the communal rights of his social milieu. Thus, in general, but especially in the event of discrepancy or conflict, the communication rights of society (as a whole or in terms of its majority groupings) should prevail over those of individuals in isolation.

2. As a juridical person, the state has communication rights on behalf of public interests. In democratic societies these rights express the aggregate freedoms of communication held by the national collectivity. When indeed such is the case, and those aggregate rights happen to be in disparity or to come in conflict with private communication rights that express individual freedoms, state rights are to prevail because they purport the interests of the majority, without, however, ignoring the rights of minorities.

3. A nation's rights to communicate as a total society, internally and with the world outside, hold priority over the communication rights of international organizations of any type, or of other nations desiring to communicate with the former. Only when nations sovereignly and freely agree among themselves to allow, fos ter, or cooperatively conduct multinational communication operations may international communication rights, public or private, take partial, specific, or even temporary precedence over the respective national communication rights.

Theory and practice, statements and realities, must evolve hand in hand, mutually influencing each other, toward a truly democratic and humane world in which interactive and participatory communication should be the torch of authentic freedom for all. 


\section{NOTES}

1. Edward Ploman, "The Right to Communicate," Paper presented at the International Broadcast Annual Meeting, Cologne, September 1-4, 1975, contribution to Working Committee IV. Reprinted in Right to Communicate: Collected Papers, L. S. Harms, Jim Richstad, and Kathleen A. Kie, eds. (Honolulu: Social Sciences and Linguistics Institute, University of Hawail, 1977).

2. "Communications: Individual Rights/State Rights," Stanley House Seminar, New Richmond, Quebec, August 1973 (Ottawa: Canadian Commission fnr Unesco, 1973), pp. 3-4.

3. Salvador Lopez, Libertad de información 1953, Documento E/2425 (New York: Naciones Unidas, Consejo Económico y Social, 1953). Documento del Período de Sesiones, 160., Consejo Económico y Social de las Naciones Unidas. Suplemento no. 12 .

4. Ibid.

5. Fernand Terrou, L'Information (Paris: Presses Universitaires de France, 1965).

6. Allan R. Brewer-Carias, "Las limitaciones a la libertad de información en el derecho comparado (Prensa, radio, cine, televisión), " Orbita (Caracas) 5, 6 (1973): 58.

7. Peter Schenkel, La estructura del poder de los medios de comunicación en cinco países latinoamericanos, ILDIS, Estudios y Documentos no. 21 (Santiago de Chile: Instituto Latinoamericano de Investigaciones Sociales, 1973).

8. Jonathan P. Lane, "Functions of the Mass Media in Brazil's 1964 Crisis," Journalism Quarterly 44 (Summer 1967): 297-306.

9. Dennis T. Lowry, "Broadcasting's Expanding Social Role in Mexico, " Journalism Quarterly 46 (Summer 1969): 332-336.

10. Fernando Mas, "La televisión contra la cultura," Visión (México, D. F.), 10 Octubre 1969, pp. 32-42.

11. M. Alisky, "Growth of Newspapers in Mexico's Provinces," Journalism Quarterly 37 (1960): $75-82$.

12. Heriberto Muraro, "La manija. II. Los dueños de la televisión argentina," Crisis (Buenos Aires) 2 (Junio 1973): 52-60.

13. Carlos Malpica, Los dueños del Perú (Lima: Ediciones Ensayos Sociales, 1968).

14. Luis Roca, "Los intereses económicos y la orientacion de noticias sobre el movimiento campesino," Campesino (Lima) 1 (1969): 37-52.

15. Ricardo Lagos Escobar, La concentración del poder económico (Santiago de Chile: Editorial del Pacífico, 1962). 
16. Elmo Catalán, La propaganda; instrumento de presión política (Santiago de Chile: Escuela de Periodismo, Universidad de Chile, 1967).

17. Armand Mattelart, "Los medios de comunicación de masas; la ideología de la prensa liberal en Chile. II. Estructura del poder informativo y dependencia. I. La estructura de poder de la información," Cuadernos de la Realidad Nacional (Santiago de Chile) 3 (Marzo 1970): 37-51.

18. Ibid., pp. 40-41.

19. Elizabeth Fox de Cardona, "Broadcasting in Colombia: Communication Structures and Regulatory Frames," mimeo (Bogota, 1975).

20. Héctor Mujica, El imperio de la noticia; algunos problemas de la información en el mundo contemporáneo, Ediciones de la Biblioteca, Colección Avance no. 15 (Caracas: Universidad Central de Venezuela, 1967).

21. Luis Roca, op. cit.

22. José Joaquín Brunner, "El Mercurio, la educación y el orden vigente, " Mensaje (Santiago de Chile) 18 (Agosto 1969).

23. Armand Mattelart, "Los medios de comunicacion de masas; la ideologra de la prensa liberal en Chile. III. Mitología de la juventud en un diario liberal," Cuadernos de la Realidad Nacional (Santiago de Chile) 3 (Marzo 1970): 77-175.

24. Peter Schenkel, op. cit.

25. Carlos Malpica, op. cit.

26. Fernando Mas, op. cit.

27. Carlos Malpica, op. cit.

28. Antonio Pasquali, "On the Instrumental Use of Mass-Media in America for Purposes of Dependence," Paper presented at the New World Conference, San Antonio, Texas, November 4-8, 1975. Panel: Arts and Culture in the Americas (Caracas: Instituto de Investigaciones de la Comunicacion, Universidad Central de Venezuela, 1975).

29. Ibid.

30. Ibid.

31. Antonio Callado, "Censorship and Other Problems of Latin-American Writers," mimeo (Cambridge: Centre of Latin-A merican Studies, University of Cambridge, 1974). This working paper comprises three lectures given by the author at the Centre of Latin-A merican Studies.

32. "Brazil: Death of a Journalist," Latin America (London) 9 (October 1975): 337 338.

33. "Brazil," Latin American Report (San Francisco, California) 4 (October 1975): 2. 
34. "Brazil: Death of a Journalist," op. cit., p. 338.

35. "Relevado Comandante," El Vespertino (Bogotá), enexo 21, 1976, p. 8.

36. Noticiero Latinoamericano, "Derechos humanos, " El Vespertino (Bogotá), enero 22,1976, p. 8.

37. Antonio Callado, op. cit., p. 10.

38. Abelandia Rodríguez, "El papel de los medios masivos en la política cultural de la Junta Militar Chilena," Comunicación y Cultura (Buenos Aires) 4 (1975): 1516.

39. "Chile: Libertad de prensa," E1 Espectador (Bogotá), enero 10, 1976, p. 4-A.

40. "Chile: Restricción a la prensa," E1 Espectador (Bogotá), enero 16, 1976, p. 4-A.

41. "Indefinidamente suspendida en Chile Radio Balmaceda," El Espectador (Bogotá), enero 22,1976 , p. $4-A$.

42. This, apparently was not the predominant case in Allende's Chile, although some instances of message curtailment were reported during his administration: his closing of the UPI office in Santiago, along with his public criticism of the main conservative daily, E1 Mercurio, and refusal to allow Channel 13 to expand beyond Santiago. According to Latin America: "Previously there had been no evidence whatsoever of interference in any branch of the media, despite numerous allegations that this would be the case once a Marxist President came to power. Before he took office Allende publicly guaranteed the freedom of the press and subsequently has repeated his pledge, even though he had been subjected to an unparalleled barrage of criticism from the newspapers and radio stations, most of which are owned by opponents." Latin America 5 (September 1971): 308-309.

43. "América Latina: Acaban con prensa opositora," El Tiempo (Bogotá), julio 5, 1976 , p. 10.

44. See, on this experiment, Hugo Neira, "El poder de informar," In Centro de Estudios de Participación Popular, Lima, Comunicación y Participación (Lima: CENTRO, 1974), pp. 76-134. Also Carlos Ortega y Carlos Romero, Las políticas de comunicación en el Peru. s.n.t. s.p. (Versión preliminar resumida de la monografra en preparación para la Presses de l'Unesco).

45. Jonathan Kandell, "A Reluctant Antagonist in Peru: Novelist Critical of Military 'Cannot Remain Ostrich'," New York Times, February 21, 1975.

46. Ibid.

47. Ibid.

48. Francisco Abril de Viveros et al., "Comprometidos críticamente con el proceso - . apoyan a Vargas LI," Expreso (Lima), enero 2, 1975, p. 7.

49. "Perú: Deportations Galore," Latin America (London) 9 (August 1975): 253-254. 
50. Ibid.

51. "Perú: More Arrests," Latin America (London) 9 (August 1975): 263.

52. "Del Régimen peruano," El Tiempo (Bogotá), agosto 12, 1975, p. 4-A.

53. Sociedad Interamericana de Prensa, "Perú: sin cambio sustancial," Noticiero de la SIP (Miami) 269 (Octubre-Noviembre 1975): 7.

54. "Paraguay," Latin American Report (San Francisco) 4 (March 1976): 7.

55. "América Latina: Acaban con prensa opositora," El Tiempo (Bogotá), julio 5, 1976, p. 10.

56. Carlos Andrés Pérez, "Discurso del Presidente de la República de Venezuela Carlos Andrés Pérez, en el acto de instalación del primer Encuentro Latinoamericano de Periodistas," Comunicación y Cultura (Buenos Aires) 4 (1975): 118-121.

57. Eleázar Draz Rangel, Noticias censuradas, El Hombre y la Comunicación (Caracas: Síntesis Dosmil, 1974).

58. Luis Roca, op. cit.

59. Sociedad Interamericana de Prensa, "Condénanse detenciones en el Brasil," Noticiero de la SIP (Miami) 269 (Octubre-Noviembre 1975): 1, 6.

60. Alfonso Benavides Correa, La verdadera libertad de prensa (Lima: Oficina Nacional de Información, 1970), p. 118.

61. Veja (Brasil), 366 (September 10, 1975). (Weekly, ed. Victor Civita, Editora Abril, Sao Paulo.)

62. SIP stands for Sociedad Interamericana de Prensa (Inter-American Press Association), the U.S. and Latin American association of owners of major dailies. The SIP has a permanent Committee on Freedom of the Press, which presents a public report on the region of its mandate at the yearly convention of the association.

63. Eleázar Díaz Rangel, op. cit., p. 11.

64. Ibid., p. 123.

65. Unesco, "Latin America," in Mass Media in the Developing Countries: A Unesco Report to the United Nations, Unesco, Reports and Papers on Mass Communication no. 33 (Paris, 1961), pp. 24-25.

66. Mario Kaplún, La comunicación de masas en A mérica Latina, Colección Educación Hoy, Perspectivas Latinoamericanas no. 5 (Bogotá: Asociación de Publicaciones Educativas, 1973).

67. John T. McNelly, "Mass Communication and the Climate for Modernization in Latin A merica," Journal of Inter-American Studies (London) 8 (1966): 347. 
68. Paul J. Deutschmann, John T. McNelly and Huber Ellingsworth, "Mass Media Use by Sub-elites in Latin American Countries," Journalism Quarterly 38 (Autumn 1961): $460-472$.

69. John T. McNelly and Eugenio Fonseca, "Media Use and Political Interest at the University of Costa Rica," Jowrnalism Quarterly 41 (Spring 1964): 225-231.

70. Juan Díaz Bordenave, "New Approaches to Communication Training for Developing Countries," Paper presented at the Third World Congress of Rural Sociology, Baton Rouge, Louisiana, August 1972, Section on Information and Communication Problems in Development.

71. United States Information Agency, The General Pattern of Exposure to Mass Media in Seven Latin American Countries, Research and Reference Service, Survey Research Studies, Program and Media Series no. 58 (Washington, D. C. , 1961).

72. Antonio García, El problema agrario en América Latina y los medios de información colectiva (Quito: Centro Internacional de Estudios Superiores de Periodismo para Amêrica Latina, 1966).

73. Lloyd R. Bostian and Fernando C. Oliveira, "Relationship of Literacy and Education to Communication and to Social and Economic Conditions on Small Farmers in Two Municipios of Southern Brazil." Paper presented at the meeting of the Rural Sociological Society, August 1965 (Chicago: Rural Sociological Society, 1965).

74. John T. McNelly and Paul J. Deutschmann, Media Use and Socioeconomic Status in a Latin American Capital, Papers in International and World Affairs, Series no. 3 (East Lansing: Michigan State University, International Program, 1964), pp. 1-15.

75. Pontificia Universidad Católica del Perá, Escuela de Periodismo, Lima, Investigación en los medios de comunicación colectiva (Lima, 1969).

76. Roy E. Carter and Orlando Sepulveda, "Some Patterns of Mass Media Use in Santiago de Chile," Journalism Quarterly 42 (Spring 1964): 216-224.

77. Richard Martin, Escalas de accesibilidad a los medios de comunicación de masas; un enfoque socio-económico, FUDECO, Serie de Comunicación Social y Desarrollo no. 4 (Barquisimeto: Fundación para el Desarrollo de la Región CentroOccidental de Venezuela, 1975).

78. Thomas Lucien Blair, "Social Structure and Information Exposure in Rural Brazil," Rural Sociology (Rural Sociological Society) 25 (1960): 65-95.

79. Juan Antonio Canizales y Delbert T. Myren, Difusión de la información agrícola en el Valle del Yaqui, Folleto Técnico no. 51 (México, D. F.: Instituto Nacional de Investigaciones Agr (colas, 1967).

80. Percy Mej氏a, "Dominación y reacciones a la reforma agraria," Desarrollo Rural en las Américas (Bogotá) 3 (Septiembre-Diciembre 1971): $35-\overline{42 .}$

81. Jaime Gutierrez Sanchez, "Content Analysis and Readability Study of the Agricultural Pages in Five Colombian Newspapers" (M. S. thesis, University of Wisconsin, 1966). 
82. Manuel Arévalo et al., Análisis de contenido de las páginas agropecuarias de ocho periódicos colombianos, Baletín de Investigación no. 9 (Bogotá: Instituto Colombiano Agrope cuario, Departamento de Ciencias Sociales, 1971).

83. Hermann Felstehausen, "Economic Knowledge, Participation and Farmer Decision Making in a Developed and Underdeveloped Country," International Journal of Agrarian Affairs 5 (1968): 263-281.

84. Alfonso Ruanova, "Content and Readability of Some Latin American Agricultural Magazines" (M. S. thesis, University of Wisconsin, 1958).

85. Mario Cordero Rodríguez, "Anâlis is de contenido de los suplementos agropecuarios de dos periódicos de Costa Rica" (Tesis Periodística, Universidad de Costa Rica, 1973).

86. Seth Spaulding, "Communication Potential of Pictorial Illustrations," AudioVisual Communication Review 4 (1956): 31-46.

87. Alfonso Ruanova, op. cit.

88. Abdo Magdub, "Close Procedure; Its Application as a Tool for Measuring Readability in Spanish Agricultural Information" (M. S. thesis, University of Wisconsin, 1966).

89. Luiz Fonseca and Bryant Kearl, Comprehension of Pictorial Symbols: An Experiment in Rural Brazil (Madison: University of Wisconsin, Department of Agricultural Journalism, 1960).

90. Susana A maya, "A Plan for Empirical Testing of the Spaulding Readability Formula for Colombian Agricultural Publications" (M. S. thesis, University of Wisconsin, 1959).

91. Jaime Gutierrez Sanchez, op. cit.

92. Ibid.

93. Allan R. Brewer-Carias, op. cit., p. 88. 



\title{
THE RIGHT TO RECEIVE COMMUNICATIONS: \\ A THOUGHT WORTH ENTERTAINING \\ DON R. LE DUC
}

"There's glory for you!"
"I don't know what you mean by 'glory, ' "Alice said.

Humpty Dumpty smiled contemptuously. "Of course you don't--till I tell you. I meant 'there's a nice knock-down argument for you. "'

"But 'glory' doesn't mean 'a nice knock-down argument, '" Alice objected.

"When I use a word," Humpty Dumpty said in rather a scornful tone, "it means just what I choose it to mean, neither more nor less."

"The question is," said Alice, "whether you can make words mean so many different things."

"The question is," said Humpty Dumpty, "which is to be Master--that's all."

\author{
Lewis Carroll \\ Through the Looking Glass
}

The question here would seem to be whether "right to communicate" can be mastered and made to convey some generally understood legal doctrine, or whether it must remain simply a "glory" term invoked to criticize those who urge other priorities in controlling the flow of national and international communication. According to the fundamental law of most modern nations, a right to communicate or some variant of freedom of speech is not only recognized but already guaranteed to every citizen in the broadest of terms. 
The First Amendment to the Constitution of the United States, for example, pledges that,

Congress shall make no law abridging . . the freedom of speech, or of the press; or of the right of people peaceably to assemble, and to petition the government for a redress of grievances.

The constitution of the Union of Soviet Socialist Republics is even more explicit, declaring at Chapter $\mathrm{X}$, Article 125, that,

The citizens of the U.S.S.R. are guaranteed by law (a) freedom of speech; (b) freedom of the press; (c) freedom of assentbly, including the holding of mass meetings; (d) freedom of processions and demonstrations. 1

Similarly, Chapter III, Article 87, of the Chinese Constitution maintains that,

Citizens of the People Republic of China enjoy freedom of speech, freedom of the press, freedom of assembly, freedom of association, freedom of procession and demonstration.

In Yugoslavia, Third World in orientation if not in political philosophy, Chapter III, Article 40, of the national constitution promises citizens that,

Freedom of the press and other media of information, freedom of association, freedom of speech and public expression and freedom of public meetings shall be guaranteed.

Among the more typical Third World nations, the Indian Constitution states at Part II, Article $19(1)$,

All citizens have the right of freedom of speech, assembly, association, movement, residence, property and profession.

Mexico pledges to its citizens at Title I, Article 6, that,

The expression of ideas shall not be subject to any judicial or administrative investigation.

Although this brief sampling of free speech guarantees might be extended for several more pages without difficulty, even this short survey should suggest the degree of commonality among governments in acknowledging their responsibilities to citizens seeking the right to communicate. Acting upon this apparent unanimity in national law, the newly formed United Nations began to codify this consensus through a series of international declarations that reached beyond the traditional "law among nations" approach to extend free speech guarantees directly to each member of mankind. 2

Article 19 of the Universal Declaration of Human Rights, adopted by the United Nations in 1948, states,

Everyone has the right to freedom of opinion and expression; this right includes freedom to hold opinions without interference and to 
seek, receive and impart information and ideas through any media and regardless of frontiers. 3

Similar free speech rights were affirmed in the International Convention on the Elimination of All Forms of Racial Discrimination in 1965, and recognized in the same general terms at Article 19 (2) of the International Covenant on Civil and Political Rights in 1966:

Everyone shall have the right to freedom of expression; this right shall include freedom to seek, receive and impart information and ideas of all kinds, regardless of frontiers, either orally, in writing or in print, in the form of art, or through any other media of his choice. 4

As laws of nations of the world nearly universally affirm the right of free speech, why have these international and numerous other regional and multinational proclamations of nearly identical human $r i g h t s$ on a worldwide basis had so little effect in increasing the flow of communication either among individuals within many nations or among nations themselves ${ }^{5}$

Ironically, it would appear that international accords in the field of freedom of expression have been difficult to achieve and impossible to enforce primarily because of a fundamental breakdown in communication among the various national representatives to such international conferences and assemblies.

A pioneer communication researcher in the United States, Franklin Fearing, has pointed out the essential nature of "shared meaning" to the process of communication, declaring that responses to stimuli in communication situations are "dependent upon the totality of cultural and personality factors which each respondent brings to the situation. "6

Legal quotations can be extremely deceptive when used as "universal" symbols, for although a constitutional provision can be translated into many languages, generally it can be fully understood only in the nation in which it was drafted. The reason is that all translation quotes legal provisions out of context, conveying only the denotative sense of terminology to those who have a tendency to add connotations drawn from their own legal experience. Such domestic "glossing" of foreign law precepts can be extremely misleading, however, for jurisprudence is not a body of semantic analysis but a collection of decisions or traditional interpretations that define each abstract term in relation to the conflicting values it either supersedes or is inferior to in that society.

For example, the Soviet Constitution prefaces its free speech grant by stating that freedom of expression should be exercised, "In conformity with the interests of the working people and in order to strengthen the socialist system,"7 whereas the Yugoslavian Constitution adds at the end of its free speech pledge that "These freedoms and rights shall not be used by anyone to overthrow the foundations of the socialist democratic order determined by the Constitution, to endanger the peace, international cooperation or terms of equality, or the independence of the country." 8

Such qualifications might be viewed as a cynical ploy to give the impres sion of legally protected, robust, and open debate in societies still shackled by some 
degree of governmental censorship. Yet, while repression of free speech is certainly reprehensible, it does not necessarily follow that these limitations are stated either "cynically" or as a "ploy." The problem is simply that all of us are so culturally bound to certain symbols representing the highest priority of legal rights that it is difficult to accept the fact that other societies may accord conflicting values a higher status. Therefore, those educated in the Western tradition of jurisprudence tend to see others using the same symbols with a different set of priorities as perverting intrinsic meanings, rather than as simply adding cultural connotations to abstract legal concepts.

This lack of understanding is not confined to confrontations between the Western and Communist bloc nations, for, as one scholar recently pointed out, the concept of free speech as an individual right of primary importance is as alien to much of the Third World as it is to a vast majority of Communist nations.

Asian and African tradition has been as one from millennia in stress" ing the primacy of the group, assigning essentially role-playing functions to the individual and keeping thought subordinate to custom and a uthority. ...

Bills of human or civil rights on the order of those taken for granted in the West and registered explicit]y in the Chartex of the U.N. and related international documents as mankind's common heritage will therefore continue to be as deceptive to the real state of affairs as they have been in the last decade. 9

This all seems to suggest that right to communicate will always remain an abstract expression of natural law, incapable of clear definition except within the practices of each nation-state. It might suggest, however, with equal validity that the term right to communicate is simply too broad in itself to be analyzed, and requires instead that cach separate element of this right be examined individually.

A very limited and precise series of surveys along this line would seem necessary because unfortunately, right to communicate not only is without any significant body of universally accepted legal principles but lacks even a fully developed set of national communication law concepts to serve as a foundation for the creation of such a body of international law. In the past each nation has been able to resolve its own unique free speech controversies without regard for the philosophical symmetry or even the general comprehensiveness of the system of communication rights and responsibilities that has evolved from those determinations. The development of universally acceptable communication law principles will demand far more than this, for no precept of this international law will be able to be drawn from or validated by a single set of societal norms. Nor will it be possible to postpone resolution of any potential controversy by relying upon its eventual determination through similar reference.

If a body of universally understood legal doctrine is ever to emerge in the field of international communications, scholars must begin by developing a framework to transform each of these implicit national communication values into a series of explicit jurisprudential principles. Because most major conflicts in international law seem to have involved mass media rather than personal communication rights, this type of framework might focus initially only upon those channels of communication that carry public rather than private messages. 
The process of analysis might be simplified still further by the fact that each set of national broadcast laws must proceed from the same underlying limitation: a finite resource of spectrum channels. If the national allocation of spectrum space is available to anyone who chooses to operate transmission equipment, the result will be a pattern of interference that will make reception of any transmission difficult if not impossible. As a result, every nation through whatever licensing process it employs has adopted a general principle that the paramount right in telecommunications is not the right of an individual to transmit through a telecommunications channel but the right of the public to receive telecommunications service.

Given the prescnt system of spectrum distribution, then, there can be no absolute rights of freedom of expression through telecommunication channels, for each allocation or grant of channel access must be weighed in competition with the value of all other communication services thereby denied access to that channel.

A second clement common to all systems of telecommunication law is the principle that the public has a "right to be informed," at least as to those policies and programs favored by its government. There is wide variance in defining what other programming constitutes useful or even proper information, ranging from narrow restrictions upon obscene or fraudulent commercial practices in most Western nations, to either broader restraints, or simple refusal to purchase, produce, or carry any news or entertainment programming not conforming to national standards in many non-Western nations, but each set of laws is hased upon the same underlying "right to information" concept.

Thus, in reality, a universal covenant to guarantee cach citizen of the world the right to information is presently a rather meaningless exercise in statesmanship, for the crucial question is how that nation will define the term information. Similarly, a covenant declaring that each member of mankind has the right to communicate through telecommunication channels is equally meaningless unless it is augmented by a detailed, comprehensive set of priorities describing how each nation should allocate its limited spectrum resource to provide such access.

A number of other equally demanding questions must be resolved if right to communicate is to be made universally comprehensible. How, for example, can we distinguish among purely informational, editorial, or documentary, cultural or purely entertainment programming content so as to end the usage of the sterile abstraction "communication" or "message" to describe content so disparate in its societal effects? How can we build into any system of legal analysis the flexibility to evolve with technological changes that augment the number of telecommunication channels available to each nation and thus erode the validity of legal principles based upon channel scarcity? And most significantly, how can we proceed beyond the stage of defining existing telecommunication practices to the point of gaining acceptance for realistic international agreements that might attempt to modify those existing practices that tend artificially to inhibit the flow of communications on a worldwide basis?

During the International Broadcast Institute annual meeting in Cologne, Germany, in September 1975, the Right to Communicate Committee adopted the following description of the concept being discussed:

Everyone has the right to communicate. It is a basic human need and is the foundation of all social organization. It belongs to individuals 
and communities, between and among each other. This right has long been recognized internationally and the exercise of it needs constantly to evolve and expand. Taking account of changes in society and developments in technology, adequate resources-human, economic and technological--should be made available to all mankind for fulfillment of the need for interactive participatory communication and implementation of that right. 10

The remainder of this short paper. will. focts on only the last sentence of this description, relating to the "interactive participatory" nature of this right in one specific application, that of the right of various national broadcast audiences to receive entertainment programming.

\section{THE RIGHT TO RECEIVE ENTERTAINMENT PROGRAMMING}

There are a number of reasons for analyzing this particular right of audiences in some detail. For one thing, this right is one seldom considered by serious scholars.

Recently, for example, Unesco prepared al elaborate questionnaire to be completed by officials of various governments throughout the world to determine the degree of protection accorded specific free speech activities. Although this method for isolating individual national attitudes toward specific free speech rights is very useful, the makeup of the questionnaire itself reflected a rather typical emphasis on one aspect of communication to the exclusion of all others.

The questionnaire raised a number of interesting points about national attitudes toward the transmission and reception of information through individual. and telecommunication channels, but it was relatively silent about national policies regarding entertainment programming. Needs of the "great mass of mankind," which have been described as "cultural" but more honestly should be termed as "entertainment," have generally been disdained or treated lightly by communication scholars, in part because scholars tend to revere both the imparting and receiving of information, and therefore tend in a very human fashion to attribute to others their own particular biases. Yet, it would seem that the argument could be made, based upon national experience not only in the United States but in every nation where options have been accorded mass audiences, that,

The right to communicate is less meaningful to most men than-The right to receive communication.

And the right to receive information is less valuable than-The right to receive entertainment.

In addition to supplementing the rather meager research efforts in this area of special significance to modern man, this type of inquiry would also tend to trigger honest and forthright responses from national broadcast administrators. Almost a decade ago Harold Mendelsohn, in his book Mass Entertainment, advanced an explanation for the hostile attitude most intellectuals, educators, and administrators seem to have toward this type of mass media programming. 
The influences of Greco-Roman morality, Hebraic-Christian concepts of sin, Catholic and Protestant aesteticism. Puritan dogma, secular royalism, liberalism and reformism, and ideological Marxism either singly or in combination serve as foundation stones for the strength and diversity for the attack on mass media entertainment. 11

It is this basic bias that Elihu Katz has been challenging with his perceptive studies of gratification of human needs through the use of mass entertainment materials.

Inquiries of national governments concerning their dedication to the proposition that "all citizens should have adequate facilities for imparting and receiving information" are in most cases on familiar and comfortable grounds, because every government wishes to inform its citizens of its policies and to allow for sufficient feedback so it can determine whether these policies are understood and being effectively carried out. If, instead, government communication regulators were asked to what extent they were willing to allow the public to exercise the right of escape from what at times may be an overburdening flow of information and to gratify their needs from other communication options available to them, we might have more insight into the concern of that particular government to accord its citizens true freedom of communication choice. A federal court in the United States recently declared that "the right to receive diverse programming should not be limited to ideas and information, but should apply with equal force to the representation of entertainment formats, since entertainment itself provides a significant social, if not communication function." 12

\section{A PROPOSED "RIGHT TO ENTERTAINMENT" QUESTTON}

If this type of inquiry were to be attempted, some of the following questions might be usefully put to broadcast and telecommunication administrators.

Every person or social cultural community requires cultural information from the outside for survival and seeks gratification of a number of needs through the entertainment options available. The basic human need for entertainment generates a number of specific issues:

1. How should cultural or entertaimment needs be determined for a person or for a social cultural group? Axe there universal, basic, cultural or entertainment needs for literate/illiterate, young/old, male/female, traditional/modern?

2. How should access to available cultural entertainment material be accomplished for persons, sociological communities, regions, etc.?

3. Do certain categories of people have special requirements?

4. What are the appropriate channels for various types of cultural or entertainment exchange patterns among communities, regions, and international structures?

5. What are the indicators of balanced cultural or entertainment flow in a region and in the world? 
6. What should be the test for value for citizens seeking cultural

or entertainment programming of different types: sports, documentaries, action-adventure, situation comedies, and other genre?

7. Who should formulate and apply these tests?

8. What ought to be the role of audience research and feedback in seeking or attempting to satisfy public needs and augment the exchange and flow of entertainment a mong cultural groups and among nations?

9. How can communication regulatory apparatus be designed to minimize the tendency of bureaucratic inertia to restrain the expansion of communication channels and the flow of communication?

10. How can communications control be made more sensitive to the needs and demands of various segments within a society?

11. How can existing entertainment industries such as film, stage, publication, and musical entertainment be encouraged to provide a broader range of creative products for use in expanding telecommunication channel options?

12. To what extent must national regulation protect the native enter tainment industry from foreign competition, and how can this protectionism be reviewed adequately on a continual basis so that it does not unnecessarily restrain the freedom of choice of the citizens within that nation?

\section{JUSTIFICATION FOR SUCH RESEARCH}

What would be the advantages of research focusing so narrowly upon the right of audiences to participate in the selection of their entertainment programming and to exercise the right to interact with broadcast administrators in making this process an effective means of escaping from information overload? It is interesting in itself that this question must be raised, and answered with sufficient disclaimers so as to purge the argument of any taint of "cultural imperialism."

It is true, of course, that cach nation's capacity to provide domestic audiences with entertainment programming is determined in large part by factors not correctly within the control of that nation. For example, presence or absence of a vigorous film or record industry; the pool of trained technicians and artistic talent available to create such programming; the foreign markets that might be expected to help defray the expenses incurred in such production; the economic base available to support such programming; foreign sources of programming suitable for domestic transmission; each of these in part determine the relative ability of each nation to satisfy the demands of its audience for such programming.

It also must be conceded that governments might use entertainment programming as a "bread and circus" technique to distract citizens from shortcomings in their national administration. Equally, of course, each nation must be concerned with the long-term as well as the short-term implications involved in satisfying public demands for entertainment programming, at times deferring immediate 
gratification from foreign sources so as to build the capacity to provide such programming domestically.

Granted these essential disclaimers, it still can be argued that, consistent with each nation's broadcast programming capacity and its long-range national. programming objectives, the interest of its broadcast administrators and regulators in determining the entextaimment needs of national audiences and seeking to satisfy these needs within that capacity remains a cruclal element, one that determines that system's responsiveness to its citizens' right to communicate. It is not suggested that these needs or interests should supersede all other communication priorities within any nation. It is suggested, though, that these needs should not be ignored by administrators, nor summarily dismissed as being inconsequential or unworthy of scholarly investigation.

Those communication models that have treated broadcast or cable simply as an extended channel of personal communication, or as another manifestation of information theory in operation, have distorted both the manner in which such services operate and their societal functions. What is necessary, then, is to broaden the scope of these investigations to a point where they cover all elements of the right to communicate, including the right of citizens to participate and interact in the creation and programming of entertainment on national radio, television, and cable channels.

\section{SUMMARY}

This brief survey would suggest the following points:

1. The right to communicate is not a single unified doctrine; rather, it is a descriptive term for a number of individual and specific com munication rights.

2. National communication statutes, being essentially denotative in character, do not serve as a reliable standard for the comparative studies necessary to isolate each of these individual communication. rights.

3. The type of questionnaire designed by Unesco, with its emphasis upon national administrative attitude and behavior, rather than upon. specific broadcast code provision in each nation, is very useful for this type of survey research.

4. However, the present questionnaire, with its emphasis upon the information function of communication and the exercise of communication rights, excludes a substantial and important element vital to citizens of all nations.

5. Information relating to the receptiveness of broadcast and cable systems to the needs and demands of citizens is a significant element of the "responsiveness" and "interaction" aspects of the right to communicate principle as described by the IBI. working committee. 
6. Through the isolation of principles of basic communication law common to all nations, a synthesis of the present elements of the right to communicate can be formulated on a more universal or international basis.

7. Once this synthesis has been formulated, it will be possible to communicate in a more useful fashion on an international basis, both in isolating existing right to communicate practices and in promoting the broadest possible exercise of communication rights by all citizens of the world.

It certainly would be reasonable to argue that even if this type of research were to raise the level of understanding at international telecommunication law conferences concerning right to communicate, this understanding in itself would not produce international accords to guarantee these rights to each citizen of the world. Yet, it would seem equally reasonable to contend that lack of understanding about the principles contained in this term is virtually a guarantee of continuing discord. Under these circumstances, any research of this type would seem worth the effort. 
1. Each of these quotations has been taken from Leslie Wolf-Phillips, ed., Constitutions of Modern States (New York: Frederick A. Praeger, 1969). Phillips has used the official translation of the Soviet constitution of 1936 , with revisions through 1968; the official translation of the constitution of the People's Republic of China of 1954, with revisions through 1968; the official translation of the constitution of the Socialist Federal Republic of Yugoslavia of 1963; the constitution of the Republic of India, 1950, with revisions through 1968; and the constitution of the Mexican United States, 1917, with revisions through 1965.

2. Since the time of Hugo Grotius, De Jure ac Pacis (1625), international law experts have been in general agreement that nations and not individuals were the proper subjects of international law. Thus, to declare that individuals had certain inherent rights as citizens of their own nation in terms of international law was a revolutionary idea, for as William W. Bishop, Jr., points out in International Law (New York: Prentice-Hall, 1953) p. 209, "A state's treatment of its own nationals would not at the present time ordinarily involve any question of international law and the individual would have no enforceable rights under international law arising from such treatment." The United Nations sought to sidestep this problem by making its "human rights declarations" treaties, and thus enforceable at international law when subscribed to by each nation. The theory may be sound, but nations in general have been extremely reluctant to ratify treaties dictating any aspect of their domestic policies.

3. Adopted by the UN General Assembly, Resolution 217 A, December 10, 1948.

4. Racial Discrimination convention, adopted by the UN General Assembly, Resolution $2106 \mathrm{~A}$, December 21, 1965; Civil and Political Rights covenant adopted by UN General Assembly Resolution 2200 (20), December 16, 1966.

5. Among the regional and multinational agreements adopting similar protections for free speech have been the European Convention on Human Rights (1959), the American Declaration of the Rights and Duties of Man (1948), the American Convention on Human Rights (1969) and the Proclamation of Teheran (1968).

6. Franklin Fearing, "Human Communication," Audio-Visual Communication Review 10, 3(1962): 78-108, reprinted in Lewis Anthony Dexter and David Manning White, eds., People, Society and Mass Communications (New York: Free Press, 1964), p. 41.

7. Soviet Constitution, Chapter X, Article 125.

8. Yugoslavian Constitution, Chapter III, Article 40.

9. Adda B. Bozeman, The Future of the Law in a Multicultural World (Princeton, New Jersey: Princeton University Press, 1971), pp. 162-164.

10. Working Group IV, IBI Annual Meeting, September 3, 1975, "The Right to Communicate" (mimeo), p. 2.

11. Harold Mendelsohn, Mass Entertainment (New Haven: College and University Press, 1966), p. 31 .

12. WGKA v. Federal Communications Commission, 436 F 2d 263 (DC, 1970). 



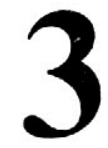

BASIC ISSUE AREAS: RESOURCES, NEEDS, RIGHTS 

There has always been an inherent but not always recognized and certainly seldom fulfilled relationship between resources, needs, and rights. Com munication is recognized as a resource we all depend upon for social intercourse, for our common humanity. The Universal Declaration of Human Rights has recognized this since 1948. Communication since then has been regarded as an essential human resource, to be planned and developed and used by individuals and societies.

Needs without resources to meet them give rise to continuing social frustration. Over the past decade or so there has been increasing attention to human communication needs in a variety of contexts. In the developing world, the reed for participation in the planning and implementation of such development programs as population planning, agxiculture, education, and public health is long recognized. But recognition is not enough--the communication resource for participation must be available. In many parts of the world we still see that communication resources are scarce; in other parts of the world they are perhaps in too much abundance. The great differences in the communication resources available to individuals and communities around the world have had a profound effect on the development and exercise of the right to communicate.

One of the great tasks in development of the right to communicate is the determination of how the human and technological communication resources of the world can be used to enable everyone to have a balanced, participacory right to communicate.

Communication needs as perceived vary widely from person to person, from society to society. The process of determining these needs is important, as is the priority-setting function and the resource-allocation function. Communication needs inevitably come up against some hard economic, political, and social values that may at least hamper meeting those needs. The technological ability to meet most communication needs seems to be available, given economic, political and social support, but we must be able to define those needs in terms sufficiently precise for the technologists to develop the communication systems needed. In the past, it has often been the technology that shaped the communication system. We are just entering the time when ascertainment of communication needs is preceding and guiding the development of technology, as evidenced by programs in Canada and in the PEACESAT demonstration in the Pacific Islands.

Communication needs may be in conflict: an individual may have need for certain kinds of information, yet his government may feel the need to exclude such information from its society to protect its culture or cohesion. The need for certain kinds of information about other people may well conflict with another person's need or right of privacy, the right to be left alone, to not be communicated 
about. There are a great many questions that arise in communication needs, as well as in the resources required to meet those needs.

The essays in Part III address a broad range of issues concerning communication needs and resources, and their relationships with each other and with the emerging right to communicate. The point is made over and over in the essays, for example, that communication resolurces are needed to give meaning to the right to communicate; yet it is realized that such resources will never be fully available, that they are and will continue to be unequally distributed, and that there would be other real contraints on the right to communicate even th the facilities were available. It becomes very clear from the essays that the resources for the right to communicate must exist fox the right to have full meaning. The authors differ on the means to provide the resources.

Another recurring point is that a right to communicate has special relevance to developing countries and countries in strife. We are told that during strife, the right to communicate becomes more important, and during rational development the right to communicate is essential for the kind of participation by the people that is needed for successful development progxams. The concept of participation, together with the need for two-way communication, is stressed in several papers. Third World concerns over cultural impexialism are examined in the right to communicate context, with stress on national control of communication and on development of communication policies at national and regional levels.

Perhaps the most anguished parts of the following essays deal with the differences between abstraction and reality, between theory and practice in the right to communicate context. Coming to grips with the realities in various cultures under a wide range of sociaJ and political organizations is clearly one of the great challenges in development of a multicultural right to communication; and, as several of the authors noted, we have a long way to go.

Ithiel de Sola Pool wonders whether the right to communicate is really just a needless duplication, and even dilution, of presently accepted freedoms. He rejects the idea, and then notes that "no one can ever have all the facilities, resources, and access to make himself fully effective in his exercise of speech. " Pool examines the difference between a freedom (you can if you can) and a right (someone or something must make sure you can). In a communication resource-scarce society, the distinction is important, Pool notes, but in a communication-resource-abundant society it is not so important. "There is no way in which all demands for access to the major media can be met," he says. The claims far exceed the resources, even in a communication-rich society. Social policy can do much to alleviate the frustration that results, Pool says, and he notes parallel patterns in such fields as economi.cs, using the right-to-work model. Communication is most hopeful, Pool says, because it calls on so little in energy and physical resources. The right to communicate, he continues can be bought at a price in quality of service in certain elite sectors. The author then develops distinctions among rights, duties, freedom, liberty, and power. The right to communicate, to be effective, must impose an obligation somewhere, and Pool prefers a government-funded medium rather than the private media. A collective resource will not force others into carrying messages they abhor. In any case, a right to communicate must have free speech as a prerequisite. "Without free speech and free press there can be no right to communicate." 
Asok Mitra begins his essay with a review of the history of the right to communicate idea and relates that review to "the nineteenth-century tradition of the one-way street." He notes that information imbalance occurs when available feedback is ignored. He then turns to an examination of "little communication empires." Observing that "an administrator somehow feels uneasy at the bottom of his heart about this business of communication," he recounts a story of a conversation in a small village between an administrator from the city and the village inhabitants. In the last section of his essay, Mitra reviews the case for development journalism and provides a model of it "on the assumption that the right to communicate will be more than feedback or participatory and in effect will be fully interactory."

B. M. Firsov opens his essay with the observation, "to live in society, to reproduce themselves and to develop the complex network of social relations, people have always needed the continuous acquisition and renewal of their sociocultural knowledge." Throughout human history the ways and means of acquiring this knowledge have varied. In his cxamination of the right to communicate, Firsov notes that the word communication itself has many meanings but is usually closely associated with social interaction. He points out that "the fact that scientific and technological progress is different in its social consequences for different social systems is of great philosophical importance." As other authos have done, Firsov documents the imbalance in world communication $f l o w$, and he discusses some of the technologies that may be used to deai with this problem in the future, Firsov concludes, "The conditions of real liberation of man are connected with the extermination of all the kinds of social and national oppression and exploitation as well as with the establishment of a genuine people's power and with their confidence in the future. . . interacting, participating and shared communication."

The essay by Donald McL. Lamberton uses a traditional approach in economics on the allocation of resources applied to communication. The second stage of analysis is when the effects of communication must be taken into account. This is where traditional economics is inadequate. Economics seeks stability, information creates instability or change. "Information resources," Lamberton says, "may already have become the most important basis of economic and political power." A detailed functional classification is called for, opening up economic analysis of information. A right to communicate that gives equal access to information may not result in equal benefits, Lamberton says, because of other inequalities built into the system: education, size, capacity to control, and so forth. He notes that the right to communicate and information policy are intrinsically linked with government, and government could subvert either by wrong emphasis or by outright control for its own purposes.

Hamdy Kandil tells the tale of Sherif Al-Akhawy of Radio Lebanon to illustrate the communication situation in the midst of a civil war, and especially with a state-owned radio system. Kandil notes that when government does not make its presence felt in such a situation, the radio cannot, and hence the people lose their voice. But what is even worse, Kandil says, is when all political parties have their own voices but there is an "absence of a voice that represents the people." The needs and the resources may be clear but the political and economic structures must be such as to permit the use of the resources to meet the communication needs. Even in strife-torn countries, the author contends, the right to communicate is significant. "Individuals and groups should know the value of the right to communicate 
and that without it, no sound sociopolitical structure could survive." Using examples from the Middle East, Kandil says that "political relaxation in the international scene helps the possibility not only of communication across borders but also the practice of the right to communicate inside the country itself." He cites Gulf states communication policy and exchange of information between those states and with other countries in the world as developments from the October war. He notes that a communication plan can be a useful means to ensure "maintaining the culture of the area and exercising on equal footing the right to communicate (or not to communicate) among states." Sophisticated technology needed for a multicultural right to communicate "could not be realized unless there is a shift in power and in wealth." Another key point is that the right to communicate calls for participatory approaches, especially in development communication, and that the "right to communicate cannot be practiced unless the governments are ready to apply to their countries what their delegates proclaim on international rostrums concerning rights and liberties." Theories and abstractions on the right to communicate may serve a purpose, "but at a time when Beirut is burning," how can we "identify the dimension of that right?" 


\section{SCARCITY, ABUNDANCE, AND THE \\ RIGHT TO COMMUNICATE}

ITHIEL DE SOLA POOL

\section{A GENERAL STATEMENT OF THE THESIS}

Freedom of speech is perhaps the central concept of modern liberalism. It is a criterion against which a libertarian holds up any policy for judgment. There are various other desiderata for a free society, such as freedom of assembly, freedom of the press, establishment of post offices and post roads, and habeas corpus. Each of those concepts describes a political practice with merit in its own right, but each is also important, above all, because of its specialized contribution to the global concept of freedom of speech.

Does the term the right to communicate describe such a distinctive contributory political practice, or is it redundant verbiage to describe less precisely something that is already better described in terms of freedom? One worries about such multiplication of terms. In the world today, freedom of speech is a controversial political concept. Authoritarian regimes and ideologies snipe at it, insisting that free speech is not absolute, that it is not as important as other things such as the right to eat, or that it can exist only under special political and economic circumstances. In response to such political attacks on the liberal concept of freedom, there is some tendency to retreat to alternative formulations, for example, "free and responsible press" instead of "free press," or "freedom to" instead of "freedom from." One worries whether the introduction of the term the right to communicate is not a way of denigrating freedom of speech by introducing the argument that various kinds of power and access are equally or even more important than a "merely nega tive" freedom.

That is an argument I categorically reject. The primary criterion and sine qua non of any libertarian policy is that it provide freedom from interference with exercise of speech. No one can ever have all the facilities, resources, and access to make himself fully effective in his exercise of speech. That is too bad, but it is the nature of life. The problem can be ameliorated in ways that we shall see below, but it can never be avoided. "Freedom of speech" implies only that whatever the resources a person or group can mobilize with which to express themselves, they may do so freely without control.

If the phrase "right to communicate" can have a legitimate and important meaning different from "freedom of speech," the difference between the terms freedom and right is that while one's freedom is a constraint on others against interference by them it levies no positive obligations on them to assist in any way. A right is a claim on others. It imposes an obligation on them to do something or to yield some resources. It follows that in a libertarian society there is, under most circumstances, a freedom of anyone to communicate and, under a much more restricted set of circumstances, also a right to communicate. 
The distinction is particularly important where there is scarcity of resources. The distinction tends to disappear where resources are abundant. When the Founding Fathers wrote about freedom of speech and of the press in the First A mendment, they did not to any extent consider the question of the right to communicate because they assumed that the necessary resources to communicate were generally abundant.

The prototypical situation for the exercise of freedom of speech was a man expressing himself by word of mouth in his congregational chapel, village tavern, or town square. There was no resource he needed to enable him to do that. All he required was that no one should interfere. The exercise of freedom of the press was not quite that easy. If, however, a man belonged to that small minority of individuals who were literate, ambitious to write, and motivated to bring out their views in print, the odds were that he could assemble the necessary resources to make a try at it. The chances of success on a continuing basis were small. Most newspapers folded after a few issues, but those who were motivated had a chance to try to attract readership and support. The main unfair obstacle a would-be printer and publisher had to fear was governmental repression.

Ironically, with the vast increase of communications facilities in modern society, our consciousness of scarcity of resources has grown, too. The most obvious example is the radio spectrum. Our forefathers were not concerned about it: they did not know it existed. Today we use it on a massive scale but there is not enough of it to satisfy the demand. In a similar way the growth of giant newspapers has generated discriminations that did not exist before. At the end of the eighteenth century, a newspaper was typically a single sheet, often written by a single man. Today it may have a hundred pages and contain expressions or views by scores of individuals. Nonetheless, the very importance of a major metropolitan newspaper makes it a unique platform not replaced by the handbill or underground paper that a dissident can freely issue. Hundreds or thousands of persons would like to have the platform of the standard newspaper available to them, but oniy a small subset get it. There are numerous frustrated individuals who would like to see their views in the New York Times or on the front page or editorial page of their local paper. The massive audience that these special platforms possess makes them desirable and scarce resources, something quite different from mere access to a printing press. The situation regarding the television networks is even worse,

There is no way in which all demands for access to the major media can be met. The cumulative claims on other individuals represented by each individual's desire to communicate far exceed the resources available. People are bound to feel frustrated that their freedom to communicate cannot be translated into a right to the particular platform they seek. And yet there is much that social policy can do to improve and extend the opportunities of people to communicate. That is the legitimate goal of those who address themselves to the issue of the right to communicate.

The pattern of development that we have described regarding communication can be matched in a number of other fields. There has been a similar sequence in regard to economic freedom and the right to work. Classical economic liberalism was concerned with allowing people to exercise their skills and initiatives without interference. That was an unexceptionable goal for people who had adequate resources with which to operate. However, people without such resources thought freedom of enterprise hollow and responded with the slogan "the right to work." 
That was more than a claim to be allowed to work, as it was presented in the movement of 1848; it was a claim on others in society that a job be provided.

At some level claims such as the right to work or the right to communicate become impossible to satisfy. "There are limits to how far society can make scarce resources available. Public policy can be designed to some degree to distribute and redistribute resources more equitably than they would be otherwise, but despite the dreams of utopians, a right can never be as absolute as a freedom.

In the nineteenth century, for the first time in human history, it occurred to utopians that ali might live in a condicion of abundance rather than one limited by scarcity. Aristotle in his discussion of democracy and oligarchy took it for granted that the poor are the many and the rich are the few. Today as we discuss the war on poverty we assume that the problem is to eliminate the sufferings of that minority who are below the poverty Jine. Until the ninetecnth century no one considered that a goal of society could be elimination of want.

In the nineteenth century, thanks to the Industrial Revolution, there came into view the grand prospect of unlimited progress Jeading to an economy of abundance. The young Marx described the communist world as one in which all constraints of resoumces would disappear and man could realize in full his potential as he wished. Socialism on earth replaced salvation in heaven as a possible dream.

It was not a totally foolish notion, though today we are more disillusioned. Sophisticated futurists now talk of "the limits of growth" and the crisis of resources. We recognize how elastic human demands can be. Even those in the affluent jet set do not find their demands satiated. It takes very little arithmetic to see that 10 billion people will not easily be able to enjoy the standard of living of the the jet set.

Yet it is too easy today to be pessimistic. As a first approximation the notion of an economy of abundance has something to it, as does the notion of unlimited progress. The kind of poverty that has been the normal condition of human existence may well be eliminated, and continuous improvement in the human condition is a reasonable expectation. There may be limits to the ergs we use but not to the ingenuity with which we use them.

Clearly, vast increases in access to communication are possible. There is nothing to prevent the creation of a society in which everyone has substantially more access to means of communication than any but the top 2 or 3 percent have today. Broad band telecommunications, xerography, and other devices promise a future that is better approximated by the utopian fantasies of the nineteenth century than by the antiutopian pessimism of the present.

The expectation of progress is particularly plausible in regard to communication because it is so little dependent upon consumption of energy and physical resources. One of the characteristics of the $1940 \mathrm{~s}$, 1950s, and 1960s was that labor-intensive services became exorbitantly expensive while manufactured goods remained relatively cheap and utilities, including both energy and communication, were extraordinarily cheap. In the 1970s and probably in the 1980s and 1990s, as a result of shifts in the terms of international trade and in resource shortages, energy and goods joined labor in becoming expensive. The cost of processing of 
electronic bits of communication, however, has continued to fall. There is no reason to anticipate a reversal of that tendency.

Communication does, of course, use some resources, Paper has been one of the most important resources in the modern world and one that in many societies is or has been in very short supply. Until the 1950 s that was the main resource constraint upon Soviet communications. Copper also is a commodity that at times has been scarce, and it would become so again if we were dependent upon it. However, the communications systems of the future may depend more upon electronic memories and displays, and on transmission through optical fibers made of plentiful silicones. That will be increasingly true to the extent that paper and copper become expensive.

At the same time the spectrum shortage will be overcome by the availability of broad band, microwave, coaxial cable, and fiberoptical transmission. It is not unreasonably optimistic to anticipate that communication facilities and capacity will grow very much faster than population or GNP in general. The resources will increasingly exist to provide people with a variety of low-cost means of communication.

We can anticipate that in the 1990s, cable television channels will be available for rental by organized groups or individuals at costs well within the budget of ordinary people. We can anticipate that there will be low-cost video recorders capable of reading visual images onto tape or onto some other medium that will present no more of an economic obstacle to the average person than still-camera film is today. We can anticipate that long-distance and international telecommunications will cost very little more than local telecommunications: satellites and other developments are making communications costs relatively insensitive to distance. Given such increased opportunities for communication, it is entirely appropriate to consider how to make them equitably avallable. The issue is how to organize anticipated communications resources to assure equal and easy access to them by all sorts of would-be users.

For example, it is important to assure that the present communications monopolies and oligopolies in such fields as broadcasting do not establish regulations that are designed to protect them against the competition of new and more pluralistic modes of communication such as cable television. It is also important to see that monopolies in the underlying transmission facilities such as the Post Office, telephone system, or public roads are not used to constrain or restrict the types of messages, services, or usage to which the facilities are put. Although present American practice is pretty good in regard to access to common carriers, it is not completely consistent. In general, mails are not opened, but there are rules that bar pornography and unsolicited foreign propaganda from the mails. In general, the phone company pays no attention to what people say on the phone lines, but the company does have the support of the Federal Communications Commission in objecting to middlemen as wholesalers purchasing the company's telecommunications services for resale. It is hoped we can move to a policy of total and unlimited access to common carriers so long as the user does not interfere with the operation of the system.

The issue of price is more complex. A case can be made for redistributive cross-subsidization to make access to communications media more nearly equal for the poor and the rich. Alternatively a case can be made for charging its true cost for every service. Subsidization to manipulate who gets access, it may be 
argued, inevitably will be done by governments in ways designed to achieve goals other than pure justice. This paper is not the place to argue those issues or to attempt to reach conclusions. Suffice it here to note that those are legitimate issues of public policy that, subject to the limits of human fallibility, can be rationally considered with an eye to increasing the right to communicate.

One further point needs to be made: the right to communicate is bought at a price. Every institution and every policy has its advantages and disadvantages. If one adopts as a goal the equalization of access and the widespread distribution of the right to communicate, one cost is the undermining of certain exceptional, high-quality communications institutions. Elitists always have argued that privileges for those with taste and talent encourage good work, and they are right. The British Broadcasting Company subsidized by license fees puts on more excellent material that if it were broken into several self-supporting channels competing for shares of the audience and bound by limited budgets. A large number of newspapers in any city, representing a variety of views in that city, would not add up in their news gathering and editing resources to one great newspaper. Equality of access is desirable, but it has its price. There is no magic solution that will give us the best of all possible worlds. If we value a pluralistic society and are anxious to promote the right to communicate, we must be ready to pay the price.

\section{A MORE FORMAL RESTATEMENT}

The distinction we have drawn between rights and freedons is not a new one. It has been the subject of much serious semantic and philosophic analysis. The distinction here introduced is that of Hohfeld. 1

A right ${ }^{2}$ is a claim that another should do (or refrain from doing) a certain thing, such that if the other acts wrongly one may claim reparation. (Obviously if $A$ has a right, $B$ has a duty.)

A liberty, however, does not involve a claim on another; it is what one may do on one's own. If $A$ has the liberty to do a certain act, $B$ has no right to claim reparation; in Hohfeld's phrase, B has a "no-right."

To exemplify: If $A$ has rented a meeting hall for an evening, $A$ has a right in that hall and $B$, its owner, has the duty to let $A$ in. Once in, A may give whatever speech he wishes; that is his liberty, and all others have a no-right regard" ing these remarks. Perhaps this distinction between rights and liberty is still unclear. Perhaps one may object that the hearer (B) has a duty not to mob the speaker (A), not: merely a no-right. As a statement of fact this is correct, but it does not meet the point of the distinction. The duty not to mob the speaker is indeed a genuine duty, that is, it is the correlative of a right of the speaker: the right to be unmolested. But he has this right whether or not he is at liberty to talk. He always has a right against assault and battery. His special liberty as a speaker is to say what he wishes, and that is a liberty and not a right because it itself imposes no new obliga tions on others. The others are obliged neither to concentrate on what he says nor to agree. The speaker merely enjoys the liberty of choosing at will which words to string together. The distinction is logical, tenable, and not unimportant, although a given concrete situation such as that in the lecture hall may involve all concepts at once. 
Hohfeld clarifies his explanation with a diagram:

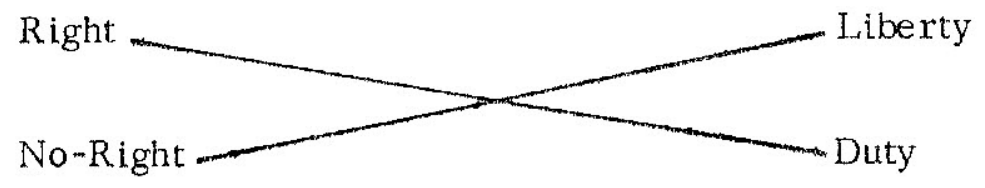

The terms vertically opposed are opposites, If a person has one of the pair he cannot in the same respect and in the same situation have the other. One either has a right to the hall, in which case one does not have no-right to it, or one has a no-right to it, in which case one clearly has no right to it. Similarly if one has liberty to talk, saying whatever one wishes, one has no duty one way or the other. Those terms are thexefore opposites. The terms diagonally across from each other. are not opposites but correlatives. They refer to the simultaneous position of the two members of the relationship. If one man has a right, another must have a duty, etc., etc. If $\mathrm{A}$ has a right, or no-right, or duty, or liberty, $B$ has in each case whatever is in the diagonally opposite corner.

Hohfeld complicates his analysis with a further set of distinctions. He introduces a kind of metalanguage for talking about rights and liberties pertaining to rights and liberties. The hall we have been talking about has been hired: $A$ has a right. $B$ has a duty. But let us suppose $A$ or $B$, or, for that matter, $C$ has right to change the legal contract between $A$ and $B$, for example, to force $A$ to give up his right or to release $B$ from his duty. Then $A$, or $B$, or $C$ - whoever may do this-has a power. A power is a right over rights and liberties. The opposite of a power Hohfeld calls a disability. This "disability" merely means that one has no power in a given set of circumstances. This pair of terms in turn has correlatives. If $C$ has a disability (in other words, no power) to change the contract between $A$ and $B$, then the latter two have an immunity. If, on the other hand, $C$ has that power, then $A$ and $B$ are laboring under a liability to have their contract changed. The diagram is as follows:

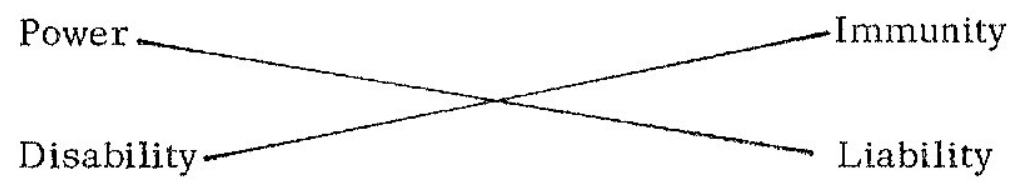

Now let us see why those distinctions are important, Let us take four freedoms:

trial by jury

free speech

democratic self-government

free love

These freedoms are clearly not commensurable. Their conditions of existence are different. The arguments to justify them are different. These freedoms may even conflict with each other. The great political disputes about the conditions of freedom 
have often been disputes about the relative values of such different kinds of freedom. Under Hohfeld's classification we can see how they differ.

Of these four freedoms, one is a right, one a liberty, one a power, and one an immunity. Trial by jury is a right. A trial before a jury of one's peers is something the defendant may claim from the court. Free speech, as we have already seen, is a libexty. Self government is clearly a power. It may involve many rights, such as the right to vote, and many liberties, but governing is itself the exercise of the power to change legal relationships. Finally, free love is an immunity. Loving, unlike speaking, is inevitably a social act invoking jural relationships of two persons. It is therefore not a freedom. What it does mean is that when two persons have themselves established certain relationships of rights, privileges, duties, and no-rights between themselves, a third party (usually the state) is disabled from interfering to change these relationships; the couple has an immunity.

To simplify our proceedings we can collapse Hohfeld's last distinction and not ask whether a right is a right over rights or whether a liberty is a liberty from duties. We can thus merge powers with rights and mexge immunities with liberties, and concern ourselves with only the first fourfold diagram examined. In other words, we can deal simply with the common distinction between positive and negative freedom. 3 Positive freedom is the right to things that others must bestow. Therefore, it involves social problems of a character not involved in negative free-dom, or liberty, which exists when certain types of sanctions are not permitted against those who do certain actions. Among these rights (or positive freedoms) we have already mentioned trial by jury and self-government; we might add freedom from having troops quartered, property, freedom from want, freedom from fear, the right to work, freedom from discrimination because of color, and the right to communicate. Among the liberties or negative freedoms, we have already mentioned freedom of speech and free love; we might add the "right" (liberty) to bear arms, freedom of press, freedom of assembly, freedom to move or travel, and freedom of association. Several of these liberties (that is, those that are immunities) are nugatory in the absence of certain rights, because they involve more than one person. 4 For example, freedom of the press is meaningless in the absence of some property rights in ink. But the corporate group having such jural relations as a property right in ink still need the immunity to publish a paper safely.

The importance of the distinction is illustrated by debates about the freedom of the press. Communists ridicule freedom of the press on the ground that certain rights that make it easier to take advantage of that liberty are very unevenly distributed in a capitalist society. They attack mere "formal freedom" and claim that their system offers more substantial freedom. Such assertions may mean any one of several things, but very often it is the contrast of $x$ ights and liberties that is meant. It will be noted that many current radical slogans appear above among the list of rights. Conservatives in turn come back with arguments designed to impugn these rights while hanging on to certain liberties.

Thus the structure of the two propagandas can be explained faixly easily. Both sides laud certain liberties, for example, freedom of speech. Certain rights, however, are anathema to each side. 'To archconservatives, the $\mathrm{xight}$ to work in its nineteenth-century sense is anathema; to extreme radicals, private property. Because onerous duties are included among the consequences of rights, rights become more controversial than the liberties. As the goodness of a liberty is apt to be an undisputed premise, the defender of a right often tries to justify his right in 
the name of a liberty. We present the right either as itself a liberty or as inextricably interwoven with a liberty into one big whole called freedom. On the other hand, the side opposing a right will stress the distinction between rights and liberties and will point out that whereas the liberty is infinitely extensible (as by definition it involves no duties on anyone else), the right is quite different. Every extension of the right to one person imposes a duty on another. The leftists make this criticism of private property, the rightists make it of the right to work.

The duty it entails is the tragic flaw of a right. "The shepherd drives the wolf from the sheep's throat, for which the sheep thanks the shepherd as his liberator, while the wolf denounces him for the same act, as the destroyer of liberty. "5 Whether a given right is called an expression of freedom or a restraint upon freedom depends on the point of view from which it is observed rather than upon the act itself. For example, the Supreme Court's ban on enforcement of restrictive covenants gave owners a right to sell by depriving others of a right to sue. In the words of Bentham: "No right without a corresponding obligation."

\section{HISTORICAL EXAMPLES}

The points we have been making about the relation of rights and freedoms can be illustrated by some historical ideological debates. We cannot illustrate them well by debates about the right to communicate, for that is a new slogan. We can illustrate them by the very lively debates about the right to work.

The right to work is a slogan that has reversed its meaning in the past two decades. The slogan first became popular during the revolution of 1848 , at which time it referred to a right to be given a job--a right whose correlative was an obligation on the state to be an employer of last resort. That slogan was revived in the United States around 1945 with the same meaning. However, by the 1960 s, employers' groups had appropriated the term for themselves and changed the meaning. It came to refer to an immunity: if an employer and worker agreed on giving a job to the worker, no union could interfere, whether or not the employee chose to join a union. That is the form of the right to work that has been incorporated in a number of state laws in the United States and against which unions have fought. In its earlier form, however, the right to work (now usually called the right to a job) was a union slogan.

The right to work viewed as a positive right to a job, not as the liberty from monopolies and corporate privileges, dates from the peak years of the French Revolution. One of the many draft declarations of rights of 1789 contained the following article: "5. Any citizen who is completely lacking in means to meet his needs should be helped by the nation." 6 Another said, "the political body owes every man the means of subsistence either by property, or by work, or by the aid of his fellow men."7 The 1791 constitution provided for public charity, but guaranteed no right to aid. 8 But in 1793, Robespierre proposed a constitutional provision as follows: "Society is obligated to provide for the subsistence of all its members, whether by procuring them work or by ensuring the means of livelihood to those who are unable to work. "9 The Declaration of the Rights of Man actually adopted that year stated: "The public aid is a sacred obligation. Society owes support to needy citizens, either by obtaining work for them, or by giving subsistence to those who cannot work." 10 After the years of reaction, this was picked up again in 1848 . On 25 February, the day after the overthrow of Louis Phillipe, the provisional government promised in a decree edited by Louis Blanc "to guarantee work to all the 
citizens."11 The National Workshops were formed, lasted a few months, and, with the ebb of the Revolution, were liquidated. The workers revolted against this liquidation, and from 23 rd to 25 th of June, Paris had fighting on the barricades. The revolt was bloodily suppressed; thousands were killed or wounded. Then in September, with the leftists already beaten, a new constitution, that of November 1848 , was debated. Mathieu proposed to add, to paragxaph eight of the preamble, the right to work. It was this notion that produced the great debate to which we have alluded. In arguing against the motion, Thiers and others proclatmed themselves for the right to relief. The motion for the right to work was beaten, and paragraph eight as adopted read:

It is the duty of the republic . . . by fraternal assistance, to provide the means of existence to necessitous citizens, either by procuring employment for them, within the limits of its resources, or by giving relief to those who are unable to work and who have no relatives to help them.

The phrase about limits of resources stands out clearly. Similar was Article 13.

Society favors and encourages the development of labor by . . the establishment by the state, the departments and the communes, of public works proper for the employment of unoccupied laborers. Society will also give aid to deserted children, to the sick, and to the destitute aged who are without relatives to support them.

A lmost all the constitutions since. World War I followed in the footsteps of these French documents and assured the right to relief. In this century this has taken the form of rights to social insurance. Among the constitutions pledging social insurance were the Weimar Constitution, 12 the Danzig Constitution of 1922,13 the Jugoslav Constitution of 1921,14 the Roumanian Constitution of 1923,15 the Esthonian Constitution of 1920,16 the Polish Constitution of 1921,17 and the Spanish Constitution of 1931.18 Constitutions since World War II have continued this practice. 19

Also closely identified with the right to work and often offered as a conservative substitute for it is the liberty to work. This compromise was incorporated in several twentieth-century constitutions. The Weimar Constitution conta.med both the freedom to choose one's work (in Article 111) and the right to work (in Article 163, section 2). More such documents, however, like the Czech Constitution of 1920,20 the Esthonian Constitution of 1920,21 the Polish of 1921,22 the Roumanian of 1923,23 the Jugoslav of 1931,24 and the Spanish of $1931^{25}$ promise only freedom to work and not the right to work. It is this freedom to work, regardless of union membership, that, under the misnomer the right to work, has been a conservative proposal of the $1960 \mathrm{~s}$, opposed vigorously by labor unions.

A full-dress debate about the right to work took pla proposed full employment bill was before the Congress. The debate faithfully echoed a similar debate almost a century before. Probably few congressmen had heard of the 1848 debate on the right to work, which took place in the French National Assem -. bly, 26 and generally they traced their arguments to much more recent sources. The advocates of the bill consciously deduced their program from the philosophy of the New Deal and the war aims of the government expressed in Roosevelt's "Four. Freedoms." The right to a job was presented as a concrete expression of freedom from 
want and freedom from fear. The opponents of the bill traced the idea of the right to work to another recent source: the Soviet Constitution of 1936, whose promise of economic rights had attracted wide attention. Despite the erroneously assumed recency of the issue of the right to work, the arguments in 1848 and 1945 were much the same.

Both in 1945 and in 1848 the economic rights exemplified by the right to work were said to be a new kind of right different from the traditional rights proclaimed by the Founding Fathers. In the earlier period Laboulaye called the right to work, the right to relief, and the right to education "new rights which our fathers did not know and which the socialists have discovered." In the 1945 debate Beardsley Ruml said that

There has been a tendency in recent years for those who desire a more widespread enjoyment of such benefits as education, housing, health, nutrition, and recreation to attach to these truly desirable fruits of social progress the high dignity of fundamental human rights.

These "new" rights are said to differ from the others in no of two ways, It is sometimes argued that the traditional rights of man were liberties or negutive rights, whereas the "new" economic rights are rights strictly speaking. Herbert Spencer said this very clearly in 1851 , although his terminology does not distinguish between the words rights and liberties.

First let us make sure of the meaning wrapped up in this expression. - -right to labour. Evidently, if we would avoid mistakes we must render it literally--right to the labour; for the thing demanded is not the liberty of labouring: this no one disputes; but it is the opportunity for labouring. . . The word right as here used, bears a signification quite different from its legitimate one--.. not something of a claim to do, but of a claim to be done unto. 27

He makes the same point aga unst public charity.

Some will assert that by satisfying the wants of the pauper, a government is in reality extending his liberty to exercise his facultics. - But this statement of the case implies a confounding of two widely different things. . . Insturing to ach the righ to pursue yithin the specified limits the objects of his desires without let or hindrance, is quite a separate thing from insuring him satisfaction. 28

\section{Also,}

In the same way that our definition of state-duty forbids the state to administer religion or charity, so likewise does it forbid the state to administer education. . . .

Should it be said that the rights of the children are involved . . the reply is that . . . their rights are not violated by a neglect of their education. For as repeatedly explained, what we call rights a re merely arbitrary subdivisions of the general liberty to exercise the faculties; and that only can be called an infringement of rights which actually diminishes this liberty--cuts off previously existing power. . . 
Omitting instruction in no way takes from a child's freedom to do whatsoever it wills in the best way it can; and this freedom is all that equity demands. 29

More succinctly and cavalierly, Henry Hazlitt in 1945 criticized the Full Employment Bill on the same grounds: that it involved an illegitimate type of positive right rather than merely negative liberties. Hazlitt said that, in contrast to the right to work, the rights in the Bill of Rights "are all liberties. "30 This astonishing pronouncement apparently excised trial by jury, indictment, compulsory process for obtaining witnesses, confrontation of witnesses, and all other procedural protections from the Constitution. All these create enforceable claims, that is, duties of a very substantial kind. There is nothing new or radical, Spencer or Hazlitt to the contrary, about the doctrine that all pexsons should be guaranteed certain rights as well as certain liberties. Nor are all the rights that were part of the mainstream of Anglo-American liberalism juridical. The right of the taxpayer to representation is the core of Lockeian doctrine. The right of the property owner to exclude others is part of the classic definition of property that was one of the key rights of English and American liberalism. Proletarian demands for rights to jobs, social insurance, and similar measures were, of course, not heard of before the Industrial Revolution, but demands for rights, and even economic rights, were. The thesis that classical liberalism sought only liberties is utterly unfounded.

More sophisticated is the argument that the right to work and other similar newfangled rights differ from the classic ones in that no correlative duty is enforceable against specific persons. Thus, it is argued, the right to a trial by jury creates an enforceable claim against a specific judge; or, it is argued, the right to exclude from one's property creates an enforceable claim against the trespasser. The right to work, on the other hand, creates no obligation to hire on the part of any one employer, and so the claimant cannot sue to enforce his right. It is, therefore, according to this argument, not truly a right. As no one is obligated to grant work, the act of doing so is an act of charity. The so-called economic rights are, therefore, according to this argument, matters not of rights but of grace.

In sum, the French Revolution, wished--and it is this wish which has rendered it not only sacred but saintly in the eyes of the people-it wished to introduce charity into politics. 31

It [the French Revolution] conceived a bxoader, more general and higher idea of the duties of the state to the poor, to citizens who suffer, than had ever been conceived before. . . .

There is nothing there which gives workers any rights against the state. 32

Certainly the state can promise to give to the extent of its power education, work, relief; but this promise does not create a right. It does not stop being an act of charity. 33

These views of 1848 had their counterparts in 1945 when one of the chief arguments against the preamble of the Full Employment Bill was its explicit recognition of the right to work. That, said the critics, would promote the misapprehension on the part of the unemployed that each had a legal claim to be provided with a job. All the government could do, according to these critics, was to follow a 
policy designed to promote a high level of employment, but it could create no genuine right to a job. 34 'This view won out in the wording of the bill as passed.

When this criticism of the right to work is taken to mean that there can be no such right, rathex than that there should be no such right, it is clearly grounded on a misapprehension. Since 1848 the state has created a legally enforceable right to an education, which is no longer an act of charity. The school authorities are bound by law to teach every child brought to them. In the same way a right to work could be created, and was well on the way to creation in the depression. To establish it, certain authorities must be required to give work to anyone who does not have, and cannot find, another job. That the right to work, if it is to be an enforceable right, requires the provision of this kind of made work was recognized by both the advocates and opponents of the right, both in 1848 and in 1945 . In 1848 the work-making agency was the National Workshops; in the years not long before 1945 , the Works Progress Administration (WPA). The opponents in both cases depreciated the efficiency of those agencies. They saw horrendous visions of society becoming totally dominated by this kind of work. 35 Most proponents of a public guarantee of employment could see nothing revolutionary in a promise of low-grade last-recourse employment. Without such an enforceable last recourse, the unemployed worker clearly has no legally enforceable right to work.

We may distinguish three kinds of rights that have entered into the discussion above. First, there are rights that create a claim that is in no way legally enforceable. These may be called "moral" rights. Second, there are rights that may in certain circumstances be enforced against anyone. Such are the rights of property owners against trespassers, or of workers for accident compensation ox against unfaix labor practices. Finally, there are rights that are enforceable only against a specific institution or person set up to provide the object of this right. Such are the right to trial before a jury of one's peers, the right to transportation by a common carrier, the right to an education, and the right to work. The critics of the right to work generally play up the distinguishing features of this third class of rights. They call these a "new" kind of right; or they contrast them with libercies; or they contrast them with the second group of rights; or they deny that they can be guaranteed and therefore call them charity. It is clear that such rights are different from both liberties and indiscriminately enforceable rights, but they are neither new nor impossible.

A grant of rights is apt to involve extensive bureaucratic organization to ensure that the right is granted. Whether the organization consists of courts, or schools, or administrative agencies, it often may have some compulsive and centralmizing effects. Also it will have effects on the operations of the economy, which though often desirable may also often prove detrimental. The duties involved in meeting the rights may prove onerous, or unduly expensive; the organization required may prove excessively large or cumbersome. Where a mistake in estimating cost is made and ill-considered rights are granted, prosperity and security may be diminished, thus endangering political freedom. This, however, is in each case an individual question of fact about which nothing useful can be said a priori. On such concrete grounds the impact of any right can be validly contested. There is no justification for any of the simplified generalizations made about economic or social rights such as the statements that they represent as a whole a qualitatively different class of $r$ ights from the traditional liberal rights and are destructive of the latter. 


\section{THE RIGHT TO COMMUNICATE}

The principles just outlined apply to the right to communicate. If such a right is to exist, an obligation must be imposed on some specific operator of communication facilities. That operator may be the private owner of a medium of communication, or it may be a special governmentally funded medium.

I would argue for the undesirability of the former and the desirability of the latter.

An example of the imposition of an obligation on private media owners to provide access is the requirement of a right of reply to personal attack. There are exceptional cases in which this may be justified. For example, given the absolute limits on the electronic spectrum, it may be justified to treat as trustees rather than owners those who receive a license to use it. Also, when a court has made a finding of libel, perhaps as part of the penalty, it may be justified to require publica tion of a correction. But in general the American press was justified in its alarm at the Tornillo case. A general requirement that a medium be required to publish statements by those who disagree with it is in effect a superimposition of the right to communicate on the freedom of speech of those who publish a medium. That is a dangerously illiberal reversal of values. Would one wish to require The pilot to carry abortion ads, or require an SDS (Students for a Democratic Society) paper to carry William Buckley? If one values freedom of speech, the right of reply should be drawn very narrowly indeed.

On the other hand, there is no possible objection from a free speech point of view to society using some of its collective resources to make more communication facilities available to persons who would otherwise be without them. Towns pave, clean and maintain meeting areas such as the Athenian Agora or London's Hyde Park Corner. Schools are publicly supported, and their auditoriums are often made available for community groups. Public broadcasting has provided access to the ain for various minority tastes. The Post Office is perhaps the largest single governmental facility designed to facilitate communication, and access to it is wide open. Proposals to extend such public access facilities must be judged on their merit in terms of cost and benefit. In principle they are desirable.

Among the possibilities of particular interest at the present time in the United States are citizen feedback phone and teletype lines, low-cost cable television rental channels, subsidized basic minimum phone service, and subsidized postage rates for print media. Elsewhere, important issues are the subsidization of two-way communication facilities in remote village locations and the removal of taxes and discriminatory rates that burden communication services. Also in many countries that now prohibit the delivery of messages outside the government's telephone and postal service, it is important to remove the bans on interconnection with the monopoly electronic network of the user's equipment and of other communication channels and perhaps also the bans on competition with that network and with the monopoly postal system, for example, the ban in many countries on cable television.

Finally and most obviously it is essential to combat and remove censorship. The right to communicate is not the same thing as free speech, but free speech is its prerequisite. Without free speech and free press there can be no $r$ ight to communicate. 


\section{NOTES}

1. Wesley Newcomb Hohfeld, "Some Fundamental Legal Conceptions as Applied in Judicial Reasoning," in Fundamental Legal Conceptions as Applied in Judicial Reasoning and Other Legal Essays (New Haven: Yale University Press, 1923), pp. 23-114.

2. I am omitting the term enforceable often put in here. I am not interested in differentiating perfect and imperfect rights in this part of the discussion. I am substituting the synonym liberty for privilege, which Hohfeld himself points out is often done and is the original sense of the term liberty (ibid., pp. 48-49). I will save the term privilege for another use. The term positive right is sometimes used as I use right, and negative right as I use liberty; compare J. R. Willingston, "The Right to Work," in The Annals of the American Academy of Political and Social Science 242 (January 1946): 33.

3. See George Cornwall Lewis, Remarks on the Usc and Abuse of Some Political Terms (London: S. Fellowes, 1832), pp. $197 \mathrm{ff}$.

4. See William Ernest Hocking, Freedom of the Press (Chicago: University of Chicago Press, 1947), pp. 54 ff.

5. Abraliam Lincoln, Speech, Baltimore, Maryland, April 18, 1864, in Complete Works, vol. 2 (New York: Century Co., 1922), p. 513.

6. Anonymous, Projet de Declaration des Droits d'un Citoyen Francais (Versailles: L'Imprimerie Royale, 1789), p. 2.

7. Target, Projet de Declaration des Droits et de l'Homme en Societe (Paris: Baudouin, 1789), Article 6.

8. In A. Aulard and B. Nirkine-Quetzevitch, Les Declarations des Droits de l'Homme (Paris: Payet, 1929), p. 18.

9. J. M. Thompson, Robespierre, vol. 2 (New York: Howard Fertiz, 1968), p. 43.

10. Article 21 .

11. Albert Schatz, L'individualisme economique et sociale (Paris: A. Colin, 1907), p. 269 .

12. Article 161, Sweden Fang, Etudes sur les Declarations des Droits (Paris: P. Bossuet, 1939), p. 93; Sweden Fang, Les nouvelles Declarations des Droits (Paris: J. Raumont, 1939), p. 156.

13. Fang, Les nouvelles Declarations . . , p. 156; Fang, Etudes . . , Article 114, p. 125 .

14. Ibid., Article 31, p. 148.

15. Ibid., Article 21, sect. 3 .

16. Ibid., Article 25. 
17. Ibid., Article 102, sect. 2.

18. Ibid., Article 45, sect. 2 .

19. For example, Italian Constitution of 1947, Article 38; French Constitution of 1946, Preamble. Of the twelve Constitutions of the German Laender (Berlin: Office of Military Government [U.S.], 1947), all but two Soviet ones provided for social insurance.

20. Fang, Etudes . . , p. 132.

21. Ibid., p. 168.

22. Ibid., p. $112 \mathrm{f}$.

23. Ibid., p. 162.

24. Ibid., p. 152.

25. Fang, Les nouvelles..., pp. $154 \mathrm{f}$.

26. The debates in the Congressional Record and the transcript of the hearings contain, as far as the author could find, but one reference to the enactment of the right to work in 1848. That was a rather ill-informed statement by Congressman Manasco (Congressional Record 91, Part 9: 11975).

27. Herbert Spencer, Social Statics (New York: D. Appleton, 1866), p. $313 \mathrm{f}$.

28. Ibid., p. 311 .

29. Ibid., pp. $330 \mathrm{ff}$.

30. Henry Hazlitt, The Full Employment Bill, An Analysis (New York: American Enterprise Association, 1945), p. 5 .

31. Tocqueville is referring to Article 21 of the Declaration of the Rights of Man of 1793. Compare p. 364 inf.

32. Alexis de Tocqueville, "Droit du Travail," Oeuvres completes, vol. 9 (Paris: Michel levy freres, 1876), p. 551.

33. Albert Schatz, L'individualisme economique et sociale (Paris: A. Colin, 1907), pp. $323 \mathrm{ff}$, , summarizing views of Laboulaye.

34. Compare United States Senate, 79th Congress, Report from the Committee on Banking and Currency to Accompany S. 380 (Washington, D.C.: U.S. Government Printing Office, 1945), Part 1, p. 26, and Part 2, p. 8; Congressional Record 91, Part 7, pp. $8958 \mathrm{ff}$.

35. Compare Tocqueville, "Droit du Travail," pp. $536 \mathrm{ff.}$; Albert V. Dicey, Lectures on the Relation Between Law and Opinion in England During the Nineteenth Century, pp. xxxvi f.; H. Lecky, Democracy and Liberty, vol. II (New York: Longman's Green, 1896), pp. 269 ff. 



\section{DEVELOPMENT JOURNAL.ISM AND THE \\ RIGHT TO COMMUNICATE.}

ASOK MITRA

It is possibly students of the history of European philosophical thought who would be in a position to trace the origin of the right to communicate, enshrined in Article 19 of the Universal Declaration of Human Rights, passed in 1948 by the United Nations General Assembly. Intimations of the need to affirm this right may be read into Thomas More's Utopia, but the Reformation perhaps gave it its own interpretation and pinned it on its high mast. The right is discussed by Hobbes, even though he pleaded for the royal prerogative. But the right to communicate probably was established unequivocally in John Locke's Letter on Toleration, written in Latin and translated into English, and in his On Civil Government. The connotation of Locke's message in British life was that government had to be constantly watched and kept on a close leash; that, if vigilance slackened, all governments would tend to be arbitrary, to encroach upon the liberty of the individual, and gradually tend to stifle him; that man's natural attitude toward all governments should be that he has very limited use for them wherever they are. This was developed in an atmosphere of British repression in Ireland by the Irishman George Berkeley and later by Jeremy Bentham. When, in his early twenties, Bertrand Russell tossed a tin of tobacco in the air as he walked down Trinity Lane and shouted to himself "God in his boots, the ontological argument is sound!" he was perhaps worshipping more the British philosophical tradition than the greatness of Hegel.

The loot of India that brought the first grist to the mill of the British Industrial Revolution, followed by the carving of empires, colonial and industrial, by other European powers, soon established, however, that the right to communicate flowed one way, from the imperial power to the empire and to the colony and, among and within colonies, from the rich to the poor. Oddly enough, the sword and buckler for the person or group at the receiving end turned out to be the British judicial system along with Parliament. The latter, however, in most cases considered it the more valiant act to hold what it had in the end, even when it condemned the means to that end. It is a curious fact of history that at any time in the nineteenth and first half of the twentieth century there were at least a handful of colonial administrators who believed in the sacredness of the white man's burden yet would passionately invoke Berkeley, Bentham, Mill, and Comte in their criticisms of their own government. In short, they would uphold only a very tenuous right to communicate from the receiving end.

The strength of the nineteenth-century tradition of the one-way street in the last quarter of the twentieth century is acknowledged by all thoughtful persons who are exercised over the right to communicate from the receiving end. In a paper on Information Imbalance in Asia, presented at the Regional Conference on Informa tion Imbalance in Asia, held in Sri Lanka, 21-24 April 1975, I gave details of how the receiving end in Asia suffers at the hands of the big western giants of mass 
communication. These details have not yet, to my knowledge, been refured by any authoritative source. There are plenty of other areas in which this concept of the right to communicate is mocked and unceremoniously spurned.

A word in common use now is feedback. It is not the same as inter action. You can pay heed to feedback if you want to. If you do not want to, you can ignore or forget it. That is what feedback is. The right to communicate acquires meaning only when it results in active interaction or participation and not mere feedback. Even when a communicator at the top modifies his previous message that has percolated downwards as a result of suggestions or facts contained in a feedback, the modification comes more as a magnanimous gesture from the top in its infinite wis dom, because the bottom is not explicitly told, nor does it have much way of knowing, what effect the feedback it offered had produced. A feedback therefore is not the same as active interaction or participation in a decision-making or communicating apparatus. It is a one-way process so far as the source of the feedback is concerned, because he would never completely know what happened to it or what precise impact it produced.

The right to communicate, therefore, acquires its full meaning only when the transmitter and the receiver are interacting or participacing on equal terms, even though the transmitter possibly is responsible for making the ultimate decision which he must convey as the last word on the subject for the time being, after the round of interaction or participation is ovex. The right to communicate does not end merely in the right to speak or write or react; it acquires meaning only when it produces interaction, modification, and reaction and both sides know precisely what produced the interaction, modification, or reaction.

The right to communicate can be grievously distorted ox vitiated by the interruptor or the interceptor. The interruptor or the interceptor claims to know the backgrounds of both ends and the language that each end will fully understand. In the process the interruptor or the interceptor, or the interpreter, carves out his own communication empire and battens on the foibles of the parties at either end of the communication system. Let me illustrate with reference to a level with which professional communicators may not be fully acquainted.

An administrator somehow feels uneasy at the bottom of his heart about this business of communication. Convinced, like Tennyson's Ulysses, of his sacred duty at all times and in all regimes to "mete out and dole unequal laws unto a savage race," he suffers from qualms over the unequal laws, the savage race, and his own meting out. He therefore wants to find out how unequal the laws are, how savage the race is, and how he has doled. A very honored tradition has been for the administrator to voyage out to a remote village and directly assess the effect. When he had sought out his village and thought he had found the right sounding board in a group of apprehensive, timid, poorly fed, poorly articulate, and often poorly clad people, he would settle down with a self-satisfied chuckle to the prospect of an hour of unbridled interaction. Suddenly he would find interposed, as though from nowhere, between him and his original audience a group of articulate, well-fed, smart-looking men of the world, clad in clean good clothes, who would offer to explain what the group of villagers they have placed behind them in the room "really 
meant," because the latter, poor fellows, never had seen an administrator before, and were therefore "too confused to speak up or express themselves properly."

Beaten, the administrator owns defeat unto himself. If he still persisted in his quest he would have to take a lot of crouble. He would have to find a bicycle and pedal about twenty miles, or walk about ten miles with a shotgun on his shoulder on the pretext of shooting birds, in the hot sun. The well-fed, well-clad ones would not be that anxious, after all, to accompany their administrator and keep him well informed. He would then seek out a group of humble folk along the wayside or in a small hamlet to find out how the chips were falling and on whom. Or he would have to live in a remote village for two or three nights, in mean surroundings, to let his villagers muster sufficient courage and confidence to come up to him at night and furtively communicate. That this still is true is borne out by the following account (an interesting facet of the debate on the right to communicate) of an administrator anxious to fulfill one of the important points of the twenty-point program of the prime minister of India, that of freeing bonded agricultural labor. This is how the story begins:

Stealthily they emerged from the shadow. They came there in twos and threes. Their voice was hushed. There was terror in their eyes. Still they came in, perhaps to unburden themselves to a few sympathetic listeners from afar.

It was the village of $M-\cdots-K \cdots-$. By the roadside a former Collector had built a few pucca tenements for the Harijans. He had also constructed a separate room for the school. That was the assembly point. We went there without any prior notice on the evening of February 18 , 1976. A friend of ours who had visited the Harijan colony earlier was with us. They knew that he had no evil intentions. So when we sent word around that a few of his friends had come from Delhi to talk to them, they mustered courage and assembled there in small groups. Darkness had started setting in on that moonless evening. It was $7: 45$ p.m.

The school was a simple set-up. It had a table, a stool, a wooden box, and a blackboard. Our interpreter-friend procured a lantern and placed it on the table. He sat on the stool and two of us made our selves comfortable on the wooden box. About 35 to 40 Haxijans stood round us with fear and expectancy writ large on their faces.

As our friend started conversation in Telugu a small chit was handed over to him. It was wxitten hurriedly in a shaky hand. It started "when you visited us last time, we narrated to you our woeful tale of hard labour without remuneration. The sarpanch's wife came to know about it and she threatened us with dire consequences."

We were in a dilemma. Perhaps, to satisfy the curiosity of a few transitory strangers, they were going to expose themselves to severe reprisal. We would be off within a few hours, to a place a thousand miles away from M-- - K--- and they would be left helpless to face the seething rage of their masters. Was it all worth it? But they had gathered and we too had come. The news would spread whether we 
talked or not. Chances of reprisal would be the same. So we decided to go ahead with our conversation.

III

The debate will continue over how the right to communicate has in effect amounted to the right of industrially or technologically advanced countries to communicate to the less advanced, and of the rich to the poor. It also seems very plain that those at the top who possess the prime right to communicate will continue to hang on to it, while loudly upholding the underdog's right to communicate, participate, interact, and supply feedback. This will hold as much for rich and poor nations as for rich and poor communities within a nation, rich and poor regions within a country, and rich and poor groups within a region or a city, or, as we have just seen, within a village. But that is no axgument for folding one's hands on one s lap and contemplating one's navel. The matter, so far as development journalism in the underdeveloped countries is concerned, is inextricably intertwined wich the right interpretation of the right to communicate.

In most underdeveloped countries, development journalism becomes the new boy with the attainment of freedom. This is the boy that will deliver the goods, boost morale, restore self-reliance and confidence, take us to town. In authoritarian regimes, beginning with the Iberian peninsula in the late thixties, development journalism has been entrusted with an added function: to interpret and convince the villager of the sacred, selfless, and disinterested responsibilities of the regime in power and its avowed mission to confer the utmost development in the shortest possible time. Development journalism is thus frequently equated with impressive listing of so many dams and megawatts, so many miles of railway track and roadways, so many tons of concrete, so many more millions of tons of foodgrains, steel, and aluminum, so many hundreds of thousands of housing units, and so much more of increment to the per capita income. But just like the overall per capita income computation, there is hardly a mention of who benefits where, and how much, or who suffers by comparison, where and by how much.

Development journalism, to have the right meaning, must really be a searching probe into the interaction between a new naterial achievement of the state or of a region or of a community and its effect upon the various sections of the people or the community or, more appropriately, what the effects of a certain material development are likely to be on the least endowed section of a community and how that section is going to profit or suffer from it. This aspect of development journalism has been neglected, in many countries, for the essential philosophical basis of such journalism is the attitude endorsed by Locke, Berkeley, and Bentham that governments must be kept under close watch, that they are capable of harm, wastefulness, and arbitrariness unless closely observed, that they tend to build up tyrannical power and corrupt pressure groups, for which the common man would not have much use, unless each investment and its ultimate effect is persistently questioned.

The other task of development journalism, for which the right to comm municate from the other end becomes even more relevant, is the effect of a piece of development investment on transformation of human values, attitudes, and behavior patterns and their conduciveness to that indefinite phrase, modernization and social change. To keep track of this area and keep it on the rails, a great deal more of 
communication is necessary between the top and the bottom and the innumerable intermediate levels. In such a situation, development journalism means that it has to depend upon a much more complex model than has so far been devised by communication experts. In fact, such a model of development journalism can take on the complex features of a centralized planning machinery and a highly decentralized array of regional planning and implementing systems. It seems therefore that parts of $\mathrm{J}$. Kornai's formulation of algorithms in The Place of Mathematical Planning in the Control of the Economic Systems are in many ways applicable to the problems of development journalism. The following may serve as a brief delineation.

In development journalism, particularly in a country of some size with plural societies, instead of having one giant but simple model covering all aspects of development communication, flowing more or less in one direction, one needs a variety of models. Every partial, segmental model must have a "profile," and must be specialized to fit one aspect or some limited aspects of communication, while at the same time keeping a tab on other aspects.

At the present moment we have, in most developing countries, a wildgrowing development of different media and their respective models, so far as development is concerned, sometimes with superfluous overlapping in some areas and a lack of representation in others. The different models live side by side but are not interconnected. Instead of a loose bundle of single models, the task of development journalism may well lie in constructing a united system of models.

On the assumption that the right to communicate will be more than feedback or participatory and in effect will be fully interactory (which is still a far cry from what we have seen in the second section of this paper) we may think of the several arms of development journalism and communication media as falling into convenient groups or models. Let us consider the accompanying figure.

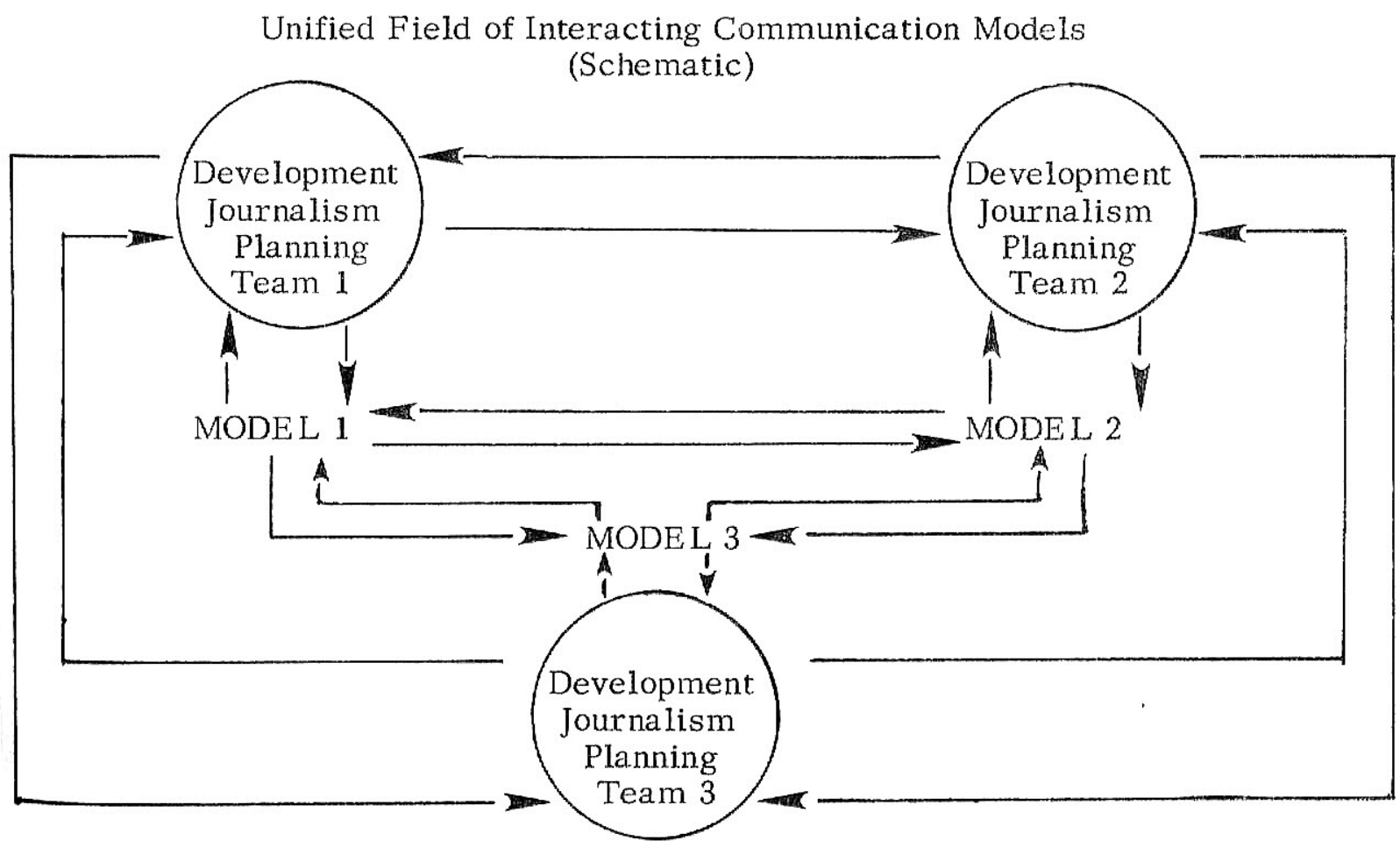


The rectangles represent communication media models. The circles represent development journalism planning teams. The latter perform a variety of tasks: (1) they collect data, which, however, are unfortunately subject to subjective preselection of data sources; (2) they build up a model, which unfortunately depends upon the planner's knowledge of the state of the art, his "taste" and imagination; (3) they evaluate results, which, unfortunately again, are prone to subjective judgment. All the same they have to decide on the forthcoming computations, make a selection, and decide what to advise or transmit.

It will be seen that some rectangles are directly connected with each other. Others are indirectly connected. Some information flows associated with a particular rectangle are directed from the rectangle to the circle, and vice versa. Finally, there are information flows between the circles.

In communication science the rectangles are very well described and elaborated. There is a large amount of practical experience in the operation of the "circles," but it is here that innumerable identified and unidentified interruptions and interferences with the right to communicate--from the bottom to the top, from the periphery to the center, from the poor to the rich--inflict dire consequences and end up meting out and doling unequal laws unto a savage race. 


\section{PROGRESS OF TECHNOLOGY AND SOCIAL PROBLEMS OF MASS COMMUNICATION}

B. M. FIRSOV

Research of recent years proves that the modern world is strongly affected by scientific and technological progress. Positive changes can be seen in all spheres of human activity. The decisions that should be taken as a reaction to the impetuous development of science and technology are of great importance and of complex character. As a rule, ir is necessary in each concrete case to synthesize (very skillfully and with foresight) political, cultural, economic, and ideological views and experience. International dialogues concerning the present and the future of communication (and particularly mass communication) in society should be carried on in a realistic language with due consideration to the complexity and diversity of the modern sociopolitical picture of the world. However, we should explain this conclusion more thoroughly.

\section{INDIRECT PERCEPTION OF THE WORLD: CHARACTERISTIC OF THE REVOLUTTON IN SCIENCE AND TECHNOLOGY}

To live in society, to reproduce themselves, and to develop the complex network of social relations, people have always needed the continuous acquisition and renewal of their sociocultural knowledge. Nevertheless, in different periods of history the ways of acquiring this cumulative knowledge were various. Tribal man was personally involved in almost everything that composed his social experience. The man of the twentieth century, on the contrary, relies on the experience of others: a considerable and often essential part of what he knows and what he is guided by in his activities is received by him secondhand. People became oriented to "the axiomatic knowledge," that is: "Development of personal and social mind consists both in ever growing expansion of the sphere of what men conceived and created personally and in ever arising new realms of new knowledge which men are bound to take for granted." I In other words, the "traditional" method of the accumulation of knowledge and skills gives way to qualitatively new processes.

This "metamorphosis" of the methods in the perception of the world has its own deeply objective basis. The formation of man as a social being is connected with the necessity to perceive the experience accumulated by former generations. The higher the degree of development of a society, the greater the necessity to acquire the diversity and wealth of human culture. As culture cannot be transmitted from one generation to another genetically, social production as well as the accumulation and dissemination of social information, 2 which includes life experience and the knowledge of the world, turn into processes that affect the variability and development of the society itself. In its turn the intensity of the rotation of information flows in a social organization depends on the nature of social interaction. In tribal societies, verbal and interpersonal forms of transmitting the meaningful in formation played the main role. The growing complexity of the system of contacts 
between people led to changes in the ways of social interaction. Along with face-toface contacts, different kinds of collective and mass interaction began appearing. Modern man is involved in the complex network of social relations at different levels. His interaction is in many respects going on by means of mass media. And the more developed the social organization, the higher the degree of these means. Soviet social psychologist Xu. A. Sherkovin says: "The development of society, beginning from the earliest stages, has necessarily been accompanied with the improvement of means of interaction and looking for more capacious channels of transmitting the ideas and emotions with minimum distortion. "3 In principle, technology has helped to find almost universal ways of orienting and relating men with regard to their environment. However, there is a legitimate question whether each man in society was benefited by the promising possibilities.

\section{COMMUNICATION DEPENDS ON SOCIAL RELATIONS}

Before we begin to appreciate the perspectives that technological progress opens to the people, we should specify the meaning of some concepts. This volume is devoted to the problem of the right, or the somcalled right to communicate. As the right is endowed with the meaning of one of the basic and fundamental rights of man, it is necessary, for instance, to elucidate the object of the right, that is, the communication phenomenon itself.

The word communication has many meanings. It is used to designate a wide range of phenomena concerned with people's lives, material and spiritual. This polysemy is being intensified by linguistic differences and, to greater degree, by the distinctions that are determined by the diversity of social outlooks.

Man is distinct in the realm of living organisms by his particular way of interaction with his kind. In Russian this quality, inherent in man's social nature, is called "obshchenie," which is close to English "social. interaction." To minimize the "noise" resulting from the translation from one language to another it is useful to reduce these words to their common denominator. The German word verkehr will be best suited for this role. Karl Marx used this word in the context of human history to mean any exchange of people's activities. Or, to be more strict, verkehr ("obshchenie," "social interaction") in the sphere of material life means the interrelation between labor and production; and in the spiritual sphere it is mutual information of people concerning their thoughts, intentions, emotions, wishes, experience, etc.

The concept of verkehr is closely connected with that of communication. Psychologists apply this capacious term to the processes of exchange of products of mental activity (ideas, etc.), while sociologists consider communication to be the "transmission of social (semantic, nongenetic, expressed in signs and symbols) information. "4 Points of view of sociologists and psychologists only supplement each other, underlining the idea that is important for us, namely, if verkehr is a reflection of universal connections between people, then communication plays the role of a main condition without which verkehr cannot exist. In other words, "the principle of sign and symbol regulation of activities and behaviour, being a psychological basis of phylogenetical development of man and his distinction from the world of animals, has become at the same time a psychological basis on which all forms of social inter* actions and man's culture originate and become consolidated." 
Man has not come at once to the highly developed forms and systems of social interaction and communication that are so notable for modern civilization. Peoples living now are removed by thousands of years from that historical moment when our remote ancestors felt, as Friedrich Engels said, "the need to say something to each other." This need embodies the most essential qualities of people, as social beings, and has one very important characteristic. Having arisen in the ancient past, this need not only accompanied man (developing with him and developing man himself) but has brought with it always and everywhere an indelible mark of human beings.

To be more precise, when in the process of history the forms of social organization of people become complicated and the relations of property and exploitation came into existence and antagonistic classes appeared, "the need to say something" became fully colored with social relations. One cannot disregard this circumstance while discussing the problems concerning the right to communicate. The exchange of thoughts and ideas in the frames of a particular society (on each level of its structure) and even more so between societies based on different principles, reflects the interests and purposes of quite definite social forces. Hence the idea of "communication without shores" in any form of expression is not realis tic (if not doubtful). The idea should be introduced into the sphere of real social relations within the states and between the states.

\section{SOCIAL CONSEQUENCES OF THE SCIENTTFIC AND TECHNOLOGICAL REVOLUTION}

Now we should come back to the technology that is considered to be a quite definite guarantor of the general right to communicate. There is no doubt that technological and scientific progress is a basis for the changes of the forms of communication in society. Nevertheless, while attempting to construct the future of communication and the international norms connected with it, one should rely on another very important thesis. The progress of technology undoubtedly affects all areas of modern life, and at the same time strongly depends on socioeconomic conditions where it develops. For this reason "the discovering of the nature of scien tific and technological revolution demands the studying of the whole complex of its social aspects, consequences and preconditions as well as the examination of the social process of its development in different social systems." 6

Thus, when we speak about the application of mass communication technique in society at the present stage of scientific and technological development (or in the foreseeable future) we cannot ignore the real contradictions of monopolistic capitalism. These contradictions are strained in the epoch of scientific and technological revolution, emphasizing the inherent inability of capitalism to overcome the antagonistic differences between labor and capital.

At the same time we cannot but notice that scientific and technological revolution complicates the relations between the Third World and the developed capitalist states (the gap in the economic indicators and the export of foreign capital are increasing; the rate of industrialization is beginning to be restrained, etc.). These tendencies characterize the social, economic, and political situation of the countries that are trying to follow the capitalist way. 
In the socialist society, the process of scientific and technological revolution has a quite different character. Along with the impetuous increase of science and technology we see changes in the way of life, in the relations between man and nature as well as in the relations between people and in all the modes of man's self-realization. It serves as another argument in favor of the theoretical conclusion of Marxism, according to which the fact that the development of the material forces will sooner or later liberate man and subordinate these forces to the task of stimulating and developing man's abilities. Socialism brings closer that time when society gains the ability to realize, according to Marx, all the plentitude of the "human manifestation of life. "7

The purposes and tasks of modern Soviet society prove all these arguments. Here are some of the aims of the program of the developed socialism, the realization of which has become true only on a certain and properly developed stage of the scientific and technological progress: to speed up strongly the rate of growth of labor productivity; to increase the amount and reduce the time of introduction of the scientific achievements into all the spheres of public production; to provide equal facilities for education and access to the wealth of culture for all the people, men and women, born in a city or in a village, in a worker or in a professional family; to equalize the standards of urban and rural life; to remove the differences between work and leisure time and between labor and consumption and to combine them as different spheres of the materialization of man's activity and the development of his activities.

The antagonistic and nonantagonistic societies will use the achievements of progress in science and technology differently (with other conditions equal).

\section{MASS COMMUNICATION TECHNOLOGY AND MAN (PHILOSOPHICAL ASPECT}

The idea that scientific and technological progress is different in its social consequences for different social systems is of great philosophical importance. The point is that a number of western authors formulate the problems of the development of technology differently, relying on the idea of the "identity" of social consequences of the scientific and social revolution for socialism and capitalism. By this the picture of reality is being distorted and serious social delusions arise. As far as the understanding of the role and significance of mass communication technology is concerned, we should underline the considerable impact of the technocratic views and the ideas of social pessimism.

For instance, the facilities of new technology bring about various kinds of social illusions. Such innovations as cable television, the portable videotape recorder, and the space satellite are often and very insistently considered as the "heralds" of the electronic and technological era. From the purely technical point of view, that is unquestionable. But the objections begin as soon as the electronic technology is considered a main generating power of social development.

Thus, as Canadian experts say, the electronic technology at the earliest stage of genesis appears in the role of a tool of social therapeutics: it equalizes the distortions and disproportions created by geography and economics and contributes to the development of mutual understanding between different strata 
of society. 8 This technology, having the opporunity to realize in full its "genetical" virtues (the capability of momentary and general dissemination of information) pre" sumably becomes able, in higher stages of its development, to play the role of a basis of even more and greater social change. Canadian authors state that new technology will "inevitably promote an egalitarian society in which control over individuals who know too much, too quickly, becomes less and less feasible. "9 The error of that position is connected with overestimation of the real facilities of technology. Technology is not able by itself to remove barriers between the interests of different strata of a society, to change the relations in property, and, even more important to overcome the contradictions connected with social inequality.

Gloomy forebodings of a number of western experts concerning the information storm and the "ninth billow" that may lead to the downfall of mankind are an altexnative to technological "optimism." The strong influence of the ideas of technical determinism is very noticeable here. According to this philosophy, the technical monsters created by man's hands and minds are becoming mightier and stronger than their creacors, transforming man into a servant and a slave of machines. Fxom this philosophy the statements originate concenning technological tyranny and other pessimistic views.

The application of technology to the interests of personality as a whole dissipates the question of antagonism between technology and man. It is obvious that this antagonism is fully abolished by the organization of life on socially fair pxinciples.

In other words, the problem of "humanization" of technology is mostly connected with the aims of social progress, and thus the way of deliverance from "tyranny" consists not so much in mutiny against it but in change of the nature of social relations.

\section{THE WAYS OF DEVELOPMENT AND USE OF MASS MEDIA}

In the conditions of scientific and technological revolution, the task becomes one of actually studying ways of development and ways of social use of mass media, that is, television, radio, press. The evolution toward national and intranational networks of radio, television, and press has been long enough. Each stage of this evolution has been, in principle, constantly enriching man and widening his opportunities in overcoming the linguistic and other barriers and obstacles connected with the diffusion of information in a society. This gives us a right to assume that each medium of mass communication, on every stage of its technological development, is equivalent to a certain range of individual and social needs that the medium is, a priori, able to satisfy.

But reality inserts considerable amendments into a priori estimations and assumptions. Any medium of mass communication is being programmed by a social system whose interests it serves. Just that very circumstance and no other determines the real functions of television, radio, and press in different social en vironments.

The way in which a society uses one or another medium at different levels of its social structure reflects in full measure the outlook of this society concerning the historical role and predestination of man. It is possible to exploit un" developed taste and to spread forcedly low -grade pieces of "mass culture," thus 
hampering the acquisition of genuine intellectual and aesthetic experience. On the other hand, it is possible to proceed from the social need to spread the standards of cultural and creative activities and at the same time ensure that the culture of a nation would remain differentiated and capable of increasing the spiritual potential of its people.

The absence of worldwide regulations for the development of mass media technology is well illustrated by the statistics of the dissemination of television, radio, and press. These media are being developed unevenly. This unevenness is affected not only by purely economic factors (the level of the industrial development, the amount of national income, etc.) but also by the historical and cultural factors, to say nothing of the political ones,

Quantitatively, the unevenness can be shown by the distribution of radio and television receivers and of newspaper copies for the whole world and for its different areas, shown in the accompanying table.

Worldwide Distribution of Mass Media, 1972

\begin{tabular}{|c|c|c|c|c|}
\hline & $\begin{array}{l}\text { Population } \\
\text { (in millions) }\end{array}$ & $\begin{array}{c}\text { Newspaper copies } \\
\text { per } 1,000 \\
\text { population }\end{array}$ & $\begin{array}{c}\text { Radio receivers } \\
\text { per } 1,000 \\
\text { population }\end{array}$ & $\begin{array}{c}\text { Television receivers } \\
\text { per } 1,000 \\
\text { population }\end{array}$ \\
\hline The world & 3,658 & 100 & 227 & 86 \\
\hline Africa & 362 & 9 & 60 & 4 \\
\hline $\begin{array}{l}\text { North America } \\
\text { North America }\end{array}$ & 306 & 240 & 1,260 & 363 \\
\hline (without USA) & 97 & 80 & 405 & 128 \\
\hline USA & 208 & 314 & 1,695 & 470 \\
\hline South America & 198 & 63 & 147 & 74 \\
\hline $\begin{array}{l}\text { Asia } \\
\text { Asia (without }\end{array}$ & 2,026 & 38 & 61 & 15 \\
\hline Japan) & 1,920 & 11 & 40 & 3 \\
\hline Japan & 106 & 530 & 441 & 229 \\
\hline Europe & 746 & 268 & 346 & 210 \\
\hline Europe (withou & & & & \\
\hline USSR) & 501 & 236 & 306 & 220 \\
\hline USSR & 245 & 3.33 & 430 & 185 \\
\hline Oceania & 20 & 255 & 262 & 183 \\
\hline
\end{tabular}

SOURCE: The author, on the basis of Unesco statistical data (World Communications: A 200-Countries Survey of Press, Radio, Television and Film (Paris: Unesco Press, 1975).

This picture will be even more full and convincing if we compare the data in the table with the norms recommended by Unesco. 10 Our calculations show 
that of the total population of our planet, the percentages of people who live in areas that meet the Unesco norms are as follows: newspaper copies, 68 percent; radio receivers, 50 percent; and television receivers, 60 percent. 11

The Unesco experts say: if we assume that a statistically average family consists of four to five persons, then 2,00 to 250 daily newspapers, 200 to 250 radio receivers, and the same number of television receivers per 1,000 population will symbolize the fact that practically all the population of one or another country has access to the mass media system. Only twenty one states (USSR, USA, Canada, a number of European states, Australia, Japan, and some others) can satisfy such a criterion. But the overwhelming majority of the countries (and, we repeat, the population of the world) have more modest facilities. Essentially, they have just begun their communicative development and show dramatic contrast with the above states and their population.

The unevenness of development is even more apparent in the qualitative differences. Nowadays it has become quite obvious that almost every country is trying to create the communicative structure that would best fit its own social. and political purposes. This rule may be regarded as a general one. It concexns the developing countries, which, far: from being unanimous in perceiving the standards of organization and the context of western press, radio, and television, aspire to form their own national policy in the sphere of mass information. This rule also characterizes the developed capitalist countries, especially in the cases of overcoming the expansionist tendencies and impact of television and news agencies and the press trusts of other (capitalist) states. And, last, this rule is acting in the socialist countries, which are going and will undoubtedly go their own way, taking care of raising the ideological level, coordination, and operativeness of the work of television, radio, and press and widening the influence of these media on the progress of economics, culture, science, and all the life of society.

The exclusive role and significance of mass media in the life of society demand that the regulation of their dissemination and use should have a strict scien tific basis. Attempts to develop such a basis have recently been made everywhere. Some authors describe the processes of mass media development as a logistic curve. 12 Others, in an attempt to overcome the mathematical formalism of the approach, build their arguments with due regard for social factors. For instance, the American authors Merrill and Lowenstein 13 assert that the dissemination of mass media goes through three stages. The first is characterized by the fact that the innovation appeals to and is consumed by primarily the "elite" of power, property, and education. The tastes of the elite predetermine the content of messages. And the great majority of population is deprived of the innovation by the barriers of illiteracy and poverty. Once these barriers are overcome the second stage comes into existence, that is, the period of mass dissemination and communication media. Popular access in this stage is connected not only with a relatively low, "democratic" price of information media but also with their content. The latter, according to Merrill and Lowenstein, loses the features of social and cultural caste that are characteristic of the "elitist" stage. In the third stage, the process of development is completed with the beginning of the period of specialized use of one or another medium of communication. This period is considered to be an alternative to everything uniform, standardized, and monotonous introduced to a medium's use by the very fact of its being "mass."

The above model obviously is inadequate. It does not show the principal differences in the process of mass media dissemination and the character of 
their use because of social relations. In socialism there is no "elite" whose social and property status gives them the advantage of being the foremost in purchase of a new medium and the possibility of enforcing their tastes. The attempts to underline the main impact of such barriers as poverty and illiteracy are anachronistic for the socialist countries, because the necessity of common use of all the wealth and culture is one of the main principles of a socialist state from the very moment of its foundation. Nevertheless, all that does not withdraw the question concerning the obstacles in the way of mass media development. But the essence of the obstacles, as soon as they exist, in many respects will be different for capitalist and socialist systems as well as for the different stages of economic progress.

For this reason one cannot fully interpret the process of mass media development in terms suggested by the American authors cited, though the idea of periods in development is worthy of consideration. French experts report that "from ten to twenty years are necessary for innovation to reach the general public." 14 Among the factors that affect the fluency of the dissemination of imnovation and the kind of a time curve for dissemination are: economic factors (the ability of industry to organize mass production of equipment for information media), sociocultural facm tors (the formation of social needs for new media), and psychological factors (the realization by people of the individual usefulness of media). Hence, natural steps are the beginning and then the increase of mass media development, and, eventually, the approach to the level of saturation. This level is characterized by common access to a medium and at the same time by the complex structure of its use. Knowl." edge of this structure in detail is a matter of urgency.

Once a medium becomes common the spectrum of demand for it widens and opens the way to individual use. We have been watching this individualization for a long time, as far as the relations between readers and press are concerned, and relatively recently (after the invention of the transistor) in the relations between radio programs and their audience. The inevitability of individualization should be realistically foreseen in the sphere of television. Development of broadcasting by means of satellites, multiprogram systems of cable television, and technology for video-taping in home conditions will soon individualize the use of television, which is now a medium of a collective (family) use. All that will lead to the establishment of a new set of stable connections between television and millions of its consumers.

\section{THE FUTURE PRESENTS NEW TASKS}

A qualitative leap will be made in the mass communication systems and consequently in their public use when "traditional" (present day) radio and telemedia synthesize with computers and more modern means of communication.

This seems rather logical from the technical point of view. The sys tems of communication that will come into existence as a result of that synthesis will allow us to receive, to keep, to transmit, and to process practically unlimited amounts of information. Furthermore, not only states and nations or separate institutions of society will be active consumers. The flows of information are now nearing man's house: family and individuals will have all the facilities for unrestricted access to information banks and systems. Man's home will become a place where terminal devices of telecommunication systems are mounted. 
One should notice that contemporary generations of people already have at their disposal: the channels of transmission that can carry hundreds of thousands of simultaneous telephone calls; real-time computers capable of responding to many distant terminals of telecommunication lines; code systems that allow all signals, including music, facsimile, and moving image, to be converted into signals that can be stored in a computer memory; electronic storage of information that can be easily manipulated and indexed by computers in a fraction of a second, etc.

All these things together enable us to imagine a universal signal transmitted through the telephone line (or line of cable television) to a television screen. It is also possible to use a device that causes responses from the computer to be displayed on a television set as well as fed into a printing device. By all these means, it is the individual consumer who is principally enriched. On the basis of the synthesis of various techniques, premises are created for more flexible multiaimed. (dialogued) systems of mass information service to the population of separate regions and a country as a whole. There is no doubt that the purposes of such systems will be fully subordinated to the aims of man's perfection and to the multilateral development of personality.

The essence of scientific and technological revolution consists of radical changes in the productive activity of man, who "transfers from the dixect. process of production to the control of all the production and constructing new tech nology. In connection with this redistribution of functions not the spending of man's physical energy but his abilities for creative solution of complex tasks begin playing the decisive role in the material production itself. "15 Hence there are new demands toward the development of cultural outlook, the widening of the educational and professional-technical level, and the improvement of many-sided and operative social orientation of all the strata of a socialist state. It is possible to solve these problems on a principally new technological basis and by means of scientifically oriented analysis of the information and communication needs of society.

\section{SUMMARY}

It is not difficult to prove that a wide range of problems connected in one or another way with the history, the present state, and the future of the processes of mass communication in human society is by no means limited by social aspects of the use of technology only. Our main task was to demonstrate with concrete examples the steady connections between communication and principles of the organization. of people's lives in different social systems. It is noteworthy that the above point of view is now more and more being understood. Nordenstreng and Schiller have recently written: "There is a growing awareness . . that technology as it is designed, installed and utilized may be an embodiment of the social system which first creates and uses it." 16

Social conditioning of mass communication processes becomes even more obvious when we shift from the technique of dissemination of mass communication to the contents of the disseminated mass communication and then to the sphere of the exchange of information between different states. 
The discussion concerned with the so-called free flow of information (and many representatives of practically all the states of the world took part in it) has obviously demonstrated the wish not only of peoples for the widening of contacts, the strengthening of connections, and the development of mutual understanding. Another important side of the discussion was the care for the sovereign equality and respect for the rights inherent in the sovereignty of each state. It is no mere chance that in the Final. Act of the Conference on Security and Cooperation in Europe, the principal proposition that was formulated concerned the fact that participating states pledged to "respect each other's right freely to choose and develop its political, social, economic and cultural systems as well as its right to determine its laws and regulations." 17

Beyond any doubt, the future of the communication processes in the world must be guided by the above principle (as we speak about the deliberate interference of man and the mobilization of technological, economic, and human resources for a greater development of all the kinds of social communication). This principle should be applied also to any kind of international regulations in the sphere of communication. All that creates the definite frames and boundaries of application of the idea of the right to communicate, the elaboration of which is the charge of a special group of the Unesco experts.

Being a norm of social life of the modern world, the concept of the right to communicate cannot but be affected by the direct influence of real socioeconomic relations formed in different countries. Moreover, this concept must take into full consideration the structure and dynamics of these relations.

The idea of the right to communicate, as an "improved variance" of an individual's right, does not change the hierarchy of the aims in the struggle for man's progress in society. The conditions of real liberation of man are connected with the extermination of all the kinds of social and national oppression and exploita tion as well as with the establishment of a genuine people's power and with their confidence in the future, with the guarantee of the access to the high cultural values accumulated by civilization.

"Interacting, participating, and shared communication" as an ideal of active involvement of an ordinary man or a certain group of population in the life of society is the result of practical realization of all the above mentioned conditions. 


\section{NOTES}

1. "Man-Science-Technology" (editorial), Voprosi Filos ofii (Moscow) 8 (1972): 35.

2. Social information in a wide sense of this phrase is information that "circulates in a society and goes through the people's consciousness." (V. G. A fanasiev, Social Information and Administration of Society [Moscow, 1975], p. 39). In a narrow sense this is "information which concerns first of all people's relations, their interaction, needs, interests, etc." (Ibid., p. 40).

3. Yu. A. Sherkovin, Psychological Problems of Mass Information Process (Moscow, 1973), p. 3 .

4. A. N. Alekseyev, Some Problems of Mass Communication's Sociological Research (Ph. D. thesis, Novosibirsk, 1970), p. 13.

5. Yu. A. Sherkovin, op. cit., p. 4.

6. "Socio-Philosophical Problems of Scientific and Technological Revolution," Voprosi Filosofii 2 (1976): 40.

7. K. Marx, F. Engels, From Early Works (Moscow, 1956), p. 596.

8. Instant World: A Report on Telecommunication in Canada (Ottawa: Information Canada, 1971), chap. 3.

9. Ibid., p. 30 .

10. As is known, to obtain certain aims in the development of the processes of mass information in the world, such a minimum has been defined by Unesco: 100 copies, of daily newspapers, 50 radio receivers, 20 television receivers, and 20 cinema seats per 1,000 of population of a country.

11. Calculated on the basis of Unesco statistical data in World Communication: A 200-Countries Survey of Press, Radio, Television and Film (Paris: Unesco, 1975).

12. See, for example C. Cherry, World Communication: Threat or Promise? (London, 1971), pp. 26-56.

13. J. Merrill and R. Lowenstein, Media, Messages and Men. New Perspectives in Communication (New York: McKay, 1971), pp. 33-41.

14. New Techniques for Dissemination of Culture (Strasbourg: Council of Europe, 1972), p. 3.

15. "Socio-Psychological Problems of Scientific and Technological Revolution," Voprosi Filosofii 2 (1976): 45.

16. K. Nordenstreng and H. Schiller, "Helsinki: The New Equation," Journal of Communication 26, 1 (Winter 1976): 134.

17. "The Final Act of the Conference on Security and Co-operation in Europe," Izvestia, no. 179, August 2, 1975. 


\section{THE ECONOMIC DIMENSIONS OF THE RIGHT TO COMMUNICATE}

DONALD MCL. LAMBERTON

\section{THE ECONOMIST'S DILEMMA}

As an economist invited to discuss the economic dimensions of the emerging right to communicate, I face a clilemma. I intexpret communication as the transmission of information to elicit a response: for example, to provoke a decision in an interdependent situation; to alter the state of preferences as in advertising; or to modify a capacity for thought and action as in education. If I attempt to use the established theory and techniques of economics, I am equipped with some useful concepts and dichotomies, for example, factor proportions, complementarity and substitutability, and investment and consumption, but I inherit a basic approach that seeks to avoid full recognition of the role of information. This is typified by the most developed of the economist's models: the perfectly competitive economy. There, perfect knowledge is assumed and nothing worthy of the label decision occurs. To the extent that this assumption is relaxed, information becomes just another commodity. If information is one of $n$ commodities, it becomes difficult to discuss a case for a right to communicate. Logically, there should be a "right" to each of the other n-1 commodities: to bread and wire, to medicine and entertainment, to shelter and lollipop.

Alternatively, I can reject the notion that information is just another commodity. In broad terms, this would impose several responsibilities: first, awareness of the conflicts and inconsistencies created by the differences between the underlying vision of the world on which conventional economics has been built and the information-society concept that underlies the emerging economics of information; second, willingness to define the special, noncommodity characteristics of information; and, third, capacity to specify the relationships between the information activities and the rest of the economic system. These responsibilities are onerous; and at the present stage of development of the economics of information, it would be foolhardy to give the impression that they can be discharged.

Having entered this disclaimer, I shall attempt to use the approaches of traditional economics to outline an analysis of the allocation of resources to communication. This must be done in two stages. In the first stage we would be concerned with the use of existing resources in communication for immediate, identified purposes. It is at the second stage of analysis, when the effects of communication must be taken into account, that great difficulties are occasioned by the fundamental inadequacies of an economics customarily based on assumptions of given tastes and given technology. The basic patterns of thought are related to equilibrium, stability, and order; they reflect the pursuit of certainty. Once we are deeply immersed in these patterns of thought, it becomes difficult to accommodate science and technology and all the other information activities that owe their very existence to, or create, instability, disorder, and change. 
The magnitude of these difficulties is well illustrated in J. Robert Oppenheimer's comments on the effects of science on society:

Science has changed the conditions of man's life. It has changed its material conditions; by changing them it has altered our labor and our rest, our power and the limits of that power, as men and as communities of men, the means and instruments as well as the substance of our learning, the terms and the form in which decisions of right and wrong come before us. It has altered the communities in which we live and cherish, learn and act. It has brought an acute and pervasive sense of change itself into our own life's span. The ideas of science have changed the way men think of themselves and of the world. 1

An economics that ignores the changes in "the way men think of themselves and of the world" has limited potential. If reality is a man-made process, a new kind of economics is needed. As I have said on an earlier occasion, 2 economics in an information society must be an economics of information.

\section{THE PERFECTLY COMPETITIVE ECONOMY}

It will be helpful to return briefly to the characteristics of the perfectly competitive economy. The participants, the firms and households, are small independent units. They have clearly defined objectives and they are well informed. So well informed are they, that the model builders go further and assume "perfect knowledge." Precisely what is perfected is not specified. Even an attempt at such specification is usually lacking. The historical economic process is analyzed in terms of equilibrium and stability. We are in a world where wars and defenseinduced expenditures do not exist; where externalities and inferior goods are abnormal; where change is gradual and its impact marginal; where processes are reversible and events can be replayed once we are wise enough to solve the social problems inherent in them - -a mechanistic world where we try to avoid decision in any meaningful sense; a world in which information is just another commodity. We might go further and say that this model amounts to a denial of the process nature of economic activity, for it can be argued that perfect competition can exist only in equilibrium.

I have dwelt upon this model because it helps establish two points that are of considerable importance for the right to communicate. The first point relates to different types of information. Even in this highly simplified model, where it is found necessary to assume perfect knowledge, there are information flows. There are money flows and there are price signals. The assumptions of the model make it unnecessary to provide for such nonprice information flows as those relating to quality and production technologies. 3 This points to a need to develop a classification of types of information and types of communication processes.

The second point relates to the atomistic assumptions. These are shared with free-enterprise democracy, liberalism, and Pareto's welfare principle. I suspect they have played too great a part in the discussion of the right to communicate. I shall suggest later that to the extent that information is an economic resource, it may be expected to serve, as other resources have, as the basis of economic power. Even the customary shares of income--wages, profit, and rent-derived from the circumstances of the Industrial Revolution and could be related to 
resources and politicoeconomic classes. Technological and organizational change may have broken down the tidy correspondence that once existed. If, in our world, information resources are the most important requirement for economic development, the analysis of income shares ought to mirror that state of affairs. It might be objected that nobody "owns" the unexpected in a legal sense. Nevertheless, information resources may already have become the most important basis of economic and political power. What determines national science and technology budgets? Perhaps it is the distribution of power, including that of industry, professional groups, and governmental agencies. There has been a secular boom in education. Has it produced a new "property" class catering for the communication needs of modern society? Multinational corporations have extended their activities. Does their strength reside in economies of scale in information processes? These considerations suggest that the atomistic assumptions are inadequate. Clearly, a taxonomy of communication must take accQunt of different types of information and different types of participants in the communication process.

\section{A TAXONOMY OF COMMUNICATION}

A taxonomy of communication is needed. Can the economist's approach help in its development? Communication activities can be classified in a variety of ways: according to the type of information transmitted; according to the type of participant; according to the nature of the response to be elicited; according to the means of communication or the communication technologies. A systematic taxonomy would be facilitated by the extension of Leontief-type input-output tables from their existing use in the description and analysis of product flows to a parallel treatment of information flows. Despite the diversity of production in an industrialized economic system, this method of analysis has captured much of the structural detail and the dimensions of change. However, its form has reflected the traditional preoccupation with real processes. Information activities, to the extent that they have been separated out from physical production, have slipped into a general residual category.

We need a detailed functional classification of the information sector's component activities. Here I deliberately emphasize information rather than communication because the communication process can be understood only in relation to the more comprehensive information process. I believe that information transfer cannot be isolated from the other activities of creation and collection; storing, retrieving, and processing; distribution; marketing; and consumption of information services.

Once there is an adequate data basis, the participants can be identified and the nature of market and other power relationships perceived. There may be cases that approximate to the atomistic assumptions of the economist's models, but most likely most cases will be characterized by an unequal balance of power, for example, households versus large corporations, that has generated some Galbraithian countervailing power and/or governmental supervision. Message flows can be recorded and analyzed. In this way our knowledge of both the structure of the information sector and the relationships between that sector and the rest of the system can be specified. These relationships can be expected to undergo change in the same fashion as the Leontief coefficients' relations to product flows have changed. 
Technologies can then be described in terms of the input-output relationships. Their alternative economic consequences can be explored and, it is hoped, predicted. Three points should be stressed in this connection. First, there is a reasonably well-based understanding of the production process in most manufacturing processes. This cannot be said of either communication or information processes. Much of the difficulty that arises in studies of manufacturing processes is associated with a lack of understanding of information flows, for example, scientific and technological information flows. The second point relates to a particular aspect of information processes and their associated technologies; namely, economies of scale. These are important because they may become the basis of largescale organization and concentrations of power. The third point is that as new technologies are introduced, cost reductions will be observed. It is of great impor m tance that decisions take account of the total social cost of change and not be based upon spectacular reductions in the cost of what are merely components of larger systems.

\section{ECONOMIC EFFECTS OF COMMUNICATION}

Given the diversity of information flows in an economic system, no simple overall assessment of the economic effects of communication is possible. We can, however, distinguish some of the potential influences.

Where organizational arrangements have been established and there is a pattern of stable growth, it might be possible to use the notion of an optimal level of information expenditure insofar as that expenditure represented transaction costs. Movement toward this optimal level, or system changes to reduce this optimal level, might be viewed as contributing to greater productivity.

Where the information flow enables the achievement of a reduction in the utilization of other resources, as is mostly assumed to be the case with scientific and technological information, communication can be seen as contributing directly to economic growth. I need not comment on the evaluation of economic growth in view of the modern debate.

Well-informed people are necessary to the efficient functioning of the entire economic and social system. The provision of information services can help people make better use of their leisure and working time, adjust more easily to change, plan their education and that of their families more effectively, get better value from their incomes when they shop, make a better contribution to public decisions, and live in greater harmony with their neighbors. All these things can be achieved, provided certain basic assumptions are satisfied. The recipients of the information must have the capacity to use the information, and their opportunity to do so must not be restricted or neutralized by the actions of others.

Many types of information flow will be productive of change, including displacement. Where growth coupled with qualitative change and displacement of employment assumes great importance, we can expect increased value to attach to successful prediction. This is a cumulative process.

Perhaps the most widely expected effect of communication or, rather, of increased communication, is a reduction of inequality--inequality of power, wealth, and income. If this is the purpose of establishing the right to communicate it would 
be well to consider whether this expectation is well based. If the effect of communication is to equalize the states of knowledge among buyers entering a particular market, the expected result might eventuate. Even in this simple case, we have to ask whether the buyers have the same capacity to use the information. Differential capacities may reflect prior educational experience or even demonstration effects that raised aspirations. Similar statements could be made about the sellers' side of a market. Where new information became available to small households (buyers) and large firms (sellers), the likely social disadvantage is more obvious: the firms may have not only greater capacity to use the information but also capacity to take counteraction. In broad terms, equality of access to information does not ensure equality of benefit. Differential capacities to use information will not only preserve but accentuate concentrations of power, wealth, and income.

Is more communication a guarantee of greater social cohesion? Insofar as it achieves economic growth without sacrificing the quality of life, I am inclined to answer in the affirmative, Despite all recent criticism of the growth dogma, there is a general merit in the reduction of conflict within an integrated community. Each individual can gain without being a threat to his neighbors. Here again many special assumptions must be made. Short-run enlightenment can in the long run give way to hostilities.

\section{THE RIGHT TO COMMUNICATE VS. INFORMATION POLICY}

I have neither said nor implied very much about the role of the state. Clearly, the right to communicate can be a reality and be beneficial only if the policies of the state are carefully coordinated to that end. The information process is such a pervasive influence that almost all aspects of government are involved. The coordination would, for example, need to extend to policies relating to employ ment, regional development, immigration, science and technology, patents, foreign investment, consumer protection, and fiscal and monetary management.

Not only is such perfection in coordination unlikely to be achieved, but governments may well undermine the right to communicate in two ways. First, by emphasizing some information processes and neglecting others they may fail to achieve the full potential. Second, information policy may become primarily an instrument of the state.

\section{CONCLUDING REMARKS}

In summary, the International Broadcast Institute descriptive statement contains no recognition of the economic limitations on the ability of individual societies to meet the basic human need to communicate. "Adequate resources" will differ between communities and between individuals. There is serious danger that well-intentioned policy efforts will lead to undesirable consequences unless they are reinforced by carefully coordinated action on a wide front.

Some important research priorities are:

1. economics of information, with special reference to income distribution. 
2. comparative study of national communication systems

3. property rights in information

4. the formation of information policy and policy coordination at national and international levels 


\section{NOTES}

1. J. Robert Oppenheimer, Science and the Common Understanding (New York: Simon \& Schuster, 1953), p. 3 .

2. Donald McL. Lamberton, "The Economics of Communication Technology," Paper presented at the East-West Communication Institute, Honolulu, May 1975.

3. For a pioneering discıssion, see Jańos Kornai, Anti-Equilibrium: On Economic System Theory and the Tasks of Research (Amsterdam: North-Holland Publishing Co., 1971), Chap. 5, "In:ormation Structure." 


\section{SELECTED BIBLIOGRAPHY}

Arrow, K. J. "Limited Knowledge and Economic Analysis" American Economic Review 64, 1 (March 1974).

Hirshleifer, J. "Where Are We in the Theory of Information?" American Economic Review 63, 2 (May 1973).

Kornai, Jafios. Anti-Equilibrium: On Economic System Theory and the Tasks of Research. A msterdam: North-Holland Publishing Co., 1971.

Lamberton, D. M. ed. Economics of Information and Knowledge. Harmonds worth: Penguine Books, 1971. . "The Information Revolution." Annals of the American Academy of Political and Social Science 412 (March 1974).

Machlup, Fritz. The Production and Distribution of Knowledge in the United States. Princeton: Princeton University Press, 1962.

Shackle, G. L. S. Epistemics and Economics. New York: Cambridge University Press, 1973.

Spence, A. M. "An Economist's View of Information." In C. A. Cuadra and A. W. Luke, eds., Annual Review of Information Science and Technology, vol. 9. Washington, D. C.: American Society for Information Science, 1974.

Tomasini, L. M. "The Economics of Information: A Survey." Economie Appliquée 27 (1974). 


\section{THE RIGHT TO COMMUNICATE AND THE ARABIAN NIGHTS TALES}

HAMDY KANDIL

\section{THE RADIO TRAFFIC-POLICEMAN}

The most famous man in Lebanon at the present time is an unknown radio announcer who has suddenly found himself under the spotlights. Sherif AlAkhawy has become so famous and popular that he is envied by many political leaders. The story of Al-A.khawy began with the eruption of the civil war in Lebanon. He was chosen by Radio Lebanon to work as its news reporter to the headquarters of the Internal Security, so that the citizens would know which of the roads were more secure.

Hence, his job was merely that of "radio traffic-policeman." But several weeks later he realized the great catastrophe the country was passing through and the huge audience who listened to his reports. So one day, instead of starting his routine reading of the names of the streets where firing was exchanged, he urged the deputies to go down to the streets and share the people's sorrows, or head to the Parliament and work on halting the bloodshed. The deputies were angered because Al-Akhawy had cornered them before their voters, and the Speaker of the Parliament asked Al-Akhawy to stand before a punitive council.

Before Al-Akhawy's stand for trial, he appealed to the ordinary citizens, to those who have no interest in fighting, to those who love their country and do not work in the interest of foreign powers or arms-mongers, and to the Moslems and Christians whose sons are killed without being identified as to their religion. He appealed to all these to come out of their houses, to assemble in the streets (which were empty except for barricades and snipers), to shout "Long live Lebanon," and to impose their opinion on those who are selling the country.

While some of the officials were trying to pull him away from the microphone, a strange incident took place, an incident that could not have been organized by any political group since the eruption of the civil war. The ordinary citizens came out into the streets where explosions had occurred and death prevailed, carrying nothing but branches of green leaves and placards calling for peace, thus attempting to stop the massacre.

Al-Akhawy has also presented a program dealing with the people's complaints. He used to receive about one thousand five hundred letters per day on sufferings as regards bread, prices, etc. When he received a complaint, he just telephoned those who were responsible and persisted in following up the matter with any official, no matter what his rank. He used to threaten to unmask the officials before the people if they did not fulfill their promises. He never rested in peace until corrective action was taken. 
Then the great opportunity loomed to attack his enemies when he called upon the citizens, in mid-November 1975, not to resume their work as the government instructed, "as my conscience is not at ease; the roads are unsafe, and kidnapping has started." The storm began. It reached its peak when the security forces cut off the telephone lines through which he was transferring his appeals to the radio. The result was that the government employees refused to go to their offices, the taxi drivers abstained from work, and the chairman of the chamber of commerce contacted the prime minister and threatened that if Al-Akhawy did not return to the radio, the tradesmen would remove all goods from their shops.

When the officials discovered the great confidence of the Lebanese people in Al-Akhawy, they started to exchange charges among themselves. The Ministry of Information charged the security forces with hampering its work; the latter charged the former; while Al-Akhawy charged the two parties with interfering between him and his audience. After a suspension of no more than thirty-six hours, the man who "lost the state's estimation and won the peoples trust"1 returned.

The name Sherif Al-Akhawy means "the honest brother." He actually was honest and brotherly. He stood up for the people's rights to know, to express themselves, and to be heard. He owed his fame to the failure of Lebanon's broadcasting to advocate any of these rights. Radio Lebanon was living in quite a different atmosphere. While bombs, rockets, and heavy artillery shellings were slammed around its building, Radio Lebanon simply turned a deaf ear, closed its eyes, and broadcast light music, highbrow discussions, and, ridiculously enough, reports on Angola, Ireland, and Portugal.

\section{WHEN COMMUNICATION IS ABSENT}

Although Radio Lebanon was daily devoting 145 minutes to programs produced by French broadcasting in Paris, in accordance with a protocol concluded between the Lebanese and French governments in 1946, the legislative decree 7276 does not allow political dialogue through the radio. "No access to the radio was now possible for any political group. Not even the right of access to answer accusations was recognized to any individual except government officials who are in office. "2

Radio Lebanon is state-owned. It is one of the main branches of the Ministry of Information and its budget is part of the Ministry's budget. Therefore it is not strange that the "expenditure on programmes and talents is often carried through political pressures." 3 As the government is the financing source, all the programs are expected to glorify it. This tradition has been established since 1973, particularly following the announcement made by the Lebanese premier at that time, who said that as there was no newspaper that defends the government, therefore Radio Lebanon is that newspaper.

When the presence of the government is not felt, as is the case from time to time during the current civil war, the radio presence also is unfelt, sometimes deliberately. Hence the opportunity is presented for more than one person like Sherif Al-Akhawy. But what is really dangerous, in the absence of a voice that represents the people, is that every sector establishes a private broadcasting, as happened during the 1958 revolution in Lebanon when there were three stations, each an organ of a different party or sector. Similarly, on the eve of 2 September 1975, the Lebanese people were surprised by the broadcast of military march music 
and an announcer calling from the "Voice of Lebanon; voice of freedom and dignity." This station, which spoke in the name of the Phalangists, broadcast from $8 \mathrm{~A} . \mathrm{M}$. to $10 \mathrm{P} . \mathrm{M}$. on a medium wave that covers all Lebanon and also on a short wave that addresses the Lebanese emigrants in Southern and Northern America. In confrontation to this broadcasting, the "Independent: Nasserists" established another station, under the name of the "Voice of Axab Lebunon," to "reveal the incorrect information given by the other party." In the meantime, there are two other stations fully ready to start transmission at any moment. One of them is afriliated with the Pxogressive Socialist party and the other, "the Voice of Zagherta," was established by the president of the Republic prior to his election.

Hence, the state of broadcasting in Lebanon has become the same as that of its press. Since the press started in Lebanon in 1958, each newspaper has spoken on behalf of a certain group or sector. They published more commentaries and opinions than news. These conditions, in addition to the liberal "freedom" exercised by the Lebanese press, "make publishers open to overtures of financial assistance from foreign groups in exchange of editorial support, 4 and "this characteris tic has become so prominent today that any claim to objectivity made by the press is viewed with skepticism."5

The situation provoked one of the Lebanese writers, who summarized the situation as she saw it:

The least we could say about information is that it is absent. Most of the newspapers have become papers for obituaries with no guidance or awareness of the message of press as to rise to the standard of fate-determining issues and no courage in facing the realities except in rare cases. History will not forgive the Lebanese press for abandoning its national role in the most critical stages of its history.

The Radio is a lackey, it echoes the opinion of the state . . and it does not reflect the sufferings of the people. Apart from what Sherif Al-Akhawy says, the rest is but trash.

The catastrophe of the $T \cdot V$. is greater--a degrading language and an ugly face. 6

\section{A LUXURY OF ABUNDANCE?}

Television in Lebanon is different from radio. It is a commercial institution censored by the government in some fields. While the French institution (SOFIRAD) shares in the capital and assists in running one of its channels, the other channel was at the start supported by the American Broadcasting Company, which has been replaced since 1965 by the London-based Thompson Organization. Thus it is not strange that attempts would be made by foreign powers to use television as a medium through which they could contact the I.ebanese people. The president of the Order of Journalists announced that "there are contacts and secret deals which link certain television announcers and non-Lebanese parties, to promote the news of other countries, thus giving the impression that the Lebanese state is biased in its Arab and Foreign politics. "7 Although the accusation was made in 1973, it is still valid today. Its dangerous indication has increased with the start and continuation of the civil war, where all the communication media--including the press, generally known. 
to be the most liberal and the most sophisticated in the Arab world--have failed to appeal to the "silent majority."

The distortion, caused by the communication media, of the ideals embodied in the right of communication removed the masks, and revealed the foreign as well as the Arab interests and blocking. But the issue of Sherif Al-Akhawy today is "selling" the right to communicate to the masses and has made them realize its significance. Everyone has realized how valuable is that right, sometimes considered a luxury of abundance in countries where most of the citizens lack the right to food, clothing, medical treatment, education, and wealth--the right to live. That is one of the important elements of our topic: individuals and groups should realize the value of the right to communicate and know that without it, no sound sociopolitical structure could survive.

We should urge them to defend that right. We need to "sell" that right, not only in countries where the communication media are dominated by the government but in other countries as well. Even in the United States we find that Elmer W. Lower, vice-president, ABC, states: "My mail in the last twelve years convinced me that there are many Americans who do not value freedom of the mass media. Many of them think that if we would just stop talking about political, economic and social troubles, they would all disappear. Others are convinced that when we yell First Amendment, we are just trying to protect our jobs." 8 Lower holds the professionals responsible for selling these rights which are in the best interests of their people. He believes that this necessitates a continuing struggle.

Let us admit that we, the professionals, are partly responsible for abandoning the freedom of the press, the rights of information, of access, of participation, of balanced flow, etc.

We, particularly in the Third World newly independent states, are usually torn between the state's policy on the one hand and the people's needs on the other. If any contradictions occur between the two, we usually take the state's side, because it is the state that gives us our pay and our future is in its hands. Also, the state's wishes are usually spelled out in clear-cut instructions (mostly in negative form), but the people's needs are not known to us. (In this connection it is important to underline the necessity of undertaking a study of needs of the individual and of communities. )

In addition to that, the people themselves do not represent enough weight, at least in comparison with that of the state. The individual, who is looked after by the paternal state, has not yet obtained his basic rights. Hence it becomes clear to us that the right to communicate is closely linked with all the other human rights, provided for by the Universal Declaration of Human Rights. The struggle, which continued for about thirty years and is still carried out in order to achieve the aforementioned rights in this declaration, is part and parcel of the struggle to realize the right to communicate. Every one of these rights is a part of the whole.

\section{EXAMPLES FROM THE MIDDLE EAST}

The example that could be presented from the Arab area on the link between these rights is found in Iraq and the Sudan. In both states the Ministry of Information, or the party, owns, operates, and dominates all communication media, 
including books. When the Kurdish war in Iraq as well as the war in Southern Sudan came to an end, the minorities were granted autonomy rule, which provides for the rights and guarantees of which they were deprived. At the same tince a decision was adopted welcoming the Iraqi and Sudanese Jews who had immigrated to Israel, inviting them to exercise the right to live in their homeland. This was also accompanied with more press freedom, the people's participation in the communication media, access of foreign pressmen, and basing of censorship.

These healthy indications, which occurred in the Iraqi stand, paralleled the lessening of tension with neighboring ladn. This proves another principle, namely, that political relaxation in the international scene helps the possibility not only of communtcation across borders but also to practice the right to communicate inside the country itself.

We will also find that the October war, during which the $\Lambda$ rabs scored a partial military victory by which they restored some of their rights in the occupied territory, has led to a relicxation in the political and military tension; this in turn has paved the way for the possibility of establishing intercountry communication in the area. Such communication was impossible in the past and could not be properly carried out in the future without the restoration of all the other rights, including the right of the Palestinians to self-determination and communication.

The Octoler war also led to two other results. The first was that the Arab states excrcised their rights over their natural resources (oil a major one), and the seconit was the push given by the comrades in arms for cooperation in the time of peace in a healthy atmosphere of self-confidence. Political relations improved among the Arab states (though there are some exceptions), leading to the consolidation of communication between them. The best example was the Conference (the first) of the Ministers of Information in the Gulf states in January 1976. At this conference they announced the establishment of five major regional communication institutions in the Gulf, namely, (1) the Gulf-vision Network with its center in Saudi Arabia, (2) the Programme Co-production Center stationed in Kuwait, (3) the Radio and Television Training Center in Qatar, (4) the Gulf News Agency in Bahrain, and (5) the Communication Documentation Center in the United Arab Emirates.

The work done by the seven participating Gulf states in the meeting 9 meant that the grouping of their resources and drawing a regional communication policy would lead to the establishment of a communication infrastructure able to improve the possibility and rights of these countries to:

1. Communicate with each other: the study on the Gulf-vision Network ${ }^{10}$ indicates that these states were to start during 1976 , a daily ten-minute change of news via satellites. It is expected that within three years satellites would be used for transmitting special events and exchanging programs for about thirteen hours per week. By that time, work in the Gulf terrestrial network will be almost completed.

2. Communicate with the elite countries in the world: during the past, and until the present, the flow of information has been unbalanced. In giving an example of the flow of television news, we find the following: most of the available news in the area is being dispatched through the international film news agencies. The rate of news coverage is very low. Kuwait Television has issued a report 11 on the year 1974, the year in which world interest in this area grew as a result of the 
political influence and economic activity practiced by its countries following the enormous increase in their oil revenues. According to this report, the UPITN dispatched only five items, concerning four countries, during the whole year. The VISNEWS dispatched sixty-one items, of which fifty-one were on Iraq (as a result of a special agreement between Iraq and the agency, which provided that the agency would dispatch such news as part of its Arabic Service). During the same year, the television stations in these countries, some of whom are members of the European Broadcasting Union (EBU), have introduced only three news items in the Eurovision network (all three pertaining to the incident of occupying the Japanese Embassy in Kuwait). However, since October 1974 Kuwait and Saudi Arabia were receiving a daily ten-minute news package from the French television via satellites (the transmission for French overseas territories). 12 These two countries as well as others were negotiating with the EBU to receive Eurovision service daily.

The unification of the Gulf-vision resources undoubtedly will provide higher quality, more timely news. This will enable the Gulf states to reform the shaken balance of flow of information between them and the outside world.

\section{SOME DIMENSIONS}

Unesco has helped the Gulf states in preparing studies on the Gulfvision Network and the three other communication organs, whose establishment has been approved by the Conference of the Ministers of Information. Unesco has also helped the Arab states in preparing the studies related to the Arab Satellite Network. This proposed network, and the other Gulf communication institutions, reaffirm the relationship between drawing a regional policy for communication aimed at mobi lizing potentials and the flow of information, hence surmounting the communication imperialism, maintaining the culture of the area, and exercising fairly the right to communicate (or not to communicate) among states.

The idea of launching an Arab satellite emerged following the 1967 Middle East war, when the Arabs felt incapable of communicating with each other or with the outside world. At the meeting of Arab Ministers of Information in Benzart (Tunisia) it was decided that a study on the use of modern technology for developing Arab information media should be undertaken. But plans for implementing the satellite network were completed after the 1973 war, when the joint will, international influence, mutual confidence, and financing were available. Thus, an expensive and sophisticated technology allowing for multicultural right to communicate could not be realized until there was a shift in power and in wealth.

The advantages of an Arab satellite interconnected network, with a community reception capacity, are said to be the elimination of the sense of distance, support to the broadcasting services in the Arab countries, more educational chances, and the possibility of connection with international networks. But Clergerie and Dill add other responsibilities to the network. They say it can function better than presenting, explaining, and handing down government views.

Through broadcasting, a permanent dialogue between the various groups of society is installed and kept alive. Rural audiences share the entertainment of the cities. The highly educated learn about the struggle of the worker and the farmer, the young and the old learn more about each other. . . Field workers responsible for the 
execution of government policies need constant motivation and confirmation. . . Whether the problem is nutrition or child care, agricultural growth or spread of knowledge, ... the job of broadcasting and the horizontal co-operation of many branches of government must be secured and institutionalized to make the tool an effective one. 13

This example demonstrates another dimension of the right to communicate, namely, the extent of its relationship with the need for participatory approaches. Despite the fact that the function of various means of communication is often regarded in many developing countries as a mere reflection for the state's opinion, in these states the participation concept receives growing support. In November 1975 a Round Table Discussior on Development Information in Khartoum underlined "the necessity to think of development information as a concept that supports the maxim: development is popular participation." 14 It also indicated the need to "establish a coherent comprehensive and integrated two-way flow of communications for development:."

The link between the right to communicate and development communication becomes clear when we find that the three partners who must cooperate with one another to achieve these two objectives are the governments, the public, and the professionals. The right to communicate cannot be practiced unless the governments are ready to apply to their countries what their delegates proclaim on international rostrums concerning rights and liberties. As for the public, they have to know what are their rights and form "any legitimate grouping... which have set or are working on setting common goals, and see communication and its technologies as one of the ways to achieve them."15 As for professionals, their roles should not be restricted to their being mere amplifiers of government communication messages; in addition, they have to represent the two-way relay station between the individual and the government, the simultaneous and instant upward and downward communication.

I have no doubt there are many and intolerant warnings, restrictions, and pressures, especially in the recently independent Third World countries, that hamper the realization of cooperation among the three parties in each country because of their unequal weight. But it is hoped that: (1) the government will make sure that when a citizen attains some right, this does not undermine the authority of the state, or mean that what is added here is lost there; (2) the individual will make sure that the rights he attains are always bound to the rights of the society as a whole; (3) professionals will ensuxe that rights entail responsibilities and obligations.

\section{NOT TO COMPARE}

There was an attempt in Egypt in 1970 to reach a formula within which the three elements will work for broadcasting through the law passed on the reorganization of "the Radio and Television Union." The law stipulates that the high authority of the union is the Board of Trustees, which comprises a number of broadcasters as well as public figures who represent various disciplines. "Though such public figures are appointed by a republican decree, their presence besides the professionals guarantees the availability of advice . . and link between the various activities of public life and broadcasting. It helps the Union to carry out its tasks in a way which makes it worth more independence and at the same time renders it committed for expression 
which is more associated to the people in every field."16 Though the minister of guidance is the link between the union and the state, and is entitled to attend the Board of Trustees meetings and be immediately informed of its resolutions, there is no article in the law giving him the right to object to the board resolutions. In the United Kingdom, for example, the postmaster general can ask the British Broadcasting Company not to broadcast at any time certain specified material or materials, whatever they may be.

Of course I am not here to compare the Egyptian Radio and Television Union with the $\mathrm{BBC}$, or to say which is more independent or committed (finally, to what?) or which is more capable of providing to the public the right to communicate. It is not my objective to say that my country, Egypt, is more or less democratic (according to the Western concept) than is Britain or any other country. In Egypt, there is only one party representing "the alliance of the peoples' working forces." The work of this party, the Arab Socialist Union, has been overshadowed in the past by errors that were painful. Sometimes the press right of freedom and other rights that were no less vital were sacrificed with the hope of attaining objectives such as liberation from neocolonialism, building the High Dam, and opening two schools every three days to educate the farmers' children. I am not here to justify the waste of the individual's rights (if anyone believes they have been wasted), but I only want to say that the criteria of liberties and rights differ from one society to another.

Confining my observations now to the field of broadcasting, I will cite several examples that could be regarded as basic impediments in the way of the right to communicate in the Western democracies. If I had said, for instance, that in Egypt the president appoints the members of the Board of Trustees of the Radio and Television Union, such a thing is not strange. In Japan, such a right is being practiced by the prime minister. Nor is it strange to the Federal Republic of Germany where every "Land" appoints the regional council of the broadcasting station, or to Italy where the Radiotelevisione Italiana Board of Directors includes representatives of the president of the cabinet and the Ministries of Foreign Affairs, Interior, Treasury, Economy, and Telecommunications. My background does not permit me to understand how a person in the United States is allowed to own five television stations and seven radio stations, and how companies are allowed to own more than that. Neither could I understand from my own viewpoint how advertisers, who represent major industrial and commercial monopolies, could control culture and information transmitted to the public through the mass media. Who, then, is to own the right to communicate in such an environment? And if it were possible for public broadcasting corporations in Western Europe, for instance, to achieve more independence through the collection of license fees (which have undoubtedly amounted to $\mathrm{E} 100$ million or more in the $\mathrm{BBC}$ ), with the hope of attaining more rights for communication, then how can I attain this in a country like Egypt where the number of television sets is about seven hundred thousand (the largest number in the Arab countries), most of which are not licensed because of administrative inefficiency and the citizens' sense of irresponsibility.

What I want to say is that our minds (and why not also our hearts) should absorb the fact that criteria vary from one country to another. Mahmoud El-Sherif, president of the Arab States Broadcasting Union, tells us the story of "a woman journalist who came to Qatar and said that her interest is mainly focused on exciting stories about the Gulf. . . I categorically told her that the image in 
the mind of the publisher about the desert princes is unfair and probably a production of the imagination of those who regard Arabian Nights tales as the sole source of their information about the Orient. Before leaving Doha, the journalist made it clear that what she failed to understand was how the people managed to achieve such a standard of progress without political parties, or elections, or parliament, or even a press speaking for the opposition. The thinking of that lady was based on the special visualization of a Western political system which she believed was one of the necessities accompanying human existence anywhere. "17

\section{AMIDST'ABSTRACT THEORIES}

I believe, like any other communicator, or like any other individual, in the right to freedom, to self-determination, and to communicate. How I wish that my faith were without reservations. But at a time when Beirut is burning, and the future of simple Palestinians and Lebanese and perhaps the future of the entire area is threatened by a real danger, I fear the falsity of some democratic slogans that use a large sector of the press as voices of foreign powers and that tie the broadcasting tongue.

I call on all those concerned with the right to communicate and the freedom of the press to look at the facts of the Lebanese situation. A case study can help us identify the dimensions of that right amidst abstract theories on which discussions in this field were sometimes based, with a view to communicating this new philosophy to individuals and to professionals in particular.

If those individuals and professionals could not exercise that right in our present generation, for "the younger generation, raised in the midst of a communication revolution, a generation now about to assume leadership, this [the new age of free circulation of the message] will not be a stumbling block. . . . For them the problems in relationship between the state and a mature public will be solved by a new style of government and of public life."18

Let us work for the sake of that generation. 


\section{NOTES}

1. Ortent Press, Radio Sherif Al-Akhawy from Betrut, Roz Al-Yousstf, 2480, (n.d.), p. 17.

2. Hassan Al-Assan, Public Oplnion, Informatton and Public Relations (Beirut: Ad-Dar Al-Lubanteh LII Nashr [n,d.]), p. 170.

3. Nabil H. Dajant, Lebenese Broadcasting: Control Amldst Freedom, to be pubIished by the Internathonal Broadcast Institute, London, p. 27 (draft),

4. Baha Abu-Laban, "Factors in Soctal Control of the Press in Lebanon," Journalism Quartexly 43, 3 (Autumn 1966): 510-518.

5. Dajani, Lebanese Broadcasting, p. 7 (draft).

6. Abu-Rabl, Al-Hawadeth, 994, Belrut (28 November 1975).

7. Rlad Taha, at a press conference on September 7, 1973.

8. In a speech delivered on recelving the Paul W. White Memorial Award at the Annual Convention of the Radto and Televiston News Directors Assoctation, Dallas, Texas, September 19, 1975.

9. BahraLn, Iraq, Kuwalt, Oman, Qatar, Saudi Arabia, and the United Arab EmLrates.

10. Hamdy Kandi, Gulf-vision Network, English vergion to be published by Unesco In 1976.

11. "Report on the Televiston News Exchange in the Reglon of the Gulf and Arab Penlnala between 1 January 1974 and 31 December 1975," Kuwatt Televiston, February 1975.

12. Michel Hédayat, "Outlying Organizations and EVN Transmisgions," EBU Revlew 26. 3 (May 1975): $30=31$.

13. Bernard Clergerie and Rtchard Di1l, The Arab States Media Innovation Syltem (ASMiS) = Communteation Satellites in the Service of Broadeasting, Edueation and Development, to be published by Unesco in 1976, p. 12 (draft).

14. Report of Round Table Direussion on Development Information (Khartoum: UNICTET, Novermber 1975)。

15. Gunnar Naesselund, "Relations between and Perspeetives whth 'Development Support Communication, 'Communications Poliey and Planning;, and 'The Right to Communicate' as Seen by Ünesco, " Paper presented at the fnternational Broad = cast Institute Annual Meeting, Cologne, September $1=4,1975$. Reprinted in Right

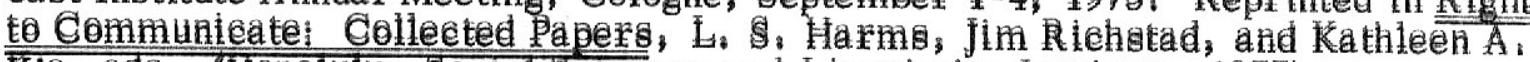

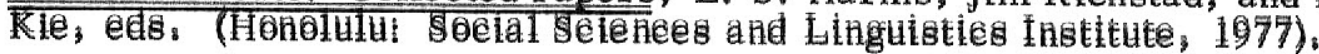

16. Hamdy Kandil, "Broadeasting! Between fndependence and Obligations;" Al-Ahram; Apri1 8,1970 , 
17. Mahmoud E1-Sherif, "Communication Media and Political and Economic Pressures," Al-Doha, n.d.

18. Jean d'Arcy, "The Right of Man to Communicate," Paper presented at the International Broadcast Institute Annual Meeting, Nicosia, October 1973. Reprinted in Right to Communicate: Collected Papers, L. S. Harms, Jim Richstad, and Kathleen A. Kie, eds. (Honolulu: Social Sciences and Linguistics Institute, University of Hawaii, 1977). 


\section{4}

COMMUNICATION ENVIRONMENT:

SOME GENERAL PERSPECTIVES 

One of the great challenges of the right to communicate is development of a multicultural statement of some universality, one that takes into account the many perspectives of humans in their communication environment. That these perspectives vary widely is clear, as virtually all the essays in this volume show. But instead of adding confusion and disarray to the concept, they add a richness to our understanding of the communication environment itself as well as to the right to communicate.

A universal statement of the right to communicate does not necessarily mean there will be a single guide for every individual, every society. But there can be a flexible guide, one that accounts for the differences in individuals and in societies and for differences that arise over changed conditions. A nation at war, for example, is likely to take a different view of the right to communicate than does a nation at peace; one in the midst of communal conflict is likely to place a higher priority on public order than it does when there is quiet and cooperation.

The approach to the right to communicate begins with the wide differences; it respects such differences and tries to accommodate them in an overall, multilevel, differential concept of communication rights. There has always been a temptation to rush to specific communication rights--speech, press, access, privacy, and so forth--because they are something "concrete," something that can be argued, for which legal and philosophical precedents are available, and for which hard comparisons between societies can be made.

This last group of essays deals with the broader issues, the environmental perspective of the right to communication. The authors bring in a wide range of viewpoints, concepts, and relationships.

Some basic perspectives on the right to communicate emerge from the essays in Part IV. Perhaps one of the most important, at least to those with a Western view of the world, is that the principles of the right to communicate can be found in other parts of the world, with a long history and tradition of their own. Many of the principles related to a right to communicate, Ali Mohammad Shummo tells us, can be found in the broadly religious way of life found under Islam. He details eloquently the central role of religion in the broad sense of a way of life, and how such principles as dialogue and argument to bring out facts, independence of mind, personal discretion, and individual liberty relate to a right to communicate.

When the editors started seeking right to communicate literature in Asia a few years ago, we had a great deal of difficulty at first. Then we were given some advice: "Look to the religious writings." Shummo has given us some insight into the fertility of that approach. 
A nother broad perspective that comes from the essays is the sense that the right to communicate is important in both developed and developing countries, perhaps for different reasons. Colin Shaw notes that in developing countries a unifying communication system is needed, whereas in developed countries the need is to ma inta in pluralism.

Many of the themes of the preceding essays come through here and will be recognized by the reader. But the overall impact of such themes is that by their differences they give us a multicultural perspective of what the right to communtcate means, and can mean, on a global scale.

As a sociologist, Pavel Campeanu opens his essay with the concept that "social structures . . . determine the way people communicate," and that there are great inequalities within communication environments. Although a social environment may not be conducive to a right to communicate, this should not discourage efforts to outline the right for the future. "The right to communicate appears to me to be ... [a] utopia--with some expectations, not imminent, of course, of becoming history." The right to communicate shifts the focus of study from a "free flow" consumer to the human as both a "consumer and producer of communication." Campeanu notes that the more professional and complex the process and instruments of communication become, the less likely it is that a consumer of communication will also be a producer. Distinctions are drawn between the public and private communication systems, and further concepts in a definition of communication are explicated. The right to communicate, Campeanu believes, is "thus a synthesis of individual liberties," and he lists nineteen specific points. These include "to choose the conlocutor," "to accept the conlocutor," "to refuse the conlocutor," and similar choices such as "to answer," "not to answer," and "to receive an answer." Campeanu then enumerates important changes to be made in the model of communication if a right to communicate is to become a reality. These include "gradual deprofessionalization of the public circuit" of communication and "worldwide regulation of social and national. inequalities in the field of communication." Study of the right to communicate "implies in the first place to transcend a historically determined situation and to outline a choice model."

The second essay in Part IV immediately raises the question of whether the right to communicate is something for only the developed countries with sophisticated science and technology. Shummo notes that most people in the Third World are not aware of Article 19 in the Universal Declaration of Human Rights, much less the newer concept of the right to communicate. And, he asks, is even Article 19 implemented? Shummo is objecting not to the concept but to the "practice and exercise of the right to know" in most. Third World and some first and second world countries. Shummo draws on Islamic tradition to show that the right of expression and opinion and to be informed are included. Dialogue and argument are encouraged, he says, to bring out the facts and to inform. He notes that although "normal inhabitants of the Third World are unaware of the existence of such a right . . . they practice it." He says the people "employ their instinct in seeking information needed for everyday life, they receive what is meant for them to receive, and they impart what the system of the society allows." Thirteen factors are given that relate the right to communicate with the Third World conditions and are recommended to researchers in assessing the right to communicate. Three factors, culture, tradition, and media available, are listed as the most important ones. Shummo notes the domination of behavior by the Islamic faith in the Arabian peninsula and in the Middle East in general. He notes that religion is more progressive concerning communication rights than is custom or 
tradition. Another general perspective Shummo discusses is the need both to inform people of the right and to educate them in communication skills so they can employ the right. Special attention is given to the electronic media, and their actual facilities and means to open communication. The worst practice concerning Third World countries, Shummo argues, is the imbalance in the international flow of communication, because little information about the Third World goes into the global communi cation systems. The right to communication in declarations is not enough, he says; the scientists and professional communicators "should go further and examine the practice of the right of the individual, to see whether it is honored or neglected." Shummo charges communicators with the task of seeing that the right to communication is respected.

The perspective taken by A. F. Kalimullah is from his background of broadcasting in a developing country. The problems inherent in a right to communicate, though immense, can be overcome, he says. Stress is placed not only on the right to communicate but on the willingness to listen, on developing mutual understanding. Communication by its nature needs a mutual interest-otherwise it is not effective. The author joins others who urge better implementation and practice of Article 19 rights before expanding into the right to communicate. Conflicts are inevitable, he says, between the state and the individual on communication rights. While an individual has an "equal right and opportunity to communicate," the same right and opportunity must be accorded to others. Concern is expressed that existing communication facilities are not being used effectively, and that what is available is not evenly distributed throughout the world. The means of communication are stressed, as is the access to the means, as a foundation for the right to communicate. Given adequate facilities and access, the major constraint on the right to communicate is political. The process and consequences of communication must be considered in developing the right to communicate. "The content, the quality, and relevance of communication to the cause of world peace and progress must be judged before we can speak of the right to communicate." The lack of a universal language is viewed as a great handicap to world communication. The imbalance in distribution of information, unfavorable to developing countries, is seen in a context of neocolonialism, and the reaction of the Third World is that it makes difficult "a meaningful exchange of communication among all the peoples of the world." Kalimullah ends with an optimistic note that the world is in a mood of "compromise instead of confrontation, mutual exchange instead of isolation." Everyone should have an equal right to communicate, and should be "at the same time, equally willing to receive others' communication with patience, sympathy, and understanding."

Astrid Susanto looks at the right to communicate in Indonesia, noting that "For countries like Indonesia that have a traditional and feudal as well as colonial background, the enjoyment of these liberties [freedom of speech and information] is not a matter of fact; it has to be encouraged by the government itself." She moves from the formal documents of freedom of speech to field data. The right to communicate varies because of the educational and social background of the individuals and the political situation of the country. Documents stressing "interdependence of the individual and his society," and of a right to communicate, including a "talking back" provision, are examined. The government is charged with giving information to the people, providing means accessible to the public, and stimulating the public to communicate more actively. "The right to communicate," she notes, "depends a great deal on . . internal stability." Susanto traces the importance of a right to communicate in the development process: it is a means of getting upward communication from the people to the government. Susanto notes that the right to communicate 
does not guarantee that what is said "will be accepted and carried out by the government." Stress is put on utilization of indigenous media by the electronic media to increase two-way or interchange communication. It also was found that the introduction of electronic media in a village increased the horizontal communication with nearby communities, as compared with the vertical viliage communication pattern. The government has also started pilot projects on regional newspapers, to increase communication, she notes. Several other communication activities by the Indonesian government are noted as a positive fulfillment of aspect of a right to communicate. This effort at upward communication, Susanto says, indicates a "spirit of the government" that is more important than communication rights in official statements and documents.

Colin Shaw's essay provides a broad perspective on the right to communicate, with special emphasis on the role of broadcasting in giving meaning to the right. He notes the differences in societies and how they relate to developing a multicultural right to communicate, and says the hope for success "lies in the cultivation of mutual respect for the significance of these differences wherever they occur." The right to communicate, Shaw says, "reflects a fundamental human need to communicate as the basis of any kind of social existence, "but he questions whether. acceptance of this now is "more than intellectual." The right must be seen as an "evolving" one. In what he calls "fair sharing," Shaw calls for correcting the imbalances in communication facilities between nations; the exercise of the xight to communicate is dominated by the "unequal share of communications resources." This will entail new priorities both on an international scale and on national scales, giving communication larger shares of the attention of planners and aid-givers. National radio and television programs have high priorities for Shaw because they can be received virtually everywhere by everyone, and he stresses that postal, telegraphic, and telephonic services, while largely personal, are strongly two-way. He contrasts the use of national broadcasting in developing countries to achieve a. "measure of homogeneity" with its use in developed countries to maintain a plurality of interests. He raises the question of how far plurality can go before the nationstate disintegrates into anarchy and "the right to communication is vitiated by a refusal to listen." A parallel question is how practical is access to the media for all groups in a country, and what are the means through which such access can be achieved? International communication, Shaw notes, has its benefits and risks. High on the scale of risk is the chance that a culture will be overrun by, say, imported television programs.

Shaw comes down strongly for national control of international communication, much as Beltran and Fox de Cardona do in Part Il. "A community, by whatever means it chooses to adopt, has the right to regulate communications of this kind [what are perceived as detrimental television programs] from outside its boundaries as a legitimate aspect of its right to defend itself and its identity against physical and moral dangers." Shaw recognizes the inherent conflict between a nation's right of control and the individual's right "to a free flow of information, even wrong information."

Shaw also examines the differences in thinking in a communicationabundant world--the world the coming generations axe finding--and the thinking carryover from communication-scarce worlds. Although the instantaneousness and wide reach of broadcasting is often a positive value, it does remove much of the earlier moderating process of slower means of communication. The need for mediating steps will be necessary "for those who seek the preservation of coherent 
communities operating at more than relatively primitive levels of organization." Without "some kind of moderation . . . to place what is seen or heard in the context of the knowledge and experience of individual communities or people," the right to communicate may simply mean television has "a right to construct a latter-day Tower of Babel, visual in character as well as verbal." Another broad consideration is the growth of the concept that some rights of individuals "are not necessarily coterminous with the right of the states in which those individuals live." International public opinion, Shaw notes, "may be a precondition of survival," and "single ears and tongues of governments may be insufficient for understanding when their peoples have ears and tongues of their own." 



\section{A SOCIOLOGIST'S VIEW OF THE RIGHT TO COMMUNICATE \\ PAVEL CAMPEANU}

It is not the way people communicate that determines the social structures, it is the social structures that determine the way people communicate. Opportunities are scarce for an equal right to communicate to become effective in a world so unequal as to sanction its actual division by numbering its very fragments. We know there is a Third World; perhaps in time we shall find a second and a first. What we know certainly is that neither disparity nor its awareness has ever before reached such a peak.

Striking inequality between nations and peoples is doubled by that of the members of the same society. Democracy is most often reduced to mere equality before laws avering basic forms of inequality.

The social environment in which communication systems are set is not, as a rule, the kind to stimulate the practice of the right to communicate. This outward tendency, so to say, becomes even more manifest when it is considered together with the inner development of the communication system itself. I will not dwell here any longer upon this point, the development of communication technologies.

This context is seemingly not very encouraging for the effort to define a right to communicate. However, progress has seemed to occur not by simply adjusting the thought to a given condition, but, on the contrary, by courageously transcending that condition and striving to project the outlines of a future that at first look seems unlikely to occur.

Not all utopias were rendered historically real, whereas all definite historical changes have been backed up by fertile utopias. The right to communicate appears to me to be such a utopia, with some expectations, not imminent, of course, of becoming history.

I attach to the passing from the idea of free flow of information to that of right to communicate the significance of factual development integrating into scientific thought. Such development essentially showed that the freedom of this flow does not involve the freedom of man in the field of communication.

The above distinction implies philosophical and methodological aspects.

The philosophical aspect: in his capacity as beneficiary of the free flow of information, man is univocally defined as the object of an outer and thus strange action. This approach is at the same time correct and disarming. It acknowledges the reality of man's alienation before the main processes of social communication. The concept of free flow casts an image of man as receiver. Political 
and scientific recognition of this image brings all research down to a strictly descriptive function.

The right to communicate makes possible for the first time the creation of a different image: instead of man as object, man as embodying the unit subject-object in the field of communication activity. Under the incidence of such an approach, that system which we call the human person is connected to social com munication not only by input but also by output. He is at the same time consumer and producer of communication.

However, this is only the image of a possibility. And an image is usually hiding the dormant power of a model to be. The real world distinguishes between the object and the subject of communication, the sender and the receiver. The right to communicate transcends this limit. It maintains a possible world in which the human person would acquire his position of subject and object of history. Man would cease to be but the possession of this history, which would belong to him. A product of communicational environment, he might act as its producer, too.

The methodological aspect: this indeed requites, as some authors suppose, among them L. S. Harms and Jim Richstad, a redefinition of the concept of communication.

In what follows I intend to outline, from a sociologist's point of view, a couple of premises that I consider useful for the definition of communication, and thus of the right to communicate.

Any human communication implies the elaboration of a controllable technique. In the case of speech, as initial and constant modality of human communication, this technique is double:

1. the physiological technique of articulated sounds emission and accurate perception of this emission, and

2. the technique of information formalization into acoustic codes, words, and their fluent decoding.

These techniques are easily acquired by all normally gifted individuals, being assimilated in the appropriate span of training. Their accessibility is included in the genetic, psychophysiological code of man.

Speech is the genesis of all communication. The first revolution of this social activity is writing. By writing, the psychophysiological centers of emis sion and reception change. Writing means a double formalization of information: formalization of the initial formalization, that is, speech. The essence of this revolution is by no means of a technological kind. Besides other conditions, such as codification of acoustic codes, writing implies:

1. an instrument of performance, and

2. a proper object to be acted upon 
The revolutionary essence of these two factors is given by the fact that it is through them that human communication techniques are for the first time separated from the human body. Communication becomes, this way, no longer a psychophysiological performance but a technological one. Psychophysiological aptitude is acted out by means of freestanding instruments, introducing an original element between sender and receiver: a mediating technique whose development in fact coincides with subsequent development of communication. The ancient scribe is the forerunner and peer of the contemporary cameraman.

The appearance of the first technological element, in connection with writing, coincides with the appearance of the first professionalization of communication. From a rather accessible activity, speech, communication becomes a choice privilege, writing. Writing deprofessionalization has been an extremely long historical process, and as a matter of fact has not yet been fully accomplished. Still, to understand the present situation, what seems essential to me is neither the duration nor the imperfection of this process: what counts is the fact that it takes place.

The instrument of communication can be employed while meeting at least three requirements:

its possession, access to the use of it (for those who do not possess it), and the capacity to use it effectively.

Communication development is tracing a nonsynchronous chain of discrepancies:

--between development of instruments and the opportunity to possess them

--between development of instruments and the capacity to use them

- -between the property forms of the instrument and the competence to handle them, etc.

The more sophisticated communication technologies become, the more difficult and complex the condition of capacity becomes. The profession of communicator is not only more and more precisely delimited but also more and more difficult of access. It indulges not only in distinguishing itself from the rest of society and other professions but also in subordinating more and more individual professions, such as engineers, technicians, tailors, and joiners, so that a television studio comes to incorporate such a diverse and widely distributed staff as is hardly available in other enterprises or institutions.

The profession of communicator is distinct in two ways: it distinguishes itself both from the specific communication property and from presumptive consumers of communication. These two are, however, not equally rigorous: it is difficult for a professional communicator to become owner of a communication property, whereas an owner of such a property can assimilate the role of communicator, too, even if not the professional status. However, on a mass scale, the chances for the communication consumer to become a professional producer of communication are few. 
The model of this double division of communication activity tends to take the social pyramid form:

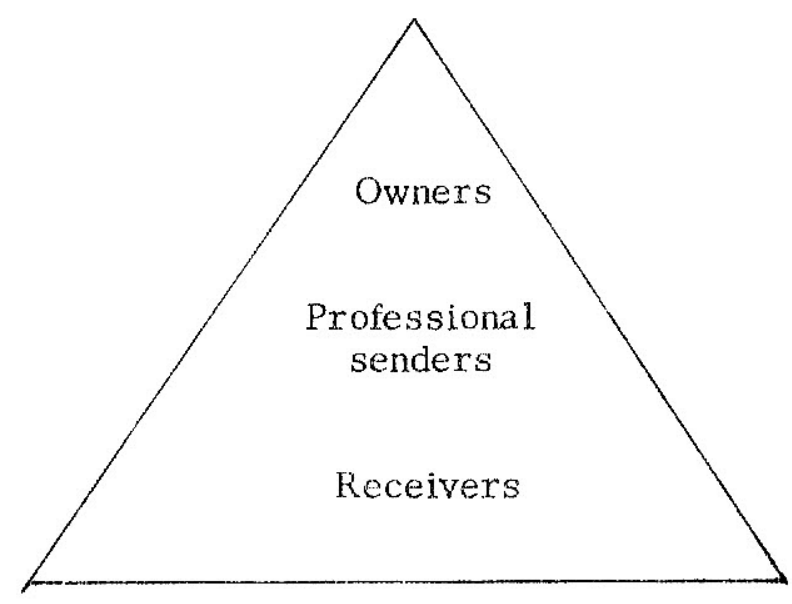

The statistical dimension of these groups rapidly narrows from base to top. Mobility relations between them are preponderantly unidirectional: from top to base.

The rigorously defined condition of professionalized sender imposes the rigorously defined condition of nonprofessionalized receiver. The invariable activity of reception is the complement of the coherent activity of emission.

The right to communicate is insistently correlated with the professional's situation, his freedom of opinion, protection against various social, politi cal, or economic pressures (the latter from owners), etc. The Code for Journalists, for instance, represents a perspective for future regulation of the existing situation. The question is whether this situation is to be regulated or, in the first place, eliminated. The eventual application of this code can be understood as a guarantee for the professional senders to express their opinions freely, which implies the absence of freedom of nonprofessional receivers to become professional senders.

The professionals have to be defended as long as they exist, without forgetting, however, that it is their very existence that expresses a continuing fundamental social inequality in the field of social communication.

The practicing of this profession is prohibitive: it requires specialized education, that is, means, and, among other things, a certain social status. Whether the profession is defined by the function of sending, so the object of prohibition is just this function.

The scribe was a direct producer of signs. The contemporary journalist is the producer of a score capable of being turned into a journalistic message exclusively as a result of the growth of the polygraphic industry. Because of the electronic technology of long-distance transmission and reception of sounds, the radio journalist is the stentor of modern times. Industrial processing of speech and of writing does not assume giving up "nonindustrialized" speech and writing. These are but perennial forms of communication that feed all subsequently invented forms and coexist with them. 
The process of social communication is thus subjected to the general laws of industrialization, which are essentially strange in this connection. Among these, I mention:

1. the tendency toward monopoly or nationalized forms of property

2. the social division of labor, which in the present case becomes social division of communization activity as expressed in the distinction between senders and receivers

3. mercantilization of the product

4. in accordance with such mercantilization, a tendency to increase the quantity of specific products, to eliminate competition, to increase consumer modeling and forcing

As far as it is compelled to adopt the industrial model, communication is bound to a crippling process. A synthetic expression of this crippling is given by the centralization of social communication, a process simultaneous and parallel with the centralization of political powers, to be seen in so many countries.

Communication centralization represents the most direct and decisive premise of inequality in the practice of the right to communicate. The main mecha nisms by which this premise becomes effective are, in my opinion, the distinction between public and private, and manipulation.

The decisive instrument that civilization elaborated to assure the cohesion of society is power. The expression of this cohesion is res publica: the public matter. The implication of such a cohesion is the distinction between public and private spheres and, further on, subordination of private existence to the public one.

The reflection of this segregation in the field of communication has variable forms within a constant structure.

The main variable: The stentor was an exceptionally gifted person from a physiological point of view. The point to which his voice could carry determined the radius to which the town was built. The function of this unit of measure was essentially communicational: it stood for the possibility that all the inhabitants should simultaneously receive the important information. But which was the important information? Of course, it was not that which the stentor himself considered to be so, but that which the leaders of the town asked him to announce: information that became of public interest because it came from the power, personification of the public matter.

I insist on these already known aspects with a methodological aim. They prove that the stentor acted not as a citizen-sender of information but as an instrument of communication, mediating between the public authorities and citizens. This means that in the field of social communication the mediating instrument appears under two circumstances:

1. when the communication technique is distinguished from the human body, irrespective of the specific character of communication, and 
2. when the specific communication consists of messages that the public authority addresses to private individuals, irrespective of communicational techniques controlled by the society (thus, also, in periods in which this technique is exclusively made up of speech). If these remarks are right, than the development of communication technique and of public communication spontaneously converge toward the introduction of mediators in the flow of communication. In this case the two tendencies, although autonomous in the sphere of causality, complete reciprocally in the sphere of effects, thus favoring each other. Advances in communication technologies are in this way consolidating the practice of authority. They represent an innocent way to get the citjzens accustomed to the role of receivers of no retort.

The constant structure: Power messages belong to the public sphere by their content. Mass communication messages belong to the public sphere by the magnitude of the zone they penetrate. Technology is thus in the service of power no matter what the intentions of the people who create or supervise it. The interference of technology and power makes up what could be called the public circuit of social communication. This circuit includes:

1. all messages addressed by the power to citizens, irrespective of the sending channels (so interpersonal communication is included), and

2. all messages sent by channels having a large range of action, no matter what kind of information the channels carry.

Together with this public circuit there continues to exist what might be named the private circuit of social communication. This circuit includes:

1. all message exchanges carrying information of private interest

2. all message exchanges that do not use the channels having a large range of action, no matter what kind of information they carry

A possible remark that two statesmen can privately talk about some public matters is not peremptory. The statesman represents the personification of the public matter. He is forbidden a right to privacy, even regarding his most intimate affairs, so the private circuit is closed to him.

There are additional aspects of the private circuit of communication:

1. Private communication amounts to fundamental forms of speech and writing. It includes some mediating techniques, which, however, bestow on the message no other range of action than that intended by the sender: typewriter, telephone, etc. The secrecy of correspondence or Watergate's bugs and wiretaps are but examples of measures society adopts to maintain the private character of this circuit.

2. Private communication implies as a rule the interchangeability of sender and receiver. The public communication archetype is the speech, while that of private communication is the dialogue. The latter is characterized not by a linear but by a cyclical process. It 
does not stretch between two terminal points, the sender and the receiver; it is a relation between virtual equals.

3. In the public circuit, the given information is transmitted by a unitary message (its variations being, in general, reduced to the number of subsystems: radio and television stations, newspapers, etc.). In the private circui.t, however, the given information is transmitted by a multiplicity of messages whose variations are aimed at equalizirig the number of people circulating it.

4. The private circuit has a larger group of subjects than does the public one, because the first involves personal and group events, and events of social importance, too, whereas the latter conveys only events of social interest. Even when transmitting personal and group events, the public circuit covers events of social significance, by modifying their character in this sense.

5. On the other hand, all communication takes more or less explicitly an axiological position to the event that forms its object. A new distinction between the two circuits presents itself: in the private one, the axiological position aims at a maximum disparity, whereas in the public one, following from outer command and a number of general, relatively stable criteria, there is less tendency to disparity.

The constant structure of social communication is thus represented by its dissociation into two distinct circuits: the public and the private. The first has a systemic character, made up of steady elements and with relatively coherent functions. The second is based on the interchangeability of main elements, its rules of discharge are less clear, so its systemic character is doubtful. It tends rather to dissolve into the supersocial, global system, including virtually all its members.

The importance of this structural organization comes from the fact that it circumscribes the right to communicate. Usually the members of the society have whole access (both as senders and as receivers) to the private circuit, but only partial access to the public one.

Politology deals with the political system as though it is a network of informational circuits. This seems to me a legitimate approach: as long as power is the main factor of social cohesion, communication is the main instrument of power. The prevailing bulk of public communication therefore has a coercive character. By its various formulas, this indicates the degree of the continual disjunction between the social organization and the individuals it integrates. Such historically elaborated forms of integration are war, repression, threat, constraint, manipulation, persuasion, education, and option. Some of these coexist in time or space. The preponderance of some of them characterizes the most distinct epochs, but generally their mixture varies from one epoch or country to another.

Our epoch, far from evincing an exquisite delicacy in reconciling individual with society, seems to me distinguished especially by a new qualitative appeal to manipulation. It was not the twentieth century that invented manipulation. We have, however, settled it on some other bases. Between the young Egyptian who offered his life for the ritual sacrifice and the modern consumer of useless products, 
the difference is not only of proportions but of decision mechanism. Once, manipulation was action (the religious one, for example). Today it is a system. Once manipulation was based on organization; nowadays it is based on two techniques: a communication and a psychological technique of influence. The passing from organization to technique means the passing from the perceptible to imperceptible manipulation. This is why sermons are less and less employed. The place of the sermon has been taken by "Mamix" who does not ask his receivers to be virtuous, only to let themselves be entertained.

Manipulation is the benign form of coercion. Its specific action consists of disturbing the mechanisms of individual decision. By manipulation, individual behaviors are determined or barred in accordance with an outer program. The subject is spared both the displeasure of violence and the trouble of persuasion. The essence of manipulation consists in dissimulated subordination. It is a succedaneum of adhesion. Thanks to it, explicit oppression becomes implicit.

By manipulation, man is expropriated by the very essence of his inferiority. Manipulation is an impersonal imposed action, which the subject perceives as a personal free option. The command has the appearance of a inner initiative. Whereas open oppression causes indignation, manipulation causes pleasure for its victims.

The principal domains couched by manipulation are consumption, politics, and morals. Its by far most decisive instrument is the public communication circuit. Its technique is scientifically elaborated by an interdisciplinary effort supported by fabulous financial means.

And there are not, as far as I know, any laws to protect a person against this strategy of his own deterioration, with social and psychological consequences whose seriousness could compete with that of ecology in some scores of years.

With regard to what was said above, the definition of communication should include such elements as:

the relation between the private and the public circuit

the distinction between active communication (emission) and passive communication (reception)

reciprocity

finality (of sender, receiver, conlocutors)

The right to communicate is thus a synthes is of individual liberties:

to choose the participant in an interpersonal dialogue (conlocutor)

to accept the conlocutor

to refuse the conlocutor 
to give information

not to give information

to receive information

to refuse information

to answer

not to answer

to receive an answer

to agree to be conlocutor

to refuse to be conlocutor

to enjoy access to the public circuit as protagonist

to enjoy access to the public circuit as receiver

to take part in the social control on the public circuit

to have opportunities to choose among different public messages

- -that is, to resist aggression.

to influence the programs sent by public circuit organizations (radio, newspapers, television, etc.)

to enjoy access to the whole inventory of stored or actual information not to be manipulated

With the scope of this approach, to pass from a proclamatory stage to that of social reality, the right to communicate would assume some important changes in the present model of communication. Among these are:

1. gradual deprofessionalization of the public circuit

2. social control of the public circuit

3. elimination of quantitative excesses in the public circuit: reduced duration of television programs and number of channels, reduced investments in advertising, etc.

4. broad public information with regard to manipulation mechanisms

5. the establishment of scientific centers for manipulation prevention

6. the establishment of a substantiated equilibrium between the private and public circuits 
7. worldwide regulation of social and national inequalities in the field of communication

All rights express a moral aspiration as well as a force relation. The right to communicate is no exception to this rule. To study it does not mean to impose it. Like all studies, this one implies transcending a historically determined situation and outlining a choice model, whose first function is not application but pointing out the weakness of the existing one. 


\section{THE RIGHT TO COMMUNICATE AS SEEN \\ IN DEVELOPING COUNTRIES}

ALI MOHAMMAD SHUMMO

It seems that the concept of the right to communicate will remain sophisticated and somewhat luxurious in most of the developing societies. Although it is fundamental to every society and each individual in the society, it does not in reality pose as such. It is regarded in some areas by a number of scholars as the right that comes next to the right to live, the right to work, the right to be educated, etc. Even the right to know, which was clearly expressed by Article 19 of the Universal Declaration on Human Rights, has not been fully exercised by all nations, particularly in the Third World, for different reasons, largely political. Therefore the right to communicate, which is a step forward or an expansion of the right to know, might not sound logical to a man who is deprived of knowing what goes on around him in the world. Such a factor must be borne in mind when a scientist from a highly developed society attempts to write about the right to communicate in the world or to analyze what is written on the right to communicate in a developing nation.

There is no doubt that the right to communicate is an established scientific concept. In the meantime, some scholars have discovered that the right to know fell short of satisfying the needs of mankind, which have developed greatly since the right was recognized as a human right in 1948. Therefore, when we consider the right to communicate, we embrace the right of the individual to know and we expand it to a wider area of human needs. What I mentioned above regarding the practice of the right to know in developing countries might lead to a false conclusion. It may suggest that I deny the recognition of the right to communicate in the primitive or undeveloped societies. That is not so. I refer only to the practice and the exercise of the right to know at the present time in most of the countries of the Third World and slightly in some of the other, first and second worlds, and not to the concept. In this connection I cannot claim that I am an expert in the whole of the Third World or developing societies. My experience is confined to certain parts of East and North Africa and "the Middle East," whose great part belongs to Asia. Therefore I hope that my views will be interpreted accordingly and not taken as general judgments.

\section{BACKGROUND}

In the Arabian peninsula there were societies that had existed for centuries before the advent of Islam; it was a cradle of cultures and religions. What was described in our culture as "Jahlia" (The Ages of Ignorance) was followed by the appearance of the Prophet Mohammad whose teachings called for the establishment of the system of government that prevailed during the Khalifa's reign, and this system continued for centuries. The religion of Islam and the system of government it founded secured civil rights to each individual in the state and defended his rights 
against any violation, even by the ruler. Among the rights were the right of expression, the right of opinion, and the right to be informed of what is happening. To substantiate this statement I will give certain examples before proceeding to the existing situation in the area.

1. A dissatisfied woman, full of anger, came to the audience of the Prophet Mohammad and started complaining publicly about what was known as an old pagan custom in the procedure of divorce. The formula was known as Zihar and consisted of the words "thou are to me as back of my mother." This was held by pagan custom to imply a divorce and released the husband from any responsibility for conjugal duties, BUT it did not leave the wife free to leave the husband's house or to contract a second marriage. The teachings of Islam abolished this custom because the woman was correct in proving the implausibility of such a practice. This story was told in the Koran as, "If any men among you divorce their wives by Zihar [calling them mothers], they cannot be their mothers except those who gave them birth. And in fact they use words both iniquitous and false, but truly God is one that blots out [sins] and forgives [against a sin]."

2. Omar, the second Khalifa after Prophet Mohammad, was challenged publicly by a lady in a manner that showed the respect and the recognition of the right to know by the authority. Omar was addressing a rally in the affairs of the state when he asked his audience not to exaggerate in dowry and wanted to suggest a maximum limit. A woman among those present stood up and explained to the Khalifa that what he said was contrary to the text of the Holy Koran, which says, "But if ye decide to take one wife in place of another, even if ye had given the latter. a whole treasure for dower, take not the least bit of it back: would ye take it by slander and a manifest wrong." Omar stopped here and said to himself: "Everybody knows more than you do. Even women. A woman is right, Omar is wrong."

3. In the Koran, the Holy Book of Islam, there are several verses that call for the expression of opinion. They encourage dialogue and argument in order to uncover the hidden facts and to inform the people of what goes on in their society. They are, in my opinion, equivalent to what is known today as the right to know. The following verses are examples.

Invite all to the way of the Lord with wisdom. And beautiful preaching. And argue with them in ways that are best and most gracious. For thy Lord knoweth best who have strayed from His path and who receive guidance.

And dispute ye not with the people of the Book except with means better [than mere disputation] unless it be with those of them who inflict wrong [and injury]. But say, we believe in revelation which has come down to you--Our God and your God is one: And it is to Him we now bow [in Islam].

Other religions such as Christianity and Judaism might have the same directive to their believers. I am quoting Islam not because it is my religion or the dominant belief in the area I am writing about. I do so because Islam is the main instrument that influences the culture of the inhabitants of that region. One cannot talk about duties, rights, behavior, norms, etc., without bearing in mind the major factors that affect the way of life that the individual leads in his own society. In our case Islam is a factor that cannot be overlooked. 
Outside the peninsula you find in the region a blend of cultures coupled with traditions and conventions, a small Christian society, pagans, and modern and tribal systems. These are all factors that in my opinion contribute to the appreciation of the concept of the right to communicate and those who exercise it.

\section{HOW FAR WAS ARTICLE 19 CARRIED OUT}

Let us forget for awhile about the concept of the right to communicate and try to examine the implementation of what was encompassed in Article 19 of the Universal Declaration on Human Rights. One might ask these questions: Is it exercised by all nations? Do all members of the United Nations abide by Article 19 as they vowed to do? Do the founding members of the UN who had the honor of drafting and voting for the charter carry out its meaningful text? Does the individual in the world, whether it is first, second, or third world, enjoy the right of expression and the right of opinion? What is the role of the communicator toward these ques tions? Is it to keep silent and watch the game or to play an active role, and what is the role?

Before attempting to answer some of these questions I want to make clear that I do not intend to sound like a political statement bearing the touches of certain political overtones. I will try to be as objective as possible although one cannot talk about rights, any rights, without affecting somebody. It is because such rights are either there or extorted by someone, in which case he should be honest and courageous enough to bear the responsibility. It takes a great deal of bravery to strip a person of his basic right, particularly if the right in question is the right to know or to communicate, which is considered in the world of today as a preeminent right.

Most nations in the Third World have written constitutions. Most of these constitutions include articles that guarantee the freedom of expression and religion, etc. These articles in most cases are regarded as part of the decor. They make the constitution look nice but are not taken as essential. They can easily be forgotten or seldom thought of. They are there as ink on paper and not meant for serious practice. Some countries are very serious about the right of the individual to know. They respect it, exercise it, and leave it to the court to decide contraventions or violations by the individual or the state. However, certain factions might take advantage of the freedom of expression and try to follow undemocratic means to achieve their ends by overthrowing the constitutional government. This kind of act might persuade the legitimate authority to suppress the article of the constitution that deals with the freedom of expression and opinion, to avoid the peril of being ousted. This is indeed a bad example of the practice of freedom of expression in developing society. The communicators should exert some effort to rescue the freedom of opinion and expression from being buried and to reconcile the two conflicting parties. They should advise the politicians not to exceed their limits as indicated in the constitution and the laws, and advise the government not to sacrifice the freedom of opinion in combating its political enemies. Everything should be left to the court and to the rule of law.

I claim that most of the normal inhabitants of the Third World are unaware of the existence of such a right, although they practice it. They move about within the limits drawn up by the authority that controls the society. They employ their instinct in seeking information needed for their everyday lives, they 
receive what is meant for them to receive, and they impart what the system of the society allows. This sort of practice does not permit the concept to develop, and thus the society will remain where it is, without any progress in this respect.

The right to freedom of expression and opinion needs to be publicized and made known to every individual in every country; it should not be confined to the communicators or the controlling authority. All means of communications should be employed to accomplish this task, particularly the electronic means that are capable of penetrating the barriers and reaching the public all over the world.

As I said before, the average citizen of the developing world is not very concerned with the evolution or the extension of the freedom of expression and opinion into a right to communicate. He is not even aware of what Article 19 of the Univexsal Declaration on Human Rights covers, that is, "seek, receive, impart," let alone the expansion of its content. This plight in the Third World should not prevent us from offering the masses a wider concept so that they could discover their right and proceed with the practice prevailing in the world at large. Therefore the communication scientist will not be contradicting himself when he talks about or analyzes the right to communicate in the developing world.

\section{THE RIGHT TO COMMUNICATE IN THE THIRD WORLD}

The right to communicate in the Third World should be examined in the light of the following factors:

1. Culture and traditions that dominate the dally lives of the individuals

2. The system of governments that controls the society

3. The rate of illiteracy

4. The economic situation and the development plan

5. The presence of mass media

6. The coverage of all parts of the country by the electronic media

7. The accessibility of radio and television receivers to all citizens

8. The programs designed to meet the needs of the people

9. The participation of the normal citizen in the programs aired by the local station

10. Person-to-person means of communication and its availability to all or most inhabitants

11. Whether education is free for everybody

12. Transportation network allowing people to move from one place to another

13. Vulnerability of the people to aired or written messages from outside the country

By analyzing each item, researchers will learn what brought about the present situation in each country and will be able to propose certain steps for improvement. Furthermore, the three elements involved in Article 19, "seek, receive, and impart," will vary in practice from one society to another within the Third World and could be selected as a subject of study. The degree of practice of the same right could be compared, as between. West and East and among the three worlds. Such a study could also help in determining the major factors that affect 
the pattern of the free flow of information and cause the imbalances in the direction of flow.

It is not my intention to discuss all the factors listed above. Rather I would limit the discussion to the most important ones, such as culture, tradition, and the media available.

As a background, I mentioned Islam as a religion that influences the behavior of the people in the Arabian peninsula and of the people of the Middle East in general who have other cultures and traditions. Therefore the right to communicate is affected by, besides other things, the recognized and observed traditions. It operates also within the context of the dominant culture and religion. The religion in that area is more progressive in recognizing the right of the individual to communicate than are the deeply rooted traditions and conventions. Everybody, in accordance with the teachings of the religion of Islam, has the right to communicate, irrespective of creed, sex, and social status. In the same area where Islam is adopted there exist certain traditions that oppose the right to communicate for a certain class of people, despite the approval of Islam. Women, for instance, do not enjoy this right absolutely. They are allowed to communicate within certain limits, not with everybody, not on any subject, and not anywhere. This practice is limited to some rural districts with a very conservative society. But in urban areas women, in most cases are treated no differently from men. They enjoy almost the same rights: to attend school, to work in a government department or the private sector, to own a business, etc. In some countries they even enjoy the right to vote, to be elected to parliament, and to hold a political office. The limits are those imposed on the whole society, no matter what the individual's sex.

Children and junior members of the family have to observe the rules of the society, which do not allow an unrestricted right to communicate within the social system by which they abide. Pagans regard women as commodities that can be traded like any other commodity, such as horses or cattle. They can be inherited by the son or the nearest relative. They have no rights. Therefore, to speak about the right to communicate in such a society is just a waste of time and a futile effort.

The governmental authorities in most of the countries of the region recognize the right of the individual to communicate. This recognition is sometimes theoretical. As long as the right to communicate does not conflict with the interest of the government, the right of the individual is not interfered with. By the interest of the government I mean not only to remain in power but also to keep good relations with other friendly countries and to safeguard the security of the country and its neighbors.

\section{THE RIGHT TO COMMUNICA TE AND THE MASS MEDIA IN THE THIRD WOR LD}

The right to communicate depends on the mass media in its evolution and expansion, particularly in developing countries. Person-to-person communication in the developing countries is dependent on means that, if compared with those available in the advanced world, would be significantly less effective. That is why the impact of mass media in the practice of the right to communicate is far greater in developing countries. In the following paragraphs I deal with the status of the 
mass media in regard to the right to communicate in the region with which I am familiar.

\section{The Print Media}

The print media do not exist for the bulk of the audience. They are not of primary concern unless the contents of their messages are related to the people through the gatekeepers. The main reason for that is the high rate of illiteracy, which in some cases amounts to 80 percent of the total population of a developing country. Although efforts are being made to eradicate illiteracy through radio, television, and classroom instruction, a great deal of time and investment will be required: at least two decades, or until the end of the century.

The illiterate individual cannot use his right to communicate if the code is written. He cannot read a paper or a book. He cannot write a letter or an article. He cannot seek, receive, or impart any written information. He is helpless. There is no other solution but to speed up the process of educating the illiterate if we are to make the majority of the inhabitants capable of exercising their right to communicate. The eradication of illiteracy should be the basic element of the right of these people to communicate. Otherwise, the right is meaningless.

This situation is reflected in several papers and studies presented by specialized institutions and organizations. They manifest how inadequately the societies in developing countries are informed. The readership of the daily papers and weekly magazines is so low that one must deplore it. I feel very strongly that a litexacy campaign with the use of modern technological means will shorten the period needed to end illiteracy in the world.

In the majority of the countries of our region, regular education is compulsory until a certain stage or the attainment of the age of thirteen. This definitely will solve the problem of the new generations in exercising their right to communicate through the print media.

When analyzing the present situation in regard to the written material already available or that could be available to the literate citizen, one cannot ignore the role of libraries and archives in furnishing valuable information needed for the users. They are important sources of information and knowledge not only for scholars but also for those who use them to enrich their experience and widen their horizon. They could be used by students, researchers, and the general public, whose need is never satisfied.

The mobile library is one of the inventions that contributed greatly to the solution of the standing question: how can we respond to the clamor of the people who dwell in the remote areas and cannot be easily reached? These people have the right to communicate and are entitled to services enjoyed by those who live where the seat of government is located. It is not their fault that they are not close to all sources of information. Article 19 of the Universal Declaration on Human Rights does not stipulate any conditions in regard to the location of the individual. It says: "Everyone has the right to freedom of opinion and expression. This right includes freedom to hold opinion without interference and to seek, receive and impart information and ideas through any media and regardless of frontiers." So the right to communicate has no value whatsoever unless the means of exercising the right are 
accessible to the individual. By that I mean a literate person capable of using all his senses; otherwise his practice of the right to communicate is limited.

The Electronic Media

Radio, television, and motion pictures are widely used in the developing countries. But the use varies considerably. It can be explained as follows:

1. Most, if not all, of the countries in the Third World have radio stations of their own and are within the reach of the signals coming from neighboring countries or covered by international broadcasting, such as the British Broadcasting Corporation, Voice of America, and Radio Moscow.

2. The power of the transmitting station in some cases falls short of blanketing the whole country with clear signals that provide a reasonable fidelity of programs.

3. Some developing countries have television services confined to areas around the capital or the major cities. The reason is purely economic, because the expansion of television services is not at the top of the priority list. Few of such countries have a nationwide television service. It is expected that television will be established in all developing countries within ten years.

4. Radio sets are accessible to the majority of the people in the developing world. Television sets are not. The prices of television sets are almost prohibitive, no matter what make or size they are and from what country they are imported. Television is regarded in many countries as the medium of the elite.

5. Commercial cinema theatres are known in the Third World. But they are few and centered in the major cities. Most are within the areas covered by television programs. The number of seats in these cinemas appears insignificant as compared with the total population of the country.

6. Most of the television programs and the feature films are imported from abroad. A limited number of Third World countries have founded their own film industry; however, they still could not dispense with the Western films and television series and they have failed to provide an alternative to their sister countries, long-time dependence on the West as the major source of this sort of program material.

There is no need to say that radio and television are the dominant and most effective communication media in the Third World, for they can reach almost everybody instantly and carry messages at the right and convenient time to the individual and his society. The right to communicate, as far as the electronic media are concerned, is highly respected and observed by most nations of the developing world. By that I mean the element of receiving the transmitted message if the means of reception are guaranteed or provided. In all the countries of our region there is no ban on listening to foreign broadcasts, no jamming or jumbling of signals coming from other 
countries. To seek information through electronic media, one need only choose a television channel or a radio frequency that transmits the message he needs to receive.

I cannot imagine anybody wanting to impart information by radio or television in a society whose system of government controls the media and prohibits an active participatory sort of communication. Exercise of the right to communicate is most difficult under such conditions, because it involves the use of means that the user does not control. 'The audience participation program is known in most of the countries and constitutes a very prominent part of the schedule.

The system of broadcasting adopted by different countries plays an important role in the implementation of the right to communicate, particularly in areas where the use of media is essential for the individual to express his views and ideas. If the radio and television stations are owned and operated by the government, then chances of the citizen to exercise his right to impart information are less than if the stations are independent or commercial. Yet very few governments relinquish their power to control, or surrender the facilities to the society which could express, freely and without inhibitions, thoughts and opinions on what is going on in the society, including the political system itself.

The scope of the practice of the right to communicate in a given developing country is governed by the physical limits to which the mass media of that country can reach, and by the extent of penetration of the country by international mass media. International broadcasting extends the area of the use of the right to communicate in that country and at the same time causes an imbance in the reception and impartation of information. To substantiate this argument one can review the present situation of the clectronic media and their coverage worldwide in these respects:

1. The number of radio transmitters in the developed world as compared with that in the developing countries

2. The frequencies presently allocated and those reserved for future use

3. The volume of radio and television material flowing from the West to the developing countries

4. The flow of information and sports programs via satellite to Africa, Asia, and Latin America as compared with the flow of the same sort of programs to North America and Europe.

These are the problems that should be studied seriously if we are ever to think of exercising the right to communicate on a global scale with a fair chance for all.

Most of the developing countries that are economically well off have included in their development plans projects to improve their radio transmitters, to build microwave networks, and to establish earth stations linked to Intelsat. When they are completed, these projects will definitely result in improving the internal communication system and enabling the people in those countries to enjoy more extensively the use of their freedom to know or right to communicate. However, 
advances in communication technology, such as Intelsat, increase the disadvantage of developing countries that cannot afford them.

The developing countries cannot reciprocate or exchange the same amount of programs with the developed countries, nor can they produce programs or create news that may equally interest the highly sophisticated audience on the other side of the globe. So the space over the area of the Third World will remain open and unprotected for cultural invaders to come through. This, in my opinion, is the worst aspect of the right to communicate, so far as the developing countries are concerned, and it is the solemn responsibility of the communicators not to permit such unfair communication to take place.

I am not sure whether restriction of the use of satellites to domestic or regional purposes could be the solution to this problem, which should be the subject of concern to all scholars, communicators, and specialized organizations.

The right to communicate should not be partial. It should be absolute, giving everybody the same opportunity to practice the right. We cannot, and we should not, use this as a pretext to demand the halt of the march of others until we are equally able to avail ourselves of the technological means. But we do expect the scholars in developed countries to consider this question and try to direct their societies to recognize the need for the developing countries to improve their systems of communication. We expect them to create some sort of understanding among their own people of the messages intended for them by the inhabitants of the developing countries. This will remove the shadow of partiality and prejudice from the sacred right to communicate and satisfy those who are worried about the inequality between their right to communicate and that of their fellows in the developed world.

I would like to conclude by stressing the importance of implementing the right. We all believe that the right to know or to communicate is essential for every individual in every society. Without recognition of this right, the society will not be able to achieve any progress and will remain where it is. The freedom to express oneself or to hold opinions or ideas will render the society more dynamic and will allow it to exist and progress among its members. Therefore, the scientists and the professional communicators should not be concerned only with what is written in the Universal Declaration on Human Rights or in the constitution of any member countries of the UN. They should go further and examine the practice of the right of the individual, to see whether it is honored or neglected. They should stand as custodians to this right and keep hammering on those who deny it until they heed and submit to what they once vowed to respect. This, in my opinion, is the prime role and responsibility of the communicators in the world of today. 



\title{
THE RIGHT TO COMMUNICATE
}

\author{
A. F. KALIMULLAH
}

Today a worldwide debate on the right to communicate is going on. This reflects a mood of discontentment and despair. Technologically, man has made great advances. But the fruit of these advances has been bitter rather than sweet. In the last century, when the Industrial Revolution was in its infancy, there was great hope that someday man would become master of his destiny. Today we find that this naive hope is largely belied. Scientific progress has not lived up to our expectations. We are vulnerable as never before. We are on the brink of total annihilation, and this is our own doing. Now we are having second thoughts. And one glaring cause of our present predicament is lack of communication--between nations, between regions, between races, between communities, and finally, between men.

But this lack of communication has not been the result merely of absence of the right to communicate. There has never been, nor could there ever be, a total suppression of this birthright of man, not even in the most regimented or totalitarian states. We must realize that we have failed to utilize fully the opportunities we have of communicating with our fellow beings. We must ponder over this before we claim the enlargement of our right to communicate. For this we must look inside ourselves individually. There is a famous Eastern saying, "One must right one's own house before insisting that others right theirs." Only when each of us realizes his shortcomings, and sincerely tries to correct them, will we be able to communicate with others in the true sense. Only then will we have something to communicate.

\section{Basic Human Need}

The very concept of man as a "social animal" presupposes communication between men and between groups. "No man is an island," men live together because they have to live together. We speak of the right to communicate because its urge is inherent in man's nature. Nothing on this earth (or above it) can make this urge obsolete. This is the same truth that is illuminated in the "myth" of Eve's creation from Adam's ribs.

The processes of communication have in fact continued through the ages, and today we are living in an era of instant communication, thanks to incredible technological advancement. Speaking historically one can say that from the time Plato developed the city-state concept and spelled out the canons of citizenship for the Athenians in his Republic, to the time of drafting the Declaration of Human Rights, freedom of speech and the right of communication have been accepted as basic needs of human society. This concept of freedom has, however, remained debatable for centuries. It continues to be so even today. A condition of continual conflict exists between the individual and the state, between man and his society. This condition is marked by the insecure posture of smaller states even on their rightful claims. It is demonstrated by the drowning of the feeble voice, of men and 
groups of men, both by the "tyranny" of law and by the traditional organized dissent of society. It is violated when the individual becomes prey to censorship. The need to safeguard the right to communicate, even in our own times, has been felt in quarters where the parliamentary system is strongly entrenched in history. This situation has been vividly explained by David Hardman:

That such a freedom requires fighting for can be admitted, when we even in freedom-loving Britain realize that many obstacles are put in our way, preventing us from buying the books we want and need from other countries; when we realize the impossibility of buying works from abroad, the controls, the quotas, the restrictions, that prevent us from moving freely about the world. Food and health and decent conditions of work we must have, but there are other freedoms for which the signators of the UN must be prepared to fight; they must agree to pull down these national barriers with classic works of art and books, and facilities for the best intelligence to confer freely, 1

Meaningful communication is "give and take," and this is possible only among persons each of whom has something to give, "to communicate," that the other lacks. Authentic communication means mutual fulfillment; this is as true of two persons as of two groups or two nations. Communication between two homogeneous automatons is meaningless because there is no fruitful exchange, only a barren corroboration of that sameness.

A bigger question looms behind the question of the right to communicate: not just do I have the right to speak out, but rather, do I have something to say? This is not merely a question of literacy or I.Q. or relative cultural development. We must first consider the development of one's identity or self or soul. The right to communicate is not a boon to be conferred on a person or group arbitrarily; one must earn this right.

\section{Equal Rights, Equal Responsibilities}

Every individual must have equal right and opportunity to communicate. Insisting on our own rights while ignoring those of others will lead us nowhere. One must demand the fulfillment of obligations due to him, and therefore one must fulfill his own obligations to others. This should be the spirit when we talk of the right to communicate.

We must be wary of discussing this question, universal and of utmost human importance, in a pedagogic vacuum. The very fact that in different parts of our planet this question is being discussed and debated is significant. Or rather, the prominence of the problem of communication is quite symptomatic. To my thinking there are two basic factors that are jointly responsible: one is technological and the other politicoeconomic.

\section{Neglected Options}

In the three decades since the last global war, an infinitesimal period of time from the historical point of view, there have been tremendous advances in the field of communication. Invention has almost outstripped imagination. But this mechanical progress was inherent in the national and international systems. The accent was on the better (technically), the quicker, the vaster. Of necessity, this 
élan mechanic was amoral. The inventors didn't bother about the consequences and applications of their inventions. Their moto was "the more the better." But the superstructure of national and international. communication (or rather, suprana tional communication, when you consider all the communication satellites orbiting our globe) has by its sheer size forced us to take cognizance of its implications, consequences, and further possibilities. One fact has been distressingly obvious: optimum use is not being made of the existing facilities of communication. In most parts of the world the common man doesn't have any access to a medium of electronic communication, be it radio or television. In some countries even the daily newspapers hardly mirror the aspixations of the masses they serve. So we see that great technological advances in the means of communication have been poorly matched by the use that has been made of them.

A sober analysis of the present communication situation will bring home to us the fact that much of this technological breakthrough has been one-sided, pertaining to the channels of communication alone. The "source" and the "target" haven't changed at all. In communication the most important level remains that of person to person. This is a fact, although in the words of Casmir, "Large communication technologies seem likely to impose a regimenting and dehumanizing condition on all human communication."2

\section{Means Before Rights}

In the newly liberated countries of Asia and Africa, a new dimension has been added to the problems of communication: shortage of technological facilities. Moreover, the existing hardwate of communication is not evenly distributed in developing countries, so messages cannot reach the large masses, still hermetically sealed against winds of change.

The collected data of Unesco and other agencies employed for this purpose, whether of Western democratic or Eastern socialist countries, show that developing countries lack the capacity to produce independently the gear and gadgets that can transmit the idea and translate the plan for development within a geographic area. With the exception of Japan and, very recently, India, Egypt, and Pakistan, most of the countries have to look to the industrialized nations for the entire provision of machinery to conduct their communication.

It is our contention that exercise of the right of communication depends on access to electronic instruments, both to transmit and to receive. Tremendous efforts have been made by many highly industrialized countries to create such facilities. Yet in South Asia, the item most essential to communication, the handy transistor, is owned by only one out of every twenty persons. The international consensus to share technological facilities has certainly brought us closer to the idea of one world. But this idea remains in the realm of possibility. It has not yet been made a reality.

\section{Winds of Change}

Cold war has given way to détente (although it may not be as warm as one would wish); arrogance of power has had to yield to a spirit of accommodation and mutual understanding. "The superpowers have realized that in destroying the "enemy" they would destroy themselves. At long last it has come home to the 
developed nations that the developing nations cannot be kept at bay much longer. The possibility of sincere cooperation is brighter than ever. The historical process that started with colonialism is coming round to its logical culmination. If its earlier phases were tragic, the last ones may be beneficial for humanity as a whole.

Today we are on the threshold of vast changes. Only a decade ago the outlook was quite pessimistic. The question was existence or nonexistence. The atomic arsenals of the superpowers seemed poised to annihilate the entire world, jointly or singly. Neither side was willing to budge an inch. Then it seemed that humanity would fritter away its energy and all its cherished achievements in local skirmishes. In the words of T. S. Eliot, in "The Hollow Men":

This is the way the world would end

Not with a bang but a whimper.

\section{Ethics Versus Technics}

But a salutary change has taken place. Mutual vulnerability has made the adversaries edge away from the brink of total destruction. In this world everything is in perpetual motion: we must move rapidly even if we want to keep standing. The realization has come home to everybody in all quarters that cessation of hostility does not mean peace. As the noted American writer Lewis Mumford has pointed out:

Thanks to technics, men have become physically neighbors to people on the other side of the earth; but we have done little to make ourselves in habits of courtesy, in disciplines of mutual forebearance, which would keep us in amicable relations. 3

The cold war may be termed a "communication warfare." The urge to increase their respective spheres of influence has led the superpowers to give the means of communication top priority, which has resulted in a spectacular technological advance in this field. Telecommunication has almost wiped out inaccessibility of regions and peoples. Even though, in the seventies, détente has superseded cold war, the infrastructure of international communication has come to stay. Now it remains to be seen what use is made of it in the service of international cooperation and mutual understanding.

Today we can no longer ignore the hiatus between profession and performance. The best minds are taxing themselves to find ways and means of bringing about mutual understanding and universal harmony, so that humanity as a whole moves forward toward the goal of emancipation from hunger, misery, and ignorance. This whole effort is pivoted on the question of the right of communication. Unless this most fundamental right is conceded to every individual, all endeavors to achieve universal harmony and progress will be frustrated. This seemingly obvious truth is being given renewed stress because we have lagged in giving concrete shape to the ideals formulated three decades ago in the UN Charter on Human Rights.

We have touched upon the politicoeconomic and technological aspects of this question. Now it remains to be seen how much right of communication the different governments are willing to concede to their respective citizens. The outlook is not as bleak as it may appear to some, though there are exceptions. It is much better on the international level than on the national one. The joint space and 
terrestrial experiments are quite significant in this respect. But on the national scene, mostly of underdeveloped countries (in some developed nations, too), we find the communication situation not quite satisfactory. The major factor behind restrictions on the right of communication is political, but from time to time economic, social, and ethical considerations also play their part.

\section{Diversity Through Unity}

Much havoc has been created by an illusory sense of national interest. In the words of Lewis Mumford:

Our techniques have become universal in an ideological epoch that has turned to the false tribal gods of nationalism. Today, we have been forced by the circumstances to reconsider our past priorities and options. A revision is in order. The tendency to unite into different peoples with conflicting interests must give way to a move towards universal brotherhood. 4

But we must also be on guard against a blind thrust toward unity at any cost. As Altaf Gauhar has pointed out:

Unity cannot take precedence over knowledge nor should it be followed at the cost of principles. Unity is a social and political concept and as such it must be regarded as a means to certain ends. If the end is the solidarity and strength of the "Umma" (Followers of Islam) then unity is a means to that end. But unity is not a precondition of good moral behaviour. A united people do not necessarily mean a moral people. Indeed, the reverse has sometime been the case. A people can easily unite to pursue immoral ends. The history of imperialism and colonialism is replete with such examples. 5

Here lies the importance of the discussion and deliberation at the internation level of the right of communication. Thus a few norms and precepts that will be mutually acceptable may be sifted from the jumble of various and often conflicting opinions.

\section{Lasswellian Framework}

So we see that the problem of communication must be discussed at three distinct levels, ethical, political, and technological. Harold D. Lasswell's formulation, 6 "Who says what? In which channel? To whom? With what effect?" is very much relevant, and here it is necessary to pinpoint different corners of the framework of communication: the source, the means, the target, the purpose or intent, and the actual result.

Every communication is intentional, even when it appears to be automatic, a conditioned reflex. When we would judge the authenticity, the applicability, and the appropriateness of a given communication, we must analyze the intention behind it. This consideration must be the cornerstone of any discussion of the right to communicate.

As the extent of communication broadens, the responsibility for it deepens in direct proportion. Even in the most regimented totalitarian states, the 
individual's right to communicate with another individual is not directly controlled, but the more individuals involved, the stricter the control by a dictatorial government.

When discussing the right to communicate, attention to the process alone will not be of much help; the consequence will always weigh more. Political and economic considerations must give way to the all-inclusive cultuxal consideration, and when this debate is going on in an international framework, a consensus of all the important cultures of the world is in order. This question becomes a purely ethical one. The process of modern communication is turning the world into a global village. Curtains (whether iron or bamboo) are being parted. The concept of isolationism is felt to be obsolete and impractical on all sides. Now the consequences of international communication must be analyzed and pinpointed and some sort of code in this field must be evolved. Rights cannot exist in a void. The content, the quality, and relevance of communication to the cause of world peace and progress must be judged before we can speak of the right to communicate.

\section{Linguistic Chaos}

There remain a few problems that may appear marginal but in fact have a central importance in a discussion of the right to communicate. The foremost among these is language. A true lingua franca for the whole world has yet to emerge. Even Europe, which gained political and cultural ascendancy since the Renaissance, could find no common language though conditions were more congenial there than in Asia even today. Lewis Mumford has contributed this perspective:

What is the use of being able to speak to another person instantaneously on the other side of the planet if we have no common language and if we have no common purpose, except that of exterminating our distant brother before he seizes the initiative and exterminates us? We have left the problem of creating a universal language mainly to a few amateurs and fanatics who have naturally so far made little headway, although with our present skills in comparative philology and logical analysis, the problem of inventing such a language presents far fewer difficulties than did the original invention of the alphabet. 7

Language barriers in Asia and Africa axe even more impenetrable than those in Europe. There are a few languages that boast of relative "universality," such as English, French, Spanish, and Arabic. Chinese is spoken by nearly one-fifth of the total world population but almost exclusively in one country, China. This state of affairs is understandably uncongenial to an unrestricted flow of information among different regions of the world.

Then there is a large number of undeveloped countries where most of the people are illiterate. Progress is being made, but very slowly. The major portion of the population in these countries remains immune to persuasion or motivation by the printed word.

For all practical purposes, English serves as a common language for most countries of the world. 


\section{Language Texture}

With English as the language of communication there are some very intriguing facets of our social and cultural life. We in South Asia in particular, if not in the entire continent of Asia, live in a stratified society. The elite is composed of graduates of Oxford and Harvard. A little below this tier are graduates from our own universities, nurtured in the same curriculum as that of the Western universities. The administrator, the educator, and the communicator have qualified in a language that is not the language of the masses of people of our country, and the flow of information from the pool of knowledge collected through the use of English has to be translated to create a horizontal line of national thinking.

Printed words are not, however, the only means of communication; sounds and images are powerful vehicles. Radio, television, and films play an important part in educating the masses. These media are also easily portable beyond national boundaries. But the cost of establishing and maintaining these media is so tremendous that they are mostly owned by the government, or by a limited number of rich people as is the case with the film industries in developing nonsocialist countries. This fact inhibits the free access to these media by the general masses.

The language barrier, illiteracy, insufficient motivation, and a lack of rapport between the media and the masses: these are vital problems that plague communication on both national and international levels.

\section{Stagnant Status Quo}

In any discussion of the communication situation that is conducted on an international level, the lack of uniform distribution of information is highly pertinent. The less developed countries have fewer opportunities of communication with the outside world; in other words, they receive less and they produce less. Economic impoverishment leads to cultural impoverishment. A sort of stagnant status quo is maintained.

This discrepancy is the outcome of many factors. In a way it is a legacy of a colonial and imperialistic past. One can say this is one salient feature of neocolonialism, which aims at controlling minds rather than territories. The multinational giants of the information industry, which have their bases in affluent countries, control nearly the entire flow of information in the Third World. They have been consciously or subconsciously serving the interests of the governments of their countries of origin. Their policies are apparently neutral. They seem to try to present the versions of both sides in any international conflict. There is an insistence on concrete, undeniable facts. But facts are only relatively true. A biased selection and arrangement of facts may give a distorted picture of truth. The propagandist's mania for factuality is a subterfuge to veil truth. Here the socalled fact becomes a handmaiden of fiction.

\section{Studied Reaction}

Since World War II, the realization of this subtle manipulation has been growing in the Third World. A mood of chagrin and resistance has been dis cernible among the intelligentsia. There is also a little frustration and despair in 
the face of the seemingly unbridgeable technological gap between "haves" and "have nots." Unquestionably this atmosphere is not at all congenial to a meaningful exchange of communication among all the peoples of the world. But one must concede that reaction of the "have nots" has been largely tempered with reason and down-toearth reaction. At the same time, the heavy industry of information in the developed countries also has arrived at a new sense of reality and has become, to some extent, willing to cooperate with its smaller brethren in the developing countries. Mercifully, now the mood is that of compromise instead of confrontation, mutual exchange instead of isolationism. We must slowly but deliberately move forward the goal of universal harmony, with everyone having equal right to communicate and at the same time being equally willing to receive others' communication with patience, sympathy, and understanding.

\section{CONCLUSION}

While summing up this essay, let me spotlight some basic points for consideration. A mong others, they include:

1. Can we really succeed in developing communication models of sufficient scope? Will it be possible to handle, within a common frame of reference, the diversity of the subject and bring about a workable cohesion, at least on fundamentals?

With goodwill and faith it should be possible.

2. Will the vast resources of communications (satellites; computers; video-recording facilities; cable television; portable equipment to transmit sound and pictures by wave guides, optical fibers, or lasers; digital television, etc.) take us to the desired goal? The answer, of course, rests with us. In the words of Jean d'Arcy:

All that depends on the use we shall make of these countless opportunities open to us. 8

It is therefore up to us to share either the pessimism of Dostoevsky or the optimism of Marconi. Dostoevsky said the "world is getting more and more united and growing into a brotherly community by the reduction of distances and the transmission of ideas through the air," but man should put no faith in such a union of peoples.

Marconi's view was that "Communication between peoples widely separated in space and thought is undoubtedly the greatest weapon against the evils of misunderstanding and jealousy." 9

I will opt for the optimism expressed by Marconi, with the observation that when the close of the twentieth century brings us closer to one world for the coming man, the right to communicate will still not be served to him on a platter. Therefore, the use of a forum such as this and Unesco--best of the forums available for the purpose--to draft finally a document of abiding values, will stimulate man to face with confidence and the courage of his convictions the brave new world ahead of him. 
entitled:

There is a book by the Swiss scholar Sigfried Giedion, which is

\section{Mechanization Takes Command.}

A new motto must be adopted:

Let Man Take Command. 


\section{NOTES}

1. Robert Lewis Shayon, "No Exit," in Frederic Rissover and David C. Birch, eds. , Mass Media and the Popular Arts (New York: McGraw-Hill Book Co., 1971), pp. 137139.

2. David Hardman's Introduction to Reflections on Our Age; Lectures Delivered at the Opening Session of Unesco at the Sorbonne University, Paris, 1946. (London: Wingate, 1948).

3. These two lines conclude the poem "The Hollow Men," written by the American poet, T. S. Eliot, in 1925.

4. Lewis Mumford, Interpretations and Forecasts: 1922-1972; Studies of Literature History, Biography, Techniques, and Contemporary Society (New York: Harcourt, Brace, Jovanovich, 1973).

5. Ibid.

6. Altaf Gauhar's introduction to Idara Tarjuman-ul-Quran. [Translations from the Koran]. (Lahore, Pakistan: publisher not known. February 1975).

7. Lewis Mumford, op. cit.

8. Jean d'Arcy, "The Right of Man to Communicate," Paper presented at the International Broadcast Institute Annual Meeting, Nicosia, October 1973. Reprinted in Right to Communicate: Collected Papers, L. S. Harms, Jim Richstad, and Kathleen A. Kie, eds. (Honolulu: Social Science and Linguistics Institute, University of Hawaii, 1977).

9. Publisher not known. 


\section{THE RIGHT TO COMMUNICATE: THE INDONESIAN CASE ASTRID S. SUSANTO}

The right to communicate always has been closely connected with freedom of religion; through the use of freedom of speech and information, it was hoped, the individual would find the final religious truth.

Over the centuries, as freedom of religion became closely connected with political power struggles, freedom of expression came to be stressed more as a political than a religious freedom of the citizen, to enable him to find the facts of how he was being governed and, above all, about how his taxes and duties were being spent by the state. This paper examines the political developments pertaining to the right to communicate, recognizing but not developing the right's historical religious foundation.

Through these political developments it became necessary to write down and document freedom of speech and information. Thus, it became a binding charter between the authority that grants these freedoms and the citizen that enjoys them as a compensation for the obligations he has to fulfill, such as to pay taxes and to render military service in defense of his state.

Apart from formal documents such as the constitutions that mention and guarantee those freedoms, social and cultural conditions very much determine the extent that the granted freedoms are effectively used.

For countries like Indonesia, that have a traditional and feudal as well as colonial background, the enjoyment of these liberties is not a matter of fact; it has to be encouraged by the government itself. Official documents therefore cannot be taken as the only sources of analysis for effective use of the right to communicate. To get a better picture of the problem of the right to communicate and to avoid wrong conclusions, some fi.eld data are needed as well.

The use of the right to communicate very much depends on the educa tion, social background, and perhaps also the social status of the individual. Thus, within the boundaries of existing laws and regulations of the country, the interpretation of how far such right has been used depends largely on the political situation of the country itself, its history and experience with these liberties, as well as the background of the interpreter. The more a government is inclined to leave the considered misuse of the right to communicate to the courts, the more freedom of speech is guaranteed for its citizens.

Official limitations to the freedom of information and speech are generally connected with the security of the state and the protection of other individuals' freedom. Niemeyer stressed that "Every country has some freedom of speech: some things can be said at some time and places without prior consent and without fear of 
punishment. On the other hand in no country is there complete freedom to say anything at any time in any place."1

The Indonesian Constitution (1945) in its Article 28 guarantees "the freedom of society to express its opinion and thoughts orally as well as in writing." This article explains that in accordance with the Indonesian philosophy Pancasila, there should be a balance between individual and social rights. In enjoying the right to communicate, the inclination in Indonesia is to connect Article 19 with Article 29 of the Universal Declaration of Human Rights (1948), which says:

(1) Everyone has duties to the community in which alone the free and full development of his personality is possible.

(2) In the exercise of his rights and freedoms, everyone shall be subject to such limitations as are determined by law solely for the purpose of securing due recognition and respect for the rights and freedoms of others and of meeting the just requirements of morality, public order and the general welfare in democratic society.

The Indonesian Peoples' Congress, meeting in 1973, decided through its Decree No. IV/1973 on the need for a free and responsible press, to provide objective information to the people, while at the same time ordering that the press should function as a channel of constructive opinion. The Indonesian Press Law No. 11/1966 on Freedom of the Press mentions the absence of precensorship and the right of the press to exert its controlling function, deliver criticism, and propose corrections to the government. In Indonesia the right to communicate is therefore viewed mainly as the right to enjoy upward communication, to influence the government and governmental decision making.

For many an individual, the right to be heard does not alone suffice. The press, social organizations, and other pressure groups are looked upon as unofficial channels of information. The real influential channel for direct upward communication is parliament. Also worth mentioning is the decision taken by the Indonesian Press Council, No. 79/XIV/1974 on the Principles of the Freedom of the Press. This decision stresses the interdependence of the individual and his society, which in fact is the source (and limitation) of such freedom.

A more explicit formulation of the right to communicate in the sense of "talking back" is found in Chapter 29 of the Second Five-Year Plan of Indonesia. Even the choice of the heading of the chapter, "Information and Social Communication," makes it clear enough that the aim was not just one-way, downward communication from the government to the people. The aim when possible was to create a social communication situation between the two. Because the document stands right under the constitution, its content is binding for both the government and the people. In this Chapter 29 it is stipulated that the government has to create a favorable climate to enable reciprocal communication and interaction between the government and the people, and that there should be an increased freedom for the people to discuss among themselves the problems of the day. It also stresses the need for a reciprocal influence through increased communication activities, and therefore the government is to seek all means and efforts to encourage communication.

Channels of information, such as public television and public radio, are to be more accessible to the public. The government is ordered to give information 
in an informative, educative, persuasive way and to stimulate the people to communicate more actively. At the same time, the government itself is to refrain from indoctrination and propaganda. Without such reciprocal interaction between the government and the people, and communication within society itself, the development of the country would be hampered. Because freedom of information is the cornerstone of knowledge, it stimulates the creative mind to participate and speeds up development. In such a way, effective and interchange communication is thought to be an integral part of successful development of the country. 2

As years go by, more confidence and tolerance as well as selfrestraint on the part of the govermment is generally felt. This could be achieved only after Indonesia overcame the the political and economic chaos caused by the years prior to 1965 and after it managed to enjoy the fruits of development that resulted from the First Development Plan.

The formulation of the Second Five-Year Plan itself showed the serious efforts taken by the government to make it a national document, supported by potential leaders as well as technocrats. Universities were invited to participate in revising the draft of the plan, and faculty members seriously went through the pages with red pencil, crossing out many items and offering new proposals as well. This experience shows that an increase of stability within a country will at the same time increase tolerance and encourage participation in decision making.

The right to communicate depends a. great deal on this internal stability. Also, it depends on the awareness and intention of those in power to create "talk back." Interchange communication is vital to living democracy.

\section{THE DEVELOPMENT SUPPORT COMMUNICATTON SYSTEMS (DSCS)}

The DSCS were widely accepted in Indonesia, especially in university circles. However, the inclination of the Indonesian government was to experiment with selected areas first and to concentrate on "easy to understand problems." In contrast, the DSCS started with a series of pilot projects before designing an overall system. The DSCS took into consideration the social and cultural as well as the ecollogical and economic conditions of the population.

On the other hand, the proposal to the government laid too much emphasis on the organizational setup. At each level, the administrative echelons had a DSC unit; under this proposal, the highest DSC unit would have been at the National Planning Agency. This proposal met with some opposition, as the Information Ministry officially functions as the national. DSC.

A survey was carried out to inventory hardware rather than to examine governmental information activities and methods. Experiences gained by the Badan Koordinasi Penerangan (ad hoc integrated interdepartmental information activities) were not used to find the vital communication indicators. These ad hoc integrated communication experiences could at least have given information on the favorable communication conditions created by interpersonal communication. At the same time, these experiences could point out how difficult it is to have people use their right to communicate upward, and show that upward communication can be hampered by tradition. 
As the government is in constant need of the people's evaluation of and experience with the realized development projects, and facing the fact that our government officials, like those anywhere else in the world, have an inclination to give favorable reports, the government has sought another upward communication mechanism that would yield more useful facts. Thus, new surveys in all development fields were created and as many universities as possible were involved in data collecting and public opinion ratings. In addition, the experiences of the simple peasant with his local projects were evaluated. In themselves, the surveys proved to be substantially DSC and Project Support Communication (PSC) activities. University students and lecturers acted as information officers; at the same time, their objectivity enabled them to give honest reports to the government on projects worked at the village level. Human communication as the core of DSC and PSC was thus created through the surveys, knowledge transferred to the peasants, experience discussed and improved. All this was done for the sake of quality reports, as the good name of the alma mater was always at stake.

For both students and lecturers, the surveys brought theory and practice closer to one another. The social gap between rural and urban areas was bridged. The visits of university students and lecturers to remote villages increased the pride of the local people. These people knew they were not forgotten and that they were taken into consideration when projects were to be introduced and while the projects were under way in their villages. These contacts at the same time brought national pride in many peasant hearts: "seeing their clever younger generation" actively participating in development.

Correspondence was common after such surveys, and the "clever students" used their opportunities to inform the villagers more about the negative and unpleasant side of urban life than about its glamour, hoping to slow down urbanization. Local pride was nourished and participation in village development stimulated.

Many of these above-mentioned experiences were unplanned; they were an unintended part of the survey experience. After such first experiences the surveys that followed were better planned and took such spin-off gains into account and even stimulated them more. The right to communicate was encouraged via interviews, especially because the students came as government-authorized persons.

This "survey fever" is still going up, as Government Regulation known as kep. Pres. (Presidential Decree) No. 44/1974 and No. 45/1974 ordered all departments to have research and development units. The function of such units is to support the planning unit of each department in formulating governmental policies. Inputs obtained via such surveys are directly used to improve the implementation of the departments' projects. In such a way the right to talk back indirectly via the surveys has influenced government decision making, often without parliament's knowledge.

Through its many surveys, the government is in many ways better informed than the press, who because of financial constraints cannot gather information of such scope. The critical attitudes of university people are at the same time channelled and made useful in gathering development information.

Another, more difficult aspect of freedom of speech is the political opinions and statements made by student governments. The existing forums for 
exchange of information between the high public authorities and the students seem not to satisfy them, for the main reason that the students are of the opinion that their expressed wishes should be implemented then and there by the government. At the same time student parliamentary members seem to have less harmonious communications with the university student governments. For the politically active student, upward political communication is less effective via parliament than via direct communications at seminars and panel discussions as well as through survey data contributions.

This situation often gives students the impression that a right to communicate and a right to be heard as well as a right to inform and be informed (on political matters) do not exist in Indonesia. The crux of the problem then is that all these freedoms do not guarantee that what has been said will be accepted and carried out by the government.

Academic freedom (especially if literally kept within the campus walls) is guaranteed by the government. The same holds for freedom of opinion on development. But as soon as these rights are used beyond these two fields and are evaluated as being within the competency of parliament, public law often dominates. This means that actual political freedom of expression is still looked upon more as the right of institutions that have constitutionally been created for that purpose; also that pressure groups that act beyond their professional boundaries are still frowned upon. At the same time, communication between parliament and the pressure groups is not yet as harmonious as one might wish to take for granted in a democracy.

\section{INCREASE OF INTERCHANGE COMMUNICA TION AND THE USE OF INDIGENOUS MEDIA BY ELECTRONIC MEDIA}

The positive experience of the surveys and the valuable data obtained through them has brought upward communication one step further in Indonesia. Studies and inventories on indigenous communication forums and on other means of entertainment also were made. Their effectiveness for communication purposes with village people was explored. Some findings were that many traditional communication forums still exist, like the selapanan (village meeting once in thirty-five days), rapat desa (village meeting once in three months), and rapat tahunan (village meeting once a year), to discuss village problems and budget.

The rapat tahunan is usually a very formal meeting, attended by the district head and called by the village head. Usually the communication situation results in one-way communication and the villagers (male family heads) agree on the budget in acclamation (mufakat).

The rapat desa is a meeting during which the village head (chosen by the village people and sanctioned by the government) tells about the village situation and asks for the needed participation in the many village development projects.

The indigenous selapanan, where two-way communication and interchange communication between villagers and village administrators take place, are becoming rarer. They are being replaced by the more formal rapat desa and rapat tahunan. This is the case at least in Java. The process of modernization has diminished the role of many democratic, grass roots forums of communication. On the other hand, newly introduced technologies such as public television and public radio 
seem to be mechanisms for renewed communications at village level between the villagers and their headman.

A recent survey, "The Attitudes of People of Minus Areas Along the Northern and Southern Coast of Java."3 found that the presence of public television and radio in a village increased the number of topics discussed and increased knowledge of matters happening outside the village. The seven o'clock Berita Daerah (regional news) broadcast by television tells the villagers about development achievements within their region.

Further findings of that same survey were that the more open access the villagers had to the nearest town, the more social communication between different social groups (horizontal communication) took place at the cost of traditional vertical communication with the village head and village administrators. This means that for those areas, modernization has increased interchange communication through increased intercommunity communication as well as intracultural communication. At the same time the need for more sources of information is apparent, and that need explains the increasing rolle of mass media, especially radio. 4

To increase horizontal as well as upward communication, the government has started pilot projects of regional newspapers. These are issued by the Department of Information. The papers axe published in the local language and. explain how to plant bettex rice, do better cattle breeding, etc. They also bring news of the successes of other districts within the region. For this reason the dis tricts compete with each other to get their name in the regional newspaper.

A nother advantage of a regional paper is that it can function as an early waxning system. For instance, when grasshoppers, mice, etc are a threat to the harvest, the paper issues a. warning. Information through the regional papers also warns the nearby districts and enables them to take precautions.

Peasants who are able to write (or ask their village head to do so on their behalf) can write about their problems to the editor in the column "the reader. asks." They receive an answer or a solution in the same issue as the question.

These regional newspapers seem to be a successful means of two-way communication. They also provide additional field data to the govermment about its implemented programs. So, before private newspapers can be encouraged to multiply their circulation to reach these new literates, the government - through development news and directives, questions and answers--prepares the village people for newspaper reading. The private newspapers wijl bring to the villages more political thinking in addition to the relevant village news they now receive.

Another effort to create more upward communication is through the Pusat Penerangan Masyarakat (Community Information Centers). These Information Centers are equipped with mobile units, audiovisual aids, public relevision, film and slide projectors, a stage for local cultural performances, and exhibition space. The aim of these centers is to give more free entertainment to the people. Through such "light" information, close relations with the local people are created. During certain days, performances are held at the center or villages. These performances of course have development messages intertwined in their dialogues. To the village people such an occasion is a happy one and looks like a fair. It is during such gather ings that people receive information vi.a slides and films about improved agricultural 
techniques, family planning, hygiene, and other programs.

The Community Information Center also serves more serious publics via its public library. This library contains information booklets and reference books as well as "do-it-yourself" magazines.

All these communication activities have to be observed and evaluated by the information officials. These officials have previously enjoyed communication training or even have a university background with a major in communications.

Through the Community Information Centers it is hoped not only that communication in Indonesia will be two-way and be carried out in a friendly, relaxed atmosphere but above all that the people will feel that development is something to benefit from, not just an obligation for them. It is this whole philosophy that has caused the government to spend a large pert of its yearly budget on information activities. These activities are meant to reach not only from top to bottom, but also from village level to the central government. A 11 the money and efforts are thought worthwhile to make development meaningful for the lives of the Indonesian people.

Efforts to come closer to the peasants are made by using traditional cultural performances and adjusting them to the new technology. An exarnple is the beber (shadow play painted on a scroll), in which originally the scroll was unwound as the story unfolds. This wayang beber technique is now being filmed, and at the same time several villages can enjoy the same filmed show--a traditional style of performance they are familiar with since olden days.

Other indigenous means of communication are the wayang orang (traditional opera, which usually performs drama from the Mahabharata and Ramayana but recently more about Indonesian medieval knights), wayang kulit (leather shadow play), and wayang golek (wooden puppet show). As development communication becomes directed more toward the rural people, more extensive use is made of folk culture in such forms as ketoprak (the Javanese operetta), ludruk (also a kind of operetta but performed only by men) and reog (jokers discussing topics of the day in a humorous way and carrying drums to beat as an intermezzo). N. J. Colletta emphasizes the vital role that empathy plays in these indigenous performances. 5 And it is just this empathy between the actor and the audience (which is so decisive for effective communication) that makes the use of traditional media for. development information so successful.

Each traditional medium, being part of the culture, has a patterned behavior; its cultural symbolic systems such as language, dress, and art are just the factors that make this technique so familiar to the village people. Using an indigenous medium for development messages means changing its function while continuing to use the patterned behavior to achieve mental and cultural change. This change in function provides a challenge for modern technology but it also has certain dangers if the deviances from the patterned behavior are too obvious to the audience. But seen from a communication viewpoint, the use of traditional media for development messages also forces the government (being the most active communicator) to empathize with the people.

Traditional media automatically invite interaction between actor and audience; interchange communication on at least development topics is secured. This is the main difference between court culture and folk culture. Court culture 
always exhalts the symbols and patterns, preserving them and giving them nostalgic functions. Folk culture, on the other hand, is a more dynamic and lively culture and therefore can be used more effectively for rural information.

Thus, folk culture reflects a living entity and can adapt itself more easily to changing conditions of society. Yet its very dynamism makes it sensitive to direct criticism from the audience, and therefore it should be used carefully. All these aspects must be taken into consideration when electronic media, especially nationwide television are being used for purposes of indigenous culture or information. The localness of traditional media such as described above can result for a television program in success in one part of the country but at the same time total failure in others.

This finding has also been one of the reasons why the government, being conscious of the different cultural regions, has invested a great deal in regional and local radio and television hardware needs. The national government promotes interchange communication between local government and the people of different regions via the different media, and seeks to facilitate intracultural communication between the regions of the country, thus strengthening nationhood.

\section{CONCLUSION}

Although the official statements and documents referred to at the beginning of this essay only vaguely guarantee the right to communicate, through freedom of speech and information, the later developments--especially the Second Development Plan--stipulate clearly the guarantee of the right to communicate to a greater extent than had previously been known in Indonesia.

This guarantee is increased by the fact that village communication forums are mentioned, and the informal and traditional leaders are to be invited to participate in decision making at their levels. Yet the fact faced by the government is that because these grass roots forums experienced regression because of feudalism and colonialism in the past, now their activities have to be revived by the government. This is being done not through direct restructuring or training so that villagers may be effective communication counterparts for the government, but through interviews and inquiries done during surveys. The experience that anonymous as well as interpersonal "talk back" by the peasants was left unpunished, encouraged them to use their right as well as possible.

The extent that the right to communicate is actually enjoyed in a country is not determined by official statements and documents alone. Rather, it is more the spirit of the government of the day and often the political, social, and cultural stability of the country that determines the extent to which that right is used.

The way the Indonesian government tried to revive upward communication is probably not the only way and perhaps not even the best way. But at the very least, this effort has improved democratic participation within this country. This improvement happened not only through parliamentary activities and procedures but above all through the participation of the universities, their students, and teaching staff. 
For Indonesia at least it can be said that academic freedom has been more effective and successful than political freedom in supporting and developing the right to communicate. In the end, this results in the right of the citizen to join more actively in the decision-making process of this country. 


\section{NOTES}

1. Gerhart Niemeyer, Law Without Force: The Function of Politics In International Law (Princeton: Princeton University Press, 1941), pp. 80-81.

2. Repelita II, Jilid III Bab 29, p. 359.

3. Departemen Penerangan: Survai Sikap masyarakat terhadap masalah masalah nasional (non-politik) (Jakarta, 1974).

4. Ibid.

5. N. J. Colletta, The Use of Indigenous Culture as a Medium for Development:

The Indonesian Case (paper), Dept. P \& K, BP3K (Jakarta, 1975). 


\section{THE RIGHT TO COMMUNICATE \\ COLIN SHAW}

In reading, or in some cases rereading, most of the literature so far published on the subject of the developing right to communicate, I have been impressed by the general recognition given by its authors to the length and difficulty of the path toward, first, widespread acceptance of the existence of such a right and, second, its effective implementation. As far as acceptance is concerned, although it is acknowledged that the right to communicate reflects a fundamental human need to communicate as the basis of any kind of social existence, it is open to question whether acceptance at the present time is more than intellectual. Perhaps it has still to be felt emotionally, to register itself upon the pulses as forcefully as does the awareness of rights much longer established, even though they may be denied or abused in some places. I am impressed also by a recognition, first, that the establishment of a right to communicate requires a constant realization and appreciation of the political and the social, cultural, and moral differences between communities throughout the world, and, second, that hopes for success in the long term lie in the cultivation of mutual respect for the significance of these differences wherever they occur. The incapacity of some cultures, for instance, to stand up to the incursion of other cultures backed by the possession of advanced technologies is all too apparent today, but we should perhaps be encouraged by the extent to which the undesirability of such events is perceived and the general loss that follows them is recognized. (Perhaps the advance would be quicker if we could change the view that "different" is an automatic synonym for either "better" or "worse.") Those who speak of the right to communicate as an "evolving" right seem to me to be near the heart of the matter. Because it is a process of evolution, with each succeeding stage building upon what has gone before, I believe that no harm is done by some restatements and repetitions, whether my own or other people's, as they may lead yet others to that piece of perception and original insight that has been concealed from us.

\section{FAIR SHARING}

Very early in Future Shock, ${ }^{1}$ Alvin Toffler, describing the state of superindustrialism into which he believes some countries to be moving, quoted words by $U$ Thant that he thought would illustrate what he had in mind. Toffler reported $\mathrm{U}$ Thant as saying that the central stupendous truth about developed economies was that they could have, in anything but the shortest run, the kind and scale of resources they decided to have. "It is no longer resources which limit decision," U Thant was quoted as saying, "It is the decisions which make the resources."

U Thant made his statement more than a decade ago. I doubt whether his successor at the United Nations would feel able to state that proposition in anything like the same way today. Every nation has become aware, at least since 1973, of the truth that many nations have known all along: resources are finite. The 
majority of nations has also learned, if they did not know it already, that the distribution of those resources is unequal. While some enjoy abundance, others lack almost everything. To some nations and to some individuals, the message of interdependence has gone home.

In considering the right to communicate and its exercise in this changed world, the unequal share of communications resources tends to dominate the consciousness. Moreover, it is not merely that some countxies are better provided than others, but also that, within countries, wrong choices may have been made between different resources, with the result that money has been wasted and objectives missed. In time, the arguments of prestige that led to the establishment of a national airline may be seen to have contained less real force than the argu ments put forward on other grounds for expenditure on different forms of communication; for example, a new radio network or an improved telephone service. There are plenty of voices in Britain and France prepared to argue against the Concorde supersonic airliner project on exactly these grounds. Those with a special interest in communications would say that the millions of francs and pounds that have been lavished on the project axe likely, in real terms, to benefit only a tiny handful of people. The same sums directed in other ways might have made a positive contribution to the provision of those resources necessary for the effective implementation of the right to communicate. They could have helped to correct the present imbalance in communications resources between countries. To correct this imbalance, as well as to assist in the making of proper choices between different claims on national expenditure, must be one of the aims of those who press the case for the right to communicate. Something is, of course, already being done, and the concept of Development Support Communication appears to me to promise the possi-bility of more, but still more will remain to be done. In time, perhaps, there will emerge the outline of a practical world organization concerned with communications in the broadest sense. The task of such a body would be complex, compelling it to reconcile the economics of transportation and telecommunications with more intangible questions of the passage of information in many forms. But if successful reconciliation can be brought about, very real gains could follow, benefiting both developed and developing countries.

\section{THE CHOICES FOR SPENDING}

In any list of priorities for spending on communications, there appears to be a good case for giving prominence to national radio and television services capable of being received adequately everywhere within the country's boundaries. Similarly, good cases can be made for efficient postal, telegraphic, and telephonic services. The last three have particular importance because, inlike radio and television in their present forms, they offer the possibility of two-way communication, admittedly at a personal level but nevertheless of great significance at that level. They are associated in my mind with the amelioration of some of the consequences of the urbanization of populations accompanying the processes of industrialization, on which I shall touch briefly later. To return to national radio and television ser vices, however, few people nowadays would challenge the right to read, whatever disputes may arise over the choice of subject matter. The right to listen or view broadcast programs, with a parallel right not to listen or view, should be subjected to no more questioning than is the right to read. The cost of ensuring that, at least, radio programs are generally available is not high when compared with the costs of ensuring, say, access within reasonable distance to a telephone. 
Both radio and television services have come to be regarded in recent years as valuable means of achieving a measure of homogeneity in developing countries where other means of communication are difficult to provide. Indeed, it has been said in Britain that broadcasting can play something of the same kind of unifying role that was once played by the wide adherence to a national church. However, Britain could well have been one of the countries in the mind of Jerzy Pomorski when he was writing the paper ${ }^{2}$ he contributed to the 1975 Annual General Meeting of the International Broadcast Institute at Cologne. Pomorski, of the International Social and Economic Relations Institute of Krakow, contrasted, for the benefit of the Working Group on the Right to Communicate, the situation in undeveloped countries seeking national unity with that in those developed countries where more pluralistic societies were emerging. In Britain, where the process can be seen in at least its early stages, part of the current debate about broadcasting concerns the rights of different groups to access to broadcasting, as well as the practicalities of achieving it.

The culmination of the process of pluralization is impossible to foresee. In one possible version of the future, the coherence of the nation disappears into anarchy, whether physical or moral, with the right to communicate vitiated by a refusal to listen. Somewhere short of that extreme, however, there must be supposed a point at which the different groups acknowledge some common interests that need to be defended by combined action. Such a point was once, and in many cases still is, identified by the state, but it can be argued that the growth of pluralism reflects the reluctance of the state, for whatever reason, to play that part as decisively as before.

If broadcasting in Britain can fairly be described, as it has been described, as the nation talking to itself, then the broadcasting services in this country have a role in locating, in collaboration with the newly emerging centers of opinion and possible political power, the practical limits to pluralism. They provide the means by which the different elements in society remain in touch with one another, reminding them of the links that at that moment join them together. Their task is therefore a very different one in many respects from that identified earlier in developing countries. Here, there are good reasons for recognizing divisions, a different process, it must be said, than their exacerbation. It is not uncommon for British broadcasters to be accused of accelerating change, but those who make such charges overlook many programs that offer symbols of unchange and of stability. The presence of these symbols is an element in the moderating process that forms perhaps the principal contribution of broadcasting organizations to the national debate. Higher educational attainments, greater articulacy, and the wish for greater self-determination are all factors that influence the pressures for such a debate to take place. Because it is a continuing debate involving millions of people, broadcasting is clearly one of the few means by which it can take place.

The form taken by any such debate is certain to vary from country to country, just as will the voices that contribute to it. The debate must be preceded by, or produce in its course, some generally understood notion of what constitutes fairness. In Britain, for example, we would not regard it as fair that the interests of a small political party with relatively few adherents should at all times be treated as the equal of the interests of a major party to whose views millions of people subscribe. There are, however, times when those interests would be considered equal: for example, during an election when the two parties were putting up an equal number of candidates and therefore had an equal chance of winning the voters' favors. At such moments, the parties would have an equal claim to air time. Similarly, a 
group advocating a nonpolitical cause, for which there can be demonstrated little popular support, could not expect the same treatment as a group for whose aims the community generally showed approval. The decisions to be taken between rival claimants for air time are at present taken in Britain by public bodies independent of the state, but with members appointed by the state.

In at least one European country, the right to broadcasting time is determined on a more quantitative basis, with time automatically available to groups able to show particular amounts of popular support. Only considerable experience of living in both Brita in and Holland would establish whether the Dutch method of identifying some of the contributors to the national debate produces a better debate than that which takes place within the broadcasting media in Britain. Ultimately, however, whatever the method followed, the moment is likely to be reached when an editorial choice has to be made between different groups. Some times of day are more popular than others; so are some days of the week. Some frequencies give better reception than others or can be heard more clearly at night than by day. Few countries have so many frequencies at their disposal that they can ignore these practical restrictions and therefore avoid making a choice of the kind I have described, whether it is taken by the state or by other bodies acting on behalf of the state.

I have been writing of national debates in broadcasting services as one aspect of the right to communicate, but I would not wish to overlook the urgency in many countries of the use of those services to supplement more traditional forms of education, or in some cases to substitute for them. The value to the whole world of extending knowledge of even simple skills, whether in the techniques of agriculture or in hygiene, is immense. Investment in the broadcasting services that might: help this simple process of education offers rewards to tempt even the most suspicious of developed nations. It should, however, go beyond the supply of hardware, as indeed it already has in numerous instances. Developed countries are already supplying program material, whether in a finished state or in an adaptable form, to countries presently without the capacity to make it for themselves. At a third level, interdependence in the supply of communications resources should include, and again already does so in many cases, the provision of training facilities for the men and women who will eventually staff the country's own services as they develop.

\section{CULTURES AT RISK}

The supply of program material from developed countries to countries still developing raises very difficult issues for those who advocate the right to communicate. The right will remain valueless if it is seen as no more than the right of technologically developed countries to swamp with their material the broadcasting schedules of their less privileged neighbors. There are numerous examples of such dangers throughout the world. The usual situation is one in which a poorly endowed television service gratefully accepts low-cost or even no-cost programs from a richer country, very often the United States. In some of these countries, television is doing no more than maintain the tradition of importing material started many years before in the cinema. How often has the traveler in a distant place been surprised, when he has contrived a translation, to realize that the local cinema is showing nothing other than the film he saw months before in one of the world's major cities? The gratitude of the television service arises from finding that it can keep its screens alight. Television viewing is, it seems, almost everywhere a matter of habit, and blank screens are not habit forming. That some of the material acquired in this way 
from other countries may have a less than benign influence on the audience is sometimes not recognized and at other times deliberately overlooked. This is not the occasion to discuss the nature of television's influence upon those who watch it, but it is impossible credibly to deny that television does have influence. Although researchers agree, for the most part at least, that a direct cause-and-effect relationship is rarely identifiable, the longer-term effects in altering attitudes remain the subject of dispute. Where, however, the only picture of the outside world is one falsely painted by television, as it could be, then the right to communicate has been abused. There cannot be a right to communicate that which is known to be untrue, any more than can the right to eat be fulfilled by supplying poisoned food. This suggests that a community, by whatever means it chooses, has the right to regulate communications of this kind from outside its boundaries as a legitimate aspect of its right to defend itself and its identity against physical and moral dangers.

Logic holds that a community has the same right to protect itself against broadcast material that, in contrast to material physically imported for transmission, comes across the boundaries either from land-based transmitters or from satellites. Whether it is wise for a community to take protective action and whether it can then do so to a degree that makes it credible are matters for the community itself to decide. I accept that a contradiction exists between what I believe to be a community's right to debar, if it can, certain material and the right of the individual to a free flow of information--even wrong information, provided that he has opportunities to correct it. However, I think that the existence of the contradiction has to be accepted, at least for the time being. In the longer term, its presence will become less, although it is difficult to foresee a time when it will disappear altogether.

\section{OUTSIDE THE BROADCASTING SERVICES}

I have devoted the first part of this essay principally to broadcasting services in much the form we now know them. I have done so because they exist and because their existence raises questions about the right to communicate as it affects both individuals and communities. The kind of broadcasting services that I have described reflect the older view of communications as an asset in the hands of those in authority. Jean d'Arcy expressed the position well when he wrote: "The history of communications between human beings is marked out by the controls and censures instituted to simplify the act of government. "3 He went on to demonstrate, rightly it seems to me, how we are moving into a different state of affairs on which I should like to make comments. Before doing so, however, I should state my belief that the new developments do not, certainly for a long time, portend the departure of much broadcasting as we have come to know it in the past half-century. We are adding new dimensions to communications, not necessarily replacing old ones. The perception by artists of the common lot of humankind and their interpretation of it have a value that increases with the extent to which they can be communicated to increasing numbers of people. Radio and television have roles to play as communicators in this way that seem unlikely to be supplanted for a long time to come. They can help to spread knowledge of the general, as well as the national, cultural heritage and, with the original contributions of broadcasting artists and writers, help to enrich it both generally and nationally, in contemporary terms. Nor would it seem prudent for communities to overlook the capacity of radio and television to act as simple entertainers, their ability to give pleasure to people, many of whom lack other facilities for entertainment and recreation. In countries moving from an 
agricultural to an industrial economy, there are lessons to be learned, and warnings to be taken, from the experience of developed countries in the urbanization of their populations. The deracination of people drawn by industrialization to town life in many European countries during the past two centuries has produced problems that more thoughtful policies, including recognition of their needs for entertainment and recreation, could help to avert for those taking the same route later. The interrelation of entertainment and education is, after all, a complex one.

In the article to which I have referred, Jean d'Arcy introduced the factors that have entered into communications in the past few years. The first is the possibility of an abundance of means of communications, replacing the scarcity of former years; the second is the possibility of two-way communication, the right to communicate back being an important part of the right to communicate. It seems unlikely that anyone would seriously wish to contest his view that these factors will produce a radical alteration in the attitudes of coming generations toward communications. Jean d'Arcy likens the process to the liberation many years ago of printing from the monopoly enjoyed by Gutenberg and his immediate successors.

There are, it is apparent, considerable differences, however, to which d'Arcy, perhaps for reasons of space, did not allude. The process of liberation after Gutenberg was relatively controlled. To take advantage of it, after all, it was necessary to be able to read. As teachers were comparatively few, books were expensive and for many people there were such practical problems to be overcome as poor illumination at the end of the working day, the spread of reading was not rapid. The communications of which d'Arcy writes are much more readily available and can be exploited by those within reach of them who can speak or see. The absence of the time-lag that characterized the spread of reading, a process still far from complete, is likely to produce problems that may be illustrated by a comparison of the circumstances surrounding the landing on the moon and the dis covery of America. The moon was "discovered" in 1969 in the same way as Columbus "discovered" America in 1492. Both had always been there, but the landing on the moon was observed simultaneously by millions of people throughout the world. Months, however, went by before news of Columbus's landfall reached Europe. The significance of what Columbus had done could be calculated at their own pace by those to whom the news was given and then exploited in the way that seemed best to them. In the case of the moon landing, no such possibility existed for the applica tion of any such moderating process. It is true, of course, that the event was stagemanaged and that at least some of those responsible for the stage management knew what messages they wished the audience to derive. Nonetheless, there could be no guarantee that those would be the messages received by an audience able to make a first assessment of the significance of the event for themselves. There were opportunities for individual reflections that would not have existed in any earlier age.

Because of such opportunities, the right to receive communications, as part of the right to communicate, carries with it potential problems not merely for those who wish to preserve an authoritarian society but for those who seek the preservation of coherent communities operating at more than relatively primitive levels of organization. It seems unlikely, for instance, that in its present stage of development humankind can handle a ceaseless exposure to sensations or a limitless flow of information. Some kind of moderation is needed to place what is seen or heard in the context of the knowledge and experience of individual communities or people. Placing in context, context at its best, does not mean adapting the information received to suit some ideological criteria; it means enabling the recipients 
to judge what they are seeing or hearing against the norms they are accustomed to employ in their daily lives. Without such an intermediate step, there may well be a danger of disorientation.

A rather different aspect of placing in context, but one that has considerable importance, is the manner in which information is conveyed. To use visual information as an example, more research needs to be done into the relationship of the eye and mind to the layout of a picture. On the wall of my office there hangs a painting of a winter scene in Northern Europe. A track cleared of snow leads the eye into the heart of the painting. Only later scrutiny shows the details on either side of the track. The distribution of information in different parts of a television picture would provide a useful study for anyone concerned with the practical application of the right to communicate in the changed circumstances described by d'Arcy. It could be paralleled by studies of the use made of visual information in different cultures. It does not seem fanciful to suppose that the pictures manufactured under one set of cultural influences may be unintelligible to viewers brought up in different cultural traditions. By research of this kind it may be possible to rescue the right to communicate from becoming simply a right to construct a latterday Tower of Babel, visual in character as well as verbal. Earlier in this essay reference was made to the possible desirability one day of having a world communications organization, but the kind of studies described in this paragraph might be initiated by a research center already concerning itself with the importance of movements toward multiculturalism. If time is not on our side in our search for firmer bases for mutual understanding, we may not be able to wait for a common store of words with which the bases may be constructed. Pictures may offer at least a partial substitute.

The knowledge gained from studies of this kind should be made available not only to those who initiate material for mass distribution but also to those who, increasingly, will be devising their own forms of communication for distribution on a more limited scale. Just as, for example, there are magazines that are now distributed to, say, stamp collectors or beekeepers, so it is possible to foresee the development of comparable matter for distribution on video tape for use in individual homes. Something of the kind already happens in the distribution of sound tapes, and the trend seems likely to extend into other fields of activity. The circulation in print of particular sets of ideas or beliefs to limited numbers of people may be thought to lend itself to parallel treatment in other media. Nor should it be imagined that these will be simply adaptations of what is now done in a different medium. New media will breed new ways of passing information or stimulating the imagination.

In time at least, the effect of such developments should be to demystify communications technology. We take for granted the forms of our day-to-day dealings with other people, but the more elaborate the form of communication, the more elaborately it tends to be surrounded with the apparatus and attitudes of a secular kind of priesthood. It should become as commonplace, or at least as unsurprising, to be in regular touch with people remote from oneself as with people close at hand. Of course, the nature of the messages exchanged will differ, but the extent of the community of which people will come to feel part will widen considerably. We are already seeing within individual countries the growth of ties across large distances between people committed to similar occupations. These ties can be, in some cases, stronger than those between people living closer together. Their existence underlies the development of more pluralistic societies in some communities. The spread of communications resources and their readier availability to people at large should 
enhance the tendency toward cross-territorial links between, say, men and women involved in a single academic discipline. It seems possible that these occupational or professional exchanges will be the forerunners of other, more domestic exchanges affecting people in other aspects of their lives. The promise that such a development holds for international understanding is substantial, whatever doubts may be bred by past experience. The expectations awakened by the growth of tourism in the past twenty years have largely been disappointed. Only in a relatively few instances can be it be demonstrated that tourism has contributed to mutual understanding. If it is to contribute helpfully, then tourism must be seen as part of a much wider educative process, not necessarily as an end in itself. Similarly, the new communications now opening to humankind must not be taken to justify themselves simply by their existence, but must be judged by the uses to which they are put.

\section{DATA FLOWS}

In touching on broadcasting services and then on some aspects of the narrowcasting possibilities that confront us, I have dealt with two particular kinds of information: that which takes the form of an artifact shaped by the skills of professionals and, at its best, by the talents of real artists; and second, that which passes from the mind of one person through his or her mouth or expressions or gestures to another person. There is another aspect that bears on the right to communicate. That is the existence in libraries, film vaults, computer banks and elsewhere of the stored knowledge of mankind. Any right to communicate that excluded the right to communicate with this store would be only partial.

\section{CONCLUSION}

As Edward Ploman has pointed out, 4 there has been, since the passing in 1865 of the International Telecommunications Convention, a gradual recognition of the rights of individuals that are not necessarily coterminous with the rights of the states in which those individuals live. International organizations, given meaning only in this century for reasons that are part economic, part political, and part technological, have in some instances succeeded in defining common interests that may or may not overlap both states and individuals. The growth of something that without mockery can be called an international public opinion has been recorded in recent years. In such a situation, the right to communicate and its proper exercise may be preconditions of survival. In the coming age, the single ears and tongues of governments may be insufficient for understanding when their peoples have ears and tongues of their own. 
NOTES

1. Alvin Toffler, Future Shock (London: The Bodley Head Ltd., 1970), p. 16.

2. Jerzy Pomorski, "Right to Communicate: National Legislations or International Policy?" Paper read at the International Broadcast Institute Annual Meeting, Cologne, September 1-4, 1975. Reprinted in Right to Communicate: Collected Papers, L. S. Harms, Jim Richstad, and Kathleen A. Kie, eds. (Honolulu: Social Sciences and Linguistics Institute, University of Hawaii, 1977).

3. Jean d'Arcy, "Direct Broadcast Satellites and the Right to Communicate," EBU Review 118 (Geneva, 1969): 14. Reprinted in Right to Communicate: Collected Papers, L. S. Harms, Jim Richstad, and Kathleen A. Kie, eds. (Honolulu: Social Sciences and Linguistics Institute, University of Hawaii, 1977).

4. Edward Ploman, "The Right to Communicate," Paper read at the International Broadcast Institute Annual Meeting, Cologne, September 1-4, 1975, contribution to Working Committee IV. Paper reprinted in Right to Communicate: Collected Papers, L. S. Harms, Jim Richstad, and Kathleen A. Kie, eds. (Honolulu: Social Sciences and Linguistics Institute, University of Hawaii, 1977). 


\section{CONTRIBUTORS}

Aldo Armando Cocca Buenos Aires Jerzy Mikulowski Pomorski Warsaw

Henry R. Cassirer Annecy

Y.V. Lakshmana Rao Singapore

Lui-Tan Kwan Siu Singapore

Hidetoshi Kato Tokyo

Desmond Fisher Dublin

Donald M. Gillmor Minneapolis

Henry Hindley Ottawa

Luis Ramiro Beltran S. Bogota

Elizabeth Fox de Cardona Bogota

Don R. Le Duc Madison

Ithiel de Sola Pool Cambridge

Asok Mitra Delhi

B. M. Firsov Leningrad

Donald $\mathrm{Mcl}$. Lamberton Brisbane.

Hamdy Kandil Cairo

Pavel Campeanu Bucharest

Ali Mohammad Shummo Khartoum

A.F. Kalimullah Rawalpindi

Astrid S. Susanto Jakarta

Colin Shaw london

Distributed for the fast West Communication institute

Idst West \& enter

by $5 k^{2}$ a neversity Press of Hawdi

284te xolowidu St.

fornijly Hawaii 96822 